\author{
UNIVERSIDADE DE SÃO PAULO \\ ESCOLA DE ENGENHARIA DE SÃO CARLOS
}

BENCHMARKING APLICADO AO CONTROLE DAS PERDAS DE ÁGUA NO CONTEXTO DAS BACIAS HIDROGRÁFICAS PIRACICABA, CAPIVARI E JUNDIAÍ

ALINE DORIA DE SANTI

São Carlos

2018 


\title{
BENCHMARKING APLICADO AO CONTROLE DAS PERDAS DE ÁGUA NO CONTEXTO DAS BACIAS HIDROGRÁFICAS PIRACICABA, CAPIVARI E JUNDIAÍ
}

\author{
Versão Corrigida
}

Dissertação apresentada à Escola de Engenharia de São Carlos da Universidade de São Paulo para obtenção do título de Mestre em Ciências da Engenharia Ambiental.

Área de Concentração: Ciências da Engenharia Ambiental

Orientador: Prof. Tadeu Fabrício Malheiros

São Carlos 2018 


\section{FOLHA DE JULGAMENTO}

Candidata: Bacharela ALINE DORIA DE SANTI.

Título da dissertação: "Benchmarking aplicado ao controle das perdas de água no contexto das bacias hidrográficas Piracicaba, Capivari e Jundiaí".

Data da defesa: $12 / 04 / 2018$.

Comissão Julgadora:

Resultado:

Prof. Associado Tadeu Fabricio Malheiros (Orientador)

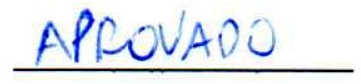

(Escola de Engenharia de São Carlos/EESC)

Prof. Dr. Erich Kellner

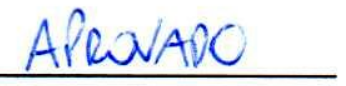

(Universidade Federal de São Carlos/UFSCar)

Profa. Dra. Maria Helena Veríssimo Colaço Alegre

(Laboratório Nacional de Engenharia Civil)

Coordenador do Programa de Pós-Graduação em Ciências da Engenharia Ambiental:

Prof. Associado Frederico Fabio Mauad

Presidente da Comissão de Pós-Graduação:

Prof. Associado Luis Fernando Costa Alberto 
AUTORIZO A REPRODUÇÃO TOTAL OU PARCIAL DESTE TRABALHO, POR QUALQUER MEIO CONVENCIONAL OU ELETRÔNICO, PARA FINS DE ESTUDO E PESQUISA, DESDE QUE CITADA A FONTE.

Ficha catalográfica elaborada pela Biblioteca Prof. Dr. Sérgio Rodrigues Fontes da EESC/USP com os dados inseridos pelo(a) autor(a).

\begin{tabular}{|c|c|}
\hline \multirow[t]{3}{*}{ S398b } & $\begin{array}{l}\text { Santi, Aline Doria } \\
\quad \text { Benchmarking aplicado ao controle das perdas de } \\
\text { água no contexto das bacias hidrográficas Piracicaba, } \\
\text { Capivari e Jundiaí / Aline Doria Santi; orientador } \\
\text { Tadeu Fabrício Malheiros. São Carlos, } 2018 \text {. }\end{array}$ \\
\hline & $\begin{array}{l}\text { Dissertação (Mestrado) - Programa de Pós-Graduação } \\
\text { e Área de Concentração em Ciências da Engenharia } \\
\text { Ambiental -- Escola de Engenharia de São Carlos da } \\
\text { Universidade de São Paulo, } 2018 \text {. }\end{array}$ \\
\hline & $\begin{array}{l}\text { 1. Perdas de água. 2. Indicadores de desempenho. } 3 . \\
\text { Práticas de controle. I. Título. }\end{array}$ \\
\hline
\end{tabular}

Eduardo Graziosi Silva - CRB - 8/8907 


\section{AGRADECIMENTOS}

Agradeço a Deus pela vida.

Aos meus pais pela educação, dedicação e amor que me guiaram até aqui e pelo exemplo de vida que inspiram minha caminhada.

A minha irmã, Amanda, que mesmo me tirando do sério em quase todas as horas do meu dia sempre me apoiou nos momentos críticos e me mimou com lanchinhos quando eu passava horas no computador trabalhando.

Ao meu companheiro, Pedro, que nunca deixou que eu desistisse dos meus sonhos, me amparou em todos os momentos em que achei que nada fosse dar certo dizendo com carinho "relaxa, no final tudo vai dar certo, você é capaz”. Obrigada por acreditar em mim sempre.

Ao meu orientador, Prof. Tadeu Malheiros, pela oportunidade de desenvolver esta pesquisa em uma área que hoje sou apaixonada, e pela oportunidade de envolvimento em tantos outros projetos que contribuíram para o meu amadurecimento.

Aos meus colegas do NUPS, em especial ao Tiago Cetrulo, por acompanhar toda minha jornada até aqui, apoiando todas as etapas de desenvolvimento do projeto. Obrigada também pelas conversas descontraídas que tornaram as viagens das visitas de campo mais leves.

Ao pesquisador Waldomiro Barioni da Embrapa Pecuária Sudeste que pouco me conhecendo aceitou o desafio de trabalharmos juntos nas análises estatísticas desta pesquisa. Muitíssimo obrigada!

Aos meus amigos e irmãos da vida, que sempre estiveram comigo em todos os momentos, seja comemorando e compartilhando as conquistas de cada um ou sendo o ombro amigo nas fases difíceis.

A todos os servidores das operadoras de água que aceitaram participar da pesquisa, disponibilizando um espaço na agenda de compromissos para nos receber. Aos membros das agências reguladoras pelo apoio na coleta de dados.

Ao CNPq e a FAPESP por viabilizarem financeiramente o desenvolvimento desta pesquisa. 


\section{RESUMO}

SANTI, Aline Doria. Benchmarking aplicado ao controle das perdas de água no contexto das bacias hidrográficas Piracicaba, Capivari e Jundiaí. Dissertação (Mestrado em Ciências da Engenharia Ambiental) - Escola de Engenharia de São Carlos, Universidade de São Paulo, São Carlos, 170 p. 2018.

As perdas de água em sistemas de abastecimento apresentam-se como um dos maiores desafios das operadoras de água em todo o mundo. Nos últimos 12 anos os níveis de perda de água na distribuição no Brasil têm se mantido próximo à $40 \%$, valor bem superior quando comparado a outras regiões do globo. Frente ao atual cenário de crise hídrica e aumento da demanda da água, as ações de controle de perdas requerem atenção. No cenário nacional, as bacias hidrográficas dos rios Piracicaba Capivari e Jundiaí destacam-se pelo empenho dos Comitês PCJ que têm atuado junto aos municípios para controlar os níveis de perdas da área. A crítica situação da disponibilidade hídrica nas bacias, o potencial de redução da pressão sobre os recursos hídricos e o ganho econômico se os níveis de perdas forem reduzidos reforçam a premência na adoção de práticas de controle de perdas eficientes. Nesta perspectiva, a presente pesquisa buscou identificar, no contexto das operadoras das bacias PCJ, quais práticas de controle de perdas de água na distribuição estão associadas ao desempenho considerado superior no controle, calculando o nível de perdas de água dos municípios e explorando quais práticas de controle são empregadas pelas operadoras. A primeira etapa metodológica correspondeu a aplicação da técnica de benchmarking junto as operadoras em estudo para avaliar o desempenho das mesmas no controle de perdas, incluindo a seleção de indicador, formulação de questionário de dados operacionais, coleta de dados online, análise da credibilidade dos dados e cálculo do nível de perdas de água de cada município com o ranqueamento dos mesmos. A segunda etapa foi direcionada ao levantamento e análise das práticas de controle de perdas empregadas pelas operadoras das bacias, mediante a aplicação in loco do questionário de práticas, elaborado a partir de revisão bibliográfica. Na terceira etapa, utilizando ferramentas estatísticas, as práticas de controle analisadas foram cruzadas com as categorias de desempenho, superior e inferior, identificando quais práticas de controle estão associadas as classes de desempenhos. A amostra final de municípios analisados incluiu 41, dos 70 membros dos Comitês, cujos dados se enquadraram nos níveis de credibilidade estabelecidos para fins de comparação de desempenho. A aplicação do benchmarking possibilitou analisar os desempenhos das operadoras que atuam na área, comparando os níveis de perdas de água e identificando quais municípios necessitam de urgência atenção em ações de controle. Testes de comparação de média, conduzidos com o produto do benchmarking evidenciaram que há diferenças significativas nos níveis de perdas de água quando considerado o porte do município, natureza jurídica da operadora e presença de favelas. A análise das práticas de controle empregadas apontou o empenho das operadoras da área em controlar as perdas de água, concentrando ações em trocas de rede, setorização e macromedição, sendo verificada diferenças significativas no índice médio de perdas quando uma prática é ou não aplicada. A análise de associação e correspondência indicaram que 24 práticas estão associadas e impactam os níveis de perdas de água. Salvo este aspecto, é imprescindível reforçar a importância do mix de práticas na obtenção de resultados mais eficientes e satisfatórios. Com caráter exploratório, as assertivas desse estudo podem nortear as ações de controle de outras operadoras sendo fundamentais estudos de custo benefício para definir quais práticas produzirão resultados de redução mais efetivos.

Palavras-chave: Perda de água. Indicadores de desempenho. Práticas de controle 


\begin{abstract}
SANTI, Aline Doria. Benchmarking for water loss control in the context of Piracicaba, Capivari and Jundiaí watersheds. Dissertation submitted to the School of Engineering of São Carlos, University of Sao Paulo, to obtain the title of Master of Post-Graduation Program in Environmental Engineering Sciences. 170 p. 2018.
\end{abstract}

The water loss in supply system have presented as one of the biggest challenges of water companies around the world. In the last 12 years the water loss levels in Brazilian's distribution systems have remained close to $40 \%$, level higher than other areas in the globe. Face of the water crisis and increasing water demand, the actions to control the water loss require attention. In the national context, the Piracicaba, Capivari and Jundiai river basins have focus by the Committees efforts that have been acting along with the cities to control the water loss levels in the area. The critical situation of water availability in the river basins, the reduction potential on hydric resources and the financial gain, if the water loss levels have lowered, enhance the urgency to adopt efficient control practices of water loss. Accordingly, the present research has searched to identify, in the context of PCJ river basins water companies, which water loss control practices are associated with the higher performance, measuring the city's water loss levels and exploiting which control practices have applied by the water companies. The first methodological step was the application of the benchmarking technique to measure the performance in water loss control, including indicator choice, questionnaire formulation of operational data, online data collection, data reliability analysis and determination of cities water loss levels, with ranking of this. The second step had directed to the gathering and analysis of control practices adopted by the companies in the area, by applying the practices questionnaire, elaborated as of bibliographic review, in loco. In the third step, using statistic tools, the control practices had crossed with the performance in water loss control, higher and lower, identifying which practices have associated with the companies' performance. The final sample analyzed included 41 cities, of the 70 PCJ Committees members, that data had fit in the reliability levels established for performance comparison purposes. The benchmarking application had enabled to analyze the companies' performance comparing the water loss levels and identifying which cities need urgent attention in control practices. Testes of means comparison had emphasized that there are significant differences in the water loss levels when deemed the city size, company's legal nature and presence of slumbs. The control practices analysis had indicated the company's efforts to control the water loss, focusing in network exchange, district meters' areas, macromediation system, been checked significant differences in the water loss average index when a practice is adopting or not. The association and correspondence analysis had indicated that 24 practices area associated and affect the water loss levels. Barring this aspect, is essential to strengthen the importance of control practices mix to achieve efficient and satisfactory results. With an exploratory profile, the results of this research can guide the control actions of others companies, been essential cost-benefit studies to establish which practices will generate reduction results more effectives.

Keywords: Water loss. Performance indicators. Practices of control. 


\section{LISTA DE FIGURAS}

Figura 1 - Perdas de água na distribuição dos municípios das bacias PCJ...............................20

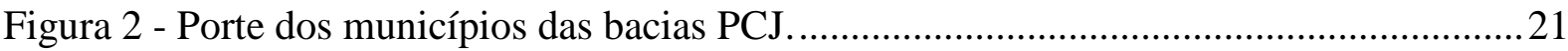

Figura 3 -Design dos procedimentos metodológicos da pesquisa ......................................... 23

Figura 4- Área de atuação dos especialistas participantes..................................................... 24

Figura 5 - Tipos de vazamentos em sistemas de distribuição................................................. 41

Figura 6 - Processos para controle de perdas reais................................................................ 46

Figura 7 - Processos para o controle de perdas aparentes. .................................................... 48

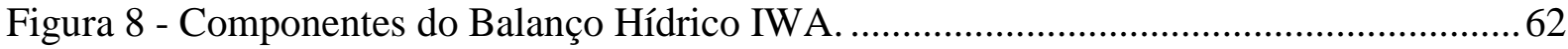

Figura 9 - Avaliação da exequibilidade dos indicadores....................................................... 74

Figura 10 - Avaliação da compreensibilidade dos indicadores ............................................ 74

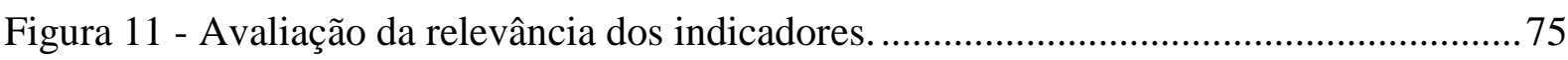

Figura 12 - Avaliação da mensurabilidade dos indicadores................................................. 75

Figura 13- Avaliação da Suficiência dos indicadores. ............................................................. 76

Figura 14- Pesos atribuídos aos critérios de avaliação de indicadores de perdas de água. ...... 76

Figura 15 - Credibilidade do volume de água disponibilizado dos sistemas em estudo. ..........83

Figura 16 - Credibilidade do volume de água utilizado dos sistemas em estudo..................... 85

Figura 17 - Credibilidade do volume de água faturado dos sistemas em estudo...................... 86

Figura 18 - Boxplot dos níveis de perdas de águas dos municípios em estudo........................90

Figura 19 - Boxplot da distribuição do IPL por porte de municípios.......................................93

Figura 20 - Boxplot da distribuição do IPL por natureza jurídica da operadora......................94

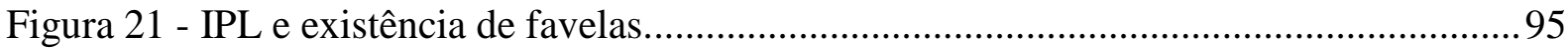

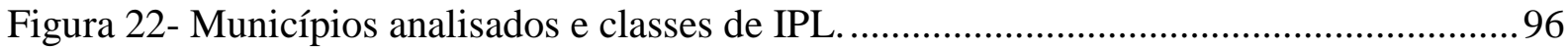

Figura 23- Distribuição das práticas de "Gerenciamento de Pressão" empregadas nas bacias PCJ.

Figura 24- Aderência das práticas de "Gerenciamento de Infraestrutura" empregadas nas

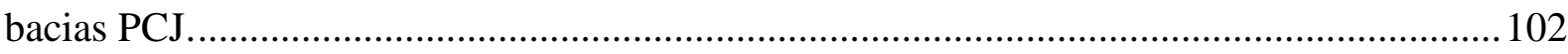

Figura 25 - Práticas para controle da corrosão das tubulações.............................................. 107

Figura 26 - Incrustações em tubulação de ferro. ................................................................... 108

Figura 27 - Aderência das práticas de controle de vazamentos............................................ 110

Figura 28 - Aderência das ações de controle de erros de medição........................................ 115

Figura 29 - Aderência das práticas para o controle de fraudes............................................. 118

Figura 30 - Aderência das práticas de "Planejamento Estratégico". ..................................... 122 
Figura 31 - Fonte de recursos para elaboração ou revisão de Planos/Programas de combate as perdas de água em sistemas de abastecimento.

Figura 32- Aderência das práticas de investimento e inovação.......................................... 125

Figura 33 - Proporção da adoção das práticas de controle na amostra de 41 municípios...... 128

Figura 34 - Práticas cuja aplicação geram os menores IPL médio. ..................................... 134

Figura 35 - Gráfico de radar demonstrando a variação do IPL de acordo com aplicação/não aplicação das práticas de controle

Figura 36 - Mapa perceptual das classes de desempenho com as categorias das práticas dos Processos 1-4.

Figura 37 - Mapa perceptual das classes de desempenho com as categorias das práticas dos Processos 5-8.

\section{LISTA DE QUADROS}

Quadro 1- Classificação dos níveis de perdas de acordo com o Plano de bacias PCJ 20

Quadro 2 - Municípios pertencentes aos Comitês das Bacias PCJ.

Quadro 3 - Escala de credibilidade dos dados operacionais.

Quadro 4 - Práticas de controle de perdas organizadas em processos.

Quadro 5 - Perdas físicas e sua origem de acordo com o subsistema.

Quadro 6- Impactos das perdas de água.

Quadro 7 - Origem das perdas não físicas de água............................................................... 42

Quadro 8 - Ganhos e benefícios da redução de perdas. .......................................................... 44

Quadro 9 - Vantagens do uso de indicadores de desempenho por atores............................... 59

Quadro 10 - Evolução dos indicadores de perdas de água na distribuição............................. 61

Quadro 11- Indicadores de perdas de água avaliados pelos especialistas................................ 73

Quadro 12 - Municípios com credibilidade nas faixas I e II para todos os tipos de volume... 88

Quadro 13- Parâmetros de referência de desempenho no controle de perdas de água. ........... 96

Quadro 14- Práticas de Gerenciamento de Pressão. ................................................................... 97

Quadro 15- Práticas de Gerenciamento de Infraestrutura. ....................................................... 100

Quadro 16 - Práticas para controlar a corrosão das tubulações. ............................................... 106

Quadro 17 - Práticas de "Controle e detecção de vazamentos". ............................................. 109

Quadro 18 - Práticas para o controle de erros de medição..................................................... 114

Quadro 19 - Práticas para o controle de fraudes e ligações clandestinas............................... 117

Quadro 20 - Práticas de Planejamento Estratégico. ............................................................. 121

Quadro 21- Práticas de "Investimento e Inovação". ............................................................. 125 


\section{LISTA DE TABELAS}

Tabela 1 - Indicadores de perda de água em sistemas de abastecimento em âmbito nacional e internacional.

Tabela 2 - Nota final dos indicadores avaliados pelos especialistas. ..................................... 78

Tabela 3 - Ranking dos níveis de perdas de água dos municípios amostrados .......................89

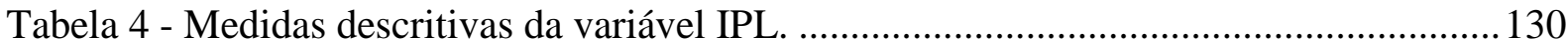

Tabela 5 - Comparação de média do IPL com a aplicação/não aplicação das práticas...........132

Tabela 6 - Comparação de média do IPL com a aplicação/não aplicação das práticas........... 133

Tabela 7 - Teste exato de Fisher IPL x P1 a P14 .............................................................. 136

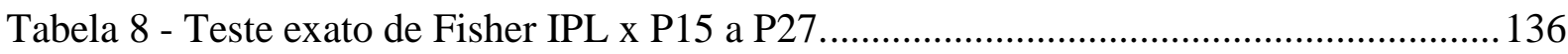

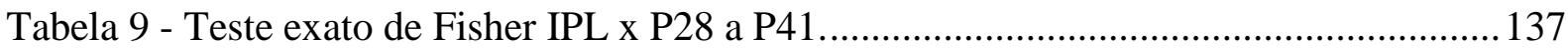

Tabela 10- Teste exato de Fisher IPL x P42 a P54 ............................................................... 137

\section{LISTA DE EQUAÇÕES}

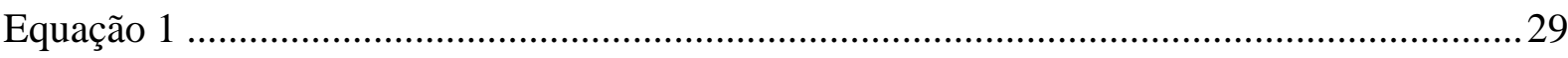

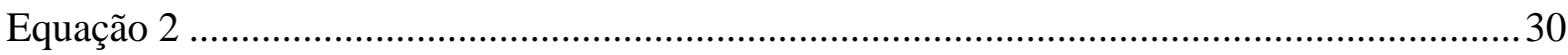

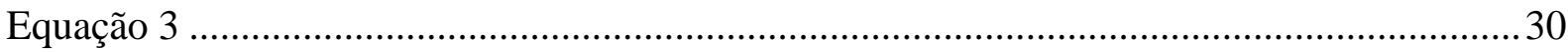

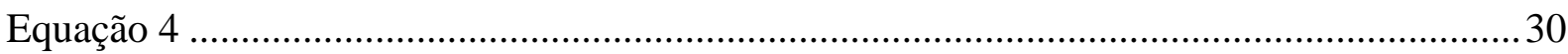

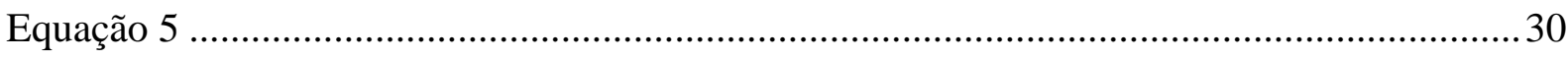

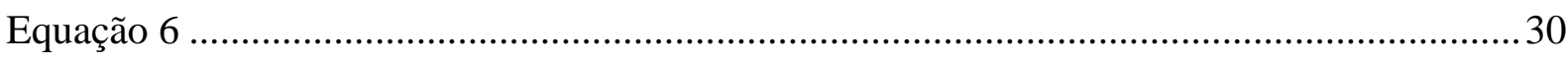

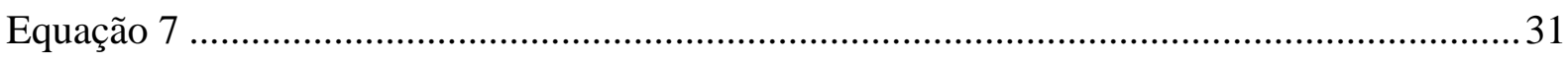

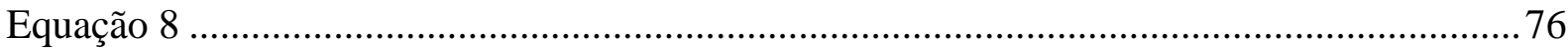

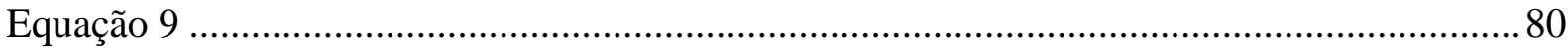

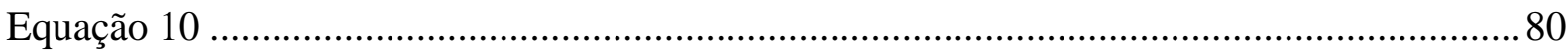




\section{LISTA DE ABREVIATURAS}

ABES - Associação Brasileira de Engenharia Sanitária

ABRH - Associação Brasileira de Recursos Hídricos

ACM - Análise de Correspondência Múltipla

AESBE - Associação das Empresas de Saneamento Básico Estaduais

AGHTM - Association Générale des Hygiénistes et Techniciens Municipaux

AMD- Acordo para melhoria do desempenho

ARSAE-MG - Agencia Reguladora de Serviços de Abastecimento de Água e de Esgotamento Sanitário do Estado de Minas Gerais

ARES-PCJ - Agência Reguladora dos Serviços de Saneamento das Bacias dos Rios Piracicaba, Capivari e Jundiaí

ARSESP - Agência Reguladora de Saneamento e Energia do Estado de São Paulo

ASSEMAE - Associação Nacional dos Serviços Municipais de Saneamento

AWWA - American Water Works Association

BDEW - German Association of Energy and Water Industries

DMA - District Meteres Area

DTA - Documento Técnico de Apoio

IBNET - International Benchmarking Network for Water and Sanitation Utilities

FEHIDRO - Fundo Estadual de Recursos Hídricos

GEE - Gases do efeito estufa

ID - Indicadores de Desempenho

INMETRO - Instituto Nacional de Metrologia, Qualidade e Tecnologia

IWA - International Water Association

ODS - Objetivos do Desenvolvimento Sustentável

OVGW - Austrian Association for Gas and Water

PCJ - Piracicaba, Capivari e Jundiaí

PLANSAB - Plano Nacional de Saneamento Básico

PMSB - Planos Municipais de Saneamento Básico

PMSS - Programa de Modernização do Setor de Saneamento

PNCDA - Programa Nacional para o combate ao desperdício de água

PNQS - Prêmio Nacional de Qualidade no Saneamento

SANEPAR - Companhia de Saneamento do Paraná

SIG - Sistema de Informação Geográfica

SNSA - Secretaria Nacional de Saneamento Ambiental

SNIS - Sistema Nacional de Informações sobre Saneamento 


\section{SUMÁRIO}

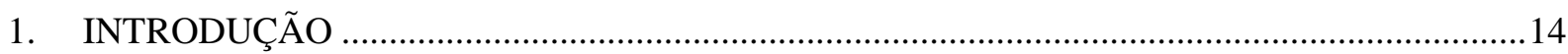

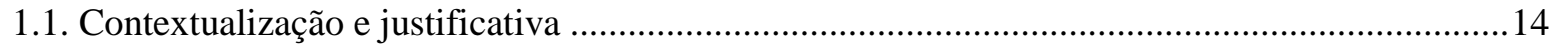

1.2. Definição do problema e questão da pesquisa.............................................................................17

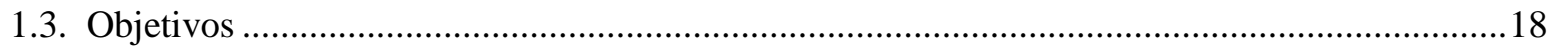

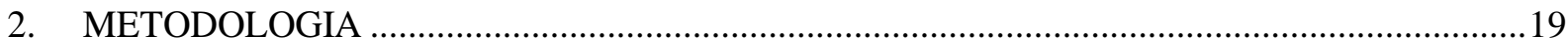

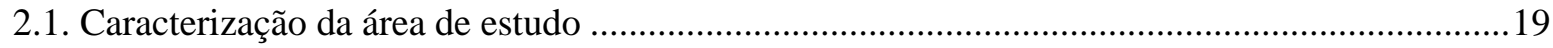

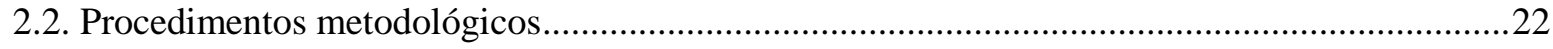

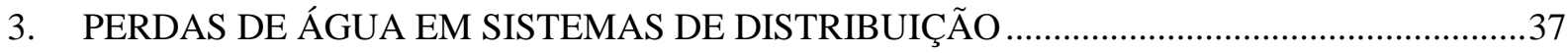

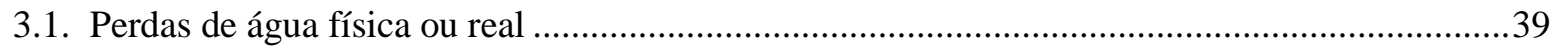

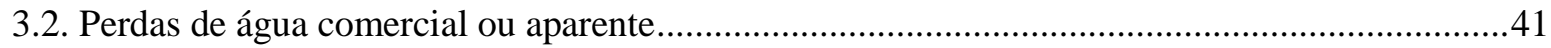

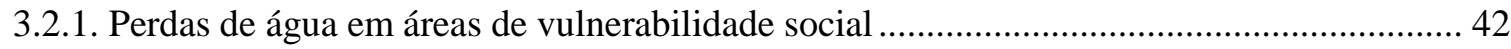

3.3. O controle dos níveis de perdas de água em sistemas de distribuição ........................................45

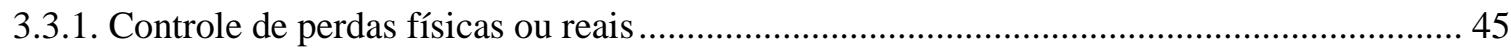

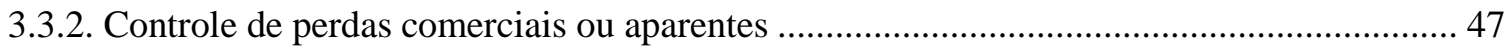

3.3.3. Programas voltados ao controle de perdas de água no cenário nacional ............................... 50

3.3.4. Barreiras para o controle de perdas de água em sistemas de distribuição............................ 52

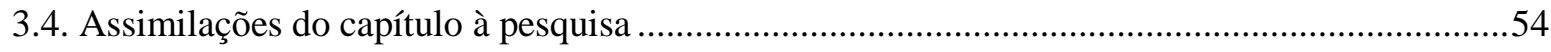

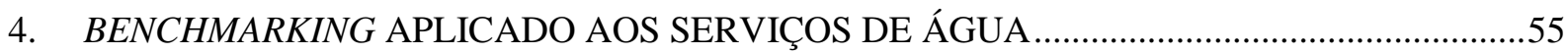

4.1. Benchmarking métrico ou Benchmarking para avaliação de desempenho...................................56

4.1.1. Os indicadores de desempenho na aplicação do Benchmarking ........................................57

4.1.1.1. Indicadores de desempenho de perdas de água em sistemas de distribuição............60

4.2. Experiências internacionais de benchmarking aplicado ao controle de perdas...........................69

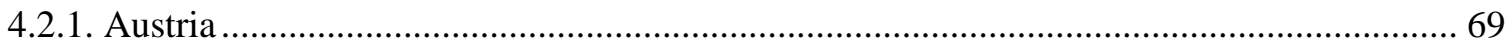

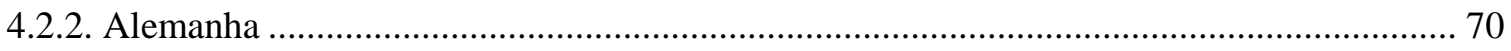

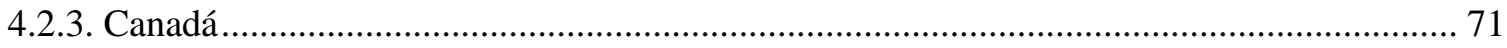

4.3. Considerações sobre a aplicação do benchmarking na pesquisa................................................72

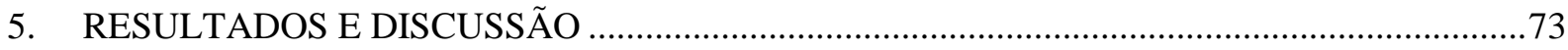

5.1. Benchmarking para avaliação das perdas de água nas bacias PCJ ............................................73

5.1.1. Indicadores de perdas de água e a aplicação do benchmarking ...............................................73

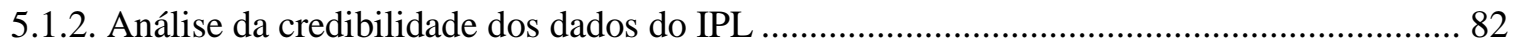

5.1.2.1. Credibilidade do volume de água disponibilizado (VD) .............................................83

5.1.2.2. Credibilidade do volume de água utilizado (VU) ........................................................... 84

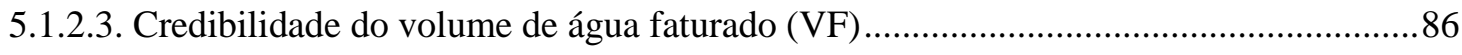

5.1.2.4. Considerações acerca da análise da credibilidade dos dados .........................................87 
5.1.3. Níveis de perdas de água na distribuição nos municípios amostrados 89

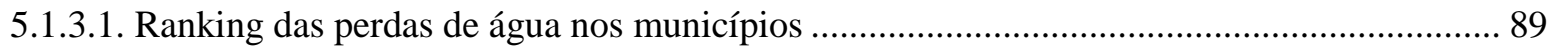

5.1.3.2. Análise de fatores de influência...................................................................................... 93

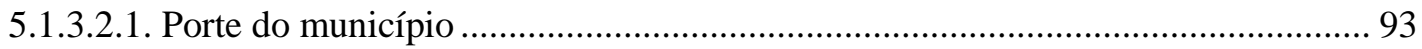

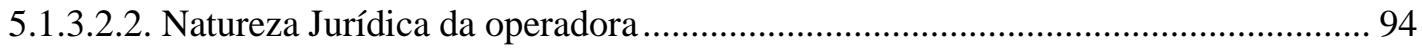

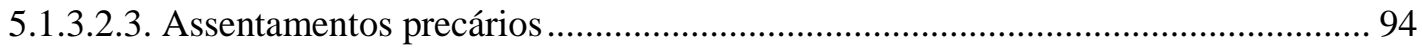

5.1.3.3. Classificação dos níveis de perdas de água .................................................................. 95

5.2. Práticas de controle de perdas de água aplicadas pelas operadoras das bacias PCJ ................... 97

5.2.1. Práticas de "Gerenciamento de Pressão" ................................................................................. 97

5.2.2. Práticas de "Gerenciamento de Infraestrutura" ....................................................................... 100

5.2.3. Práticas de "Controle da corrosão nas tubulações" ................................................................... 106

5.2.4. Práticas de "Controle e Detecção de vazamentos" ................................................................ 109

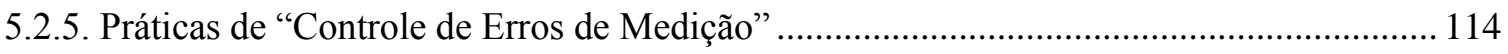

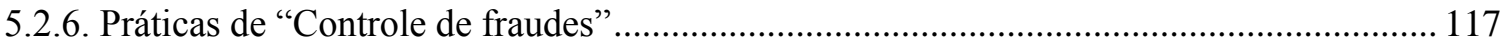

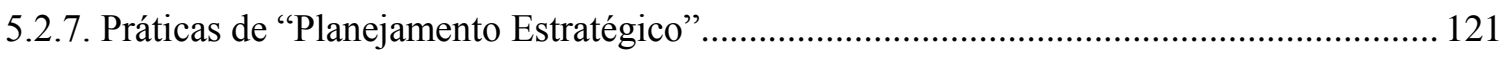

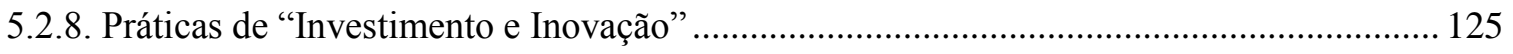

5.2.9. Considerações sobre as práticas de controle de perdas adotadas nas Bacias PCJ ............. 128

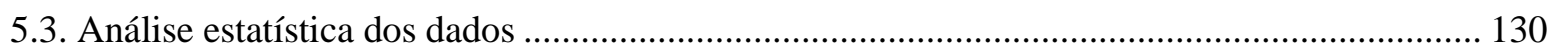

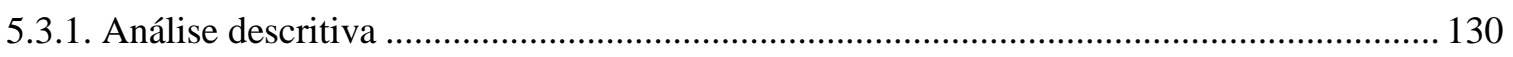

5.3.2 Teste de diferença de média das práticas de controle de perdas de água ............................ 130

5.3.3. Análise da relação das práticas de controle com o desempenho ......................................... 135

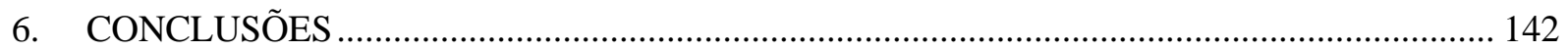

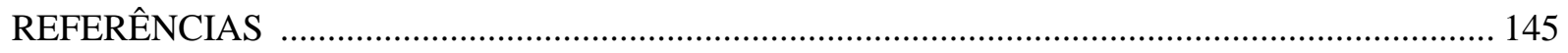

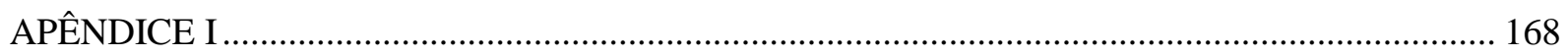

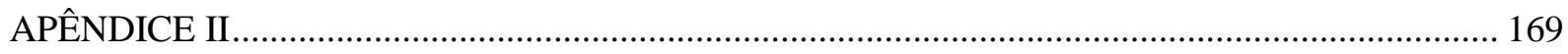




\section{INTRODUÇÃO}

\subsection{Contextualização e justificativa}

A questão das perdas de água em sistemas de abastecimento é um tema tratado mundialmente, tendo em vista que desde o início do novo milênio vive-se uma grave crise hídrica em função das mudanças climáticas, crescimento populacional e consequente aumento da demanda pelos recursos hídricos (FERREIRA, 2011; MOLINOS-SENANTE et al., 2016). As atuais tendências globais atreladas à proteção do meio ambiente e eficiência econômica destacam a importância da redução dos níveis de perdas de água, sendo o controle das mesmas, mediante a adoção de processos de gestão adequados, um dos maiores desafios das operadoras de abastecimento no século XXI (FRAUENDORFER; LIEMBERGER, 2010; SCHOUTEN; HALIN, 2010).

Os dados referentes às perdas de água são considerados um dos principais indicadores de desempenho operacional das prestadoras de serviços de saneamento em todo mundo (ReCESA, 2008; ADASA, 2015; TARDELI FILHO, 2016) e, segundo Tsutiya (2006), as suas causas estão atreladas à operação e manutenção deficientes das tubulações e à gestão comercial inadequada das companhias de saneamento. Em conformidade com o descrito no capítulo 3 deste documento, do ponto de vista operacional as perdas de água são classificadas em dois tipos: "perdas de água física" ou "real" e "perdas de água comercial" ou "aparente" (ALEGRE, et al., 2000; KINGDOM et al., 2006; ABES, 2013), as quais podem ser calculadas a partir de indicadores de desempenho estabelecidos por diversas organizações internacionais e nacionais ${ }^{1}$ (ALEGRE et al., 2000; MINISTÉRIO DA SAÚDE, 2014).

No que se refere aos níveis de perdas de água no processo de distribuição, a American Water Works Association - AWWA defende que uma rede bem construída e com manutenção adequada apresenta baixos níveis de perdas. Tendo em vista a inexistência de redes totalmente estanques a AWWA estabeleceu em 10\% o nível máximo de perdas de água na distribuição recomendado (AWWA, 1996; ALEGRE et al., 2005; CHARALAMBOUS, et al., 2014).

Em termos ambientais, as perdas de água dificultam o uso racional dos recursos hídricos, haja visto que intensificam a pressão sobre os mesmos para atender à demanda, podendo comprometer a disponibilidade de água para as futuras gerações e, em termos econômicos, provocam prejuízos no faturamento tornando a operação dos sistemas bastante onerosas, o que

\footnotetext{
${ }^{1}$ Na subseção 4.1.1.1 são apresentados os principais indicadores de perdas de água na distribuição desenvolvidos no âmbito nacional e internacional.
} 
tem impulsionado as empresas a direcionar esforços para combatê-las (PNCDA, 2003; SANTOS; MONTENEGRO, 2014).

Dados do International Benchmarking Network for Water and Sanitation Utilities (IBNET) estimam que a média mundial de perdas de água, no ano de referência 2011, correspondeu à 30\% da água total distribuída (DANILENKO, et al., 2014). Afere-se que, nos países em desenvolvimento, as perdas de água na distribuição variam nas faixas de 40 a 50\%, enquanto em países ricos as perdas são significativamente menores, como o caso da Alemanha cujo nível de perda de água no processo de distribuição é em torno de 6\% (GO ASSOCIADOS, 2013; ATT et al., 2015).

No cenário brasileiro, dados do Sistema Nacional de Informações sobre Saneamento (SNIS) indicam que, no ano 2016, os sistemas sofreram perdas na distribuição de $38,1 \%$, valor 1,4\% maior ao calculado em 2015 (BRASIL, 2018). Em termos volumétricos perde-se anualmente nos sistemas de distribuição do país em torno de 5,8 bilhões $\mathrm{m}^{3}$ de água, volume suficiente para abastecer em um ano cerca de 98 milhões de pessoas, tendo em vista que o consumo médio per capita em 2014 foi 59,1 m³ (BRASIL, 2016; SABESP, 2016). Observa-se que, a redução dos níveis de perdas para 10\%, padrão internacional, reduziria a pressão sobre os recursos hídricos, evitando que aproximadamente 4,2 bilhões de $\mathrm{m}^{3}$ de água fossem perdidos por ano. Em termos econômicos, se a meta de $10 \%$ fosse alcançada, o ganho líquido estimado seria em torno de R\$ 1,685 bilhões ${ }^{2}$ (GO ASSOCIADOS, 2013).

Entre as regiões do Brasil, o Norte e Nordeste apresentam os maiores níveis de perdas de água na distribuição, 47,3\% e 46,3\% respectivamente, seguidas pela região Centro-Oeste (35\%), Sul (36,3\%) e Sudeste $(34,7 \%)$. Nota-se que a região Sudeste é a mais próxima de atingir a meta estabelecida pelo Plano Nacional de Saneamento Básico (PLANSAB) de alcançar o nível de perdas de $32 \%$ até 2023 , o que demonstra o possível esforço dos municípios da região no controle das perdas de água na distribuição (SNSA, 2014; BRASIL, 2018).

No âmbito da região Sudeste, destacam-se as bacias hidrográficas dos rios Piracicaba, Capivari e Jundiaí (PCJ) com um forte empenho dos Comitês da área no controle dos níveis de perdas de água na distribuição, direcionando, nos últimos 20 anos, cerca de $85 \%$ dos recursos provenientes das cobranças pelo uso da água para projetos de redução de perdas nas bacias. Com o crítico cenário da disponibilidade hídrica das bacias, que em 2013 tiveram aproximadamente $90 \%$ do seu volume disponível captado, ações de controle de perdas de água devem ser focalizadas para controlar os níveis que, apesar de apresentarem bons desempenhos

\footnotetext{
${ }^{2}$ Baseado nas estimativas do Instituto Trata Brasil (GO ASSOCIADOS, 2013).
} 
em alguns casos, há ainda municípios com níveis de perdas de água superiores à $50 \%{ }^{3}$ (FUNDAÇÃO AGÊNCIA DAS BACIAS PCJ, 2013a, b).

Destarte, frente aos elevados níveis de perdas de água, em diferentes dimensões territoriais, e ao atual cenário de escassez hídrica é fundamental o gerenciamento adequado das mesmas mediante a adoção de ações de controle que promovam a melhoria da eficiência das redes de água, assegurando sustentabilidade à longo prazo (MORRISON, et al., 2007, ABES, 2013). Os processos de controle devem estar atrelados à existência de setorização, macromedição e micromedição, pois permitem contabilizar o volume de água que está entrando no setor com o que está sendo consumido, fornecendo assim informações importantes para identificar as regiões em que ocorrem as perdas (PNCDA, 2003). As estratégias aplicáveis ao controle de perdas de água são diversas ${ }^{4}$, como a redução da pressão de água nas redes, agilidade e qualidade das reparações de vazamentos e o combate às fraudes e irregularidades (MUTIKANGA, et al., 2013, BEZERRA; CHEUNG, 2013; MERKS, et al., 2016; TARDELLI FILHO, 2016).

Entre as múltiplas estratégias voltadas ao controle de perdas, Mbuvi et al. (2012) e Kanakoudis et al. (2012) incitam que a avaliação do desempenho das operadoras de água é um fator essencial para que as mesmas operem de forma eficiente e eficaz, sendo o primeiro passo para a redução dos níveis de perdas de água, uma vez que a partir desta avaliação é possível averiguar a situação do sistema e o quanto está sendo perdido. Tendo em consideração os procedimentos aplicáveis à avaliação de desempenho, ainda que a aplicação seja incipiente em países em desenvolvimento (MUTIKANGA, 2012; LANNIER; PORCHER, 2014), na indústria de água o benchmarking se destaca como uma técnica de gestão promissora na melhoria da performance das operadoras de água, por comparar as métricas de desempenho de qualquer instituição (benchmarking métrico ${ }^{5}$ ) com as melhores práticas na área (benchmarking processual $^{6}$ ) consoante ao abordado no Capítulo 4 (CARPINETTI; MELO, 2002; KÖELBL et al., 2009; MUTIKANGA, 2012).

\footnotetext{
${ }^{3}$ Maior detalhamento sobre as Bacias PCJ é apresentado no subitem 2.1 - Caracterização da área de estudo.

${ }^{4} \mathrm{Na}$ seção 3.3 são apresentadas as principais práticas usuais no controle das perdas de água físicas, bem como das perdas de água aparentes.

${ }^{5}$ Consiste em uma comparação quantitativa, mediante a aplicação de indicadores de desempenho, de diversos aspectos da gestão das prestadoras de serviço em relação ao tempo e à outros sistemas similiares fornecendo uma visão de qual o caminho que a operadora está seguindo (CABRERA et al., 2011)

${ }^{6}$ Apresenta-se como uma complementação do benchmarking para avaliação do desempenho, onde os processos adotados pela operadora com melhor desempenho são determinados e faz-se a adaptação e integração dos melhores processos em outras operadoras (CABRERA et al., 2011). Experiências internacionais demonstram que é um bom instrumento para detectar bons processos de gestão no setor de saneamento (STAHRE; ADAMSSON, 2004).
} 
Frente aos dados apresentados vê-se que, no tocante ao uso dos recursos hídricos para abastecimento, a situação brasileira é preocupante cabendo às operadoras de água que fazem uso dos mesmos gerenciá-los de forma a estimular a conservação e o uso racional. As estatísticas recentes demonstram a ineficiência no seu gerenciamento, tendo em vista que os níveis de perdas de água nos sistemas de distribuição do Brasil, em diferentes escalas territoriais, são elevados em relação ao nível recomendado pela AWWA e aos níveis de outros países. Considerando o cenário hídrico das Bacias PCJ, a presente pesquisa buscou, como primeira etapa, avaliar o desempenho das operadoras que atuam no âmbito das bacias em questão no controle de perdas de água, aplicando a técnica de benchmarking. Muito além da comparação da performance das operadoras, nas etapas subsequentes, foram identificadas e analisadas as práticas de controle de perdas empregadas pelas operadoras das bacias e, mediante o cruzamento de práticas e desempenhos, detectada a associação existente entre as ações de controle e os níveis de perdas de água presentes na área.

Os resultados desse estudo podem ser utilizados pelos Comitês PCJ e reguladoras Ares e Arsesp. Essas organizações são parceiras do projeto "Benchmarking para universalização dos serviços de água e esgoto nos municípios das bacias hidrográficas dos rios Piracicaba, Capivari e Jundiaí", financiado pela Fundação de Amparo à Pesquisa do Estado de São Paulo $(\text { Fapesp })^{7}$ ao qual a presente pesquisa é parte integrante.

\subsection{Definição do problema e questão da pesquisa}

As bacias PCJ desempenham um papel fundamental no abastecimento de água das populações que habitam a região metropolitana de São Paulo, porém a atual condição da disponibilidade hídrica das bacias é delicada (DEMAJOROVIC et al., 2015) e ações devem ser tomadas de imediato para tentar conter os problemas associados, como as perdas de água na distribuição. Tendo por base os dados disponibilizados pelas operadoras no Sistema Nacional de Informação sobre Saneamento (SNIS), os níveis de perdas de água na distribuição dos municípios da área refletem que a maior proporção dos sistemas está acima do nível considerado "Adequado" pelo Plano de Bacias $^{8}$, reforçando a necessidade da adoção de processos de gestão eficientes, que visem controlá-las, reduzindo a pressão sobre os recursos hídricos e despesas adicionais. Assim, identificar quais práticas de controle de perdas têm maior associação com o desempenho considerado superior é de suma importância para que as operadoras com desempenho inferior possam reproduzi-los ou adaptá-los, melhorando sua

\footnotetext{
${ }^{7}$ Processo no ${ }^{\circ} 15 / 23382-1$.

${ }^{8}$ Estes dados podem ser visualizados na Figura 1 do subitem 2.1.
} 
performance e reduzindo os níveis de perdas. Neste sentido, a questão que a presente pesquisa buscou responder foi:

- Quais práticas de controle estão associadas ao desempenho superior no controle de perdas de água dos sistemas públicos de abastecimento?

\subsection{Objetivos}

O objetivo geral da pesquisa consistiu em identificar, no contexto das operadoras das bacias PCJ, quais práticas de controle estão associadas aos desempenhos superiores no controle de perdas de água na distribuição.

Os objetivos específicos traduziram-se em:

- Selecionar indicadores de perdas de água aplicáveis à realidade dos sistemas de saneamento brasileiros;

Aplicar a técnica de benchmarking para avaliar o desempenho das operadoras das bacias no controle de perdas de água;

Identificar quais práticas de controle de perdas de água são empregados pelas operadoras em estudo. 


\section{METODOLOGIA}

\subsection{Caracterização da área de estudo}

A presente pesquisa desenvolveu-se no âmbito das bacias hidrográficas dos rios Piracicaba, Capivari e Jundiaí - Bacias PCJ, sendo o objeto de análise da pesquisa as operadoras de distribuição de água dos municípios pertencentes aos Comitês das bacias hidrográficas em questão. As bacias PCJ apresentam uma área de 15.303,67 km², sendo 92,6\% no Estado de São Paulo e 7,4\% no Estado de Minas Gerais contando com 44 municípios totalmente inseridos na área e 29 municípios cujas áreas de drenagem encontram-se parcialmente inseridas nas bacias PCJ (COBRAPE, 2010). Entre esses municípios, 70 fazem parte dos Comitês PCJ, sendo 65 no território paulista e cinco em território mineiro.

Os rios que compõem as bacias, do ponto de vista organizacional, são de domínio da União, e outros do Estado de São Paulo e Minas Gerais, neste sentido, os Comitês PCJ são formados pela integração de três comitês: Comitê da Bacia Hidrográfica dos rios Piracicaba, Capivari e Jundiaí no âmbito do Estado de São Paulo, o Comitê da Bacia Hidrográfica dos rios Piracicaba Capivari e Jundiaí no âmbito do Estado de Minas gerais (CBH - PJ - MG), e o Comitê da Bacia Hidrográfica dos rios Piracicaba, Capivari e Jundiaí no âmbito da União (PCJ Federal).

No que se refere a disponibilidade hídrica das bacias PCJ, Demajorovic et al. (2015) afirmam que a situação dos recursos hídricos na área é crítica, em função da expansão urbana, agrícola e industrial e pelo fato de parte significativa da água captada na bacia ser revertida para o Sistema Cantareira, abastecendo cerca de 50\% da população da Região Metropolitana de São Paulo. Dados da Fundação Agência das Bacias PCJ indicam que, em 2013, as captações de água nas bacias foram em torno de $34,5 \mathrm{~m}^{3} / \mathrm{s}$, o que representa aproximadamente $90 \%$ da disponibilidade hídrica da mesma (37,98 m³/s) (FUNDAÇÃO AGÊNCIA DAS BACIAS PCJ, 2013a). Esses dados evidenciam a situação preocupante da disponibilidade hídrica na área, reforçando a importância da redução dos níveis de perdas de água.

Neste sentido, a Figura 1 ilustra os níveis de perdas de água na distribuição dos municípios pertencentes a bacia, em 2015. Nota-se que mais da metade dos municípios apresentam níveis de perdas entre 25,1 e 49,9\%, 16 apresentam níveis inferiores à 25\% enquanto sete municípios apresentam níveis de perdas superiores à 50\%, havendo ainda munícipios que não forneceram os dados para que o nível de perdas de água fosse mensurado (FUNDAÇÃO AGÊNCIA DAS BACIAS PCJ, 2017). 
Figura 1 - Perdas de água na distribuição dos municípios das bacias PCJ.

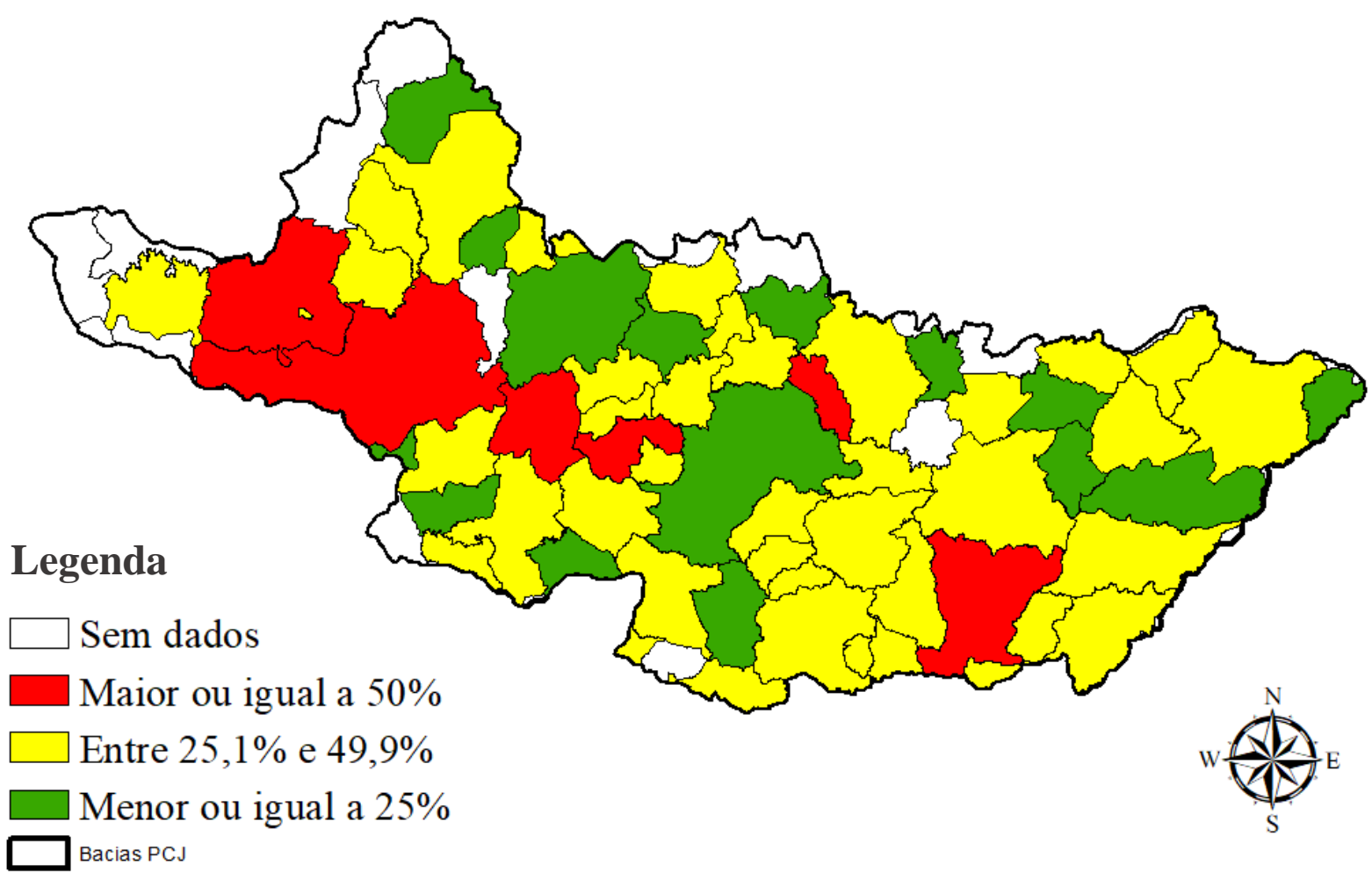

Fonte: Mapa disponibilizado pela Fundação Agência das Bacias PCJ (2017).

Atuando no tema de saneamento, os Comitês PCJ têm intervindo junto aos municípios com o intuito de que tenham Planos Municipais de Saneamento Básico, Plano de Combate às Perdas hídricas no abastecimento e Plano Municipal de Gestão dos Recursos Hídricos. No que concerne a questão das perdas de água na distribuição, o Plano das Bacias PCJ 2010-2020 (Contrato Agência PCJ $n^{\circ}$ 11/07) estabelece que cada município deve atingir, até 2020, a meta de perdas de 25\%, determinada através do Ofício Agência PCJ n.031/10 de 07 de janeiro de 2010 (COBRAPE, 2010). Os níveis de perdas na distribuição são classificados no referido Plano em três categorias, expressas no Quadro 1.

Quadro 1- Classificação dos níveis de perdas de acordo com o Plano de bacias PCJ
\begin{tabular}{|c|c|}
\hline NÍVEL DE PERDA & DESEMPENHO \\
\hline$\leq 25 \%$ & BOM \\
\hline $25 \%<$ IPD $<40 \%$ & REGULAR \\
\hline$\geq 40 \%$ & RUIM \\
\hline
\end{tabular}

Fonte: Adaptado de Cobrape (2010)

Considerando o volume de água macromedido e micromedido nas Bacias PCJ como um todo, cerca de $30 \%$ do volume distribuído é perdido no processo de distribuição ${ }^{9}$ o que, em

\footnotetext{
9 Porcentagem de perdas de água estimada a partir dos dados de volume macromedido e micromedido disponibilizados no SNIS Série História (SNIS,2018).
} 
termos volumétricos, equivale à aproximadamente 273,7 milhões de $\mathrm{m}^{3}$ de água ${ }^{10}$. Vê-se que se a meta de perdas estabelecida no Plano de Bacias fosse atingida evitar-se-ia perder anualmente cerca de 41,7 milhões de $\mathrm{m}^{3}$ de água, que em termos financeiros representaria um ganho de R\$ 16 milhões ${ }^{11}$.

Os níveis de perdas de água na distribuição podem ser influenciados por diversos fatores como o porte do município, a idade da rede de abastecimento, a presença de aglomerados subnormais $^{12}$, existência de Plano de Combate às perdas, entre outros fatores. Neste sentido, é interessante destacar que, de acordo com o Censo 2010, 32 \% dos municípios que compõem os Comitês PCJ são classificados como 'pequeno porte 1', $26 \%$ classificados como 'pequeno porte 2', $17 \%$ são de 'médio porte', $23 \%$ são municípios de 'grande porte', enquanto apenas um município é classificado como 'metrópole' (Figura 2) (IBGE, 2010). No que se refere à presença de aglomerados subnormais, dados do Censo de Aglomerados Subnormais do IBGE de 2010, indicam que 11 municípios da área contam com esse setor censitário (IBGE, 2011).

Figura 2 - Porte dos municípios das bacias PCJ.

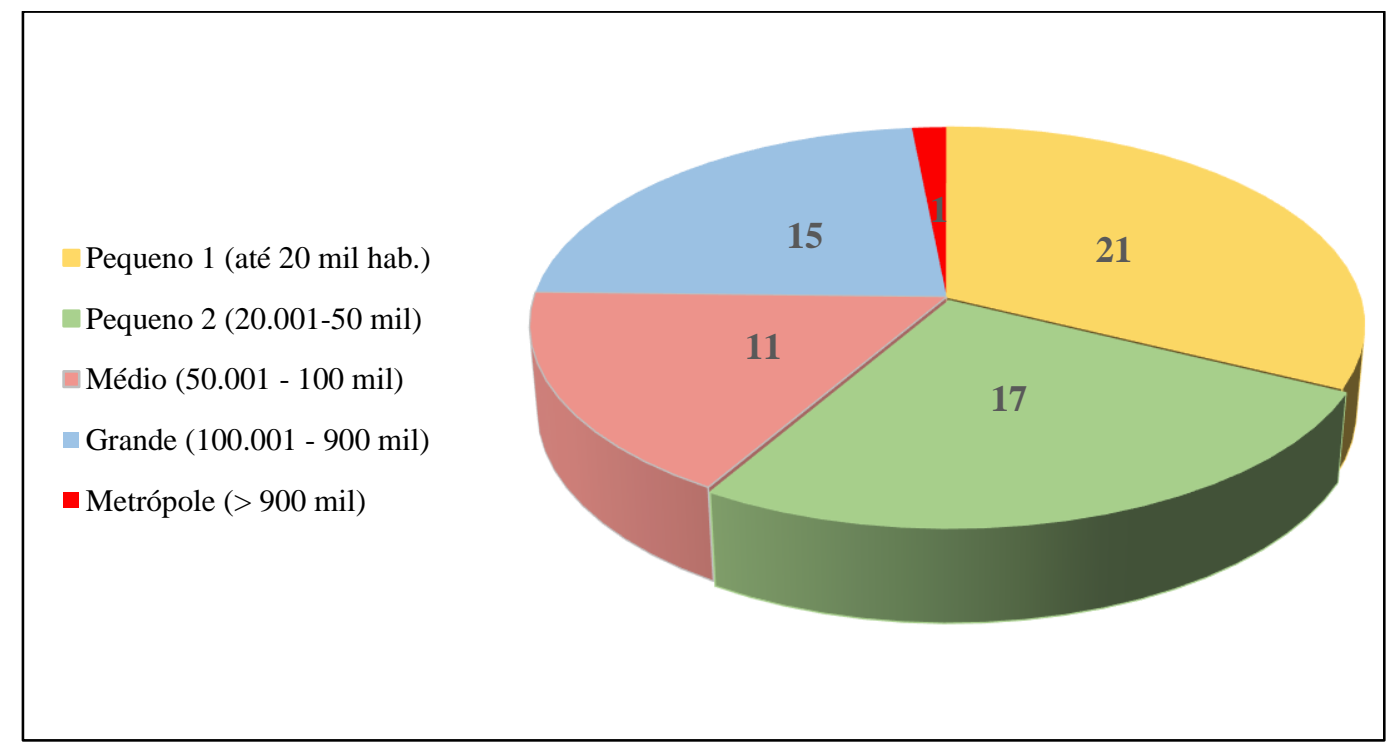

Fonte: Adaptado de IBGE (2010).

Em se tratando da existência de Planos de Combate às perdas de água, segundo a Fundação Agência das bacias PCJ, 39 municípios que compõem a bacia possuem o Plano, 1 estava em processo de elaboração, em 2013, e 22 apresentam um Plano em que é necessária complementação.

\footnotetext{
${ }^{10}$ Volume calculado pela diferença do volume macromedido e micromedido nas Bacias PCJ como um todo.

${ }^{11}$ Baseado nas estimativas do Instituto Trata Brasil (GO ASSOCIADOS, 2013).

${ }^{12}$ Conjunto constituído de, no mínimo, 51 unidades habitacionais (barracos, casas, etc.) carentes, em sua maioria de serviços públicos essenciais, ocupando ou tendo ocupado, até período recente, terreno de propriedade alheia (pública ou particular) e estando dispostas, em geral, de forma desordenada e densa" (IBGE, 2011).
} 
Desde a criação do Comitê PCJ, em 1993, a maior parte dos recursos financeiros do Fundo Estadual de Recursos Hídricos (FEHIDRO) tem sido direcionados para o saneamento básico, priorizando investimentos em projetos de combate às perdas nas redes de distribuição. No período de 1995 a 2015, 85,36\% dos recursos provenientes das cobranças ${ }^{13}$ pelo uso de água foram direcionados à projetos de redução de perdas na bacia, o equivalente a $R$ \$455,3 milhões (AÇÃO ECO CUENCAS, 2016). Para o período 2015 -2020 estima-se que serão aplicados em torno de R 620 milhões para equacionar os maiores problemas de perdas na distribuição (FUNDAÇÃO AGÊNCIA DAS BACIAS PCJ, 2013b).

O estado crítico da disponibilidade hídrica das bacias PCJ, associado ao potencial de redução da pressão sobre os recursos hídricos e o esforço permanente dos Comitês em ações voltadas para o controle de perdas são fatores que fortalecem a escolha desta área como foco de pesquisa.

\subsection{Procedimentos metodológicos}

O presente estudo configura-se em uma pesquisa aplicada que buscou analisar a associação existente entre as práticas empregadas para controlar as perdas de água e os desempenhos assumidos como superiores no controle.

Para o alcance dos objetivos propostos, a pesquisa se desenvolveu em três etapas. De acordo com o exposto na seção 4.2 do capítulo de revisão, há duas principais tipologias da técnica de benchmarking: benchmarking métrico ou benchmarking para avaliação do desempenho (como apresentado por Cabrera et al. 2011), e o benchmarking processual ou benchmarking para melhoria do desempenho.

Tendo em vista que a avaliação do desempenho é o primeiro passo para reduzir as perdas de água, como apontado por Mbuvi et al. (2012) e Kanakoudis et al. (2012), na Etapa 1 foi conduzido o benchmarking para avaliação do desempenho, determinando a performance das operadoras no controle de perdas de água, a partir de um indicador de desempenho específico avaliado por especialistas. Na Etapa 2, as práticas de controle de perdas empregadas por todas as operadoras da área de estudo foram identificadas, a partir da aplicação de questionário, e na terceira e última etapa conduziu-se testes estatísticos para analisar a relação existente entre as práticas de controle de perdas e o desempenho das operadoras, identificando quais práticas estão associadas aos desempenhos superiores no controle de perdas de água encontrados nas bacias.

\footnotetext{
${ }^{13}$ Os recursos são provenientes das cobranças federais e paulistas, um dos instrumentos de gestão dos recursos hídricos previsto na Política Nacional de Recursos Hídricos, em que a operadora paga $\mathrm{R} \$ 0,0127$ por $\mathrm{m}^{3}$ de água captado/extraída em corpos d'água de domínio da União e do estado de São Paulo (SÃO PAULO, 2015).
} 
A Figura 3 sintetiza os procedimentos metodológicos do estudo, os quais são detalhados na sequência.

Figura 3 -Design dos procedimentos metodológicos da pesquisa

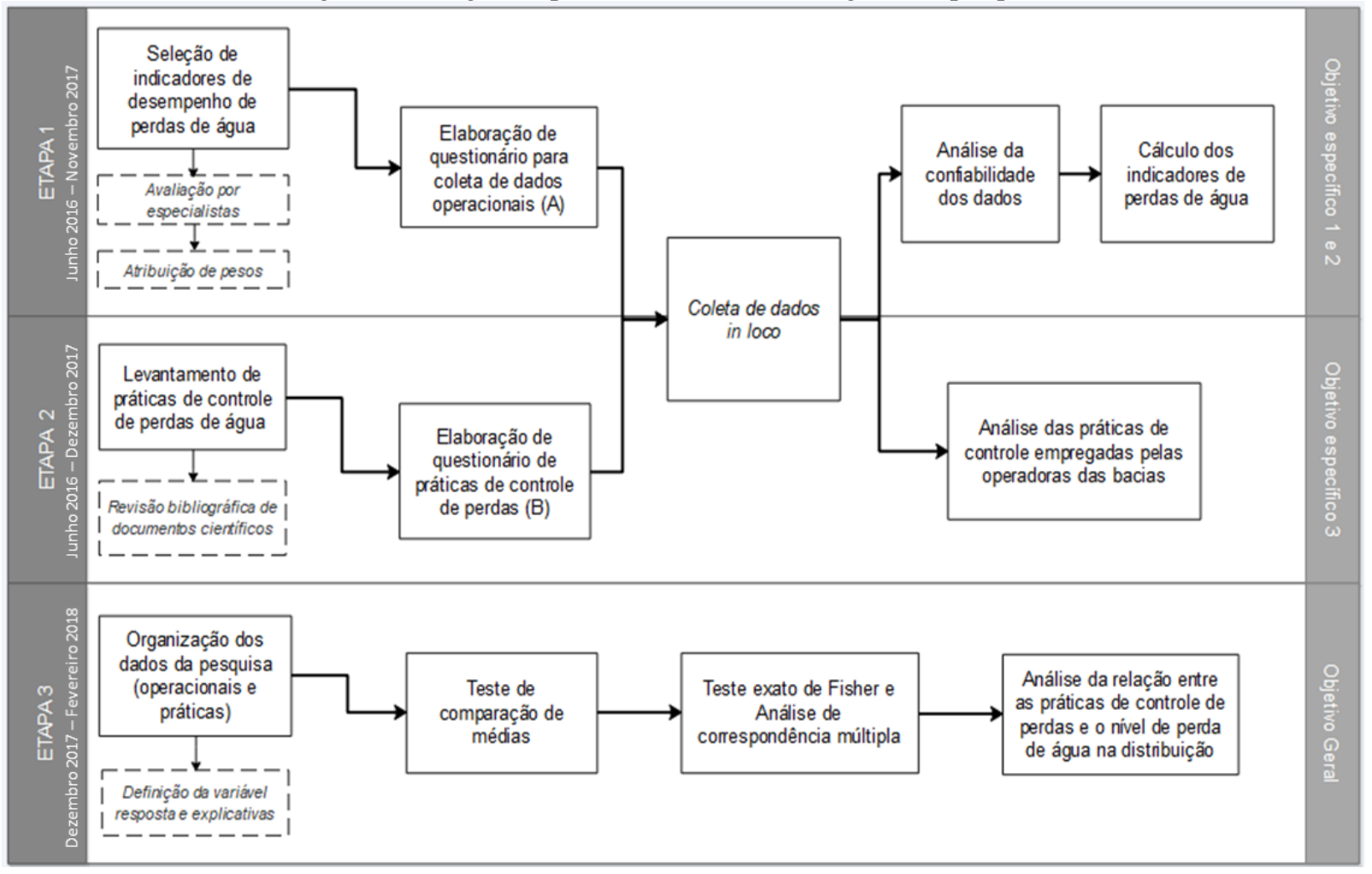

Fonte: Elaborado pela autora.

\section{ETAPA 1: Benchmarking para avaliação de desempenho (objetivos específicos 1 e 2)}

As etapas que compuseram a metodologia da presente pesquisa são integradas e os resultados das Etapas 1 e 2, executadas concomitantemente, foram essenciais para o desenvolvimento da Etapa 3. Nesta primeira etapa a aplicação da técnica de benchmarking, utilizando indicadores de perdas de água, foi conduzida para calcular o desempenho das operadoras no controle de perdas. A seleção de indicador, coleta de dados com aplicação de questionário, e análise da credibilidade dos dados coletados foram subetapas necessárias para atingir os objetivos específicos ao qual esta etapa está relacionada.

\section{Etapa 1.1: Seleção dos indicadores de desempenho de perdas de água}

Frente à diversidade de indicadores de desempenho de perdas de água (IDPA) em âmbito nacional e internacional, evidenciado na Tabela 1 do item 4.1.1.1 deste documento, fezse necessário, para o desenvolvimento da presente pesquisa, selecionar o indicador de desempenho mais adequado à realidade dos sistemas brasileiros. Para tanto, esta etapa desenvolveu-se em duas fases descritas na sequência.

Fase 1: Avaliação dos indicadores por especialistas do setor de saneamento 
Nesta fase foi elaborado um questionário online, pelo software Survey Monkey, o qual foi encaminhado para 87 especialistas (com participação efetiva de 27), que atuam em diversas áreas do setor de saneamento (Figura 4). Consoante ao exposto na Figura 4, 43\% dos especialistas participantes atuam na área de engenharia do setor de saneamento, ou seja, estão em contato direto e muitas vezes são os responsáveis por gerar dados e informações de determinado sistema, tendo conhecimento do tipo de informação produzida e disponível para avaliação. Já os outros $57 \%$ dos especialistas são colaboradores do setor de planejamento e regulação ( $40 \%$ e 17\%, respectivamente), tendo papel fundamental no processo de avaliação de indicadores uma vez que, de um lado planejam a avaliação e tomada de decisão do setor baseado nos indicadores e por outro fiscalizam os serviços de saneamento e o atendimento de objetivos e metas aplicando indicadores operacionais.

Figura 4- Área de atuação dos especialistas participantes.

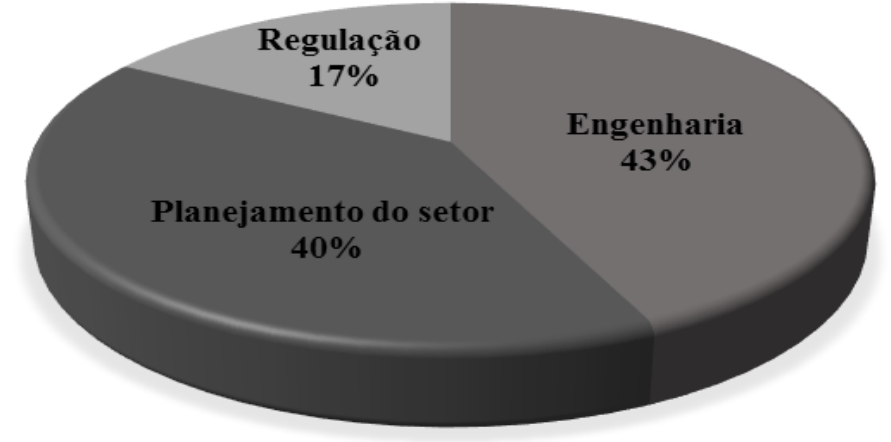

Fonte: Elaborado pela autora.

Os especialistas convidados avaliaram os indicadores de perdas de água na distribuição, expostos na Tabela 1, localizada na subseção 4.1.1.1, a partir dos seguintes critérios adaptados da proposta de Meadows (1998):

i. Exequibilidade: o indicador é mensurável em termo de disponibilidade, precisão e confiabilidade dos dados;

ii. Compreensibilidade: o indicador e suas variáveis são de fácil interpretação;

iii. Relevância: o indicador está associado aos objetivos de controle de perdas;

iv. Mensurabilidade: o resultado do indicador tem uma medida física;

v. Suficiência: o indicador apresenta um cenário adequado da situação das perdas de água.

Para cada indicador e critérios os partícipes foram instruídos a atribuir uma nota na escala de 0 a 10, em que 0 o indicador não atende ao critério e 10 atende totalmente ao critério. A partir das avaliações, obteve-se a mediana das notas de cada indicador para cada critério. 
Para analisar o grau de importância dos cinco critérios utilizados, a Fase 2 desta etapa correspondeu à atribuição de pesos para cada um dos critérios, junto a novos especialistas do setor, a qual será detalhada no subitem subsequente.

\section{Fase 2: Atribuição de pesos aos critérios de seleção de indicadores de perdas}

A metodologia utilizada para atribuição de pesos aos critérios citados previamente baseou-se no trabalho de Figueira e Roy (2002). A proposta apresentada pelos autores é uma revisão da metodologia apresentada por Simos (1990) a qual pode ser aplicada em diferentes contextos, incluindo o setor da água.

A concepção básica desta metodologia consiste em associar cada critério a uma carta de jogo em que cada cartão é classificado do menos para o mais importante. Para participar deste processo foram convidados seis especialistas que atuam em diferentes instâncias de tomada de decisão do setor de saneamento e recursos hídricos (reguladora, operadora de saneamento e agência de bacias). Na concepção da metodologia a mesma é aplicada pessoalmente junto aos atores envolvidos, porém, para fins desta pesquisa esta foi adaptada e organizada no software Survey Monkey de forma a otimizar a participação dos atores envolvidos que estão localizados em diferentes áreas geográficas.

Para iniciar o processo de atribuição de pesos aos critérios em questão os especialistas foram orientados a colocar os critérios em posições de $1 \mathrm{a} \mathrm{n}$, onde 1 deveria conter o critério menos importante, seguindo os seguintes passos:

1 - Coloque todos os critérios na primeira posição (Posição 1).

2 - Deixe na Posição 1 somente o(s) critério(s) menos importante(s); Leve todos os outros critérios para Posição 2.

3 - Entre os Critérios que estão na Posição 2, selecione aquele(s) que é(são) mais importante(s) e o(s) leve(m) para Posição 3.

4 - Entre os Critérios que estão na Posição 3, selecione aquele(s) que é(são) mais importante(s) e o(s) leve(m) para Posição 4; Siga adiante até que se acabem os critérios.

Até essa fase de pré-ordem todos os critérios foram classificados em posições, no máximo cinco, tendo em vista que cinco critérios estavam em análise, não havendo posições em branco ${ }^{14}$ entre os critérios. Na sequência, os especialistas adicionaram espaços em branco entre os critérios para determinar uma distância de importância entre as posições. Para os critérios julgados de mesma importância, ou seja, o mesmo peso os participantes foram orientados a mantê-los na mesma posição. A título de exemplo podemos citar o critério

\footnotetext{
${ }^{14}$ Posição que não esteja preenchida por nenhum critério.
} 
exequibilidade na posição 1 e o critério mensurabilidade na posição 4 indicando que o segundo critério tem três unidades de importância a mais que o primeiro. Nesta perspectiva, a partir destas subfases estabeleceu-se um ranking onde o critério localizado na Posição 1 é o menos importante e o localizado na última Posição (n) é o mais importante.

Para suprir algumas lacunas do processo proposto por Simos (1990), Figueira e Roy (2002) apresentam na metodologia revisada que os participantes devem indicar, como último processo da etapa de coleta de dados, quantas vezes o último critério é mais importante do que o primeiro do ranking, sendo esta relação denominada razão z. Sendo assim, após posicionar os critérios, os especialistas consultados indicaram a grandeza do último critério em relação ao primeiro do ranking.

Para converter as informações coletadas em pesos, os dados foram processados no software francês SRF, o qual foi desenvolvido para implementar a metodologia revisada por Figueira e Roy (2002). As características deste software possibilitaram inserir as informações da avaliação de cada especialista separadamente, gerando ao final uma tabela com os dados consolidados e com os pesos de cada critério.

Com os pesos atribuídos, os mesmos foram multiplicados à mediana das notas de cada indicador para cada critério (Fase 1), selecionando-se para uso nesta pesquisa o indicador de perdas de água com maior nota final.

\section{Etapa 1.2: Elaboração do questionário de coleta de dados}

A presente pesquisa teve como instrumento de coleta de dados dois questionários, A e B (apresentados nos Apêndices I e II) que foram elaborados nas Etapas 1 e 2, respectivamente.

O Questionário A - Dados operacionais (Apêndice I), ao qual se refere esta subetapa, foi construído apoiado na seleção do indicador de perdas de água que seria utilizado na pesquisa para avaliar o desempenho das operadoras. O propósito deste questionário foi coletar os dados referentes as variáveis do indicador de perdas selecionado e outras informações relevantes para a pesquisa. Previamente a aplicação efetiva do questionário, foi conduzido um pré-teste do mesmo visando verificar a disponibilidade dos dados necessários e o tempo de preenchimento. Para Boni e Quaresma (2005) a principal vantagem da aplicação de questionários é a obtenção de respostas rápidas destacando a importância de que as perguntas sejam bem definidas para evitar problemas de compreensão por parte do respondente.

Etapa 1.3: Aplicação do questionário de dados operacionais (Questionário A) 
O objeto de estudo foram as operadoras de distribuição de água dos 70 municípios que compõem os Comitês das Bacias PCJ. Neste sentido, a terceira subetapa correspondeu a aplicação dos questionários de pesquisa junto à todas as operadoras das bacias.

Os questionários de pesquisa foram executados em formatos distintos. Para o Questionário A foi aplicado o modelo online, via software Survey Monkey, com o intuito de otimizar o fornecimento das informações, que poderiam ser inseridas no sistema em diferentes momentos, caso fosse necessário coletar dados com outros membros da operadora. Em função da baixa taxa de resposta deste questionário por parte dos participantes foi requisitado, como estratégia para expandir o número de dados coletados, o apoio das agências reguladoras das bacias em estudo (Ares PCJ, Arsesp e Arsae - MG) na disponibilização de dados, uma vez que os prestadores de serviços de saneamento são obrigados por lei a fornecer todos os dados de desempenho de suas atividades, conforme previsto no Art. 25 da Lei ${ }^{\circ} 11.445$ :

"Art. 25 - Os prestadores de serviços públicos de saneamento básico deverão fornecer à entidade reguladora todos os dados e informações necessários para o desempenho de suas atividades, na forma das normas legais, regulamentares e contratuais". (BRASIL, 2007).

No Quadro 2 estão expostos os municípios em estudo e suas respectivas operadoras.

Quadro 2 - Municípios pertencentes aos Comitês das Bacias PCJ.

(Continua)

\begin{tabular}{|c|c|c|}
\hline \multicolumn{2}{|c|}{ População $^{\mathbf{1 5}}$} & Operadora $^{\mathbf{1 6}}$ \\
\hline Município & Estado de São Paulo $^{-1.880}$ & Economia Mista \\
\hline Águas de São Pedro & 220.545 & Autarquia \\
\hline Americana & 67.486 & Autarquia \\
\hline Amparo & 4.530 & Administração Pública Direta \\
\hline Analândia & 47.893 & Autarquia \\
\hline Artur Nogueira & 132.017 & Autarquia \\
\hline Atibaia & 21.604 & Administração Pública Direta \\
\hline Bom Jesus dos Perdões & 154.253 & Economia Mista \\
\hline Bragança Paulista & 44.719 & Economia Mista \\
\hline Cabreúva & 1.123 .241 & Economia Mista \\
\hline Campinas & 77.669 & Economia Mista \\
\hline Campo Limpo Paulista & 50.847 & Autarquia \\
\hline Capivari & 15.843 & Economia Mista \\
\hline Charqueada & 22.457 & Autarquia \\
\hline Cordeirópolis & 3.910 & Autarquia \\
\hline Corumbataí & 63.942 & Autarquia \\
\hline Cosmópolis & 24.761 & Economia Mista \\
\hline Dois Córregos & 16.438 & Concessão Privada \\
\hline Elias Fausto & 12.678 & \\
\hline Holambra & &
\end{tabular}

\footnotetext{
${ }^{15}$ População baseada no Censo de 2010 do Instituto Brasileiro de Geografia e Estatística.

${ }^{16}$ Operadoras em atuação nos municípios no ano 2017.
} 


\begin{tabular}{|c|c|c|}
\hline & & (Continuação) \\
\hline Hortolândia & 207.665 & Economia Mista \\
\hline Indaiatuba & 220.762 & Autarquia \\
\hline Ipeúna & 6.617 & Administração Pública Direta \\
\hline Iracemápolis & 21.591 & Administração Pública Direta \\
\hline Itatiba & 108.484 & Economia Mista \\
\hline Itirapina & 15.524 & Administração Pública Direta \\
\hline Itu & 154.147 & Autarquia \\
\hline Itupeva & 50.622 & Economia Mista \\
\hline Jaguariúna & 49.074 & Administração Pública Direta \\
\hline Jarinú & 26.292 & Economia Mista \\
\hline Joanópolis & 12.153 & Economia Mista \\
\hline Jundiaí & 386.677 & Economia Mista \\
\hline Limeira & 284.627 & Concessão Privada \\
\hline Louveira & 41.974 & Administração Pública Direta \\
\hline Mairiporã & 88.150 & Economia Mista \\
\hline Mogi Mirim & 88.244 & Autarquia \\
\hline Mombuca & 3.294 & Economia Mista \\
\hline Monte Alegre do Sul & 7.415 & Administração Pública Direta \\
\hline Monte Mor & 53.151 & Economia Mista \\
\hline Morungaba & 12.374 & Economia Mista \\
\hline Nazaré Paulista & 17.236 & Economia Mista \\
\hline Nova Odessa & 54.139 & Economia Mista \\
\hline Paulínia & 92.231 & Economia Mista \\
\hline Pedra Bela & 5.859 & Economia Mista \\
\hline Pedreira & 43.693 & Autarquia \\
\hline Pinhalzinho & 13.784 & Economia Mista \\
\hline Piracaia & 25.573 & Economia Mista \\
\hline Piracicaba & 375.358 & Autarquia \\
\hline Rafard & 8.738 & Administração Pública Direta \\
\hline Rio Claro & 192.460 & Autarquia \\
\hline Rio das Pedras & 31.593 & Autarquia \\
\hline Saltinho & 7.420 & Administração Pública Direta \\
\hline Salto & 109.496 & Autarquia \\
\hline Santa Bárbara d’Oeste & 183.720 & Autarquia \\
\hline Santa Gertrudes & 23.450 & $\mathrm{BRK}^{5}$ \\
\hline Santa Maria da Serra & 5.698 & Economia Mista \\
\hline Santo Antonio de Posse & 21.561 & Autarquia \\
\hline São Pedro & 32.731 & Autarquia \\
\hline Socorro & 37.608 & Economia Mista \\
\hline Sumaré & 258.801 & Concessão Privada \\
\hline Torrinha & 9.330 & Economia Mista \\
\hline Tuiuti & 6.197 & Administração Pública Direta \\
\hline Valinhos & 115.258 & Autarquia \\
\hline Vargem & 9.287 & Economia Mista \\
\hline Várzea Paulista & 112.833 & Economia Mista \\
\hline Vinhedo & 69.449 & Autarquia \\
\hline
\end{tabular}




\begin{tabular}{|c|c|c|}
\hline \multicolumn{2}{|c|}{ Estado de Minas Gerais } \\
\hline Camanducaia & 21.901 & Economia Mista \\
\hline Extrema & 32.402 & Economia Mista \\
\hline Itapeva & 9.338 & Economia Mista \\
\hline Toledo & 6.111 & Economia Mista \\
\hline Sapucaí- Mirim & 6.241 & Economia Mista \\
\hline
\end{tabular}

A amostra de municípios que responderam efetivamente o Questionário A corresponde a 74,2\% dos municípios descritos no Quadro 2. A redução no tamanho amostral do estudo está associada ao fato de algumas operadoras de água municipais apresentarem baixa capacidade técnica e financeira para gerar os dados que o referido questionário buscou coletar. Por outro lado, questões políticas e institucionais das empresas de saneamento também contribuíram na redução da amostra, uma vez que houve casos em que a operadora contestou o fornecimento dos dados requeridos, alegando serem informações de acesso restrito que não podem ser divulgadas em formato individualizado.

\section{Etapa 1.4: Análise da credibilidade dos dados coletados}

Os serviços de abastecimento de água do Brasil apresentam deficiências operacionais que prejudicam a credibilidade das informações provenientes das medições. Para calcular os indicadores de perdas deve existir a maior confiabilidade possível dos dados primários coletados para que os indicadores representem a realidade do sistema (PNCDA, 2003). Neste sentido, a credibilidade dos dados coletados via Questionário A foi verificada a partir da metodologia proposta pelo Programa Nacional para o Combate ao Desperdício de Água (PNCDA), vinculado à Secretaria Nacional de Saneamento Ambiental do Ministério das Cidades, que ressalta a importância de avaliar os dispositivos de medição com vistas a conhecer o grau de validação dos dados.

O volume de água disponibilizado (VD) $\left(\mathrm{m}^{3}\right)$, volume de água utilizado (VU) $\left(\mathrm{m}^{3}\right)$ e o volume de água faturado (VF) $\left(\mathrm{m}^{3}\right)$ são as principais variáveis que compõem os indicadores de perdas de água, assim, a credibilidade desses dados foi averiguada seguindo os cálculos apresentados na sequência.

\section{a) Credibilidade do Volume de água disponibilizado - C (VD)}

A credibilidade do VD foi expressa pela Equação 1 (PNCDA, 2003):

$$
C(V D)=k M x I M D \text {, em que: }
$$


- $\mathrm{kM}^{17}=1$

- IMD: Índice de Macromedição na Distribuição calculado pela Equação 2:

$$
\mathrm{IMD}=\frac{\mathrm{VPM}+\mathrm{VlmM}-\mathrm{VExM}}{\mathrm{VP}+\mathrm{Vlm}-\mathrm{VEx}}, \text { em que: }
$$

-VPM: Volume produzido macromedido

- VImM: Volume importado macromedido

- VExM: Volume exportado macromedido

-VP: volume produzido que inclui estimativas não macromedidas

- VIm: Volume total contabilizado como importados pelo serviço

- VEx: Volume total contabilizado como exportado pelo serviço

\section{b) Credibilidade do Volume de água utilizado - C (VU)}

A credibilidade do VU foi calculada pela Equação 3 (PNCDA, 2003):

$$
\mathrm{C}(\mathrm{VU})=\frac{\mathrm{ImVU} \times \mathrm{kM} \times \mathrm{Vm}+\mathrm{C}(\mathrm{VE}) \times \mathrm{VE}+\mathrm{C}(\mathrm{VO}) \mathrm{x} \mathrm{VO}+\mathrm{C}(\mathrm{VEs}) \times \mathrm{kMx} \mathrm{VEs}+\mathrm{C}(\mathrm{VR}) \mathrm{x} \mathrm{VR}}{\mathrm{VU}} \text {, em que: }
$$

- ImVU: o índice de micromedição do volume utilizado é representado pela Equação 4 onde Vm equivale ao volume micromedido e o VU ao volume utilizado

$$
\operatorname{ImVU}=\frac{\mathrm{Vm}}{\mathrm{VU}}
$$

- Credibilidade do volume estimado ${ }^{18}-\mathrm{C}$ (VE): atribui-se 0,95 (valor máximo) quando os consumos estimados forem fixados exclusivamente com base em monitoramento estatisticamente controlado de padrões de consumo por tipo de consumidor em áreas medidas análogas às não medidas, na mesma jurisdição do sistema considerado. Será fixada em 0,5 sempre que as estimativas se basearem em combinação de levantamentos de campo realizados sobre amostra pouco significativa estatisticamente, com resultados de levantamentos de outras localidades. Será fixada em 0,3 quando os procedimentos de estimativa forem baseados na simples analogia com casos de outra(s) localidade(s).

- Credibilidade de volume operacional ${ }^{19}-\mathrm{C}(\mathrm{VO})$ - atribuísse 1 a este fator quando os usos da água na operação são registrados individualmente e depois consolidados; quando for estimado com base na rotina operacional atribuísse 0,6 .

- Credibilidade do volume especial ${ }^{20}$ - C (VEs): dada pela relação do volume especial macromedido (VEsM) e volume especial (VEs) (Equação 5):

$$
\mathrm{C}(\mathrm{VEs})=\frac{\mathrm{VEsM}}{\mathrm{VEs}}
$$

- Credibilidade do volume recuperado ${ }^{21}$ - C (VR): calculado em função do volume recuperado micromedido (VRm) e o volume recuperado estimado (VRe) (Equação 6):

17 Corresponde ao fator multiplicador constante sobre desvios sistemáticos. Enquanto não se fixam os critérios para a sua determinação recomenda-se adotar $\mathrm{kM}=1$ para todos os serviços (PNCDA, 2003).

${ }^{18}$ Corresponde à projeção de consumo a partir dos volumes micromedidos em áreas com as mesmas características da estimada, para as mesmas categorias de usuários.

19 Corresponde ao volume de água utilizado em testes de estanqueidade e desinfecção das redes (adutoras, subadutoras e distribuição) (PNCDA, 2003)

${ }^{20}$ Corresponde aos volumes destinados ao corpo de bombeiros, caminhões-pipa e uso próprio nas edificações do prestador de serviços (PNCDA, 2003).

${ }^{21}$ Corresponde a neutralização de ligações clandestinas e fraudes (PNCDA, 2003) 


$$
\mathrm{C}(\mathrm{VR})=\frac{\mathrm{VRm}+(0,5 \times \mathrm{VRe})}{\mathrm{VR}}
$$

\section{c) Credibilidade do Volume de água faturado - C (VF)}

A credibilidade do volume faturado $\mathrm{C}(\mathrm{VF})$ foi medida pela razão entre as ligações ativas micromedidas (Lm) e o total de ligações ativas (LA) (PNCDA, 2003) (Equação 7):

$$
\mathrm{C}(\mathrm{VF})=\frac{\mathrm{Lm}}{\mathrm{LA}}
$$

Após verificada a credibilidade dos dados acima descritos, os mesmos foram enquadrados nas quatro faixas de variação, descritas no Quadro 3, sendo utilizados na pesquisa os dados das operadoras que se enquadraram nas faixas I e II.

Quadro 3 - Escala de credibilidade dos dados operacionais.

\begin{tabular}{|c|l|}
\hline Faixa de variação & \multicolumn{1}{c|}{ Credibilidade da informação } \\
\hline I (0-80 a 1,00) & $\begin{array}{l}\text { Informação plenamente crível para fins de previsão de demanda, } \\
\text { planejamento de oferta e comparação entre serviços. }\end{array}$ \\
\hline II (0,60 a 0,79) & $\begin{array}{l}\text { Informação parcialmente crível, com restrições sobre o uso para } \\
\text { comparação entre serviços. }\end{array}$ \\
\hline III (0,30 a 0,59) & $\begin{array}{l}\text { Aproximação de tendências, utilizável apenas para a fixação imediata } \\
\text { de prioridades internas, sem segurança sobre comportamentos futuros } \\
\text { e inválida para fins de comparação entre serviços. }\end{array}$ \\
\hline IV (0 a 0,29) & Informação não utilizável. \\
\hline
\end{tabular}

Fonte: Adaptado de PNCDA (2003).

\section{Etapa 1.5: Cálculo dos indicadores}

Posteriormente à coleta de dados primários e análise da credibilidade, os mesmos foram aplicados a fórmula do indicador selecionado na Etapa 1.1, para avaliação do desempenho no controle de perdas de água de cada município que, na Etapa 3 foram analisados em conjunto com as práticas de controle. Com o cálculo do indicador de perda de água de cada município, os mesmos foram categorizados em níveis de desempenho, tais como as categorias apresentadas no Plano de Bacias, porém, em níveis adaptados a unidade do indicador selecionado.

Somado à avaliação do desempenho das operadoras, os municípios foram organizados em clusters (grupos) e testes estatísticos foram empregados para verificar se há diferença significativa entre os níveis de perdas dos municípios considerando os seguintes fatores:

(a) Porte do município (Clusters: pequeno, médio e grande);

(b) Natureza Jurídica da operadora (Clusters: Administração pública Direta, Autarquias, Economia Mista e Concessão Privada);

(c) Existência de áreas de pobreza (Clusters: Presença de áreas de pobreza e ausência de áreas de pobreza). 
Utilizando o software Minitab 17, o primeiro passo para esta análise correspondeu a verificação da normalidade dos dados dos clusters aplicando o teste estatístico de Anderson Darling em que valor-p $<0,05$ pressupõe a não normalidade dos dados e valor-p $>0,05$ prediz a normalidade. A partir da não normalidade dos dados identificada com a aplicação do referido teste, selecionou-se o teste não paramétrico de Mann-Whitney, o qual busca analisar se há diferença significativa entre as medianas de dois grupos. $\mathrm{Na}$ análise em questão buscou-se responder se há diferença significativa entre o nível de perdas de água dos clusters descritos nos itens $\mathrm{a}, \mathrm{b}$ e c.

\section{ETAPA 2 - Levantamento das práticas de controle de perdas de água nas Bacias PCJ (objetivo específico 3)}

A Etapa 2 representou o levantamento das práticas de controle de perdas de água empregados pelas operadoras da área em estudo. Para tanto elaborou-se e aplicou-se o Questionário B (Apêndice II) junto às operadoras que atuam nas bacias.

\section{Etapa 2.1: Elaboração de questionário de processos de controle de perdas}

O Questionário B - Práticas de controle de perdas de água na distribuição foi formulado baseado no levantamento, na literatura, das principais práticas utilizadas no controle de perdas de água, tanto físicas como aparentes, de acordo com o exposto no subcapítulo 3.3 deste documento. Ainda que o questionário apresentasse uma série significativa de práticas de controle de perdas, não havia uma questão aberta onde o respondente pudesse citar e apresentar outras possíveis práticas que eventualmente não foram identificadas na literatura, mas, que são empregadas pela operadora. Após formulado houve um pré-teste do mesmo para reduzir problemas de questões mal formuladas, ausência de ordem nas respostas, grande número de comentários adicionais e verificar o tempo de preenchimento.

Este questionário buscou verificar quais as práticas desempenhadas pelas empresas de saneamento em estudo no controle de perdas de água. Conforme expresso pela Aneel (2012), práticas interligadas que se propõem a atender um objetivo específico compõem um processo. Mais adiante, no Capítulo 3 deste documento, são apresentadas nas Figuras 6 e 7 oito categorias consideradas como ações básicas, na literatura fundamental, para controle das perdas de água em sistemas de distribuição, tanto físicas como aparentes. Para fins desta pesquisa algumas dessas categorias foram dissolvidas dentro dos processos propostos neste estudo e outros dois novos processos de controle de perdas que envolvem aspectos financeiros e de planejamento organizacional foram criados ("Investimento e Inovação" e "Planejamento Estratégico"). 
Neste sentido, as 54 práticas de controle de perdas de água apuradas na literatura foram estruturadas em oito caixas de processos de gestão de perdas, vê-se (Quadro 4):

Quadro 4 - Práticas de controle de perdas organizadas em processos.

\begin{tabular}{|c|c|}
\hline & PRÁTICAS DE CONTROLE DE PERDAS DE ÁGUA \\
\hline $\begin{array}{l}\text { PROCESSO } 1 \\
\text { Gerenciamento } \\
\text { de pressão }\end{array}$ & $\begin{array}{l}\text { P1. Utilização de medidores de pressão e acompanhamento das pressões na rede. } \\
\text { P2. Centro de telecontrole para acompanhar as pressões na rede. } \\
\text { P3. Utilização de válvulas redutoras de pressão. } \\
\text { P4. Redução da pressão de água no período noturno. } \\
\text { P5. Pressão média da rede dentro do estabelecido pela NBR } 12218 / 1994^{22}(100 \mathrm{KPa} \\
\text { (10 mca) de pressão dinâmica e } 500 \mathrm{KPa} \text { ( } 50 \text { mca) de pressão estática). } \\
\text { P6. Reservatórios automatizados. }\end{array}$ \\
\hline $\begin{array}{c}\text { PROCESSO } 2 \\
\text { Gerenciamento } \\
\text { de infraestrutura }\end{array}$ & $\begin{array}{l}\text { P7. Substituição de ramais prediais antigos. } \\
\text { P8. Macromedição. } \\
\text { P9. Cadastro georreferenciado das tubulações. } \\
\text { P10. Plano de manutenção anual da rede (Limpeza/Reabilitação). } \\
\text { P11. Controle de qualidade dos materiais e equipamentos utilizados na manutenção } \\
\text { da rede. } \\
\text { P12. Estabelecimento de procedimentos operacionais padrões. } \\
\text { P13. Calibragem periódica dos equipamentos da rede (medidores, válvulas). } \\
\text { P14. Treinamento para a equipe de manutenção e operação (Certificação). }\end{array}$ \\
\hline $\begin{array}{c}\text { PROCESSO } 3 \\
\text { Controle da } \\
\text { corrosão em } \\
\text { tubulações }\end{array}$ & $\begin{array}{l}\text { P15. Revestimento interno da tubulação. } \\
\text { P16. Revestimento externo da tubulação. } \\
\text { P17. Priorização do uso de tubulação de material não metálico. }\end{array}$ \\
\hline $\begin{array}{c}\text { PROCESSO } 4 \\
\text { Controle de } \\
\text { vazamentos }\end{array}$ & $\begin{array}{l}\text { P18. Utilização de escutas de solo para detectar vazamentos não visíveis. } \\
\text { P19. Definição da melhor frequência de pesquisa de vazamentos. } \\
\text { P20. Equipe que atua em tempo integral no reparo dos vazamentos. } \\
\text { P21. Utilização de modelos computacionais/matemáticos de simulação para } \\
\text { detecção de fugas. } \\
\text { P22. Utilização de método de consumo zero para detectar vazamentos não visíveis. } \\
\text { P23. Utilização de método de consumo mínimo noturno para detectar vazamentos } \\
\text { não visíveis. } \\
\text { P24. Organização do sistema em zonas de medição (setorização, DMC). } \\
\text { P25. Equipe exclusiva para "caça vazamentos". } \\
\text { P26. Teste de estanqueidade nos hidrômetros. } \\
\text { P27. Canal de comunicação para que o usuário possa alertar sobre vazamentos nas } \\
\text { ruas (visíveis). }\end{array}$ \\
\hline $\begin{array}{c}\text { PROCESSO } 5 \\
\text { Controle de } \\
\text { erros de medição }\end{array}$ & $\begin{array}{l}\text { P28. Troca corretiva de hidrômetros. } \\
\text { P29. Troca preventiva otimizada de hidrômetros. } \\
\text { P30. Fiscalização de hidrômetros para verificar erros de medição. } \\
\text { P31. Utilização de hidrômetros de maior precisão. } \\
\text { P32. Utilização de hidrômetros com telemetria através de rádio frequência. } \\
\text { P33. Treinamento adequado da equipe de leitura dos hidrômetros. }\end{array}$ \\
\hline
\end{tabular}

\footnotetext{
22 Para fins desta pesquisa foram utilizados os parâmetros da versão de 1994 da NBR 12.218. Porém, em maio de 2017 esta norma foi atualizada, estabelecendo um novo limite máximo de pressão estatística, 40 mca.
} 


\begin{tabular}{|c|c|}
\hline $\begin{array}{l}\text { Controle de } \\
\text { fraudes e } \\
\text { ligações } \\
\text { clandestinas }\end{array}$ & $\begin{array}{l}\text { P34. Conscientização da população sobre o problema das fraudes e ligações } \\
\text { clandestinas. } \\
\text { P35. Inspeção regular de ligações suspeitas e inativas. } \\
\text { P36. Reparo de hidrômetros inclinados. } \\
\text { P37. Utilização de tecnologias para detectar ligações clandestinas. } \\
\text { P38. Acompanhamento do consumo mensal dos usuários para detectar fraudes. } \\
\text { P39. Atuação em áreas de pobreza para controlar as fraudes. } \\
\text { P40. Denúncia de fraudes pela comunidade. } \\
\text { P41. Atualização anual do cadastro dos usuários. }\end{array}$ \\
\hline $\begin{array}{l}\text { Planejamento } \\
\text { Estratégico }\end{array}$ & $\begin{array}{l}\text { P42. Estabelecimento de um Plano/Programa de combate as perdas de água. } \\
\text { P43. Definição de uma meta de redução de perdas. } \\
\text { P44. Departamento/Seção específica da organização voltado ao controle de perdas. } \\
\text { P45. Diagnóstico da situação das perdas no município. } \\
\text { P46. Uso de indicadores para avaliar o desempenho no controle de perdas. } \\
\text { P47. Desenvolvimento de estudos de priorização de zonas mais críticas para o } \\
\text { controle de perdas. } \\
\text { P48. Análises de custo benefício para ações no controle de perdas. } \\
\text { P49. Reunião periódicas para análise dos resultados das ações de controle e } \\
\text { planejamento das consecutivas }\end{array}$ \\
\hline $\begin{array}{l}\text { PROCESSO } 8 \\
\text { Investimento e } \\
\text { inovação }\end{array}$ & $\begin{array}{l}\text { P50. Investimento em tecnologias voltadas ao controle de perdas. } \\
\text { P51. Adoção de metodologias como MASPP e Six Sigma. } \\
\text { P52. Investimento em cursos de capacitação/treinamento dos funcionários voltados } \\
\text { ao controle de perdas. } \\
\text { P53. Uso de SIG no auxílio ao controle de perdas. } \\
\text { P54. Investimento na elaboração de manuais de gerenciamento de perdas. }\end{array}$ \\
\hline
\end{tabular}

\section{Etapa 2.2: Aplicação de questionário in loco (Questionário B)}

A aplicação do Questionário B deu-se simultaneamente à coleta de dados da Etapa 1, como demonstrado na Figura 3, porém, no formato de coleta in loco. Para tanto foram organizadas visitas às operadoras de água de cada um dos municípios pertencentes aos Comitês PCJ, excetuando-se os municípios operados por Companhias Estaduais (24 do Estado de São Paulo e quatro do Estado de Minas Gerais) cujo preenchimento dos questionários deu-se de forma concentrada por responsáveis indicados pelas empresas.

Em referência aos outros 45 municípios em estudo, que não são operados pelas Companhias Estaduais, o primeiro passo para o agendamento das visitas equivaleu a identificação dos responsáveis-chave que dominassem o assunto em pauta e poderiam responder ao questionário adequadamente. A partir disto as visitas foram agendadas, de acordo com a disponibilidade de cada responsável, ocorrendo em um período de oito meses (novembro 2016 - junho 2017). Assim como para o Questionário “A” a amostra de municípios que participaram efetivamente da pesquisa foi menor do que a amostra total. Com referência ao Questionário B, 65 municípios participaram efetivamente da pesquisa uma vez que alguns municípios, por questões políticas e administrativas relacionadas as mudanças de gestão municipal, não tiveram disponibilidade em participar do processo de aplicação dos questionários. 


\section{ETAPA 3: Análise estatística (objetivo geral)}

Na última etapa da pesquisa os resultados das Etapas 1 e 2 foram cruzados para verificar quais práticas estão relacionadas ao desempenho das operadoras no controle de perdas. Para tanto, para cada prática os municípios foram organizados em grupos de acordo com o emprego ou não de cada ação e teste estatísticos foram conduzidos para analisar os dados. O detalhamento dos testes conduzidos é apresentado na sequência.

\section{Etapa 3.1: Organização dos dados de pesquisa}

Para fins da análise estatística os dados coletados foram classificados em dois grupos de variáveis, conforme descrito abaixo:

$\checkmark$ Variáveis independentes ou explicativas: As variáveis explicativas desta pesquisa são todas qualitativas correspondendo às 54 práticas de controle de perdas de água.

Variável dependente ou resposta: A variável resposta da estatística aplicada corresponde ao nível de perda de água dos municípios (variável quantitativa).

Em referência as variáveis explicativas, frente a dicotomia das respostas atribuídas as questões do Questionário B (Sim/Não), os municípios em análise foram, para cada prática, estruturados em dois grupos: Grupo "Sim” (municípios que empregam a prática em análise) e Grupo "Não" (municípios que não adotam a prática em análise).

No que diz respeito à variável resposta, os níveis de perdas de água dos municípios, usualmente classificados em três categorias (Bom, Médio, Ruim), como as faixas de valores apresentadas no Plano de Bacias PCJ, foram organizados em duas Classes (A e B) onde A assumiu-se que se enquadram as operadoras com desempenho superior no controle de perdas, enquanto B se enquadram as operadoras com desempenho inferior, ou seja, com níveis de perdas de água na distribuição mais elevados.

Organizados os dados e estabelecidos os grupos para cada prática os testes estatísticos foram conduzidos nas Etapas 3.2 e 3.3, cada um com o seu objetivo.

\section{Etapa 3.2: Aplicação do teste de comparação de média}

Para analisar a ocorrência de diferenças significativas nos níveis médios de perdas de água entre os grupos de municípios ("Sim" e "não"), o teste t foi aplicado, utilizando o software matemático Statistical Analisys Sytem - SAS 9.4. Com um nível de significância de 5\% $(\alpha<$ 0,05) as hipóteses que nortearam este teste foram: 
- H0 (hipótese nula): Não há diferenças significativas no nível de perdas de água entre o grupo de municípios "Sim" e o grupo "Não" para cada prática de controle.

- H1(hipótese alternativa): Há diferenças significativas no nível de perdas de água entre o grupo de municípios “Sim” e o grupo "Não” para cada prática de controle.

A decisão da aceitação ou rejeição de H0 para este teste foi baseada na análise do valorp. Com valor-p menor do que o nível de significância $(\alpha<0,05)$ rejeitou-se a hipótese de que não há diferença significativa entre o nível de perdas dos dois grupos de municípios e, com valor-p > 0,05, aceitou-se a hipótese que o nível de perdas dos dois grupos não difere.

\section{Etapa 3.3: Análise da relação das práticas de controle com o desempenho}

Buscando explorar quais práticas de controle de perdas apresentam relação com os níveis de perdas de água municipais considerados nesta pesquisa como desempenhos superiores (Classe A), o teste exato exato de Fisher, complementado pela análise de correspondência múltipla (ACM) foi o método estatístico selecionado.

Assim, utilizando o software SAS 9.4 determinou-se, mediante a aplicação do teste exato de Fisher, o qual foi selecionado frente ao tamanho amostral deste estudo, insuficiente para a análise de Qui-quadrado, quais práticas de controle (P1-P54) apresentam associação com a Classe A de desempenho no controle de perdas, considerando um nível de significância de $5 \%$, isto é, quais práticas influem no nível de perdas quando adotadas ou não, representando uma relação de dependência entre as variáveis.

Na sequência, complementando a inferência do teste de Fisher e buscando analisar as relações conjuntas entre os grupos "Sim/Não" e "Desempenho Superior/Inferior", a técnica multivariada de análise de correspondência múltipla (ACM) foi conduzida utilizando o software STATISTICA 10.0. Apresentada como uma técnica de interdependência flexível à diferentes questões e empregando dados não métricos para representar as relações existentes entre as categorias simultaneamente (HAIR et al., 2009) (Sim/Não e Superior/Inferior), a ACM produziu mapas perceptuais bidimensionais que possibilitaram a visualização das relações existentes entre as variáveis em estudo, identificando assim, quais práticas de controle estão associadas aos níveis de perdas de água e como ocorre esta relação. 


\section{PERDAS DE ÁGUA EM SISTEMAS DE DISTRIBUIÇÃo}

A premência na redução dos níveis de perdas de água nos sistemas de distribuição, dentro do ciclo urbano da água, é universal em função da escassez hídrica que as sociedades têm enfrentado nas últimas décadas (DELGADO-GÁLVAN et al., 2010; LIN, et al., 2015; MOLINOS-SENANTE, et al., 2016). Os investimentos na expansão das redes de abastecimento de água brasileiras foram historicamente privilegiados no setor do saneamento, porém o emprego dos recursos em manutenção e modernização da gestão das mesmas não foi focalizado, o que gerou uma série de ineficiências, entre as quais se destacam os elevados níveis de perdas de água (TONETO JÚNIOR, et al., 2013).

Neste contexto, a adoção de estratégias de gestão sólidas e eficazes baseada em uma melhor compreensão das causas das perdas de água e dos fatores que as influenciam são imprescindíveis (KÖLBL, et al., 2009; KANAKOUDIS; TSITSIFLI, 2010). De acordo com o Banco Mundial, mais de um terço das perdas ocorrem em países em desenvolvimento onde aproximadamente 45 milhões de $\mathrm{m}^{3} /$ dia são perdidos no processo de distribuição, sendo esta quantia o suficiente para abastecer 200 milhões de pessoas (THE WORD BANK, 2008).

As perdas estão relacionadas com diversos fatores e representam basicamente a diferença entre o volume de água tratada disponibilizado à distribuição (macromedição) e o volume de água medido nos hidrômetros dos consumidores finais (micromedição), representando o uso ineficiente da água tanto em termos do recurso hídrico natural como da água potável (ALEGRE; COVAS, 2010; STURM, et al., 2014; TARDELLI FILHO, 2016). A Internacional Water Association (IWA), a Associação Brasileira de Engenharia Sanitária e Ambiental (ABES) e Kingdom et al. (2006) classificam as perdas de água nos sistemas de distribuição em duas categorias, detalhadas na sequência: Perdas de água Física ou Real e Perdas de água Comercial ou Aparente (ALEGRE et al., 2000; KINGDOM, et al., 2006; ABES, 2013).

As cidades brasileiras possuem sistemas de abastecimento com perdas que vão desde a captação de água dos mananciais até as residências dos usuários gerando problemas de dimensão econômico-financeira, técnica, ambiental, de saúde pública e social que, de modo geral, comprometem a saúde financeira e a qualidade na prestação do serviço das operadoras, limitando sua capacidade de expandir o acesso à água, especialmente em regiões mais carentes (ALEGRE, et al., 2005; THE WORD BANK, 2008; SALAMONI, et al., 2014; SANTOS; MONTENEGRO, 2014). 
Os altos níveis de perdas de água elevam os custos para as operadoras de abastecimento, aceleram o processo de deterioração da infraestrutura (D'ERCOLE, et al., 2016), além de aumentar o risco de contaminação da água potável se os níveis de pressão da rede de distribuição forem muito baixos possibilitando que poluentes infiltrem através de rupturas nas tubulações (GONZÁLEZ-GÓMEZ, et al., 2012;). Em tese, as principais causas dos atuais níveis de perdas estão relacionadas à: falta de investimento em manutenção das redes; necessidade de adoção de tecnologias requeridas para o monitoramento das redes e da produção; definição de preços que em alguns casos não refletem o grau de escassez do recurso hídrico; custos de externalidades negativas; e incentivos limitados para melhorias na gestão (OLIVEIRA, et al., 2015).

Frente a atual demanda mundial de controlar as perdas de água, as medições do volume de perdas apresentam-se como uma ferramenta indispensável para avaliar se as ações de operação e manutenção do sistema de água estão sendo bem conduzidas, sendo o nível de perda de água o indicador mais relevante da ineficiência econômica, social e ambiental dos sistemas de distribuição (HERNÁNDEZ-SANCHO, et al., 2012; VILANOVA et al., 2015; TARDELLI FILHO, 2016).

Para Renzetti e Dupont (2013) reduzir os níveis de perdas de água em um sistema de abastecimento, adotando medidas de gestão adequadas, representa uma economia financeira não só para a operadora, mas também para o consumidor. A minimização das perdas induz à redução significativa dos custos de produção podendo expandir a oferta de água a mais consumidores em um mesmo sistema, além de reduzir os impactos ambientais, minimizando a captação de água dos corpos hídricos. Karadírek (2016) assinala ainda que a gestão de perdas de água reduz os custos com energia para captação de água e com produtos químicos necessários para o tratamento da água.

Deste modo, Moura et al. (2004) assinalam que a redução das perdas nos sistemas de abastecimento de água deve ser compatível as condições ambientais e econômicas de cada região, devendo buscar sempre a melhoria dos materiais, mão-de-obra, mobilização de profissionais e racionalização dos processos de gestão das companhias de saneamento. Assim, Morrison et al. (2007) destacam que o gerenciamento das perdas de água é fundamental para a melhoria da eficiência das redes de abastecimento, assegurando a sustentabilidade ambiental e social à longo prazo. 


\subsection{Perdas de água física ou real}

As perdas físicas ou reais ocorrem quando o volume de água disponibilizado para distribuição não é utilizado pelos usuários, sendo desperdiçado antes de chegar as unidades de consumo em função de vazamentos existentes nos sistemas de distribuição e extravasamentos em reservatórios (ALEGRE, et al., 2000; AWWA, 2012; ABES, 2013). Segundo Rossigneux e Fernandes (2004), a redução das perdas físicas de água é uma preocupação constante das companhias de saneamento, uma vez que, não está relacionado apenas aos aspectos da perda de um bem de valor econômico, mas também, às alterações de qualidade da água e aumento de custos de operação.

Alegre et al. (2005) sublinham que o estado das tubulações, a frequência de vazamentos, a pressão do sistema, a densidade e comprimento médio de ramais, o comprimento total das tubulações, a localização do medido domiciliar, o tipo de solo e as condições do terreno são fatores relevantes que influenciam as perdas de água reais. $\mathrm{O}$ envelhecimento dos componentes do sistema de distribuição, decorrentes da degradação natural dos materiais ou desgaste dos mesmos, induz à redução do desempenho das operadoras ao longo do tempo, aumentando a ocorrência de rupturas, e consequentemente os níveis de perdas de água (ALEGRE; COVAS, 2010).

Em vista a estes enfoques, o Quadro 5 apresenta as possíveis origens das perdas físicas ou reais em subsistemas de abastecimento de água (PNCDA, 2003).

Quadro 5 - Perdas físicas e sua origem de acordo com o subsistema.

\begin{tabular}{|l|l|l|}
\hline \multirow{2}{*}{} & SUBSISTEMA & \multicolumn{1}{c|}{ ORIGEM } \\
\cline { 2 - 3 } & Adução de água bruta & Vazamento nas tubulações \\
\cline { 2 - 3 } & Tratamento & Vazamentos estruturais \\
\cline { 2 - 3 } & Reservação & Vazamentos estruturais \\
\cline { 2 - 3 } & Adução de água tratada & Extravasamentos \\
\cline { 2 - 3 } & \multirow{2}{*}{ Distribuição } & Vescargas \\
\cline { 2 - 3 } & & Vazamentos na rede \\
& & Vazamentos em ramais \\
& & Descargas \\
\hline
\end{tabular}

Fonte: Adaptado de PNCDA (2003).

No que concerne a questão das perdas físicas, estas podem ser subdivididas em perdas operacionais e perdas por vazamentos, descritas a seguir (PNCDA, 2003).

- Perdas operacionais: são as perdas associadas à operação dos sistemas, muitas vezes decorrentes de falhas operacionais dos próprios funcionários dos setores de operação e manutenção. Estas perdas podem estar ocultas sob a forma de usos úteis no processo produtivo, como por exemplo, água de lavagem de filtros. As medidas para controle 
destas perdas envolvem mudanças de procedimentos e melhorias operacionais associadas ao treinamento de pessoal com pequenos investimentos.

- Perdas por vazamentos: são as perdas de água decorrentes de rupturas em adutoras, subadutoras, redes e ramais prediais, trincas nas estruturas, entre outros. A decisão de reparar os vazamentos deve sempre estar acompanhada de estimativas de custos para a solução do problema e a manutenção preventiva das tubulações reduz as chances de ocorrência.

Tardelli Filho (2016) afirma que para direcionar adequadamente as ações de controle de perdas em sistemas de distribuição é essencial realizar um diagnóstico operacional do sistema de abastecimento, sendo de suma importância ter conhecimento dos três tipos de vazamentos possíveis, descrito na sequência e ilustrados na Figura 5, haja visto que diferem nos volumes perdidos.

Vazamentos visíveis: são aqueles que afloram à superfície das ruas;

$>\quad$ Vazamentos não visíveis (médias vazões): são detectados mediante pesquisas acústicas;

Vazamentos não visíveis (baixas vazões): não são detectáveis por equipamentos de pesquisa acústica, sendo denominados "vazamentos inerentes". 
Figura 5 - Tipos de vazamentos em sistemas de distribuição.

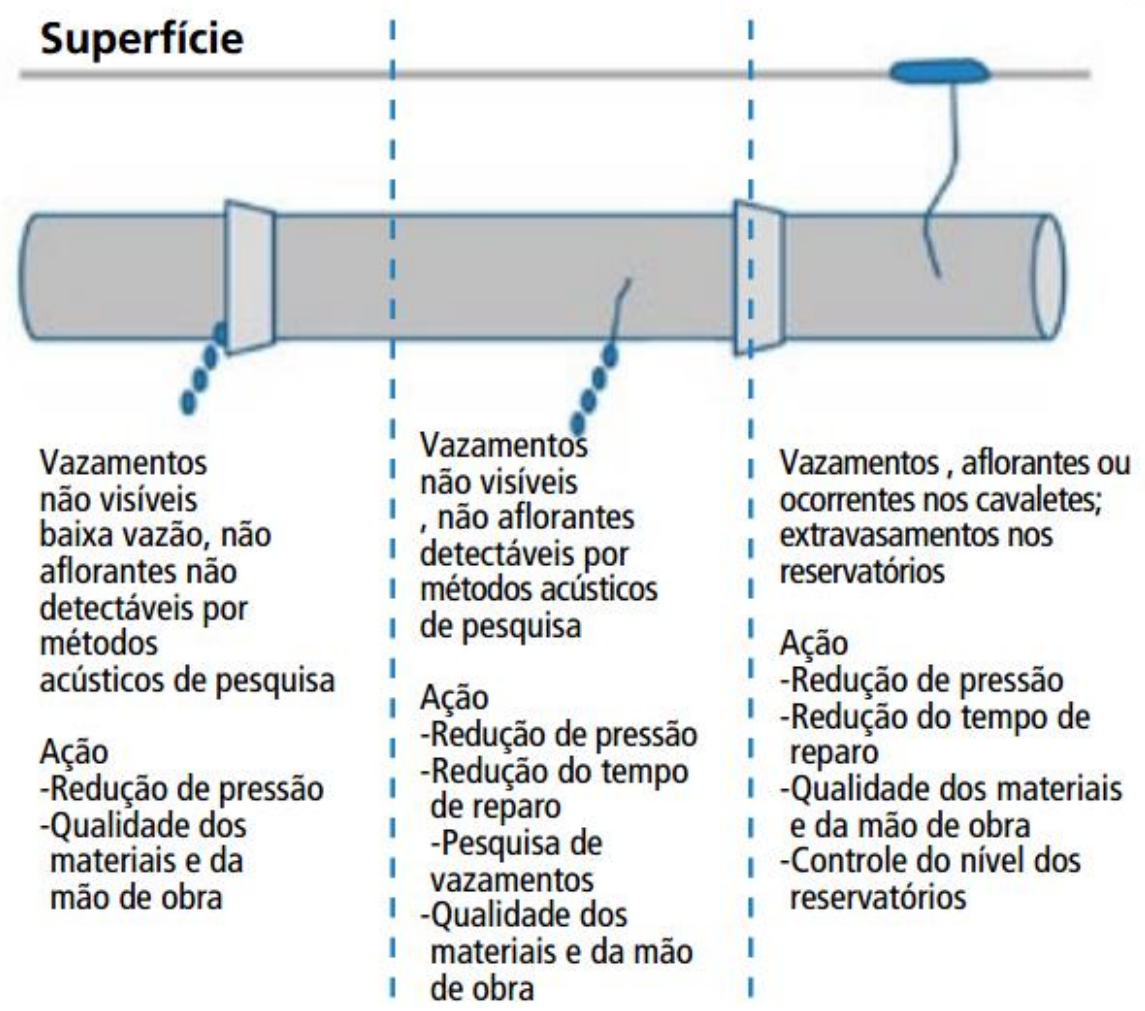

Fonte: AESABESP (2015).

Tendo em vista estes aspectos, Tardelli Filho (2016) enfoca ainda que os esforços de controle devem ser direcionados às perdas em ramais prediais, onde os vazamentos não são visíveis, correspondendo ao maior volume físico de água perdido.

Em se tratando dos impactos das perdas de água físicas, Oliveira et al. (2015) realçam que as mesmas afetam diretamente os custos de produção e a demanda hídrica gerando impactos na produção de água e no meio ambiente. Neste contexto, o Quadro 6 expõe os impactos das perdas, reafirmando a relevância do controle e redução das mesmas.

Quadro 6- Impactos das perdas de água.

\begin{tabular}{|l|l|}
\hline \multicolumn{1}{c|}{} & \multicolumn{1}{c|}{ IMPACTOS } \\
\hline PRODUÇÃO & $\begin{array}{l}\text { - Custos elevados com insumos químicos e energia para bombeamento; } \\
\text { - Elevada manutenção da rede. }\end{array}$ \\
\hline AMBIENTAL & $\begin{array}{l}\text { - Pressão desnecessária sobre os recursos hídricos, fonte de abastecimento; } \\
\text { - Elevado custo de mitigação dos impactos negativos (externalidade). }\end{array}$ \\
\hline
\end{tabular}

Fonte: Adaptado de Oliveira et al. (2015)

\subsection{Perdas de água comercial ou aparente}

As perdas de água comercial ou aparente, segundo a ABES (2013), ocorrem quando o volume utilizado não é devidamente contabilizado nas unidades de consumo, sendo cobrado de forma inadequada. Rios et al. (2014) identificaram em seu estudo que dependendo do cenário 
as perdas aparentes podem ser mais significativas do que as perdas reais, em termos financeiros. De acordo com Kingdom et al. (2006), anualmente 16 milhões $\mathrm{m}^{3}$ de água correspondem as perdas aparentes em todo o mundo.

Lambert (2000), Criminisi et al. (2009) e Mutikanga et al. (2011) defendem que as perdas aparentes são principalmente causadas por fraudes, ligações não cadastradas, imprecisão de medição e pelo sub-registro das leituras dos hidrômetros que são consideradas as perdas mais difíceis de quantificar. A causa do uso não autorizado varia em função de diferentes fatores entre os quais estão: a saúde econômica da população; o valor atribuído pela mesma à água como um recurso natural; as políticas de fiscalização das operadoras e o empenho em aplicar políticas eficazes para impedir o consumo não autorizado (AWWA, 2009). O Quadro 7 apresenta as possíveis fontes das perdas aparentes de água.

\begin{tabular}{|c|c|}
\hline & ORIGEM \\
\hline 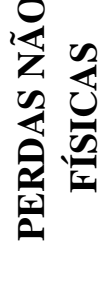 & $\begin{array}{l}\text { Ligações Clandestinas / Irregulares } \\
\text { Ligações não hidrometradas } \\
\text { Hidrômetros Parados } \\
\text { Hidrômetros que submedem } \\
\text { Ligações Inativas Reabertas } \\
\text { Erro de Leitura } \\
\text { Número de Economias Errado }\end{array}$ \\
\hline
\end{tabular}

No que se refere as fraudes em hidrômetros, Tsutiya (2006) aponta que são intervenções feitas com o intuito de medir apenas uma parcela do consumo efetivo da residência, sendo os casos mais comuns:

- Rompimento do lacre e inversão do hidrômetro;

- Execução de "by pass" no hidrômetro (desvio de água antes de chegar ao hidrômetro);

- Violação do hidrômetro (furo na cúpula e colocação de arame para travar dispositivos internos do hidrômetro;

- Inserção de um obstáculo no hidrômetro para impedir a rotação da turbina do hidrômetro.

\subsubsection{Perdas de água em áreas de vulnerabilidade social}

No que tange as questões das perdas aparentes em sistemas de distribuição é imprescindível considerar o consumo não faturado e não medido em áreas de vulnerabilidade social. A existência de centros populacionais dispersos com habitações em áreas periféricas resulta na gestão inadequada da infraestrutura de abastecimento representando um sério problema para a redução dos níveis de perda de água (GONZÁLEZ-GÓMEZ, et al., 2012). 
A questão das perdas de água nestas áreas remete as discussões acerca do direto a água. Em 2010, a Assembleia Geral da ONU declarou o acesso a água potável e limpa como um direito humano (WORLD HEALTH ORGANIZATION; UNITED NATIONS INTERNATIONAL CHILDREN'S EMERGENCY FUND, 2011). Porém, apesar de corresponder à um direito humano, a desigualdade no acesso a água é notada em todo o mundo e estudos retratam este cenário, como o relatório do Programa das Nações Unidas para o Desenvolvimento (2006) que identificou que a disponibilidade de água para os países mais ricos foi em média $85 \%$, enquanto nos mais pobres a cobertura foi em torno de $25 \%$.

$\mathrm{Na}$ maioria dos países do globo a maior proporção da população pobre habita áreas irregulares e, muitas vezes, não são incluídas nas estatísticas oficiais dos países, o que promove a discriminação e a falta de acesso aos serviços de saneamento básico, como o abastecimento de água (DE ALBUQUERQUE, 2012). A água é um elemento essencial para todas as atividades humanas e, a ineficiência ou em muitos casos a falta de acesso a este recurso induz as populações destas áreas a fazerem ligações clandestinas, aumentando os níveis de perdas de água aparente.

No Brasil, estas áreas são denominadas pelo IBGE como aglomerados subnormais, e definidas como:

"Conjunto constituído de, no mínimo, 51 unidades habitacionais (barracos, casas, etc.) carentes, em sua maioria de serviços públicos essenciais, ocupando ou tendo ocupado, até período recente, terreno de propriedade alheia (pública ou particular) e estando dispostas, em geral, de forma desordenada e densa" (IBGE, 2011).

Segundo o Censo de 2010, 6\% da população do Brasil moram em aglomerados subnormais onde é comum encontrar as chamadas "perdas sociais" que correspondem aos consumos não autorizados e não faturados, decorrentes de ligações clandestinas e fraudes. Consoante um estudo realizado pelo Instituto Trata Brasil, as perdas aparentes em áreas de vulnerabilidade social oscilam na faixa de 15 a $25 \%$ resultando numa perda financeira fundamental para a expansão dos serviços no país, além de efeitos negativos ao meio ambiente e aos usuários cadastrados (OLIVEIRA et al., 2015).

Frente a estes enfoques, Tardelli Filho (2016) aponta que para cada tipo de perda há uma abordagem diferente, recaindo sobre as "perdas reais" os custos de produção e distribuição de água, enquanto sobre as "perdas aparentes" recaem os custos de venda da água no varejo. A redução de perdas de água promove ganhos e proporciona diversos benefícios, contribuindo para o aumento da receita tarifária, melhorando o desempenho nos serviços prestados e 
contribuindo indiretamente para a ampliação da oferta efetiva (Quadro 8) (PNCDA, 2003; ABES, 2013).

\begin{tabular}{|c|l|l|}
\hline \multicolumn{3}{|c|}{ Quadro 8 - Ganhos e benefícios da redução de perdas. } \\
\hline Ganhos & $\begin{array}{l}\text { Redução de custos e postergação de } \\
\text { investimentos }\end{array}$ & Aumento da receita \\
\hline Benefícios & $\begin{array}{l}\text { Menor custos com produtos químicos, energia } \\
\text { e outros insumos; } \\
\text { Atendimento de maior número de pessoas } \\
\text { com a mesma quantidade de água produzida. }\end{array}$ & $\begin{array}{l}\text { Aumento do consumo } \\
\text { medido e faturado }\end{array}$ \\
\hline
\end{tabular}

Fonte: Adaptado de ABES (2013)

Os aspectos apresentados nesta seção evidenciam que, em meio ao cenário de crise hídrica e a importância da redução dos níveis de perdas, as ações de controle de perdas de água requerem atenção e devem estimular o uso racional dos recursos hídricos e a eficiência econômica das operadoras. Neste sentido, a seção 3.3 ocupa-se em apresentar algumas questões acerca do controle de perdas de água em sistemas de distribuição. 


\subsection{O controle dos níveis de perdas de água em sistemas de distribuição}

O controle das perdas de água e consequente redução dos níveis é visto como a chave para a gestão sustentável da água (VAN DEN BERG, 2015). Para Alegre e Coelho (2012) todas as operadoras de água devem adotar um conjunto de processos que garantam que os desempenho da mesma atenda as metas de serviço ao longo do tempo, que os riscos sejam adequadamente geridos e que os custos sejam os mais baixos possíveis. O controle das perdas nos sistemas de distribuição reduz a captação de água doce, o consumo de energia e a emissão de gases do efeito estufa (GEE), conduzindo os sistemas de abastecimento de água a serem mais sustentáveis (XU, et al., 2014; KOO, et al., 2015)

A ABES (2015) exprime que a preocupação com as perdas deve ocorrer desde as fases de projeto e construção dos sistemas de distribuição, envolvendo a concepção de processos que miram a qualidade na prestação do serviço e o controle das perdas de água. Nesta perspectiva, a adoção de tecnologias e processos adequados, que visem o controle de perdas em sistemas de abastecimento e o uso racional dos recursos hídricos, é um dos principais desafios das operadoras e quaisquer melhorias de gestão de perdas contribuem para o alívio da escassez hídrica (FRAUENDORFER; LIEMBERGER, 2010; ZYOUD, et al., 2016).

Os processos de controle de perdas, os quais variam em função do tipo de perda (real ou aparente) eficiência, complexidade, custo e impactos, devem ser adotados baseados em um acervo técnico e gerencial completo que contenha informações aprofundadas sobre a natureza das perdas, bem como, seus impactos e custos reais (ABES, 2015; ZYOUD, et al., 2016). O primeiro passo para controlar e reduzir as perdas de água é ter conhecimento do problema mediante um diagnóstico operacional do sistema, que envolve a coleta de dados e processamento das informações, de forma a vincular a necessidade da adoção de ações adequadas para avançar nos resultados de controle (ABES, 2015). Morais et al. (2010) exprimem ainda que a priorização de zonas com maior potencial de perdas é essencial para que as ações de controle sejam eficientes na redução dos níveis.

\subsubsection{Controle de perdas físicas ou reais}

As ações de controle e redução de perdas podem ser classificadas em dois tipos: ações que combatem os efeitos e ações que combatem as causas (TSUTIYA, 2006). Merks, Trow e Lambert (2016) acentuam que a pressão da água nas redes de distribuição tem grande influência na frequência de ocorrência de rupturas em ramais, sendo a gestão de pressão um dos principais processos a ser adotado para controlar as perdas reais, somado à rapidez das reparações de 
vazamentos e renovação e substituição de ativos, fatores apresentados por Thornton et al. (2008) como demonstrado na Figura 6.

Figura 6 - Processos para controle de perdas reais.

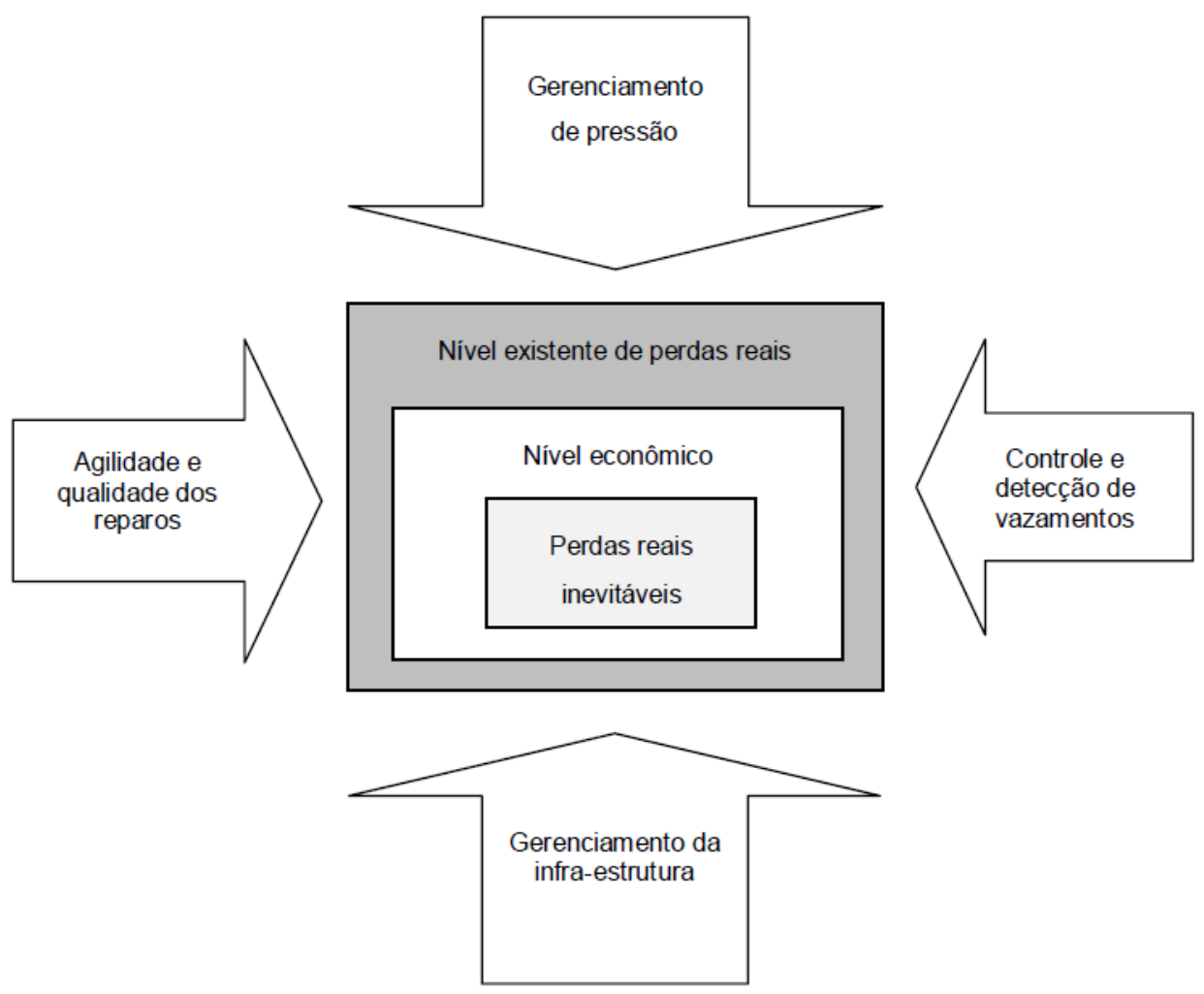

Fonte: Adaptado de THORNTON et al. (2008)

$\mathrm{Na}$ Figura 7, as setas direcionadas para a caixa central representam ações básicas e fundamentais para o controle das perdas reais. O quadro externo, representa o nível atual de perdas reais, que é o volume potencialmente recuperável pelas ações expostas nas setas. Já o quadro intermediário corresponde ao nível econômico de perdas, o qual seria alcançado se os recursos financeiros investidos se igualassem ao retorno financeiro esperado pelo custo do volume de água recuperado (THORTON et al., 2008; CORTON; BERG, 2009; ABES, 2013). A caixa menor equivale as perdas reais anuais inevitáveis, que correspondem ao nível mínimo de perdas de um sistema, tendo em vista que, como destacado pela AWWA (1996), não existem redes de abastecimento totalmente estanques.

É importante destacar que existem três pontos fundamentais para que as ações expostas na Figura 6 sejam eficazes, como observado por Tsutiya (2006): (i) materiais e equipamentos de qualidade, prevenindo que os problemas com vazamentos reincidam à curto prazo; (ii) equipe técnica treinada e preparada para a execução das ações e (iii) existência de cadastro atualizado das tubulações fornecendo informações precisas sobre as características da infraestrutura da rede de distribuição. 
A setorização ou District Metered Areas (DMA), instalação de medidores de vazão na rede de distribuição, instalação de válvulas de redução de pressão e uso de equipamentos de detecção de vazamentos são apresentados na literatura como eficientes processos no controle e redução de perdas reais (FANNER, et al., 2007; KALINKOV, et al., 2011; CHARALAMBOUS, et al., 2014; CHOI, et al., 2014; KANAKOUDIS; GONELAS, 2014; KANG, 2014; SALDARRIAGA; SALCEDO, 2015). Berardi et al. (2014) destacam a necessidade do desenvolvimento de projetos que indiquem o local ideal para a instalação e manutenção destes equipamentos, almejando os melhores resultados.

Santos e Pereira (2016) apresentam ainda o uso dos Sistemas de Informação Geográficas (SIG) como ferramentas eficientes no combate as perdas de água, pois possibilitam o cruzamento e espacialização de dados cadastrais das operadoras, favorecendo o controle operacional e a prevenção de problemas. Britton et al. (2013) exortam que a elaboração de um quadro político, que incentive as operadoras de água a identificar vazamentos, associada a implementação de tecnologias de medição inteligente, possibilitam que estas tenham acesso diário aos dados de vazamentos, facilitando que os reparos ocorram em um período de tempo razoável.

Para Xu et al. (2014), o controle de vazamentos de água nos sistemas de distribuição é uma valiosa ação para preservar os recursos hídricos, principalmente no atual quadro de escassez hídrica e mudanças climáticas, sendo essencial para o desenvolvimento urbano sustentável. Os autores citam ainda que as diversas medidas de controle de vazamentos criam oportunidades de emprego, estimulando o crescimento econômico e promovendo interesses sociais. (XU, et al., 2014). Nestas circunstâncias, Koo et al. (2015) apresentam o uso de sensores, associados à sistemas online compostos por um banco de dados virtual, como úteis para o monitoramento e otimização do abastecimento e consumo de água, sendo uma possível solução para que a indústria de água seja mais pró-ativa. Nesta conjuntura, Dziedzic e Karney (2014) e Arregui et al. (2009) apontam que o estabelecimento de um sistema de cadastro que forneça informações detalhadas sobre as condições da infra-estrutura hídrica, idade da tubulação e histórico dos vazamentos pode promover uma compreensão holística do sistema, auxiliando na maior eficiência no controle de perdas de água.

\subsubsection{Controle de perdas comerciais ou aparentes}

No que compete a questão do controle de perdas de água aparente, Leão et al. (2007) e Souza e Silva (2014) apresentam a micromedição como uma atividade essencial, que fornece informações importantes sobre os volumes fornecidos aos usuários, inibindo o desperdício de 
água e contribuindo diretamente para uma maior disponibilidade de água a ser distribuída para a população. Mutikanga et al. (2011) reforçam ainda que a substituição de hidrômetros antigos e a atualização de dados cadastrais dos usuários são importantes ações a serem adotadas para controlar as perdas aparentes, como ilustrado na Figura 7.

Assim como no controle de perdas reais, as setas direcionadas para a caixa central representam ações fundamentais para o controle das perdas aparentes. O quadro externo, representa o nível atual de perdas aparentes, enquanto o quadro intermediário corresponde ao nível econômico de perdas, o qual seria alcançado se os recursos financeiros investidos se igualassem ao retorno financeiro esperado pelo custo do volume de água recuperado (THRONTON et al., 2008; CORTON; BERG, 2009; ABES, 2013). Por fim, a caixa menor equivale as perdas aparentes anuais inevitáveis em um sistema.

Figura 7 - Processos para o controle de perdas aparentes.

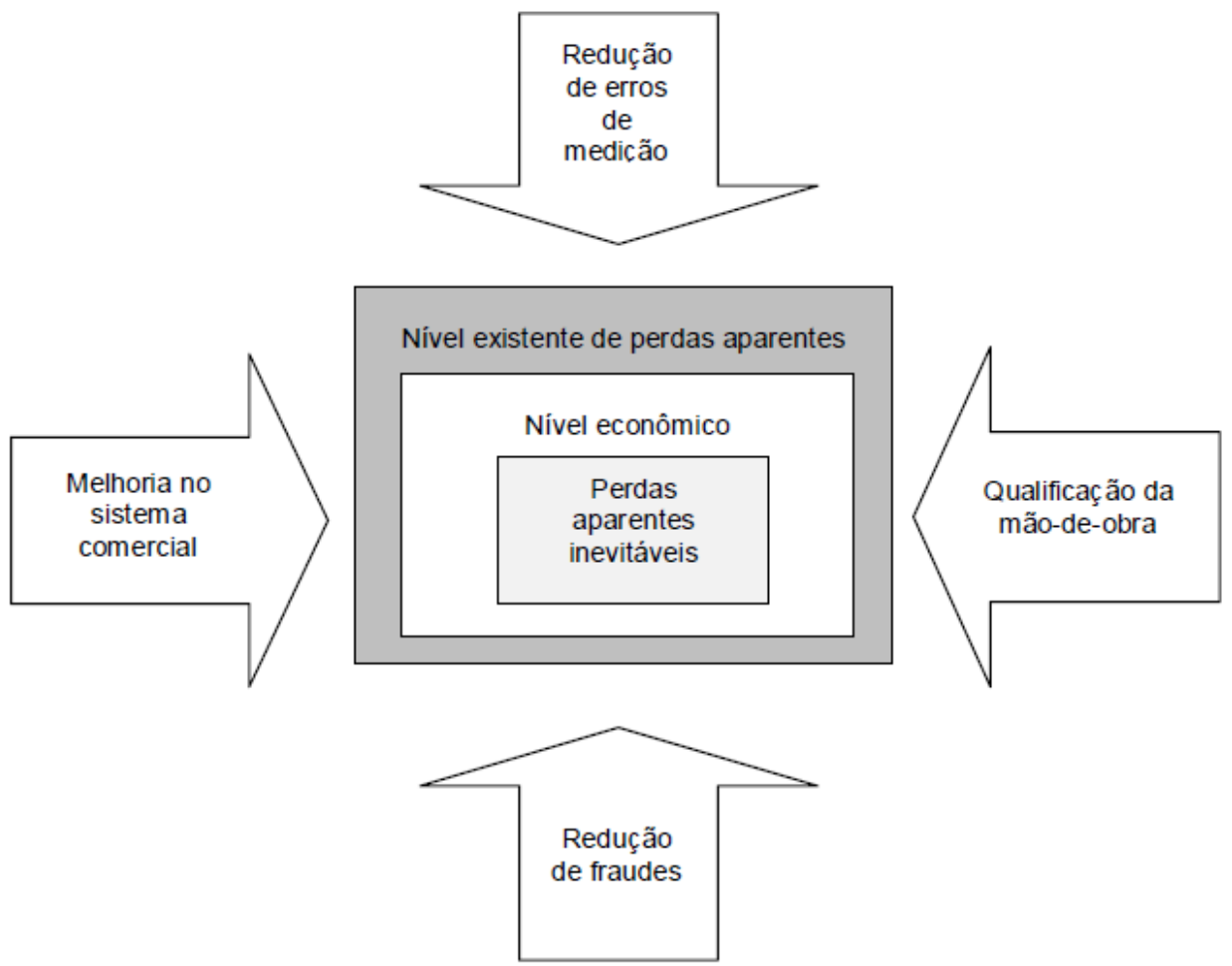

Fonte: Adaptado de THRONTON et al. (2008)

Tsutiya (2006) defende que a instalação adequada, bem como a troca corretiva e preventiva dos hidrômetros com a calibração periódica dos mesmos, inspeções de ligações suspeitas e coibição desta prática, somadas a rápida atualização do cadastro das ligações, apuração do consumo dos usuários e treinamento adequado dos profissionais são as principais ações para o controle e redução das perdas aparentes.

Carteado e Vermersch (2016) mencionam que há uma variedade de medidas que podem ser utilizadas para controlar as perdas de água aparentes, sendo tarefa do gestor das perdas 
selecionar a ferramenta mais adequada. Os métodos para controle são classificados pelos autores em dois tipos: métodos gerais e métodos específicos.

A pesquisa global sobre clientes é apresentada como o método geral mais utilizado no controle das perdas em questão, embora não seja a ferramenta com melhor relação de custo e eficácia. O objetivo desta pesquisa é elaborar um censo global de todos os consumidores, sendo possível detectar todas as irregularidades técnicas e administrativas, além de fornecer um melhor conhecimento dos consumidores e suas instalações, a fim de melhorar a prestação do serviço (CARTEADO; VERMERSCH, 2016). O levantamento de uma amostra representativa da base de dados dos clientes apresenta uma relação de custo-eficácia maior que da pesquisa global, pois consiste em uma análise detalhada de diferentes tipos de habitação da cidade. Os resultados deste levantamento auxiliam na determinação de estratégias necessárias para o combate as perdas de água.

Entre os métodos específicos de controle de perdas, a análise cartográfica permite uma análise dos planos de redes existentes e dos mapas de propriedades com consumo autorizado, dando suporte à organização de pesquisas de campo e identificação de propriedades com consumo não autorizado (CARTEADO; VERMERSCH, 2016). Os autores apontam que em alguns países europeus, as campanhas de "boa conduta", em que informantes locais denunciam ligações ilegais e fraudulentas, têm produzido bons resultados no controle de perdas de água aparente.

O uso de Sistema de Radar de Penetração no Solo (Ground Penetrating Radar System), que detecta ligações não autorizadas, e a implantação de dispositivos de controle de fluxo nos pontos de ligação, os quais facilitam a gestão da demanda de água, são também apresentados como métodos específicos de controle de perdas aparentes (CARTEADO; VERMERSCH, 2016).

Outra alternativa para mitigação das perdas é a organização do corpo de funcionários das operadoras de água que, como destacam Carteado e Vermersch (2016) depende do tamanho da mesma e da magnitude do problema. Em pequenas operadoras duas ou três pessoas são suficientes para lidar com as questões das perdas comerciais, já em operadoras de maior porte tem-se um departamento especializado na detecção de fraudes nas conexões. É essencial que todo o pessoal encarregado do controle de perdas aparentes tenha um treinamento especializado (CARTEADO; VERMERSCH, 2016).

Tendo em vista que as perdas aparentes ocorrem frequentemente em áreas de vulnerabilidade social, como apresentado na seção 3.2.1, Oliveira (2016), defende que para o 
controle de perdas de água nessas áreas, programas de abastecimento devem, além de fornecer condições mínimas para o abastecimento de água, promover a cultura da responsabilidade e da adimplência, desestimulando as ligações clandestinas e contribuindo com a melhoria das condições operacionais das companhias de saneamento, além de garantir o direito humano de acesso à água destas populações. O financiamento público é apresentado pelo Programa das Nações Unidas para o Desenvolvimento (2006) como a chave para enfrentar os problemas de acesso a água em áreas de vulnerabilidade, tornando real o direto humano a água, contribuindo com a redução dos níveis de perdas de água. Para Carteado e Vermersch (2016) a alternativa para o controle de perdas nessas áreas é a definição de uma política de gestão consistente, posto que é praticamente impossível atualizar o registro de clientes nessas áreas, uma vez que estes assentamentos não são reconhecidos formalmente pelos governos e as instalações são precárias ou muitas vezes inexistentes.

Por fim, no tocante ao controle de perdas de água aparente é interessante destacar que, em âmbito nacional, o "Programa Nacional de Combate ao desperdício de água" (PNCDA), em parceria com organizações públicas, lançou, em 2008, uma série de Guias Práticos de técnicas de operação em sistemas de abastecimento de água, entre os quais o volume 6 aborda técnicas de controle e redução de perdas aparentes (BOVO, et al., 2008), o qual elenca as ações apresentadas nesta seção.

\subsubsection{Programas voltados ao controle de perdas de água no cenário nacional}

As empresas brasileiras de abastecimento de água têm buscado continuamente controlar as perdas de água na distribuição, em função dos inúmeros problemas relacionados à sua ocorrência, como já descritos anteriormente. Não obstante a gama de ações existentes para o controlar as perdas de água apresentadas nas seções anteriores, Marques, Haddad e Guardia (2007) exortam que, além da adoção de ações administrativas e técnicas, o estabelecimento de um programa de gestão direcionado ao controle de perdas, com estabelecimento de metas e responsáveis para contínuo acompanhamento do desempenho faz-se necessário.

No Brasil, a Companhia de Saneamento do Paraná (Sanepar), a Companhia de Saneamento de Minas Gerais (Copasa) e a Companhia de Saneamento Básicos do Estado de São Paulo (Sabesp) são exemplos bem-sucedidos de empresas de saneamento que, criando Programas de Controle de perdas, conseguiram reduzir significativamente os níveis de perdas nas áreas em que atuam, sendo as manutenções preventivas, associadas ao uso de tecnologias, os fatores de destaque para o sucesso dos processos de controle destas empresas (AESABESP, 2015). Como apontado por Sobrinho e Borja (2016), a eficiência dos programas e ações de 
controle exigem a intersetorialidade e integralidade de ações, bem como a vontade política de todos os envolvidos em um sistema de saneamento, incluindo a sociedade como um todo.

Em âmbito Federal, o principal programa relacionado ao controle de perdas de água é o Programa Nacional de Combate ao desperdício de água (PNCDA), pertencente à Secretaria Nacional de Saneamento Ambiental do Ministério das Cidades (SNSA), o qual busca a promoção do uso racional da água no abastecimento público propiciando a melhor produtividade dos ativos existentes e a ampliação dos sistemas. O Programa lançou em 1999, com revisão em 2003, uma série de Documentos Técnicos de Apoio (DTA) e guias práticos que visam, mediante uma linguagem de fácil entendimento, recursos gráficos e fotos, auxiliar na melhoria das ações das equipes operacionais dos prestadores de serviços de saneamento. Os documentos abordam diversos temas relacionados às questões rotineiras vivenciadas pelas equipes de manutenção dos sistemas de abastecimento entre os quais há guias voltados ao gerenciamento das perdas de água reais e aparentes (PMSS, 2015a).

Além do PNCDA, a SNSA, por intermédio do Programa de Modernização do Setor Saneamento (PMSS), lançou o Projeto COM+ÁGUA. O principal objetivo do projeto é o gerenciamento integrado do controle e redução das perdas de água em sistemas de abastecimento mediante uma gestão participativa com mobilização interna e externa (ABES, 2015; PMSS, 2015b).

Outro importante Programa de abrangência nacional relacionado à eficiência das empresas de saneamento no controle de perdas é o Programa Saneamento para Todos, aprovado pela Resolução CC/FGTS nº76 que, através do Acordo de Melhoria de Desempenho - AMD, busca promover a eficiência, eficácia e a qualidade na prestação dos serviços de saneamento básico mediante o cumprimento de Metas de Desempenho Institucional pelos prestadores que aderirem o acordo. No contexto das perdas de água, estabeleceu-se como meta para as operadoras o nível de perdas no faturamento de $25 \%$ e o limite de perdas de 250 litros de água por ligação/dia como melhor desempenho (nível de desempenho A) (BRASIL, 2005).

Em meio as iniciativas nacionais e aos atuais debates relacionados ao controle e redução das perdas de água nos sistemas de distribuição brasileiros, a sociedade civil organizada, articulada com empresas públicas e o setor privado, lançaram em novembro de 2015, durante o Congresso da Associação Brasileira de Recursos Hídricos (ABRH), o movimento pela redução das perdas de água na distribuição intitulado "Menos perdas, mais água" (PNUD, 2015). O movimento é uma iniciativa da Rede Brasileira do Pacto Global das Nações Unidas, o qual tem como principal objetivo melhorar a eficiência na distribuição até 2030, sob a ótica do Objetivo 
de Desenvolvimento Sustentável (ODS) número 6 que busca "Assegurar a disponibilidade e gestão sustentável da água e saneamento para todos" (ONU, 2015).

O Plano de ação do movimento está estruturado em 4 pilares: (i) Políticas Públicas (influenciar o debate da pauta no Brasil); (ii) Narrativa (disseminar o conhecimento sobre perdas e buscar sensibilização e engajamento das partes interessadas); (iii) Indicadores (compreensão e harmonização de cálculo de perdas na distribuição); (iv) Soluções (disseminação de boas práticas e capacitação de atores estratégicos) (CHAPMAN; LELES, 2015). Assim, a partir destas ações a meta do movimento é reduzir o número de pessoas que sofrem com a escassez hídrica, manejando adequadamente os recursos hídricos, promovendo a redução da pobreza, o crescimento econômico e a sustentabilidade ambiental (PNUD, 2015). É interessante apontar que o Plano de ação do movimento se aproxima da estrutura de um processo de benchmarking, que busca após avaliar o desempenho das empresas, disseminar as melhores práticas na área.

As iniciativas voltadas para o controle e redução das perdas de água são evidentes e experiências nacionais têm demonstrado o sucesso das mesmas. Porém, os níveis de perdas de água nas regiões brasileiras são ainda preocupantes, o que indica a existência de barreiras no controle das perdas de água. Neste contexto, a seção 3.3.4 aborda os principais fatores que dificultam o controle de perdas de água em sistemas de distribuição.

\subsubsection{Barreiras para o controle de perdas de água em sistemas de distribuição}

Para Baggio (2015), a não execução do que foi planejado é o maior problema no combate às perdas de água. A implantação de Programas de Controle e Redução de perdas de água, que se apliquem a todas as etapas de um sistema de abastecimento de água, é fundamental em uma operadora para racionalizar o consumo de água e energia, devendo compor o Planejamento Estratégico da mesma (SOUZA; SILVA, 2014; ABES, 2015). As inovações em programas de controle e redução de perdas são crescentes e o maior obstáculo enfrentado para execução dos mesmos é a conciliação da boa gestão e a vontade política das operadoras em desenvolvê-los (THORNTON et al., 2008).

Neste contexto, Gomes, A. (2012) observa que muitos programas e projetos de controle e redução de perdas são ineficientes em decorrência de alguns fatores como o pouco conhecimento da origem das perdas, tratar a questão das perdas como um problema isolado e inerente ao gerenciamento e operação do sistema como um todo, e não considerar as ações de controle a longo prazo. É neste panorama que Sobrinho e Borja (2016) apresentam como um dos principais desafios dos gestores de perdas a necessidade ter conhecimento de todas 
tecnologias e metodologias existentes, considerando suas potencialidades e limitações para determinado sistema, possibilitando a adequação aos recursos disponíveis de forma a melhorar continuamente.

Em se tratando do controle de perdas de água, tanto reais como aparentes, é importante ressaltar que o limite econômico, no qual se gasta mais para reduzir as perdas do que o valor intrínseco dos volumes perdidos, dificulta o controle e redução das mesmas. Em alguns casos os gestores optam por aumentar a captação e produção de água para atender a demanda, ao invés de reparar os problemas relacionados às perdas, pois, as despesas de manutenção das redes ultrapassam os custos de produção (CORTON; BERG, 2009; ABES, 2013).

Outro aspecto diretamente ligado ao baixo desempenho no controle de perdas de água é o fato da gestão das mesmas ser tratada como apenas "soluções técnicas". Para o sucesso dos processos é essencial o envolvimento de todas as pessoas da companhia, em quaisquer níveis hierárquicos, estabelecendo responsabilidades, treinamentos e motivando-os a fazer a diferença neste processo (EUROPEAN COMMISION, 2015). Sobrinho e Borja (2016) demonstraram em seu estudo que programas de duração predeterminada e com abrangência limitada são pouco efetivos, reforçando a importância da adoção de estratégias contínuas e embasadas em um forte planejamento com envolvimento da alta direção da empresa garantindo recursos perenes para a execução das ações de controle previstas. 


\subsection{Assimilações do capítulo à pesquisa}

A apreensão com as perdas de água em sistemas de distribuição é notória em todo o mundo. A crescente demanda pelos recursos hídricos, associada à escassez hídrica decorrente das mudanças climáticas, têm induzido as operadoras de água à adotarem processos de gestão que visem reduzir os níveis de perdas de água, buscando a sustentabilidade na prestação dos serviços, reduzindo a pressão sobre os corpos d'água e com dispêndios de operação.

O conteúdo exposto no presente capítulo torna incontestável a importância do controle das perdas de água. A revisão possibilitou o conhecimento detalhado sobre a questão das perdas em sistema de abastecimento de água, abordando os tipos de perdas e as causas de sua ocorrência, reforçando a importância na redução dos níveis. O capítulo ainda vislumbra importantes processos de gestão para o controle, ações que têm sido conduzidas no país neste contexto e as barreiras relacionadas à redução dos níveis, aspectos imprescindíveis de se ter ciência para a compreensão da ocorrência das perdas no cenário nacional.

Os pontos apresentados evidenciam a responsabilidade das operadoras na redução dos níveis de perdas de água, indicando o uso de indicadores de desempenho como um importante mecanismo para avaliar a eficiência dos processos de gestão no controle de perdas, ao longo do tempo. Frente a estes aspectos, o capítulo quatro apresenta o benchmarking como uma técnica promissora no controle de perdas, a partir do uso de indicadores de desempenho. 


\section{BENCHMARKING APLICADO AOS SERVIÇOS DE ÁGUA}

O benchmarking é visto como uma técnica sistemático, que investiga as melhores práticas e processos operacionais altamente eficazes que conduzam a um desempenho superior, fornecendo aos reguladores e gestores de serviços públicos uma avaliação de desempenho que permita a comparação dos serviços de água ao longo do tempo (PARENA; SMEETS, 2001; BERG; PADOWSKI, 2007). Mutikanga (2012) apresenta o benchmarking como uma ferramenta valiosa utilizada por gestores públicos, decisores políticos, reguladores e instituições financeiras com o intuito de otimizar as operações e melhorar os serviços de água.

A aceitação mundial desta ferramenta decorre da sua utilidade na tomada de decisão apresentando o melhor desempenho de produtos, serviços ou processos, de qualquer instituição, promovendo a melhor satisfação dos usuários (CARPINETTI; MELO, 2002). Desde sua primeira definição, apresentada nos anos 70, o benchmarking tem sido utilizado nos processos de gestão e diversos autores têm formulado conceitos que, na essência, apresentam-o como uma ferramenta que permite avaliar o desempenho de produtos, processos ou serviços comparando uns com os outros, buscando identificar as melhores práticas, ideias e procedimentos das organizações (CAMP, 1998; STAPENHURST, 2009; AWWA, 2013).

O benchmarking pode concentrar-se no processo, no produto, no desempenho ou nas estratégicas das instituições. Independente da área de concentração, pode ser praticado na rotina das operadoras de serviço (comparando internamente o desempenho de diferentes setores) ou externamente, comparando o desempenho com outras operadoras de características similares (CARPINETTI MELO, 2002; STHARE; ADAMSSON, 2004; MOLINARI, 2006; BLOCKLAND, 2013). A ferramenta pode ainda ser aplicada para facilitar dois tipos de melhoria de processos: (I) Melhoria incremental, onde pequenas medidas são adotadas para refinar um processos, sem grandes mudanças, e (II) a Melhoria inovadora quando um novo método operacional é implementado resultando em saltos quânticos de produtividade e desempenho (BHAGWAN, 2002).

No setor de saneamento, o benchmarking foi introduzido na década de 1990 permitindo comparar os aspectos de gestão, identificando e medindo ineficiências, observar os impactos das decisões, dimensionando os incentivos para a melhora, além de assegurar o bom desempenho (ADERASA, 2007; KURIAN; MCCARNEY, 2010). Para Berg (2007), o benchmarking no setor da água é importante para avaliar desempenhos, estabelecer linhas de base da melhoria da produtividade e comparar as operadoras de serviços. O desempenho das operadoras de água podem ser mensurados mediante a aplicação de uma série de indicadores 
financeiros, técnicos, administrativos, de inovação e de outras áreas de operação (VAN DIJK; BLOKLAND, 2016).

No contexto da análise de desempenho das companhias de saneamento, destaca-se o IBNET como o maior programa de benchmarking do setor de água que, coleta, analisa e fornece acesso à informações referentes ao desempenho de mais 2.500 operadoras de água, distribuídas em mais de 110 países ao redor do mundo (VAN DEN BERG; DANILENKO, 2011). Diversas experiências demonstram o impacto positivo da aplicação do benchmarking na melhoria da eficiência, eficácia e transparência dos serviços de abastecimentos de água e a Water and Sanitation Program (2010) define ainda que esta técnica promove a eficiência, apoia o planejamento e avaliação do setor e auxilia na identificação e partilhamento das melhores práticas.

Salvo as vantagens da técnica de benchmarking, Loureiro (2013) salienta que a ausência de informações fidedignas para efeito de comparação, a confidencialidade de dados, ausência de recursos financeiros e tempo para recolha de informações e o desinteresse dos colaboradores no processo são algumas das barreiras encontradas na execução desta técnica. Não obstante, Murungi e Blokland (2016) ressaltam que a aplicação do benchmarking favorece a aprendizagem sobre diferentes práticas subjacentes aos resultados variados, expandindo a perspectiva de troca e adaptação de práticas contribuindo com a melhoria da qualidade dos serviços, além de favorecer a transparência das companhias e apoiar o planejamento estratégico.

\subsection{Benchmarking métrico ou Benchmarking para avaliação de desempenho}

As primeiras iniciativas da realização deste tipo de benchmarking encontraram barreiras relacionadas a falta de padronização dos dados, dificuldade no estabelecimento de indicadores adequados e não aderência dos dirigentes das operadoras no processo, por receio dos resultados indicarem as operadoras com desempenhos ruins (PARENA; SMEETS, 2001; CABRERA JR, et al., 2002; BERG, 2003).

Em geral esta tipologia fornece uma análise comparativa quantitativa dos desempenhos das operadoras, utilizando diferentes métodos, como por exemplo, indicadores de desempenho e análise envoltória de dados. A avaliação do desempenho permite que as empresas acompanhem sua performance ao longo do tempo comparando-a com a de outras semelhantes, auxiliando a responder a pergunta "o que eu deveria melhorar?" (KINGDOM, 1996; BHAGWAN, 2002; STORTO, 2014; SEPPALA, 2015). Neste contexto, Cabrera et al. (2011) desenvolveram em seus estudos uma extensa análise referente a aplicação desta ferramenta aos serviços de saneamento básico, definindo-a como "uma ferramenta para melhoria do desempenho através da pesquisa sistemática e adaptação de práticas de ponta”. A nomenclatura 
adotada pelos autores para as tipologias de benchmarking é distinta, apesar de serem equivalentes no conteúdo. No caso do benchmarking métrico, os autores classificando-no como benchmarking para avaliação do desempenho, no qual utiliza-se indicadores de performance para comparar o desempenho das operadoras.

O benchmarking métrico pode ser desenvolvido mediante métodos totais ou parciais. Os métodos totais retratam uma medida holística da eficiência de uma operadora enquanto os métodos parciais possibilitam a análise de diferentes aspectos da gestão da operadora, porém, não fornecem uma medida global de eficiência da mesma. Os métodos parciais são comumente aplicados no setor de abastecimento de água e são conduzidos utilizando indicadores de desempenho, que avaliam somente uma dimensão de desempenho por vez, como as iniciativas da IWA, IBNET e Word Bank (ABBOT; COHEN, 2009). Os indicadores de desempenho geralmente necessitam de dados relacionados à produção da operadora, como por exemplo o volume de água faturado, cobertura de água e dados financeiros, os quais geralmente estão disponíveis, o que facilita a aplicação deste método (PARENA; SMEETS, 2001; BERG; PADOWSKI, 2007; BERG, 2010).

Dado que a presente pesquisa utilizou indicadores de desempenho para desenvolver o benchmarking para avaliação do desempenho das operadoras da área de estudo é essencial ter conhecimento dos aspectos relacionados ao uso destes indicadores. Assim, a subseção 4.1.1 aborda aspectos relacionados à esta temática.

\subsubsection{Os indicadores de desempenho na aplicação do Benchmarking}

A eficiência das operadoras de distribuição de água pode ser avaliada mediante a aplicação de múltiplos indicadores de desempenho (IDs), vistos como uma ferramenta poderosa que incentiva uma gestão baseada no cumprimento de metas, em termos comparativos, sendo uma prática comum de benchmarking para medir a variabilidade e corrigir a operação de um processo, baseado nos valores dos indicadores (MARQUES; MONTEIRO, 2003; PNCDA, 2003; KLATT; MARQUARDTB, 2009). Muranho et al. (2014) argumentam que a incorporação de metodologias de avaliação de desempenho nas práticas de gestão cria mecanismos de competitividade, que induzem à cultura da eficiência e a melhoria contínua do sistema.

Os indicadores de desempenho podem ser classificados em três níveis, segundo o grau de complexidade, sendo que os de alto nível (nível 3) envolvem a utilização de dados de difícil obtenção por parte dos prestadores de serviços (ALEGRE, et al., 2000; OLIVEIRA, et al., 2015). 
- Nível 1: são indicadores básicos que fornecem visão geral da eficiência e eficácia da entidade gestora;

- Nível 2: são indicadores com maior grau técnico, que fornece um panorama mais preciso sobre os aspectos de gestão;

- Nível 3: são indicadores detalhados de alto padrão técnico que fornecem uma visão detalhada sobre a gestão da entidade gestora e demandam dados específicos, muitas vezes de difícil obtenção.

No contexto das perdas de água é importante destacar que para calcular os indicadores de nível 2 e 3 é necessário diferenciar os volumes de perdas reais e aparentes do volume não faturado, porém, o estágio atual dos processos e tecnologias de controle de perdas dos sistemas brasileiros dificulta a obtenção destes volumes separadamente (OLIVEIRA, et al., 2015).

Alegre e Covas (2010) exortam que, o emprego de indicadores de desempenho confere inúmeras vantagens para as entidades gestoras auxiliando a definir prioridade de intervenção. No Quadro 9 estão descritas as principais vantagens da aplicação de IDs para cada ator envolvido em um sistema de saneamento, segundo Alegre et al. (2000). 
Quadro 9 - Vantagens do uso de indicadores de desempenho por atores.

\begin{tabular}{|c|c|}
\hline \multicolumn{2}{|c|}{ VANTANGENS DO USO DE INDICADORES DE DESEMPENHO } \\
\hline \multirow{4}{*}{ Entidade Gestora } & Melhor monitorização dos efeitos das decisões de gestão; \\
\hline & $\begin{array}{l}\text { Fornece informações chave de suporte às ações proativas de gestão, } \\
\text { baseada nas disfunções aparentes dos sistemas; }\end{array}$ \\
\hline & Destaca os pontos fortes e fracos dos setores do sistema; \\
\hline & $\begin{array}{l}\text { Facilita a implementação de rotinas de "benchmarking”, internamente } \\
\text { (comparando o desempenho dentro do próprio sistema) ou externamente } \\
\text { (comparando o desempenho com outras entidades); }\end{array}$ \\
\hline \multirow{2}{*}{$\begin{array}{l}\text { Administração } \\
\text { nacional ou } \\
\text { regional }\end{array}$} & $\begin{array}{l}\text { Fornece um quadro de referência para comparação do desempenho de } \\
\text { diferentes entidades gestoras; }\end{array}$ \\
\hline & $\begin{array}{l}\text { Possibilita o suporte à formulação de políticas para o setor da água no } \\
\text { contexto da gestão integrada dos recursos hídricos; }\end{array}$ \\
\hline \multirow{2}{*}{ Reguladores } & $\begin{array}{l}\text { Confere instrumentos de monitorização para apoio dos interesses dos } \\
\text { consumidores; }\end{array}$ \\
\hline & $\begin{array}{l}\text { Propicia a verificação da conformidade com os objetivos pré- } \\
\text { estabelecidos; }\end{array}$ \\
\hline $\begin{array}{c}\text { Entidades } \\
\text { Financiadoras }\end{array}$ & $\begin{array}{l}\text { Possibilita avaliar as primazias de investimento e apoiar a seleção de } \\
\text { projetos; }\end{array}$ \\
\hline Consumidores & $\begin{array}{l}\text { Traduz processos complexos em informação objetiva e de fácil } \\
\text { interpretação transmitindo uma medida da qualidade do serviço prestado; }\end{array}$ \\
\hline $\begin{array}{l}\text { Organizações } \\
\text { supranacionais }\end{array}$ & $\begin{array}{l}\text { Permite identificar, mediante uma linguagem apropriada, as principais } \\
\text { assimetrias entre regiões do mundo, possibilitando assim dar suporte ao } \\
\text { estabelecimento de estratégias. }\end{array}$ \\
\hline
\end{tabular}

Fonte: Adaptado de ALEGRE et al. (2000).

Em suma, as entidades gestoras devem sempre buscar atingir seus objetivos de gestão com elevados padrões de eficiência e eficácia. Os IDs, que correspondem a uma medida quantitativa de um aspecto particular da organização ou do seu nível de serviço, apresentam-se como um instrumento de uso comum e universal tendo grande potencialidade na indústria de água, dando suporte à monitorização da eficiência e eficácia do sistema (ALEGRE et al., 2000). Vale ressaltar que os indicadores de desempenho devem proporcionar uma visão integrada da performance dos serviços de saneamento e expor as fragilidades e potencialidades dos mesmos, favorecendo a avaliação dos fatores que orientam as ações para o seu funcionamento (SCHNEIDER et al., 2010).

Umas das iniciativas brasileira de benchmarking utilizando indicadores de desempenho é o Prêmio Nacional de Qualidade em Saneamento (PNQS), criado pela Associação Brasileira de Engenharia Sanitária e Ambiental (ABES) em 1997. O PNQS utiliza inúmeros indicadores de desempenho para reconhecer às empresas do setor de saneamento que se destacam pelo bom desempenho e gestão na prestação dos serviços. Através da divulgação das práticas desempenhadas pelas empresas de saneamento reconhecidas, em seminários, relatórios e cases 
finalista e vencedores, a iniciativa visa estimular a aplicação de boas práticas de gestão por todas as organizações envolvidas no setor de saneamento ambiental do país, contribuindo com a melhoria do desempenho das empresas (PNQS, 2017).

Frente as vantagens do uso de indicadores no processo de avaliação de desempenho das operadoras de água, a subseção 4.1.1.1 discorre sobre os indicadores de desempenho de perdas de água em sistemas de distribuição, existentes em âmbito nacional e internacional.

\subsubsection{Indicadores de desempenho de perdas de água em sistemas de distribuição}

A importância da técnica de benchmarking na melhoria do desempenho das operadoras de água é clara. Posto que a presente pesquisa utilizará indicadores de desempenho para avaliar as operadoras de água das bacias PCJ, esta seção apresenta os indicadores de desempenho de perdas de água na distribuição, elaborados por instituições nacionais e internacionais.

Mbuvi et al. (2012) apresentam a avaliação do desempenho das operadoras de água como um fator essencial para que as mesmas operem de forma eficiente e eficaz. Na mesma perspectiva, Hamilton \& Mckenzie (2014) defendem que os indicadores são fundamentais para avaliar a eficiência das ações e planejar as intervenções consecutivas. Para Kanakoudis et al. (2012), o processo de avaliação de desempenho do sistema de abastecimento é o primeiro passo para a redução de perdas de água, o que é defendido também por Thornton et al. (2008) que apresentam o uso de indicadores de desempenho como a primeira fase de um programa de controle de perdas de água.

As perdas de água são avaliadas de distintas formas em cada país, de modo que a sistemática de medição varia de acordo com o grau de desenvolvimento das empresas de saneamento. (TONETO JÚNIOR, et al., 2013; BRASIL, 2014). O Quadro 10 apresenta uma breve descrição da evolução histórica da métrica de perdas de água ao longo dos anos. 
Quadro 10 - Evolução dos indicadores de perdas de água na distribuição.

\begin{tabular}{|c|c|c|}
\hline Período & Modelo de mensuração das perdas & Desdobramentos \\
\hline \multirow{2}{*}{ Anterior a 2000} & $\begin{array}{l}\text { Perdas de água frequentemente } \\
\text { calculadas em } \% \text {. }\end{array}$ & $\begin{array}{l}\text { IWA faz restrições quanto ao uso de } \\
\text { indicadores em \% uma vez que estes } \\
\text { variam com o consumo per capita e com } \\
\text { a presença de grandes consumidores. }\end{array}$ \\
\hline & $\begin{array}{c}\text { Propostas de indicadores de perdas } \\
\text { reais e aparentes começam a ser } \\
\text { estudados. }\end{array}$ & $\begin{array}{l}\text { Algumas organizações de saneamento } \\
\text { mais desenvolvidas começam a praticar } \\
\text { o controle das perdas reais e aparente de } \\
\text { forma desagregada. }\end{array}$ \\
\hline \multirow{3}{*}{ De 2000 a 2006} & $\begin{array}{c}\text { Perda em litros/ligação.dia ou } \\
\text { litros } / \mathrm{km} \text {. }\end{array}$ & $\begin{array}{l}\text { Para a IWA estes indicadores retratam } \\
\text { mais adequadamente a performance } \\
\text { operacional dos sistemas e facilitam a } \\
\text { comparação. }\end{array}$ \\
\hline & Infrastruture Leakage Index (ILI) & $\begin{array}{l}\text { A “IWA Task Force" propõe o ILI para } \\
\text { mensurar a eficácia das ações de } \\
\text { controle de perdas reais. Para o cálculo } \\
\text { há a necessidade de distinção entre os } \\
\text { volumes de perda real e aparente. } \\
\text { Utilização inviável em países em } \\
\text { desenvolvimento, como o Brasil, pela } \\
\text { inexistência de dados. }\end{array}$ \\
\hline & $\begin{array}{l}\text { Surgem indicadores de perdas reais e } \\
\text { aparentes }\end{array}$ & \begin{tabular}{l}
\multicolumn{4}{l}{ Dificuldade de aplicação principalmente } \\
em sistemas de países em \\
desenvolvimento.
\end{tabular} \\
\hline De 2006 - Atual & $\begin{array}{c}\text { Perdas em } \% ; \\
\text { Perda em litros/ligação.dia ou } \\
\text { litros/km. }\end{array}$ & $\begin{array}{l}\text { Apesar da não recomendação do uso dos } \\
\text { indicadores de perda em \%, muitos } \\
\text { países ainda fazem uso desta } \\
\text { metodologia pela facilidade de cálculo. } \\
\text { Diversas organizações têm desenvolvido } \\
\text { seus próprios indicadores que atendam as } \\
\text { particularidades de cada sistema. }\end{array}$ \\
\hline
\end{tabular}

Fonte: Elaborado pela autora

A primeira iniciativa de indicadores de saneamento foi apresentada em 1990 pela organização francesa "Association Générale des Hygiénistes et Techniciens Municipaux" (AGHTM), que desenvolveu um dos trabalhos mais completos sobre a eficiência das redes de água, estabelecendo uma série de indicadores para avaliação do desempenho dos serviços, entre os quais encontram-se indicadores de perdas (AGHTM, 1990).

Ao longo dos anos instituições internacionais elaboraram indicadores de saneamento e, atualmente, a Internacional Water Associaton (IWA) e a American Water Works Association (AWWA) são as principais organizações de água que desenvolvem grandes estudos na área de perdas. Em 2000, a IWA publicou um manual de melhores práticas para avaliação do desempenho de sistemas de abastecimento de água, intitulado "Performance indicators for water supply services", com o objetivo central de padronizar o entendimento dos componentes de um sistema de abastecimento mediante uma matriz que representa o Balanço Hídrico das companhias de saneamento, ilustrado na Figura 8 (KANAKOUDIS; TSITSIFLI, 2010). 
Figura 8 - Componentes do Balanço Hídrico IWA.

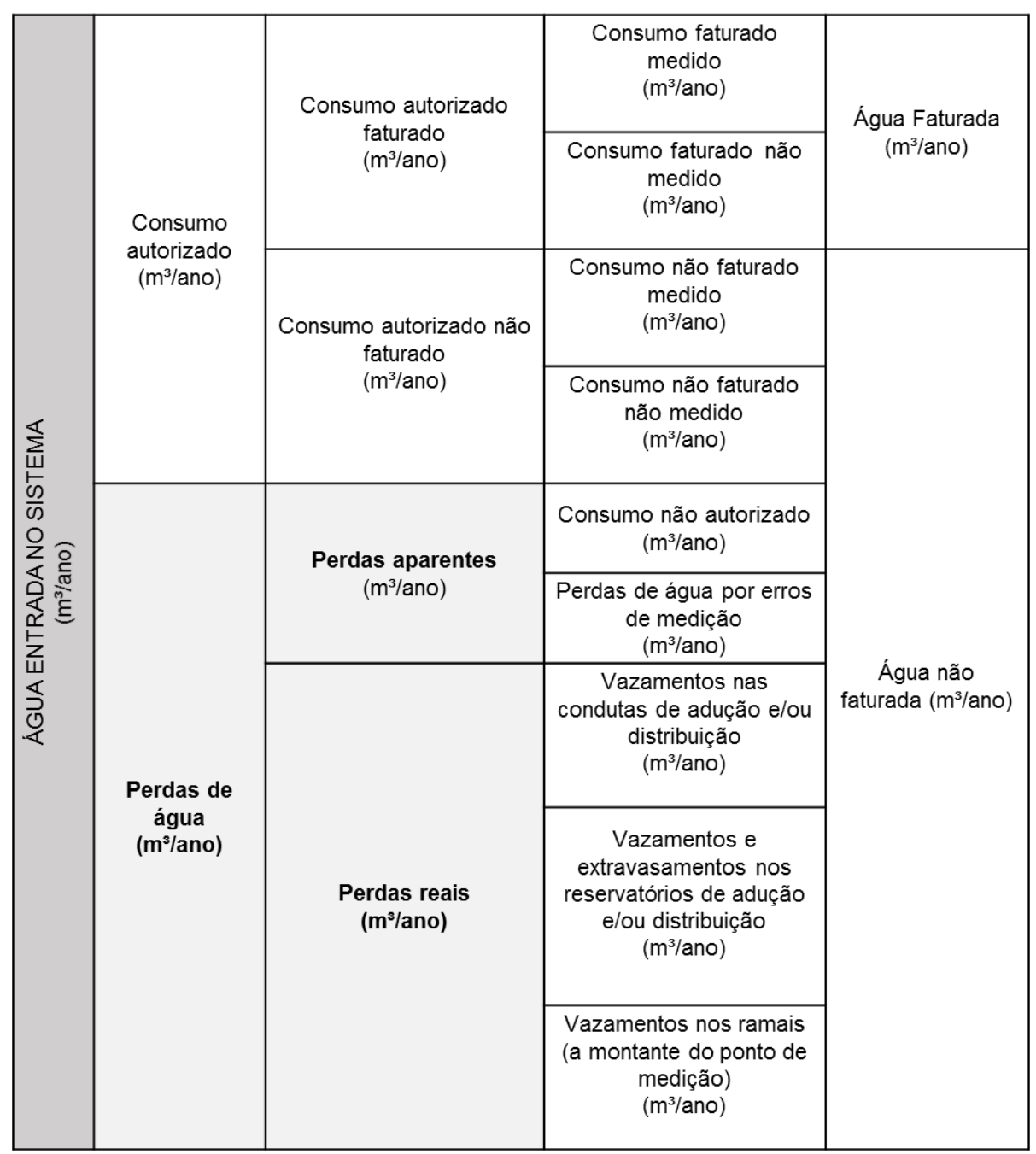

Fonte: Adaptado de ALEGRE et al. (2000)

Desde a publicação do referido manual, a AWWA recomenda o uso global dos indicadores publicados neste documento. Os indicadores estão organizados em seis categorias de indicadores de desempenho estando os indicadores de perdas de água inseridos no grupo de indicadores operacionais, financeiros e de recursos hídricos, podendo ser expressos de forma adimensional (\%) ou em um formato que expressem intensidade e não extensão, como por exemplo US\$/m³ (Alegret al., 2000).

Apesar das inúmeras vantagens do uso de indicadores de desempenho de perdas de água há uma grande discussão em torno do uso do indicador expresso em percentual. A IWA apresenta restrições quanto ao uso deste indicador, recomendando que o mesmo seja empregado apenas para análises de faturamento, uma vez que são inadequados para avaliar a eficiência da gestão dos sistemas de distribuição pois, são fortemente influenciados pelas mudanças de consumo e não distinguem as perdas reais e aparentes, como apontado por Wirnani et al. (2009). Para Bhagwan (2002), o uso deste indicador pode expressar resultados ilusivos sendo esta 
medida válida apenas quando uma organização compara seu próprio desempenho (interno) com um valor já determinado anteriormente, sendo inapropriado comparar empresas com características diferentes. De acordo com Thornton et al. (2008), as perdas mensuradas em percentual não revelam nada sobre os volumes e custos específicos de perdas no sistema, que são, segundo os autores, os dois parâmetros mais importantes na análise de perdas.

Frente a insuficiência do indicador expresso em percentual e a necessidade de mensurar as perdas aparentes e reais de forma desagregada, a IWA propôs como alternativa para avaliação das perdas de água em sistema de distribuição outros indicadores operacionais, como por exemplo o Infrastruture Leakage Index (ILI). O ILI, recomendado pela IWA e categorizado como nível 3, foi apresentado por Allan Lambert como um indicador focalizado na avaliação das perdas físicas ou reais, possibilitando a comparação entre sistemas com cenários distintos, avaliando o quão bem uma rede de distribuição é gerenciada para o controle de perdas (LIEMBERG; MCKENZIE, 2005; WIRNANI, 2009). Além de ser considerado o indicador que melhor descreve a eficiência da gestão de perdas reais de água, este indicador auxilia na identificação das áreas prioritárias para adoção de medidas de controle, como apontado por Dighade et al. (2014).

O ILI é adimensional e corresponde a proporção do nível anual de perdas atuais, em inglês Current Anuual Real Losses (CARL), e do nível anual de perdas inevitáveis, em inglês Unavoidable Annual Real Losses (UARL). O cálculo do UARL é complexo e os dados requeridos na maioria dos casos não estão disponíveis, principalmente em sistema de países em desenvolvimento, o que torna inviável a aplicabilidade do ILI em muitas regiões (HAMILTON, et al. 2006).

É nesta perspectiva que autores como Liemberger e McKenzie (2005), Hamilton, Mckenzie \& Saego (2006), Mutikanga et al. (2010) e Dighade et al. (2014) apontam que a aplicação deste indicador em países em desenvolvimento é limitada, uma vez que os sistemas destes países não têm os dados necessário para o cálculo do ILI e a maioria das informações disponíveis não são confiáveis sendo muitas vezes subestimadas pela falta de recursos e infraestrutura. Segundo Mutikanga et al. (2013) o desenvolvimento de indicadores análogos ao ILI é uma área de pesquisa ativa, sendo fundamental estabelecer novos indicadores que atendam as condições locais dos países em desenvolvimento. Frente a inviabilidade do cálculo do ILI em países como o Brasil, este indicador não foi incluído para fins de análise neste trabalho.

Ainda em nível internacional a "The International Benchmarking Network for Water and Sanitation Utilities" (IBNET) fornece um conjunto de indicadores financeiros, técnicos e 
de processos para avaliar o desempenho na prestação de serviços de água de esgoto. Entre os diversos indicadores do IBNET há o indicador denominado "Non-revenue water", que expressa o volume de água perdida durante a distribuição (IBNET, 2016).

No quadro brasileiro, a Associação das Empresas de Saneamento Básico Estaduais (AESBE) e a Associação Nacional dos Serviços Municipais de Saneamento (ASSEMAE) apresentaram em 1998, um conjunto de indicadores de desempenho operacional e gerencial dos serviços de saneamento, os quais convergem com os indicadores da AGHTM e IWA reconhecendo a necessidade de combinar indicadores percentuais com indicadores físicos como base para comparação de desempenho (PNCDA, 2003). Neste encadeamento, surge mais uma vez a discussão do uso do indicador em percentual que, para Bhagwan (2002) e Gomes, H. (2009) quando utilizado isoladamente, imprime uma característica de homogeneidade aos sistemas, o que não existe na prática, pois, os fatores que influenciam as perdas variam de sistema para sistema como a extensão da rede e a quantidade de ligações, por exemplo. Baseado nos indicadores existentes, o Programa Nacional de Combate ao desperdício de água (PNCDA) (2003) propôs um conjunto de indicadores básicos de desempenho para quantificar as perdas de água em sistemas de distribuição.

Apesar dos esforços destas organizações em propor indicadores de perdas que atendam as particularidades dos sistemas brasileiros, atualmente os quatro índices ${ }^{23}$ de perdas do Sistema Nacional de Informações sobre Saneamento (SNIS), vinculado à Secretaria Nacional de Saneamento Ambiental do Ministério das Cidades (SNSA), são os mais praticados no país e utilizados por diversas entidades para fins de fiscalização e planejamento.

Criado em 1996 no âmbito do Programa de Modernização do Setor Saneamento (PMSS), o SNIS é a principal fonte de informação sobre saneamento no Brasil, divulgando anualmente informações referentes ao saneamento dos municípios, propiciando o fortalecimento das agências reguladoras e de vários atores nas medidas de controle. Ainda que o SNIS seja uma forte iniciativa do governo federal em acompanhar o desempenho dos serviços de saneamento, a não auditoria das informações inseridas voluntariamente no sistema, como uma condicionante para o acesso à recursos de investimentos da SNSA, diminuem a confiabilidade dos dados publicados (ABES, 2015; BRASIL, 2016), prejudicando o planejamento de ações de controle que se apoiam em indicadores pouco representativos. Este

\footnotetext{
23 A nomenclatura índice utilizada pelo SNIS é atribuída inadequadamente pois, índice corresponde ao valor agregado final de todo um procedimento de cálculo onde se utilizam, inclusive, indicadores como variáveis que o compõe. O correto seria utilizar a nomenclatura indicador, uma vez que corresponde à um parâmetro selecionado e considerado isoladamente ou em combinação com outros para refletir sobre as condições do sistema em análise (SICHE, et al.,2007).
} 
aspecto justifica a não utilização dos dados do SNIS para o desenvolvimento da presente pesquisa, evidenciando a imprescindibilidade em coletar as informações diretamente com as operadoras de água.

Frente ao exposto, acerca da variedade de IDs de perdas de água, a Tabela 1 apresenta os indicadores de perdas de água elaborados pelas organizações nacionais e internacionais relatadas nesta subseção. 
Tabela 1 - Indicadores de perda de água em sistemas de abastecimento em âmbito nacional e internacional.

\begin{tabular}{|c|c|c|c|c|}
\hline & INDICADOR & CÁLCULO & VARIÁVEIS & UNIDADE \\
\hline \multirow{7}{*}{ 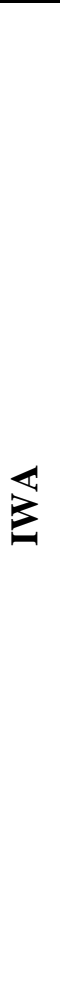 } & Perdas de água por ramal & $\frac{\frac{\mathrm{A} 15 \mathrm{X} \mathrm{365}}{\mathrm{H} 1}}{\mathrm{C} 24}$ & $\begin{array}{l}\text { A15: Perdas de água }\left(\mathrm{m}^{3}\right) \\
\text { H1: Duração do período de referência } \\
\text { C24: } \mathrm{n}^{\circ} \text { de ramais }\end{array}$ & $\mathrm{m}^{3} / \mathrm{ramal} / \mathrm{ano}$ \\
\hline & $\begin{array}{l}\text { Perdas de água por comprimento de } \\
\text { conduta }\end{array}$ & $\frac{\frac{\mathrm{A} 15}{\mathrm{H} 1}}{\mathrm{C} 8}$ & $\begin{array}{l}\text { A15: Perdas de água }\left(\mathrm{m}^{3}\right) \\
\text { H1: Duração do período de referência } \\
\text { C8: Comprimento de condutas }(\mathrm{km})\end{array}$ & $\mathrm{m}^{3} / \mathrm{km} / \mathrm{dia}$ \\
\hline & Perdas aparentes & $\mathrm{A} 16+\mathrm{A} 17$ & $\begin{array}{l}\text { A16: Consumo total não autorizado } \\
\text { A17: Consumo total de água não contabilizada }\end{array}$ & $\mathrm{m}^{3}$ \\
\hline & Perdas aparentes por ramal & $\frac{\mathrm{A} 18}{(\mathrm{~A} 3-\mathrm{A} 5-\mathrm{A} 7)} \times 100$ & $\begin{array}{l}\text { A3: água entrada no sistema }\left(\mathrm{m}^{3}\right) \\
\text { A5: água bruta exportada }\left(\mathrm{m}^{3}\right) \\
\text { A7: água tratada exportada }\left(\mathrm{m}^{3}\right) \\
\text { A18: Perdas aparentes }\left(\mathrm{m}^{3}\right)\end{array}$ & $\%$ \\
\hline & $\begin{array}{l}\text { Perdas aparentes por volume de água } \\
\text { entrada no sistema }\end{array}$ & $\frac{\mathrm{A} 18}{\mathrm{~A} 3} \times 100$ & $\begin{array}{l}\text { A3: água entrada no sistema }\left(\mathrm{m}^{3}\right) \\
\text { A18: Perdas aparentes }\left(\mathrm{m}^{3}\right)\end{array}$ & $\%$ \\
\hline & Perdas reais por ramal & $\frac{\mathrm{A} 19 \times 1000}{\mathrm{C} 24 \times \frac{\mathrm{H} 2}{24}}$ & $\begin{array}{l}\text { A19: Perdas reais }\left(\mathrm{m}^{3}\right) \\
\text { C24: Número de ramais } \\
\text { H2: Tempo de pressurização do sistema }\end{array}$ & 1/ramal/dia \\
\hline & $\begin{array}{l}\text { Perdas reais por comprimento de } \\
\text { conduta }\end{array}$ & $\frac{\mathrm{A} 19 \times 1000}{\mathrm{C} 8 \mathrm{X} \frac{\mathrm{H} 2}{24}}$ & $\begin{array}{l}\text { A19: Perdas reais }\left(\mathrm{m}^{3}\right) \\
\text { C8: Comprimento de condutas }(\mathrm{km}) \\
\text { H2: Tempo de pressurização do sistema }\end{array}$ & $1 / \mathrm{km} / \mathrm{dia}$ \\
\hline \multirow[b]{2}{*}{$\sum_{\substack{\cos \\
\hdashline}}$} & $\begin{array}{c}\text { PP - Porcentagem das perdas na } \\
\text { distribuição }\end{array}$ & $\frac{V P}{V D} \times 100$ & $\begin{array}{l}\text { VP: volume de perdas na distribuição } \\
\text { VD: Volume disponibilizado para distribuição }\end{array}$ & $\%$ \\
\hline & PV-Porcentagem de vazamentos & $\frac{V v}{V D} \times 100$ & $\begin{array}{l}\text { Vv: volume de vazamentos } \\
\text { VD: volume disponibilizado para distribuição }\end{array}$ & $\%$ \\
\hline
\end{tabular}




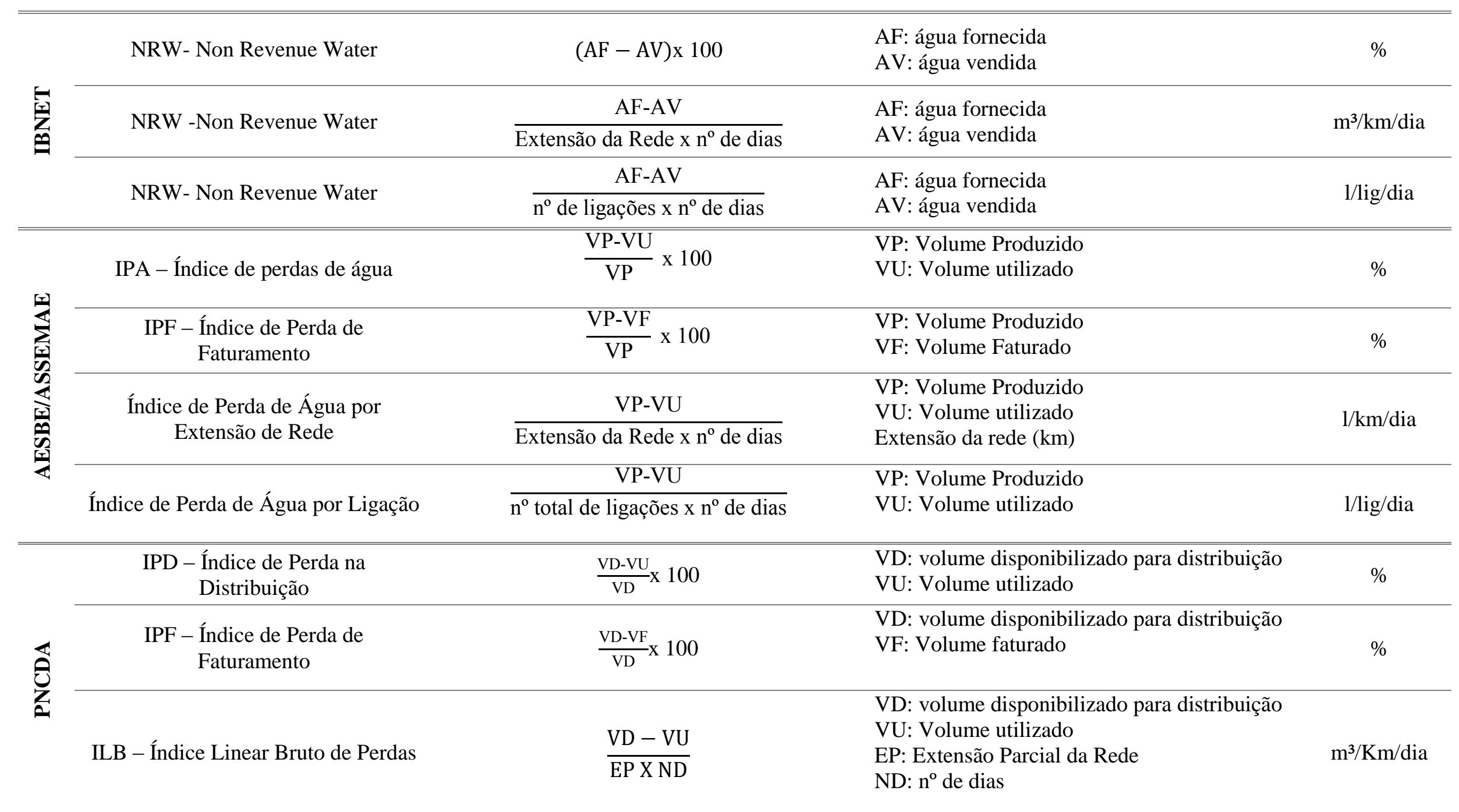




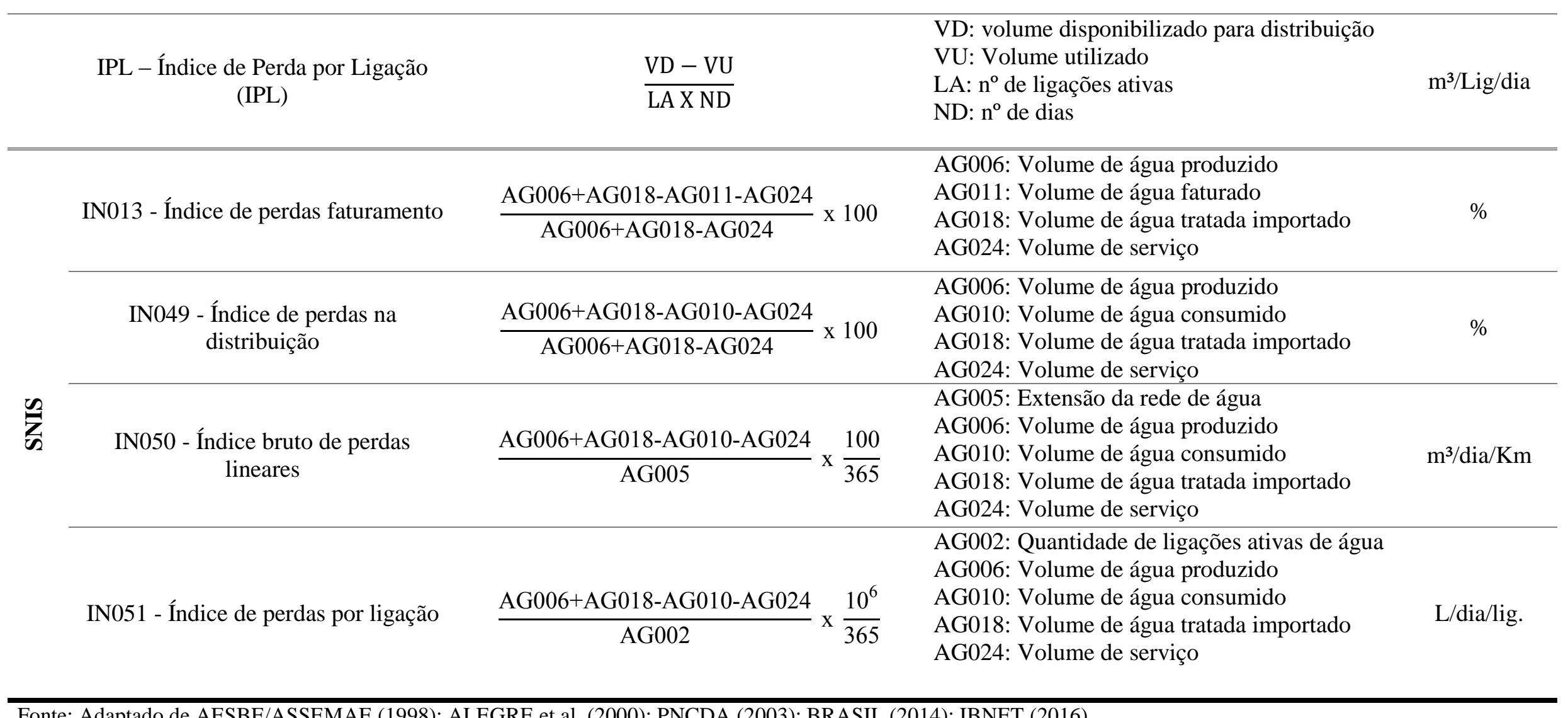

Fonte: Adaptado de AESBE/ASSEMAE (1998); ALEGRE et al. (2000); PNCDA (2003); BRASIL (2014); IBNET (2016). 


\subsection{Experiências internacionais de benchmarking aplicado ao controle de perdas}

Diversos países ao redor do mundo têm aplicado a ferramenta de benchmarking com o intuito de avaliar o desempenho das operadoras na prestação dos serviços, incluindo a performance das mesmas no controle de perdas de água. As experiências demonstram que o benchmarking direcionado ao controle de perdas não ocorre de forma isolada, estando sempre vinculado à outra área de atuação da operadora e, na maioria dos casos, os indicadores de desempenho são utilizados neste processo, tendo em vista suas vantagens já relatadas na seção 4.1.1.

A aplicação desta técnica possibilita, além de comparar o desempenho das operadoras, detectar os processos de gestão adotadas nestas áreas e potenciais de otimização definindo medidas para melhoria do desempenho, dando suporte à tomada de decisão nos sistemas e contribuindo com o controle dos níveis de perdas de água (KÖLBL, et al, 2008). Nas seguinte subseções são apresentadas experiências internacionais de projetos de benchmarking direcionados ao controle de perdas de água em sistemas de distribuição.

\subsubsection{Austria}

Entre 2002 e 2006 a Austrian Association for Gas and Water (OVGW) desenvolveu um projeto piloto de benchmarking no setor de abastecimento de água do país enfatizando a utilização desta ferramenta como um instrumento de controle para a melhoria contínua (“aprender com os melhores"). O projeto ocorreu em duas etapas A e B do qual participaram, voluntariamente e anonimamente, $50 \%$ das operadoras localizadas na área (KÖLBL et al., 2007; KÖLBL, et al, 2008).

O estágio A correspondeu ao projeto piloto e desenvolveu-se entre 2003 e 2004 com a participação de 23 operadoras de água, no qual foram utilizados os 120 indicadores recomendados pela IWA, para avaliar o desempenho das operadoras participantes, além de questões que foram elaboradas objetivando coletar informações referentes aos aspectos de organização e execução das atividades da operadora. O estágio B, desenvolvido entre 2004 e 2006, contou com a participação de 72 operadoras e seu principal objetivo foi aperfeiçoar o sistema de avaliação do desempenho dos serviços, reduzindo o número de indicadores de desempenho da IWA para 75, além de incluir novos indicadores como o "Índice de vazamento de Infraestrutura (ILI), apresentado como um indicador de desempenho de perda de água muito importante (KÖLBL, 2009).

As duas etapas de benchmarking desenvolvidas neste período corresponderam ao benchmarking métrico, ou de avaliação de desempenho, como apresentado por Cabrera et al. 
(2011). A partir dos resultados das etapas A e B, publicados em um relatório de acesso público, a OVGW iniciou em 2007 o benchmarking processual das operadoras envolvidas, realizando uma análise comparativa dos diferentes processos de trabalho adotados pelas mesmas. $\mathrm{O}$ levantamento de processos de gestão de perdas de água foi um dos focos do benchmarking processual, sendo uma das etapas mais complexas dentro do projeto por ser altamente integrativo, envolvendo diferentes ações (KÖLBL, 2009). Os resultados das comparações foram discutidos em workshops possibilitando a troca de experiências entre as operadoras, contribuindo com a melhoria dos processos e consequentemente no desempenho dos níveis de perdas de água na distribuição (KÖLBL, et al., 2008).

O desenvolvimento do projeto de benchmarking da OVGW permitiu identificar quais os fatores que mais influenciam nos níveis de perdas de água, possibilitando que as operadoras adotassem medidas para diminuir a influência dos mesmos (KÖLBL et al., 2008a).

\subsubsection{Alemanha}

O setor de água da Alemanha considera o benchmarking como um instrumento eficiente na identificação e adoção de métodos e processos bem-sucedidos de parceiros, partindo de prérequisitos de participação voluntária e anônima das operadoras para o sucesso do processo, assim como verificado no caso Austríaco. A inserção do benchmarking na indústria de água alemã é parte de uma estratégia de modernização apresentada pelo Governo Alemão, com o objetivo de identificar potenciais melhorias e otimizar os processos das operadoras melhorando o desempenho dos seus serviços (BDEW, 2012).

Atualmente são desenvolvidos diversos projetos de benchmarking no país, que objetivam avaliar o desempenho das operadoras em diferentes aspectos. A diferença dos projetos da Alemanha é que os mesmos são realizados por empresas privadas, que por um lado devem assegurar um alto nível de qualidade dos resultados, mas, por outro podem levar a resultados perfeitamente ajustados para questões particulares (KÖLBL, 2009). Desde 2005, a "German Association of Energy and Water Industries" (BDEW), em parceria com outras organizações, publicam regularmente um relatório, com os resultados dos projetos de benchmarking, intitulado "Profile of the German Water Sector" o qual demonstra uma visão geral das atividades de benchmarking desenvolvidas no país (BDEW, 2012).

No contexto das perdas de água em sistemas de distribuição, dados dos relatórios demonstram que os níveis de perdas de água apresentam um contínuo declínio. Em 1991 o país perdia em média 10,9\% de água no processo de distribuição e em 2011 os níveis de perdas foram estimados em 6,5\%, menor nível de perdas entre os países europeus (ATT, et al., 2005; ATT, et al., 2011; ATT et al., 2015). Os dados de perdas, entre outros dados dos serviços das 
operadoras, indicam que o processo de benchmarking tem contribuído efetivamente com a melhoria do desempenho das operadoras de água na prestação dos serviços, tendo em vista que a realização regular do benchmarking possibilita que as operadoras participantes identifiquem potenciais mudanças e que as mesmas possam implementar os melhores processos para aumentar sua eficiência (ATT, et al., 2011).

Neste enredo, é importante salientar que as organizações recomendam a adoção dos melhores processos pelas operadoras participantes, uma vez que, estas assinaram uma declaração ("Statement of the Associations of the Water Industry on Benchmarking in the Water Sector") em que se comprometem a promover a propagação dos melhores processos de gestão incluindo o benchmarking como parte integrante da auto-administração (ATT, et al., 2008; ATT, et al., 2015).

As organizações que coordenam o processo de benchmarking na Alemanha realçam que a continuidade do mesmo é essencial para manter os níveis de desempenhos alcançados até o momento e para introduzir melhorias sempre que possível e necessário. O sistema de benchmarking do setor de água alemão é continuamente refinado por institutos de pesquisa em conjunto com profissionais do setor de água com o intuito de obter os melhores resultados (ATT, et al., 2011; ATT, et al., 2015).

\subsubsection{Canadá}

O projeto de benchmarking canadense é considerado um dos principais projetos da área no mundo. Denominado "The Canadian National Water and Wastewater Benchmarking Initiative", a primeira iniciativa foi apresentada em 1997, com um projeto piloto, que contou com a participação de quatro empresas de água residuais, sendo que em 2001 o projeto estendeu-se para as operadoras de abastecimento de água, contando atualmente com a participação de 50 operadoras (MCCORMACK 2005; NWWBI, 2013).

O benchmarking processual é continuamente aplicado no país, desde 2001, pois, é visto como uma ferramenta que preenche a lacuna entre a avaliação de desempenho das operadoras, identificando as melhores práticas que conduzem aos melhores desempenhos. A ferramenta é aplicada por membros das operadoras participantes, que formam uma força tarefa, responsáveis por identificar os problemas relacionados ao processo, adotando medidas para aperfeiçoá-los (MCCORMACK, 2005).

Entre os projetos de benchmarking processual desenvolvidos no país, há um projeto contínuo específico para o gerenciamento de perdas de água, com mais de 10 anos, o qual objetiva calcular os níveis de perda das operadoras, investigar quais os processos adotados para 
o gerenciamento das perdas e apurar quais os custos e benefícios destes processos, determinando quais proporcionam os melhores desempenhos. Os resultados são apresentados anualmente em um workshop com as operadoras possibilitando uma intensa troca de experiências em que as operadoras com melhores desempenho podem compartilhar seus processos de forma que as com desempenho inferior possam implementá-los. A abordagem do benchmarking canadense, voltado ao gerenciamento de perdas, concentra suas análises na base qualitativa, comparando processos (MAIN et al., 2006; KÖLBL, 2009).

No que diz respeitos aos níveis de perdas de água no Canadá, dados de 2009 indicam baixos níveis, quando comparado ao Brasil, 13,3\% (ENVIRONMENT CANADA, 2011; RENZETTI; DUPONT, 2013).

\subsection{Considerações sobre a aplicação do benchmarking na pesquisa}

O desenvolvimento deste capítulo foi essencial para a familiarização com a técnica do benchmarking, fornecendo conhecimento sobre sua importância e potencial de aplicação no setor de água, apresentando casos de sucesso voltados ao controle de perdas.

Posto que a aplicação do benchmarking nesta pesquisa foi direcionada a avaliação da performance das operadoras PCJ no controle de perdas de água, o levantamento de indicadores de desempenho (IDs) de perdas de água em sistema de distribuição foi fundamental para o entendimento do que tem sido utilizado em nível nacional e internacional para calcular tal performance. A variedade de IDs identificados na literatura e a importância de se utilizar indicadores adequados, lançou a necessidade da seleção dos indicadores de perdas mais adequados à realidade dos sistemas de abastecimento brasileiros, de forma a retratar o cenário real (Etapa 1.1 dos procedimentos metodológicos). Vale ressaltar nesta perspectiva que as informações mensuradas pelas operadoras de abastecimento brasileiras são incipientes, não sendo suficientes para calcular os indicadores propostos pela IWA, que demandam um grau técnico elevado por parte das operadoras. 


\section{RESULTADOS E DISCUSSÃO}

Neste capítulo são apresentados os resultados de cada etapa de execução da pesquisa. No item 5.1, e nos seus respectivos subitens, são expostos os resultados da aplicação do benchmarking, que respondem aos objetivos específicos 1 e 2, enquanto o item 5.2 apresenta as assertivas relacionadas ao objetivo específico 3. Por fim, no item 5.3 são discutidos os resultados que atendem ao objetivo geral da pesquisa e respondem à questão norteadora deste trabalho.

\subsection{Benchmarking para avaliação das perdas de água nas bacias PCJ}

Neste subcapítulo discorre-se sobre os resultados voltados ao alcance dos objetivos específicos 1 e 2. No subitem 5.1.1 os indicadores submetidos a avaliação dos especialistas são discutidos, apontando o indicador selecionado para uso na aplicação do benchmarking. No subitem subsequente os resultados da aplicação da metodologia de credibilidade dos dados operacionais são expostos e debatidos. Por fim, no subitem 5.1.3 são determinados os níveis de perda de água de cada um dos municípios em estudo, cujos dados operacionais foram classificados como confiáveis para fins de avaliação de desempenho.

\subsubsection{Indicadores de perdas de água e a aplicação do benchmarking}

Seguindo os procedimentos metodológicos propostos nesta pesquisa, os resultados da Fase 1 correspondem à avaliação dos 17 indicadores de perdas de água (Quadro 11) avaliados pelos especialistas do setor a partir dos cinco critérios, (Exequibilidade, Compreensibilidade, Relevância, Mensurabilidade e Suficiência).

Quadro 11- Indicadores de perdas de água avaliados pelos especialistas.

\begin{tabular}{|c|c|}
\hline Sigla & Nome do Indicador \\
\hline I1 & Perdas de água por ramal \\
\hline I2 & Perdas de água por comprimento de conduta \\
\hline I3 & Perdas aparentes \\
\hline I4 & Perdas aparentes por volume de água entrada no sistema \\
\hline I5 & Perdas reais por ramal \\
\hline I6 & Perdas reais por comprimento de conduta \\
\hline I7 & Porcentagem das perdas na distribuição \\
\hline I8 & Porcentagem de vazamentos \\
\hline I9 & Água não faturada (Non-revenue water) \\
\hline I10 & Índice de perda na distribuição \\
\hline I11 & Índice de perda de Faturamento \\
\hline I12 & Índice linear bruto de perdas \\
\hline I13 & Índice de perda por ligação \\
\hline I14 & Índice de perdas por faturamento \\
\hline I15 & Índice de perda na distribuição \\
\hline I16 & Índice bruto de perdas lineares \\
\hline I17 & Índice de perda por ligação \\
\hline
\end{tabular}


Nas Figuras 9,10, 11, 12, 13 estão expressas as medianas das notas atribuídas a cada indicador considerando cada um dos critérios de avaliação. Tendo em vista que na Fase 2 foram estabelecidos pesos aos critérios e que estes influenciaram nas notas finais dos indicadores os resultados das avaliações serão discutidos mais adiante. As Figuras abaixo são apresentadas para demonstrar os resultados da avaliação dos especialistas sem a atribuição dos pesos aos critérios.

Figura 9 - Avaliação da exequibilidade dos indicadores.

\section{Critério Exequibilidade}

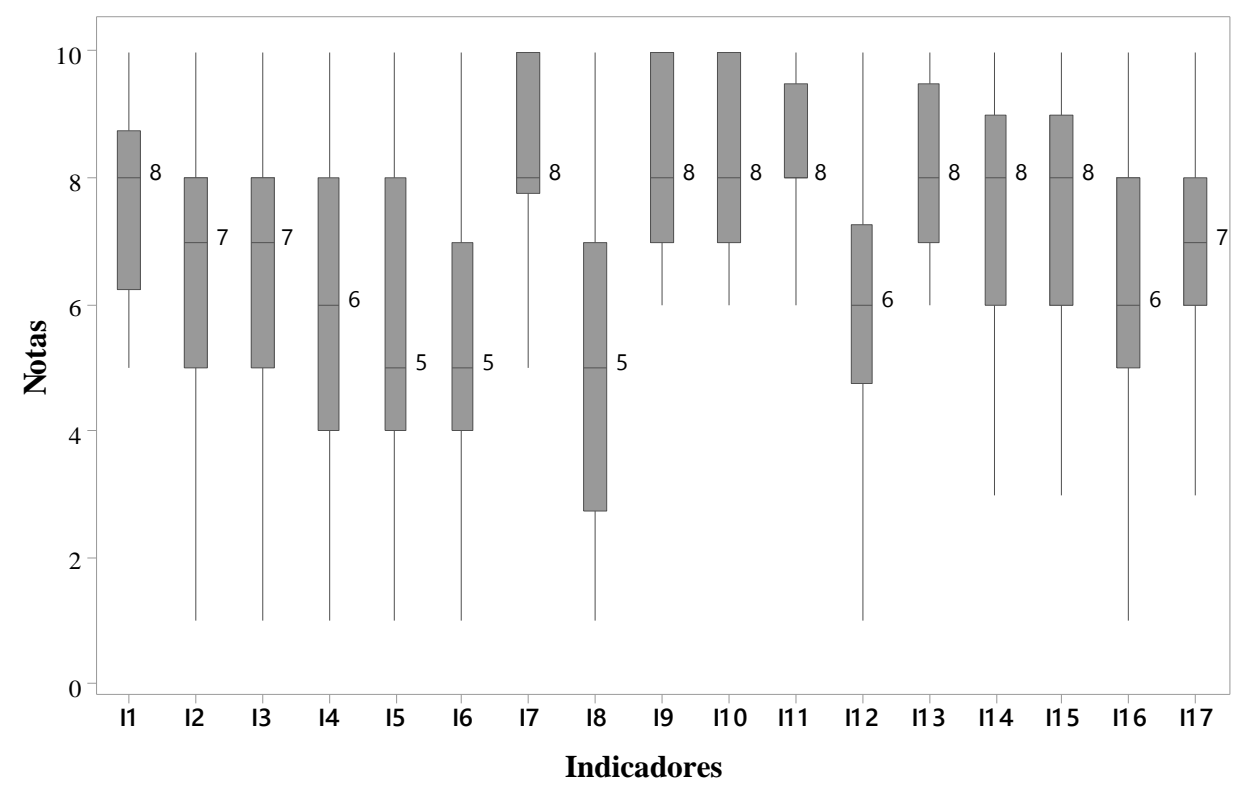

Fonte: Elaborado pela autora

Figura 10 - Avaliação da compreensibilidade dos indicadores

Critério Compreensibilidade

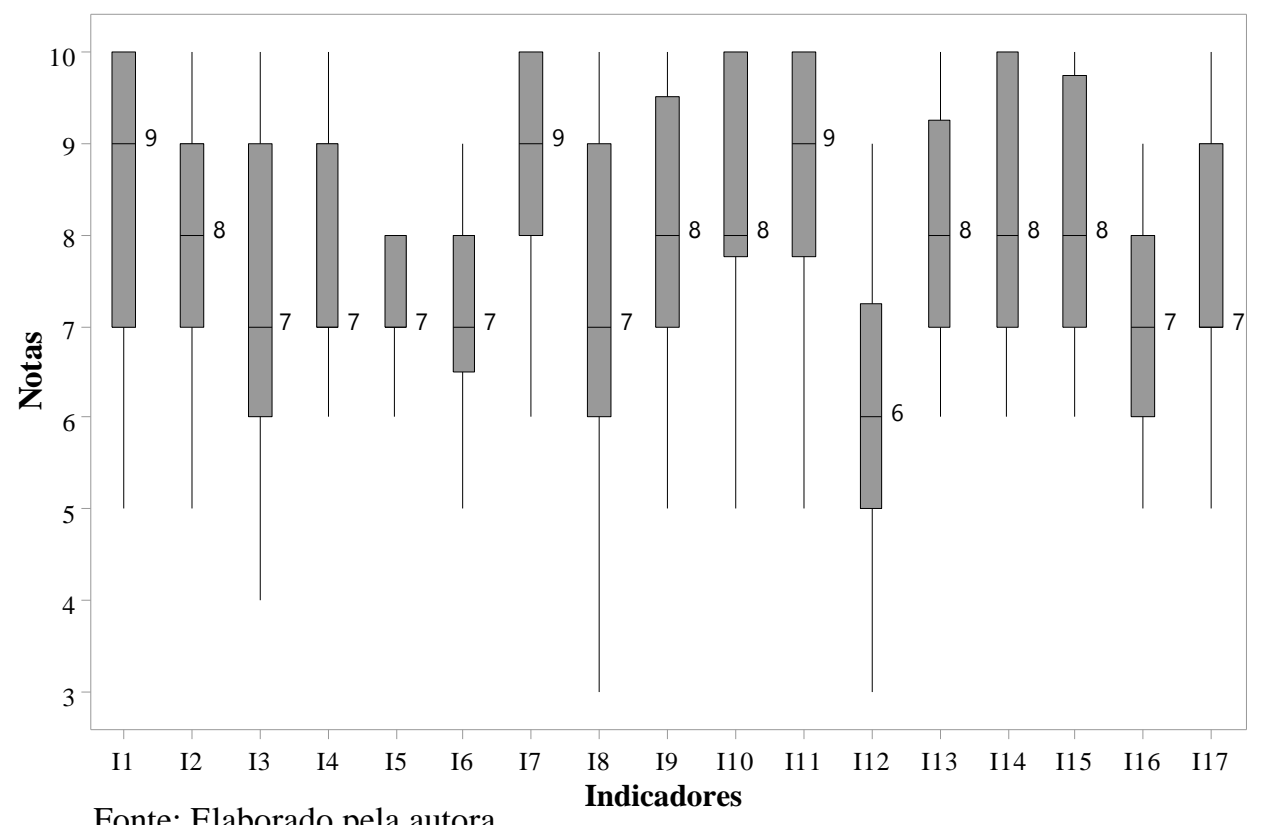

Fonte: Elaborado pela autora Indicadores 
Figura 11 - Avaliação da relevância dos indicadores.

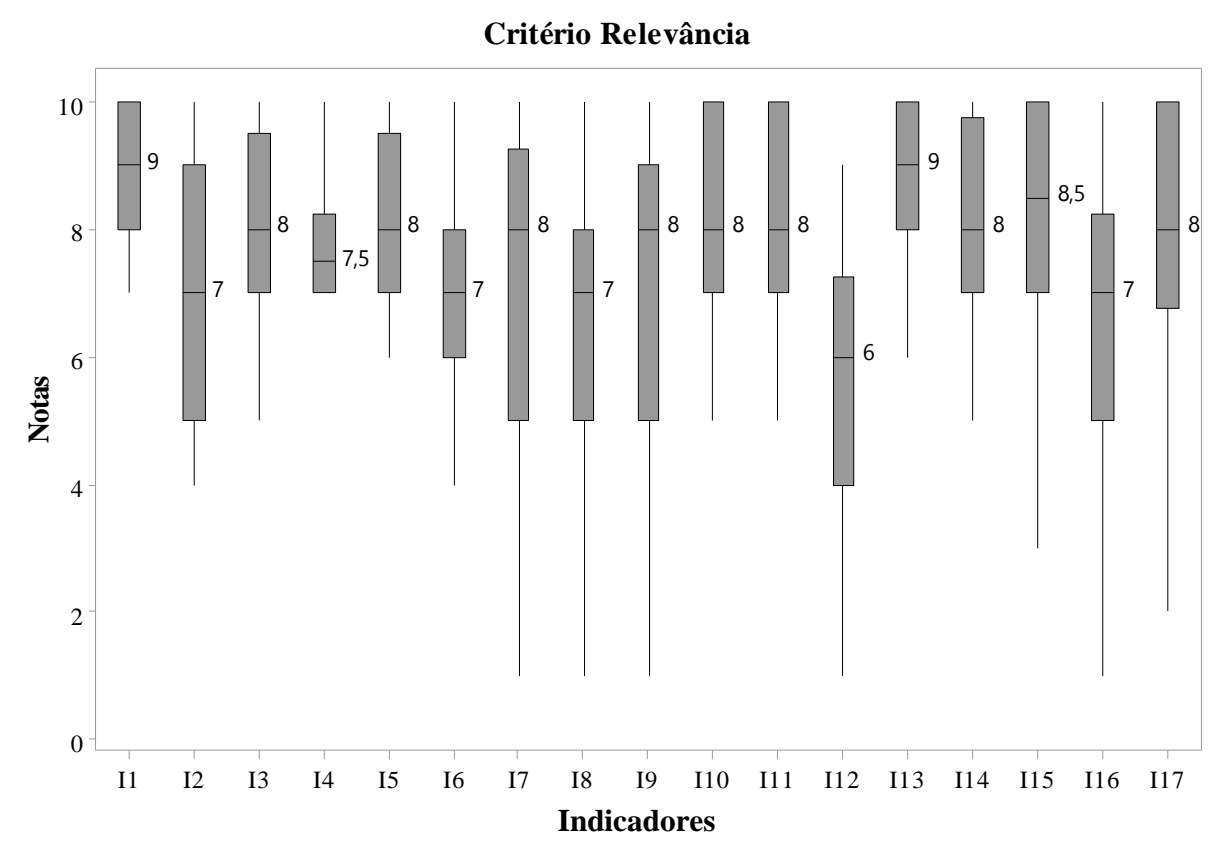

Fonte: Elaborado pela autora

Figura 12 - Avaliação da mensurabilidade dos indicadores.

\section{Critério Mensurabilidade}

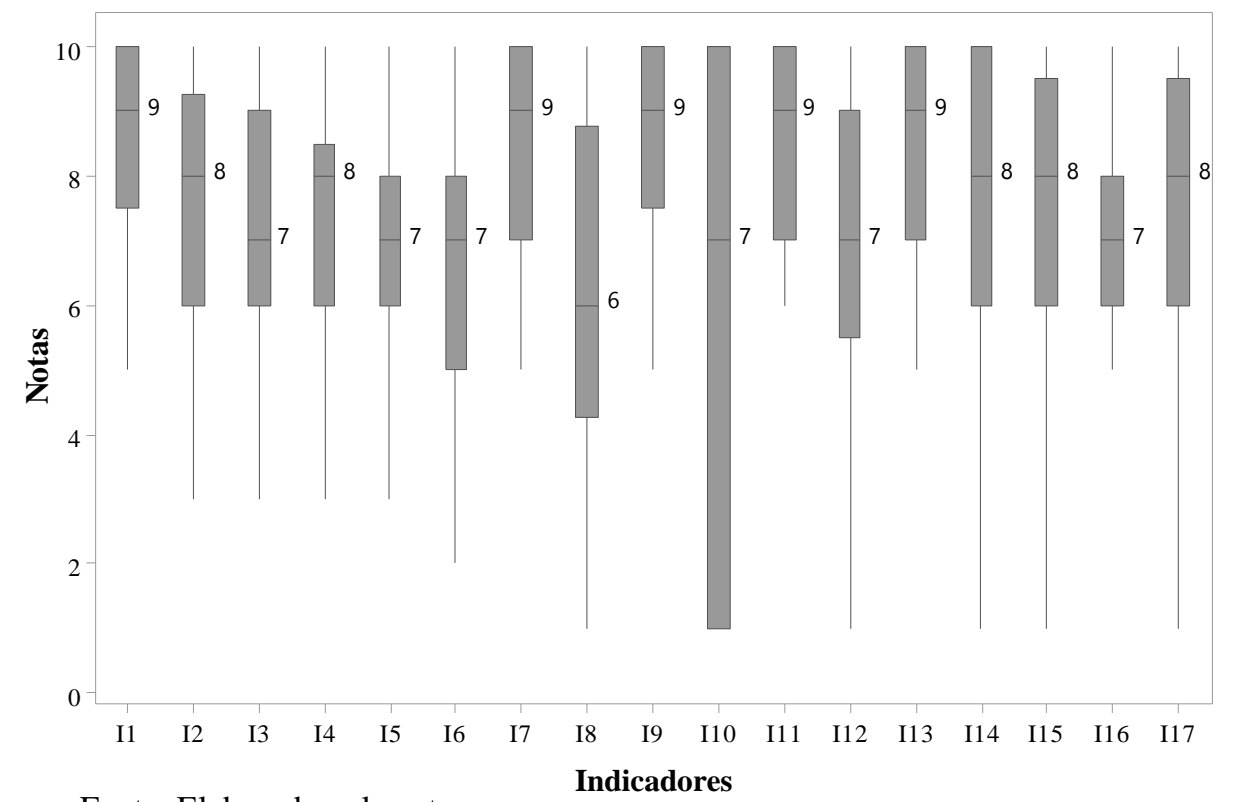

Fonte: Elaborado pela autora 
Figura 13- Avaliação da Suficiência dos indicadores.

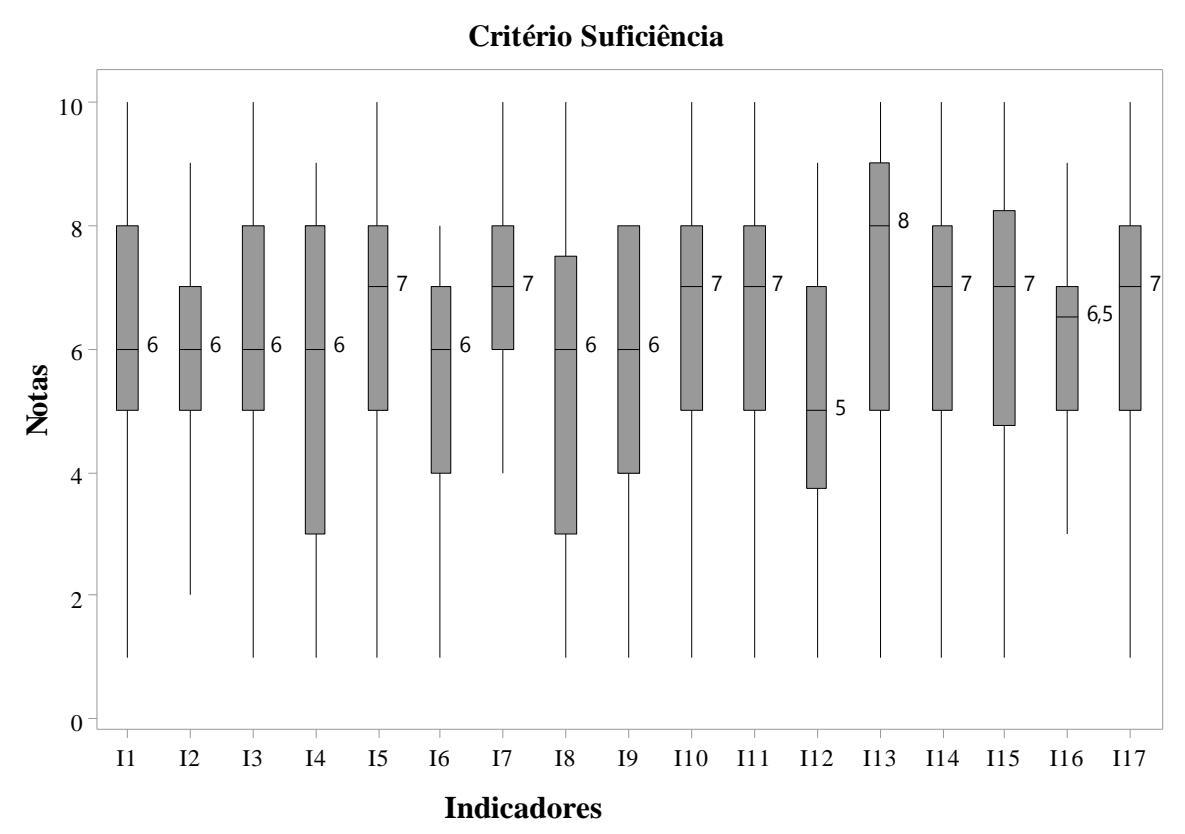

Fonte: Elaborado pela autora

No que diz respeito à Fase 2, o processamento das informações coletadas junto aos especialistas no software SRF gerou os pesos (poids normés) expressos na Figura 14. Afere-se que dos cinco critérios o menos relevante, com menor peso $(5,6)$, é o critério mensurabilidade, seguidos pelos critérios compreensibilidade $(11,1)$, suficiência $(22,2)$ e exequibilidade $(27,8)$. Na contramão tem-se como critério de maior peso $(33,3)$ a relevância do indicador, ou seja, se o resultado gerado pelo mesmo retrata adequadamente o cenário das perdas de água em um sistema.

Figura 14- Pesos atribuídos aos critérios de avaliação de indicadores de perdas de água.

\begin{tabular}{|c|c|c|c|c|c|}
\hline \multirow[b]{2}{*}{ Acteur $=1$} & \multicolumn{4}{|c|}{ Tableau des Résultats } & \multirow[t]{2}{*}{ Fermer } \\
\hline & Itération $=1$ & Variante $=1$ & Format $=1$ & Valeur Z & \\
\hline Numéro - (Code) & Intitulé & Rang & Intervalle & $\begin{array}{l}\text { Poids non } \\
\text { Normés }\end{array}$ & $\begin{array}{l}\text { Poids } \\
\text { Normés }\end{array}$ \\
\hline 4 - (4) Mens.... & $\ldots \ldots \ldots$ & …… & 1 & 1 & 5,6 \\
\hline 2 - (2) Coomp... & $\ldots \ldots \ldots$ & $\cdots \cdots$ & 1 & 2 & 11,1 \\
\hline 5 - (5) Suf.... & $\ldots \ldots$ & $\ldots \ldots$ & 3 & 4 & 22,2 \\
\hline 1 - (1) Exec.... & $\cdots \cdots$ & $\ldots \ldots \ldots$ & 0 & 5 & 27,8 \\
\hline $3-$ (3) $\operatorname{Rel} \ldots$ & $\ldots \ldots \ldots$ & $\ldots \ldots$ & 5 & 6 & 33,3 \\
\hline & & & & & 100 \\
\hline
\end{tabular}

Fonte: Software SRF

Assim, a partir dos pesos de cada critério tem-se como equação final (Equação 8) da nota dos indicadores a seguinte equação: 
$\mathrm{NF}=\frac{((\text { Medcrit } 1 * 27,8)+(\text { Medcrit } 2 * 11,1)+(\text { Medcrit } 3 * 33,3)+(\text { Medcrit4 } * 5,6)+(\text { Medcrit5*22,2) })}{100}$, em que:

Medcrit1 = Mediana das notas do critério 1 (Exequibilidade);

Medcrit 2 = Mediana das notas do critério 2 (Compreensibilidade);

Medcrit3 = Mediana das notas do critério 3 (Relevância);

Medcrit4 = Mediana das notas do critério 4 (Mensurabilidade);

Medcrit5 = Mediana das notas do critério 5 (Suficiência).

A aplicação da equação gerou as notas finais apresentadas na Tabela 2. Analisando os dados expressos na mesma, observa-se que o indicador I12, que se propõem a avaliar as perdas de água em relação ao comprimento das redes, apresenta a menor nota final entre todos os indicadores em estudo $(5,834)$. Para os especialistas, este indicador apresenta baixa suficiência e relevância uma vez que sua utilização para fins de comparação de sistemas é complexa em função das disparidades de densidades de rede nas áreas, não sendo suficiente para retratar adequadamente o cenário das perdas de água em um sistema de distribuição.

Na perspectiva destes dois critérios, destacam-se também os indicadores I2, I6 e I16 que buscam igualmente avaliar as perdas pelo comprimento das redes e apresentam notas finais inferiores aos outros indicadores (6,9; 6,2 e 6,5, respectivamente), destacando-se a baixa avaliação dos critérios suficiência e relevância para os três indicadores em questão e a baixa nota do critério exequibilidade do indicador I6. A baixa avaliação do I6 em relação ao critério exequibilidade pode estar associada as variáveis que compõem o mesmo que nem sempre são geradas pelas operadoras, pela incapacidade técnica e financeira, como mensuração das perdas reais desagregadas das aparentes e informações sobre o tempo de pressurização do sistema. 
Tabela 2 - Nota final dos indicadores avaliados pelos especialistas.

\begin{tabular}{|c|c|c|c|c|c|c|}
\hline \multirow[b]{2}{*}{ Indicador } & \multicolumn{5}{|c|}{ Critérios } & \multirow{2}{*}{ Nota final do indicador } \\
\hline & Exequibilidade & Compreensibilidade & Relevância & Mensurabilidade & Suficiência & \\
\hline I1 & 222,4 & 99,9 & 299,7 & 50,4 & 133,2 & 8,056 \\
\hline $\mathbf{I 2}$ & 194,6 & 88,8 & 233,1 & 44,8 & 133,2 & 6,945 \\
\hline $\mathbf{I 3}$ & 194,6 & 77,7 & 266,4 & 39,2 & 133,2 & 7,111 \\
\hline I4 & 166,8 & 77,7 & 233,1 & 44,8 & 133,2 & 6,556 \\
\hline I5 & 139 & 77,7 & 266,4 & 39,2 & 155,4 & 6,777 \\
\hline I6 & 139 & 77,7 & 233,1 & 39,2 & 133,2 & 6,222 \\
\hline I7 & 222,4 & 99,9 & 266,4 & 50,4 & 155,4 & 7,945 \\
\hline I8 & 139 & 77,7 & 233,1 & 33,6 & 133,2 & 6,166 \\
\hline I9 & 222,4 & 88,8 & 266,4 & 50,4 & 133,2 & 7,612 \\
\hline I10 & 222,4 & 88,8 & 266,4 & 39,2 & 155,4 & 7,722 \\
\hline I11 & 222,4 & 99,9 & 266,4 & 50,4 & 155,4 & 7,945 \\
\hline I12 & 166,8 & 66,6 & 199,8 & 39,2 & 111 & 5,834 \\
\hline I13 & 222,4 & 88,8 & 299,7 & 50,4 & 177,6 & 8,389 \\
\hline I14 & 222,4 & 88,8 & 266,4 & 44,8 & 155,4 & 7,778 \\
\hline I15 & 222,4 & 88,8 & 266,4 & 44,8 & 155,4 & 7,778 \\
\hline I16 & 166,8 & 77,7 & 233,1 & 39,2 & 133,2 & 6,5 \\
\hline I17 & 194,6 & 77,7 & 266,4 & 44,8 & 155,4 & 7,389 \\
\hline
\end{tabular}

Fonte: Elaborado pela autora. 
Vê-se ainda, pelos dados da Tabela 2, que os indicadores I4, I5 e I8 também apresentam notas finais inferiores $(6,5 ; 6,7$ e 6,1 respectivamente) em comparação aos outros indicadores, os quais variam de 7,1, a 8,3. No que diz respeito ao I4, indicador que busca mensurar as perdas aparentes de um sistema, os especialistas os avaliaram como insuficientes e pouco relevantes para aferir sobre o desempenho das empresas de saneamento no controle de perdas. Na mesma perspectiva do I6, o I4 apresentou ainda baixa avaliação para o critério exequibilidade, o que está atrelado ao fato de que a maior parte dos países com grau de desenvolvimento semelhante ao Brasil não tem capacidade técnica e financeira para mensurar as perdas de forma desagregada, como ocorre em países ricos, com sistemas de saneamento mais estruturado, como exortam Braden e Mankin (2004), Mutikanga et al. (2010) e Mutikanga et al. (2013).

Na contramão da avaliação dos indicadores discutidos anteriormente, o I5, indicador proposto pela IWA que visa mensurar as perdas de água por ramal, apresentou boas avaliações no quesito relevância e suficiência, porém, a menor avaliação, juntamente com o I6 e I8 para o critério exequibilidade. Isto indica que, assim como no caso do I6, as variáveis que compõem o I5 (perdas reais e tempo de pressurização dos sistemas) são de difícil obtenção em sistemas que apresentam dificuldades técnicas e financeiras, como ocorre na maior parte do Brasil, o que inviabiliza sua aplicação.

No que tange a baixa avaliação do I8, a principal fragilidade deste indicador está relacionada a insuficiência de indicadores que expressam as perdas em percentual, como apresentado no subitem 4.1.1.1 deste documento. A IWA apresenta restrições quanto ao uso dos indicadores expressos em percentual, recomendando que os mesmos sejam empregados apenas para análises de faturamento, uma vez que são inadequados para avaliar a eficiência da gestão dos sistemas de distribuição, pois, são fortemente influenciados pelas mudanças de consumo e não distinguem as perdas reais e aparentes, como apontado por Lambert e Hirner (2000) e Wirnani et al. (2009). Além da insuficiência do indicador na determinação das perdas, as baixas avaliações para os critérios mensurabilidade e exequibilidade demonstram que, de um lado o indicador não apresenta uma medida física adequada e de outro não tem dados disponíveis para cálculo. No Brasil, muitos sistemas ainda não contam com infraestrutura de macromedidores, o que impede a mensuração de volumes perdidos seja por vazamentos nas redes ou fraudes.

Salvo as discussões em torno dos indicadores com menores avaliações, em referência aos indicadores melhores avaliados, I1 e I13 apresentam as duas maiores notas finais, 8,01 e 8,38 , respectivamente, indicando sua aplicabilidade para fins de planejamento e fiscalização no 
controle de perdas de água dos sistemas brasileiros. Elaborados e propostos por instituições distintas, I1 pela IWA e I13 pelo PNCDA, ambos buscam calcular o nível das perdas de água por ligações, porém, com algumas diferenças nas fórmulas de cálculo, conforme demonstrado nas equações abaixo.

\section{I1: Perdas de água por ramal ${ }^{24}$ (m³/ramal/ano) (Equação 9)}

$$
\mathrm{Op} 23=\frac{\frac{\mathrm{A} 3-\mathrm{A} 14 * 365}{\mathrm{H} 1}}{\mathrm{C} 24}
$$

A3: Corresponde ao volume de água introduzido no sistema de abastecimento $\left(\mathrm{m}^{3}\right)$ no período de referência, incluído neste volume a água captada e toda água importada bruta e tratada.

A14: Corresponde ao volume de água total consumido autorizado $\left(\mathrm{m}^{3}\right)$, incluindo os medidos e não medidos, o volume utilizado pela própria empresa, incluindo também a água exportada. Inclui-se nesse volume os consumos para combate à incêndios, lavagem de ruas, regas de espaços verdes municipais, entre outros serviços.

H1: Corresponde à duração do período adotado como referência para o cálculo dos indicadores. Recomenda-se a utilização da base anual (365 dias).

C24: Corresponde ao número total de ramais de ligação na data de referência. Deve-se contabilizar todos os ramais em serviço, incluindo os de clientes registrados (residentes e não residentes, contando ramais temporários), hidrantes, fontanários ou outros pontos de consumo autorizados não diretamente ligados a uma conduta. É importante destacar que os ramais de ligação que estejam fora de serviço, por desocupação dos edifícios, não devem ser contabilizados no número total de ramais de ligação.

\section{I13- Índice de Perda por Ligação (m³/lig.dia) (Equação 10)}

$$
\mathrm{IPL}=\frac{\mathrm{VD}-\mathrm{VU}}{\mathrm{LA} \times \mathrm{ND}}
$$

VD: Corresponde ao volume de água disponibilizado para a distribuição no período de referência. Para obtenção deste volume faz-se a soma algébrica dos volumes produzidos (VP), exportado (VEx) e importado (VIm).

\footnotetext{
${ }^{24}$ Ramal corresponde a tubagem autorizada que faz a ligação da conduta ao ponto de medição ou à válvula de retenção do cliente, conforme o caso. No caso de mais do que um consumidor partilhar a mesma ligação física à conduta pública (ex.: edifícios de apartamentos com contratos individualizados por alojamento), então deve contarse como um ramal de ligação para efeito do cálculo dos indicadores que entram com o número de ramais, independentemente do número de consumidores servidos.
} 
VU: Corresponde ao volume de água utilizado, ou seja, a soma dos volumes micromedidos, estimado, recuperado, operacional e especial.

LA: Corresponde ao número de ligações ativas, providas ou não de hidrômetros, que contribuem para o faturamento mensal.

ND: Corresponde ao $\mathrm{n}^{\circ}$ de dias que compreendem os dados (geralmente 365).

Analisando as fórmulas descritas acima vê-se que os indicadores diferem em dois pontos. O primeiro diz respeito ao volume de água exportado (VEx) que no I1 é incluído como volume de água total consumido, enquanto no I13 o VEx é considerado no montante do volume disponibilizado à distribuição. O segundo ponto divergente trata da unidade de medida, enquanto o I1 avalia o volume de perdas por ano o I13 avalia as perdas na ligação por dia.

A divergência relacionada a unidade de medida pode ser solucionada por uma simples operação matemática, multiplicando o resultado gerado pelo I13 por 365. No panorama destes dois indicadores, é interessante assinalar que se o sistema em análise não exportar água para outros sistemas do entorno, ou seja, $\mathrm{VEx}=0$, o resultado dos indicadores será o mesmo se as unidades de medida forem transformadas, seja o $\mathrm{I} 1$ convertido para $\mathrm{m}^{3}$ por dia (dividindo o valor final por 365) ou o $\mathrm{I} 13 \mathrm{em}^{3}$ de perdas por ano (multiplicando o nível de perdas por $365)$.

Frente a estas análises e tendo em vista que nos procedimentos metodológicos estabeleceu-se que o indicador a ser utilizado no processo de benchmarking métrico desta pesquisa seria o que apresentasse melhor avaliação, o I13 corresponde ao indicador selecionado para aplicação no benchmarking para avaliação do desempenho no controle de perdas de água na distribuição. Os resultados desta etapa vão de encontro ao apresentado por Kingdon (2006), que defende que o indicador que avalia as perdas por ligação por conexões por dia é o melhor indicador de desempenho, haja visto que a maior parte dos vazamentos ocorre nas conexões de água.

As etapas subsequentes à seleção do indicador incluíram a coleta dos dados que compõem o I13, descritas na equação 10, junto as empresas de saneamento dos municípios em estudo, análise da credibilidade destes dados e o cálculo do desempenho das operadoras para aqueles municípios cujo dados se enquadraram como confiáveis. Assim, no subitem a seguir as credibilidades dos dados coletados para aplicação na fórmula do indicador selecionado são apresentadas e discutidas de forma que retratem adequadamente o cenário das perdas de água nas Bacias PCJ. 


\subsubsection{Análise da credibilidade dos dados do IPL}

Como apontado por Miranda (2002), há uma crescente preocupação em relação a credibilidade dos dados gerados pelos sistemas de saneamento, de forma que estes possam representar o real desempenho de sua operação. Entre os 70 municípios em estudo, apenas 52 disponibilizaram os dados para que pudessem ser utilizados na pesquisa. Alguns dados não foram cedidos por questões burocráticas da empresa de saneamento e outros, a maioria, por não terem os dados disponíveis, ou seja, incapacidade técnica e financeira da operadora em gerar dados essenciais para o monitoramento e planejamento de ações nos sistemas.

O resultado da aplicação da metodologia de análise da credibilidade do volume disponibilizado, utilizado e faturado demonstrou que há diferenças significativas entre a genuinidade dos dados produzidos por sistemas geridos em diferentes modelos de gestão. Este aspecto nos traz a luz da discussão de quem detém a responsabilidade pela prestação dos serviços de saneamento no Brasil. Nesta perspectiva, temos fundamentada no Art.30, inciso V, da Constituição Federal de 1988 a titularidade do saneamento ao município estabelecendo como responsabilidade dos entes municipais "organizar e prestar, diretamente ou sob regime de concessão ou permissão, os serviços públicos de interesse local” (BRASIL, 1988). Mais recentemente, com o advento da Lei $n^{\circ}$ 11.445/2007, ficou estabelecido no Art. $8^{\circ}$ que:

"Os titulares dos serviços públicos de saneamento básico poderão delegar a organização, a regulação, a fiscalização e a prestação desses serviços, nos termos do Art. 241 da Constituição Federal e da Lei n $^{\circ} 11.107$, de 6 de abril de 2005”. (BRASIL, 2007)

Em resumo, o conteúdo redigido nos respectivos artigos de lei estabelece como incumbência dos municípios definir o ente responsável por prestar os serviços de saneamento, seja a administração pública direta (prefeitura ou órgão delegado), indireta (autarquias) ou concessão dos serviços às empresas privadas ou de economia mista. Neste sentido, os resultados da credibilidade dos dados dos sistemas das bacias PCJ ilustram um ponto forte a ser considerado na gestão não só das perdas, mas, dos serviços de saneamento como um todo: a natureza jurídica do órgão responsável pela prestação do serviço de saneamento. Nas Figuras $(15,16$ e 17) apresentadas nos subitens subsequentes visualiza-se a significativa diferença da confiabilidade dos volumes dos sistemas geridos por órgãos de natureza jurídicas distintas. 


\subsubsection{Credibilidade do volume de água disponibilizado (VD)}

Analisando os dados organizados na Figura 15 observa-se que a maior parte dos municípios que apresentam credibilidade de dados considerados como não utilizável (Faixa IV - de 0 a 0,29) são sistemas operados no modelo de administração pública direta. A principal razão para a baixa credibilidade dos dados gerados neste modelo jurídico de gestão se deve a carência de recursos financeiros para alavancar o setor que, como assinalado por Lisboa, Heller e Silveira (2013), neste cenário ocorrem em baixa escala. De acordo com Heller, Coutinho e Mingoti (2006), no modelo de administração pública direta não há autonomia financeira e os serviços utilizam o "caixa único", no qual o recurso proveniente da arrecadação de impostos e cobranças é direcionado para o setor que está com maior defasagem ou que seja de maior interesse do gestor público, não sendo garantido que haverá investimento no saneamento municipal.

Figura 15 - Credibilidade do volume de água disponibilizado dos sistemas em estudo.

\section{C(VD)}

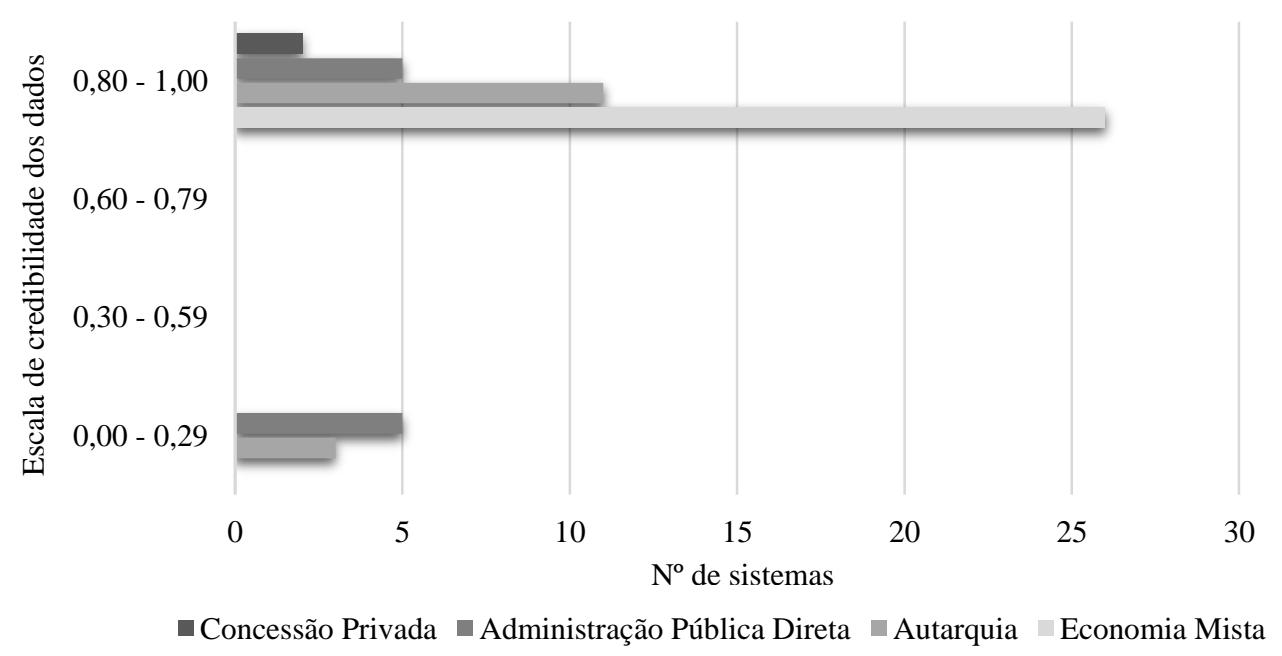

Fonte: Elaborado pela autora.

Estritamente associado a credibilidade do volume disponibilizado está a existência de macromedidores nas redes (Prática 2 do processo "Gerenciamento de Infraestrutura") responsáveis por monitorar a vazão de água disponibilizada à distribuição. Assim, a baixa credibilidade do VD verificada nestes municípios indica que o volume de saída de água dos reservatórios para a rede de distribuição não é macromedido e sim estimado, o que dificulta a mensuração e o controle das perdas de água. Confirmando este aspecto, os dados coletados em campo revelam que entre os 10 municípios operados no modelo de gestão centralizado e que responderam ao questionário de dados operacionais, seis atestaram não contar com a infraestrutura de macromedidores para mapear as vazões de água na rede, o que demonstra na 
prática a carência de recursos, apresentada por Lisboa, Heller e Silveira (2013) na aquisição de equipamentos básicos para o monitoramento dos sistemas de saneamento. A inexistência destes dispositivos torna inexequível analisar os volumes de água perdidos no processo de distribuição, uma vez que não se tem conhecimento do quanto de água é produzido e distribuído.

Para os municípios operados em um modelo descentralizado (Autarquias, Concessão Privada ou Empresa de Economia Mista) a credibilidade do VD se enquadra como plenamente crível em quase todos os casos, o que indica uma boa macromedição do volume de água que é distribuído. Entre os municípios analisados, 14 tem seus serviços de saneamento prestados por autarquias, 26 por empresas de economia mista e três por concessões privadas.

As autarquias são denominadas comumente por Serviço ou Departamento Autônomo de Água e Esgoto (SAAE e DAAE) e, como citado por Meirelles (1995), são instituídas por lei e não apresentam subordinação hierárquica tendo autonomia administrativa, com algumas limitações como contratação por concurso e compras por licitações. Em relação as empresas de economia mista, Scorsim e Glitz (2007) discorrem que a conjugação do capital público e privado é a característica básica deste modelo, reforçando que o principal benefício da adoção deste molde é a captação de recursos privados, os quais são essenciais para obras de infraestrutura.

\subsubsection{Credibilidade do volume de água utilizado (VU)}

A credibilidade do volume de água utilizado (VU) em um sistema de distribuição está diretamente associada a maior viabilidade na captação de recursos financeiros pelas empresas de economia mista e privada que favorecem, além do investimento em infraestruturas, o aporte financeiro na contratação de equipe técnica que monitoram assiduamente o volume de água utilizado (VU) tanto nas ligações prediais, com a manutenção de hidrômetros, respeitando a validade dos mesmos e instalação de novos prevenindo erros de medição, como nos usos internos da empresa (operacional e especial).

A facilidade de investimentos nestas áreas é refletida nos dados expostos na Figura 16, onde verifica-se que a credibilidade do VU da maior parte das empresas de economia mista e privadas se enquadram nas duas categorias de maior credibilidade (I e II), enquanto nas categorias de menor credibilidade (III) se enquadram alguns municípios operados pela administração pública direta, autarquias e três municípios em regime de economia mista. No caso das autarquias e administração direta, a menor credibilidade do VU pode estar associada a diversos fatores, como por exemplo, o uso de hidrômetros obsoletos, que causam erros de medição, uso de micromedidores de qualidade questionável, uma vez que a aquisição destes 
equipamentos é conduzida em um processo licitatório onde prevalece a política de menor preço, não aferição do volume operacional e especial, fraudes entre outros aspectos. Nestas situações, como já citado anteriormente, há limitação de recursos e investimentos que dificultam a aquisição de novos equipamentos de medição, que avaliem adequadamente os volumes utilizados.

Figura 16 - Credibilidade do volume de água utilizado dos sistemas em estudo.

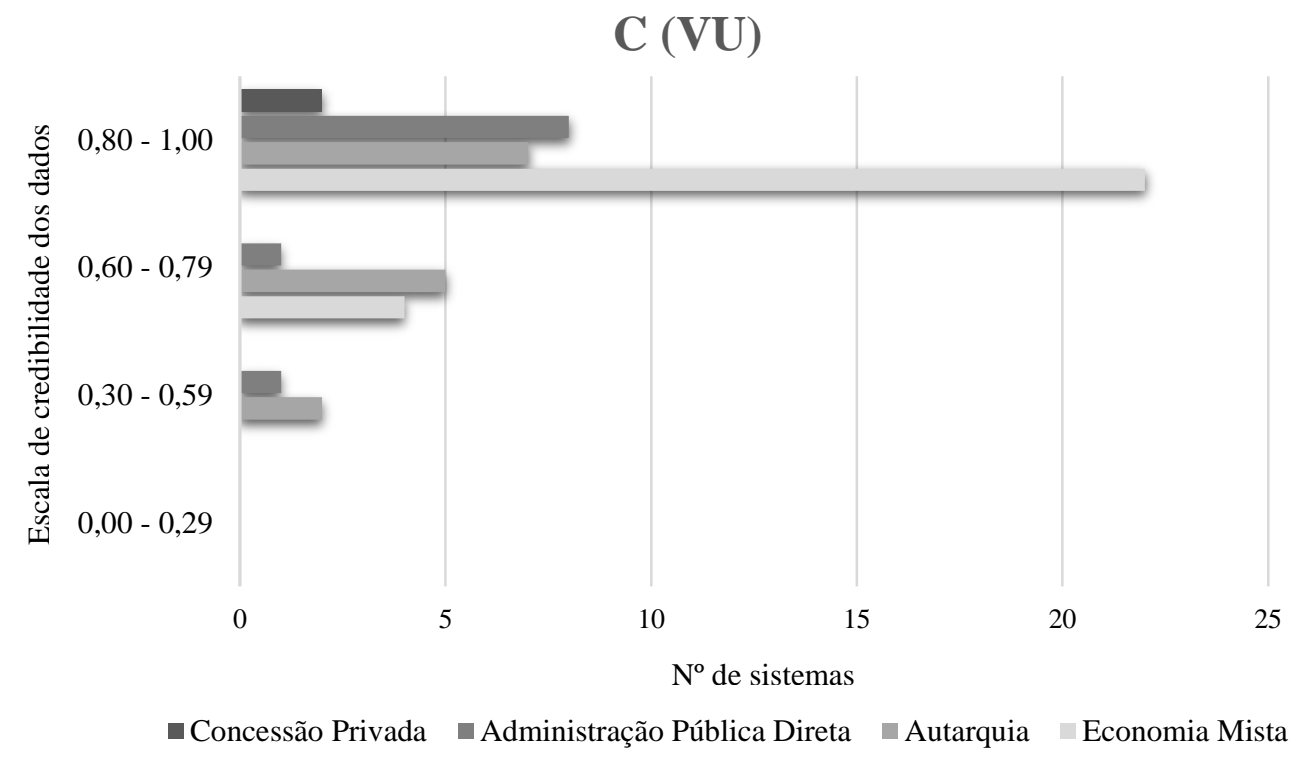

Fonte: Elaborado pela autora.

Entre os possíveis aspectos relacionados a baixa credibilidade do VU a ocorrência de fraudes recebe especial atenção neste estudo. As fraudes são comuns em muitos municípios, porém, em municípios onde há centros dispersos com habitações precárias ocupadas por populações vivendo em situação de vulnerabilidade social estas ocorrem em maior escala e afetam os dados operacionais, uma vez que, o volume de água é utilizado, porém, não contabilizado (GONZÁLEZ-GÓMEZ, et al. 2012). Excetuando-se os municípios operados pela administração pública direta, os resultados da análise de credibilidade indicam que dois dos municípios autarquiados (Capivari e Santo Antônio de Posse) apresentam credibilidade do VU em um nível inferior (Faixa III) em relação aos outros municípios enquadrados no mesmo modelo de gestão (Figura 16).

A menor credibilidade do VU em Capivari pode estar diretamente associada a existência de centros habitacionais precários, denominados pelos IBGE como aglomerados subnormais que, de acordo com dados do Censo totalizavam quatro aglomerados, em 2010, abrigando 2376 habitantes, $4,8 \%$ da população total. A presença destas áreas em constante expansão elucida a baixa credibilidade do VU para este município uma vez que, não há controle do volume de água 
utilizado pelos usuários que habitam essas áreas que, usualmente, se ligam a rede clandestinamente.

No que diz respeito a Santo Antônio de Posse, a baixa credibilidade do VU não pode estar associada às ligações clandestinas ou fraudulentas em assentamentos precários, uma vez que não há áreas deste gênero no município. Sendo assim, a baixa credibilidade do VU pode estar relacionada aos aspectos já citados anteriormente como o uso de hidrômetros obsoletos, uso de micromedidores de qualidade questionável e a não aferição do volume operacional e especial.

\subsubsection{Credibilidade do volume de água faturado (VF)}

No tocante a credibilidade do volume faturado (VF), vê-se na Figura 17 que em todos os municípios analisados a informação é plenamente crível. Estando este volume relacionado ao número de ligações de um sistema a boa credibilidade deste dado indica que todas, ou quase todas, as ligações ativas são micromedidas. Porém, deve-se dar especial atenção à existência de ligações inativas onde há consumo, as quais contribuem para as perdas de água por faturamento. Assim, para combater esta problemática, a fiscalização periódica das ligações inativas é fundamental, afim de verificar se a mesma se mantem na condição inicial ou se foi reativada sem consentimento da operadora.

Figura 17 - Credibilidade do volume de água faturado dos sistemas em estudo.

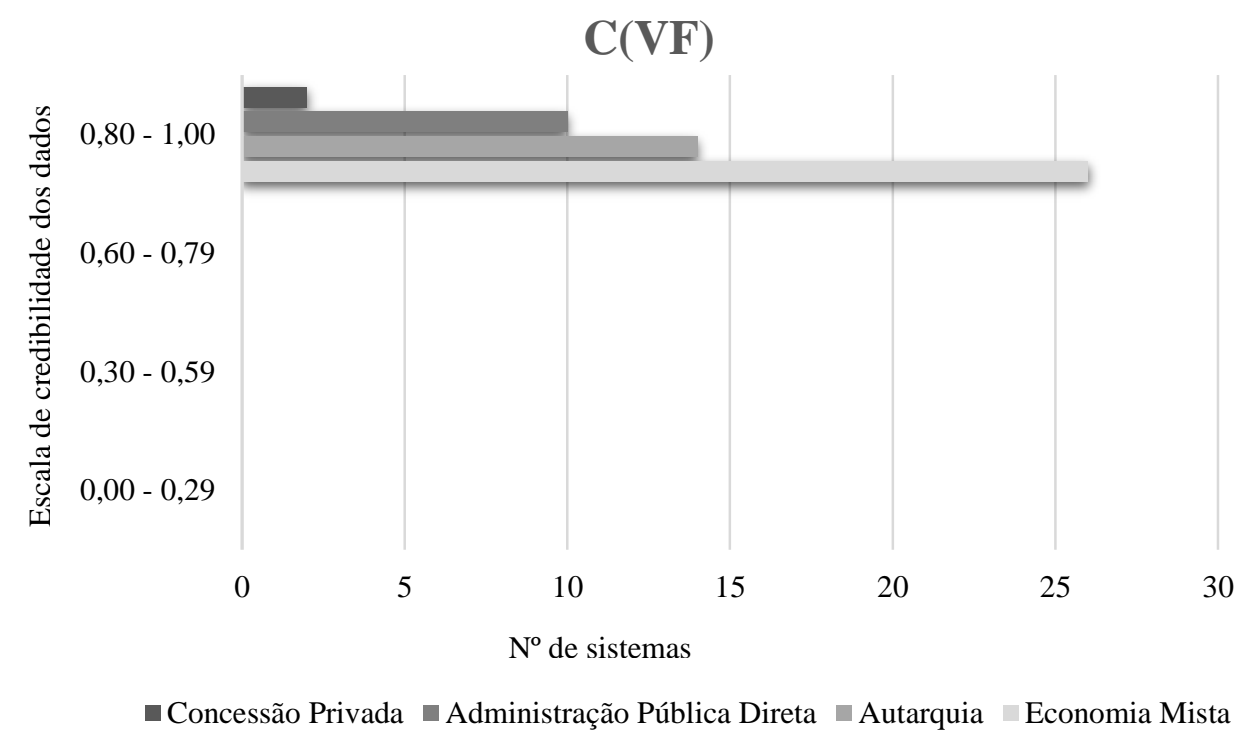

Fonte: Elaborado pela autora 


\subsubsection{Considerações acerca da análise da credibilidade dos dados}

Frente aos resultados apresentados, afere-se por fim que os sistemas operados em um modelo descentralizado (economia mista e privado) produzem dados de maior credibilidade para fins de monitoramento e planejamento de ações no controle de perdas. Em referência a participação da iniciativa privada na prestação do serviço de saneamento, presente em três casos em análise, tem-se verificado uma adversidade histórica entre a prestação pública e a particular. Já apontava Borduque, em 1997, que a privatização se apresenta como uma alternativa para suprir as urgentes demandas no setor, que tem sofrido com os cortes orçamentários e o grande déficit do país, o que é reforçado pela Associação Brasileira das Concessionários Privadas de Serviços Públicos de Água e Esgoto (ABCON, 2017). O grande entrave para a aceitação da concessão privada, seja ela plena, parcial ou em modelo de parceria público-privada (PPP), diz respeito ao aumento significativo da tarifa cobrada dos usuários, uma vez que neste modelo de concessão a empresa delegada do serviço é remunerada pela cobrança da tarifa (ABCON, 2014).

Nesta perspectiva e para o enfrentamento deste entrave, Pinto (2003) exorta a necessidade de uma estrutura regulatória adequada que fiscalize a operadora dos serviços e planeje os investimentos, além de garantir o uso adequado dos recursos hídricos e o acesso equitativo e de qualidade aos serviços, como apontado por Guérin-Schneider e Nakhla (2012). Assim, no Capítulo V, Art. 22, inciso IV da Lei 11.445, estabeleceu-se que, as entidades reguladoras devem, entre outras funções, "definir tarifas que assegurem tanto o equilíbrio econômico e financeiro dos contratos como a modicidade tarifária, mediante mecanismos que induzam a eficiência e eficácia dos serviços e que permitam a apropriação social dos ganhos de produtividade" (BRASIL, 2007).

Posto que a avaliação da credibilidade de dados atuou como um filtro de quais municípios seriam incluídos no benchmarking para avaliação do desempenho, destaca-se que entre os 52 municípios analisados 41 apresentaram credibilidade plena e parcial (Faixa I e II) para os três tipos de volume. No Quadro 12 constam os 41 municípios que participaram do processo de benchmarking, cujos resultados serão apresentados e discutidos no próximo subitem. Entre os 41 municípios, dois têm os serviços de água prestados pela administração pública direta, nove são operados por autarquias, 27 por empresas de economia mista e três por instituições privadas. 
Quadro 12 - Municípios com credibilidade nas faixas I e II para todos os tipos de volume.

\begin{tabular}{|c|c|}
\hline Município & Natureza jurídica da operadora \\
\hline Águas de São Pedro & Economia Mista \\
\hline Americana & Autarquia \\
\hline Atibaia & Autarquia \\
\hline Bragança Paulista & Economia Mista \\
\hline Cabreúva & Economia Mista \\
\hline Campo Limpo Paulista & Economia Mista \\
\hline Charqueada & Economia Mista \\
\hline Cordeirópolis & Autarquia \\
\hline Cosmópolis & Administração Pública Direta \\
\hline Elias Fausto & Economia Mista \\
\hline Hortolândia & Economia Mista \\
\hline Indaiatuba & Autarquia \\
\hline Itatiba & Economia Mista \\
\hline Itupeva & Economia Mista \\
\hline Jarinu & Economia Mista \\
\hline Joanópolis & Economia Mista \\
\hline Jundiaí & Economia Mista \\
\hline Limeira & Concessão Privada \\
\hline Louveira & Administração Pública Direta \\
\hline Mairiporã & Economia Mista \\
\hline Mombuca & Economia Mista \\
\hline Monte Mor & Economia Mista \\
\hline Morungaba & Economia Mista \\
\hline Nazaré Paulista & Economia Mista \\
\hline Nova Odessa & Economia Mista \\
\hline Paulínia & Economia Mista \\
\hline Pedra Bela & Economia Mista \\
\hline Pinhalzinho & Economia Mista \\
\hline Piracaia & Economia Mista \\
\hline Piracicaba & Autarquia \\
\hline Salto & Autarquia \\
\hline Santa Gertrudes & Concessão Privada \\
\hline Santa Maria da Serra & Economia Mista \\
\hline São Pedro & Autarquia \\
\hline Socorro & Economia Mista \\
\hline Sumaré & Concessão privada \\
\hline Valinhos & Autarquia \\
\hline Vargem & Economia Mista \\
\hline Várzea Paulista & Economia Mista \\
\hline Vinhedo & Autarquia \\
\hline
\end{tabular}




\subsubsection{Níveis de perdas de água na distribuição nos municípios amostrados}

\subsubsection{Ranking das perdas de água nos municípios}

Utilizando os dados fornecidos pelas operadoras de saneamento, a técnica de benchmarking foi aplicada aos 41 municípios, apresentados no Quadro 12, utilizando o IPL como indicador para avaliação do desempenho. Na Tabela 3 o produto do benchmarking, ranqueamento dos níveis de perdas de água por ligação, podem ser visualizados. A aplicação desta técnica demonstra, dentro da Bacias PCJ, quais municípios apresentam os melhores desempenhos no controle de perdas. Se considerado a aplicação do benchmarking como um todo a próxima etapa corresponderia ao processo de aprendizagem entre as operadoras, em que aquelas com desempenho inferior trocariam experiências com as operadoras de desempenho superior (no caso em estudo as responsáveis pela operação de Pedra Bela, Limeira e Joanópolis) para aprender o que pode ser feito dentro do contexto das perdas de água para melhorar o desempenho. Porém, para fins deste estudo o benchmarking foi utilizado exclusivamente para avaliação do desempenho das operadoras para posterior análise de associação entre os níveis de perdas e as práticas de controle.

Tabela 3 - Ranking dos níveis de perdas de água ${ }^{25}$ dos municípios amostrados

\begin{tabular}{cc} 
& (Continua) \\
\hline Município & IPL $\left(\mathrm{m}^{3} /\right.$ lig/dia $)$ \\
\hline Pedra Bela & 0,048 \\
\hline Limeira & 0,073 \\
\hline Joanópolis & 0,082 \\
\hline Mombuca & 0,100 \\
\hline Vargem & 0,104 \\
\hline Elias Fausto & 0,123 \\
\hline Socorro & 0,127 \\
\hline Pinhalzinho & 0,134 \\
\hline Nazaré Paulista & 0,136 \\
\hline Santa Gertrudes & 0,138 \\
\hline Morungaba & 0,168 \\
\hline Itupeva & 0,169 \\
\hline Bragança Paulista & 0,177 \\
\hline Campinas & 0,179 \\
\hline Monte Mor & 0,182 \\
\hline Santa Maria da Serra & 0,183 \\
\hline Piracaia & 0,185 \\
\hline Nova Odessa & 0,187 \\
\hline Jarinu & 0,200
\end{tabular}

\footnotetext{
${ }^{25}$ Indicador calculado com dados do ano de referência 2016.
} 


\begin{tabular}{cc} 
& (Continuação) \\
\hline Campo Limpo Paulista & 0,202 \\
\hline Hortolândia & 0,203 \\
\hline Paulínia & 0,204 \\
\hline Cabreúva & 0,234 \\
\hline Cosmópolis & 0,235 \\
\hline Salto & 0,238 \\
\hline Várzea Paulista & 0,246 \\
\hline Vinhedo & 0,248 \\
\hline Indaiatuba & 0,256 \\
\hline Itatiba & 0,263 \\
\hline Valinhos & 0,279 \\
\hline Águas de São Pedro & 0,281 \\
\hline Cordeirópolis & 0,290 \\
\hline Mairiporã & 0,290 \\
\hline Charqueada & 0,353 \\
\hline São Pedro & 0,389 \\
\hline Americana & 0,409 \\
\hline Piracicaba & 0,435 \\
\hline Jundiaí & 0,444 \\
\hline Atibaia & 0,451 \\
\hline Louveira & 0,456 \\
\hline Sumaré & 0,627 \\
\hline
\end{tabular}

Analisando o IPL dos municípios em estudo (Figura 18) vê-se que a média das perdas de água dos municípios equivale a 0,237 m³/ligação/dia. Na contramão de Pedra Bela, Limeira e Joanópolis que apresentam os menores níveis de perdas, Americana, Piracicaba, Jundiaí, Atibaia, Louveira e Sumaré apresentam os mais elevados entre todas as operadoras amostradas.

Figura 18 - Boxplot dos níveis de perdas de águas dos municípios em estudo.

Índice de perdas de água por ligação

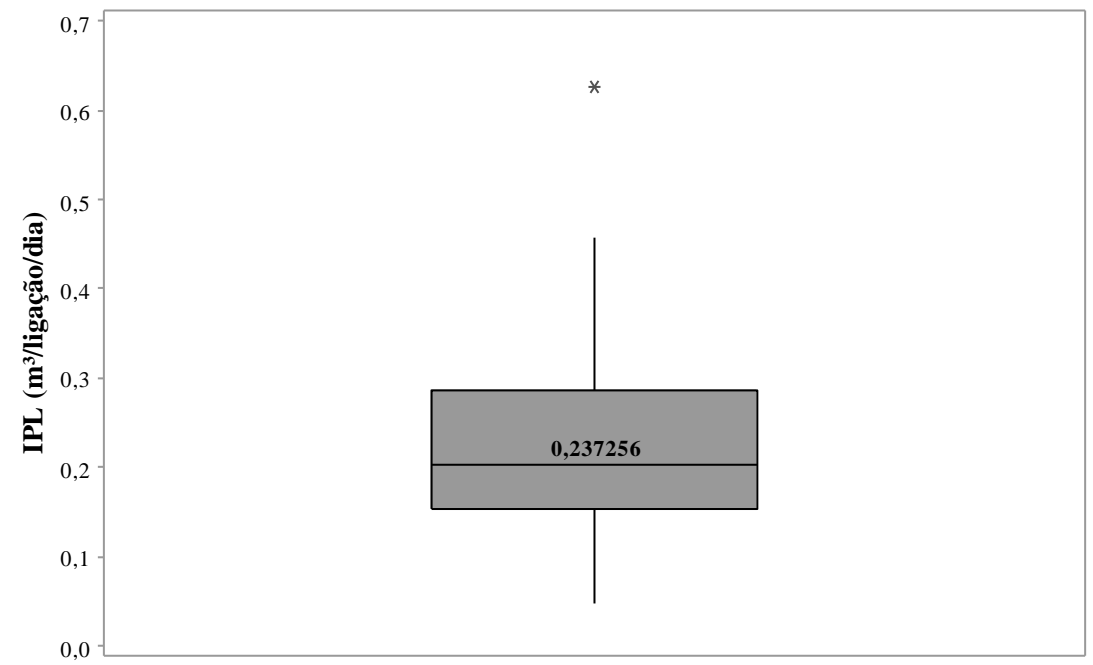


O elevado nível de perdas dos municípios citados acima pode estar associado a diversos fatores. O primeiro fator diz respeito à existência de aglomerados subnormais em Atibaia, Sumaré, Piracicaba e Jundiaí onde a ocorrência de ligações clandestinas e fraudulentas são frequentes, o que eleva as perdas de água nessas áreas, tanto físicas como aparentes. Segundo dados do Censo de aglomerados subnormais de 2010, em Atibaia existe um aglomerado que no mesmo ano abrigava 1241 habitantes (IBGE, 2011) e que hoje deve alojar uma população ainda maior, tendo em vista a constante expansão dessas áreas. Em um quadro mais preocupante, Piracicaba apresenta atualmente 40 núcleos de favelas que abrigam 15.000 pessoas (YOSHII, 2017). Na mesma perspectiva, Jundiaí apresentava no ano 2010 oito aglomerados subnormais que abrigavam 16.297 habitantes (4,6\% da população total). O município Americana apesar de não apresentar aglomerados subnormais pelo Censo de 2010, verificou-se in loco, junto a Secretaria de Habitação, a existência de áreas precárias em constante expansão no município onde a ocorrência de fraudes e ligações clandestinas são frequentes, o que contribui para o aumento das perdas de água na distribuição.

Em maior complexidade, o elevado nível de perdas de Sumaré não se restringe apenas a associação com a existência dos aglomerados subnormais habitados por $8,1 \%$ da população total do município. O histórico da prestação dos serviços de saneamento no município, influi fortemente no desempenho no controle de perdas. Sendo um dos três municípios cujo saneamento é responsabilidade de uma empresa privada, o cálculo do IPL para Sumaré contrapõe o nível de perdas em Limeira, 0,073m³/dia/lig, outro município das Bacias PCJ que também tem os serviços de saneamento privatizado. Como já citado anteriormente, a privatização muitas vezes surge como a solução para suprir as urgentes demandas no setor e neste cenário se enquadra Sumaré.

No contexto das bacias PCJ o saneamento do município sempre foi problemático, indo desde a captação de água de baixa qualidade (efluentes químicos despejados no córrego de captação do município) até a falta de tratamento de esgoto municipal. Até 2014 a prestação dos serviços de saneamento era realizada em um modelo centralizado, por um departamento instituído pela prefeitura municipal e denominado Departamento de Água e Esgoto (DAE). Frente à crítica situação do saneamento municipal foi instaurado em dezembro de 2014 a concessão privada, que passou a gerir o sistema de saneamento em parceria com o DAE (operação assistida) durante o primeiro semestre de 2015. Somente a partir do segundo semestre do mesmo ano a empresa assumiu exclusivamente a operação do saneamento em Sumaré. 
Frente às inúmeras problemáticas que a operadora se deparou, ao assumir a concessão do município foram estabelecidas ações prioritárias relacionadas as questões de saúde pública, as quais incluíram a construção de novas Estações de Tratamento de Esgoto (ETE) e ações voltadas à melhoria da qualidade da água captada, ficando as ações de perdas para segundo plano. Frente a este cenário e tendo em vista que os dados fornecidos são referentes ao ano 2016, ou seja, um ano e meio após a empresa assumir a concessão do município, a mesma não teve tempo hábil para implementar ações voltadas ao controle de perdas, o que justifica o elevado IPL no município.

Em um cenário distinto dos municípios citados, verificou-se nas entrevistas e visitas in loco que os elevados níveis de perdas em Louveira, município de pequeno porte operado pela administração pública direta estão principalmente associadas à precariedade do parque de hidrômetros do município, que abrigam equipamentos que não são trocados há quase 10 anos, ou seja, o dobro da vida útil estimada para este tipo de infraestrutura de rede, o que eleva as perdas nas ligações. A operadora responsável pelo gerenciamento do saneamento municipal desde 2013, antes gerido pela Secretaria de Obras, tem atuado desde setembro de 2017 para efetuar a troca de hidrômetros, cujo plano engloba a substituição de cerca de $70 \%$ dos micromedidores, tendo como expectativa que a troca destes equipamentos reduza significativamente os níveis de perdas que hoje correspondem à 0,45 m³/ligação/dia.

Em relação aos níveis de perdas dos municípios apresentados e discutidos acima, ressalta-se que a existência de áreas precárias nestes municípios não é o único fator que influi na ocorrência de elevados níveis de perdas de água. Para entender o cenário de cada cidade e as possíveis causas dos elevados níveis, a condução de estudos de caso detalhados, que analisem todas as partes do sistema de abastecimento de água particularmente, são imprescindíveis para concluir quais os fatores de influência. Assim, buscou-se com a discussão acima demonstrar que a existência dessas áreas pode estar associada e contribuir com o baixo desempenho das operadoras.

No que concerne os municípios com os desempenhos superiores, cruzando os valores das perdas com o número de práticas de controle de perdas discutidas no próximo subcapítulo, tem-se que Limeira emprega 100\% das práticas, Pedra Bela adota 50 das 54 investigadas e Joanópolis 46 ações.

Estas assertivas demonstram que há possíveis fatores de influência nos níveis de perdas uma vez que, apesar da boa aderência de ações no caso de Limeira, que emprega todas as práticas analisadas, a mesma apresenta o segundo melhor IPL, ficando atrás de Pedra Bela. Neste sentido, as análises estatísticas apresentadas na subseção a seguir, conduzidas para 
averiguar se há diferença significativa entre as medianas do IPL para os clusters de municípios, organizados por porte, natureza jurídica da operadora e presença/ausência de favela, é justificada.

\subsubsection{Análise de fatores de influência}

\subsection{Porte do município}

Considerando a distribuição do IPL por porte de município (Pequeno, Médio e Grande) (Figura 19), o teste de Mann-Whitney, indicou que há diferença significativa apenas entre a mediana do IPL dos municípios de grande e pequeno porte (valor-p = 0,02, <0,05). Este aspecto pode justificar o fato de Limeira (grande porte) aplicar todas as práticas e ainda assim ter maior nível de perdas em relação à Pedra Bela (pequeno porte), o que nos induz a considerar que gerenciar sistemas de abastecimento de pequeno porte parece ser mais simples do que grandes sistemas com maior complexidade que, quando associado a outras ações de controle, geram melhores desempenhos.

Figura 19 - Boxplot da distribuição do IPL por porte de municípios.

IPL por porte de municípios

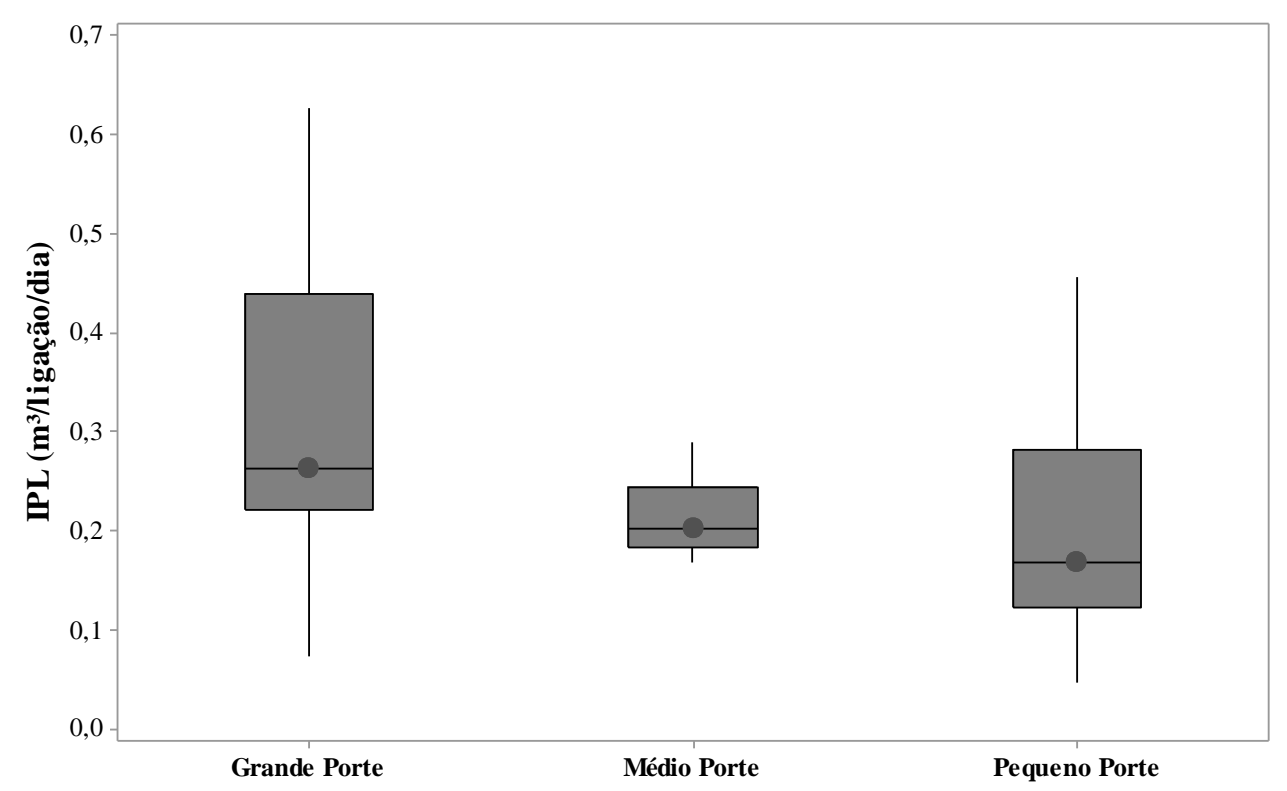

Porém, esta questão é muito mais complexa do que apenas a facilidade em gerenciar um sistema de abastecimento pequeno. Em se tratando do porte dos municípios, a natureza jurídica do órgão responsável pela prestação dos serviços é outro possível fator de influência, que será apresentado no próximo subitem. 


\subsection{Natureza Jurídica da operadora}

Divergente do cenário apresentado por Mutikanga et al. (2010), de que em países em desenvolvimento os sistemas de saneamento de pequeno porte são operados majoritariamente no modelo de administração pública direta, nas Bacias PCJ apenas 30\% dos municípios de pequeno porte são gerenciados nesta categoria. Nesta perspectiva, buscou-se analisar se há diferenças entre o IPL dos municípios considerando a natureza jurídica da operadora (administração pública direta, autarquias, economia mista e concessão privada) (Figura 20).

A aplicação do teste de Mann-Whitney para o cluster de natureza jurídica das operadoras indicou que há diferença significativa entre o IPL dos municípios autarquiados e aqueles geridos por uma organização de economia mista (valor- $\mathrm{p}=0,0005$ ), enquanto para as outras categorias não foi detectado diferenças significativas. Analisando os dados expostos na Figura 20 observa-se que os níveis de perdas de água em municípios autarquiados é maior em relação aos municípios geridos por empresas de economia mista, o que pode estar associado a autonomia financeira do segundo modelo, o que possibilita a flexibilidade de investimentos em diferentes ações de controle de perdas de água.

Figura 20 - Boxplot da distribuição do IPL por natureza jurídica da operadora.

IPL por natureza jurídica da operadora

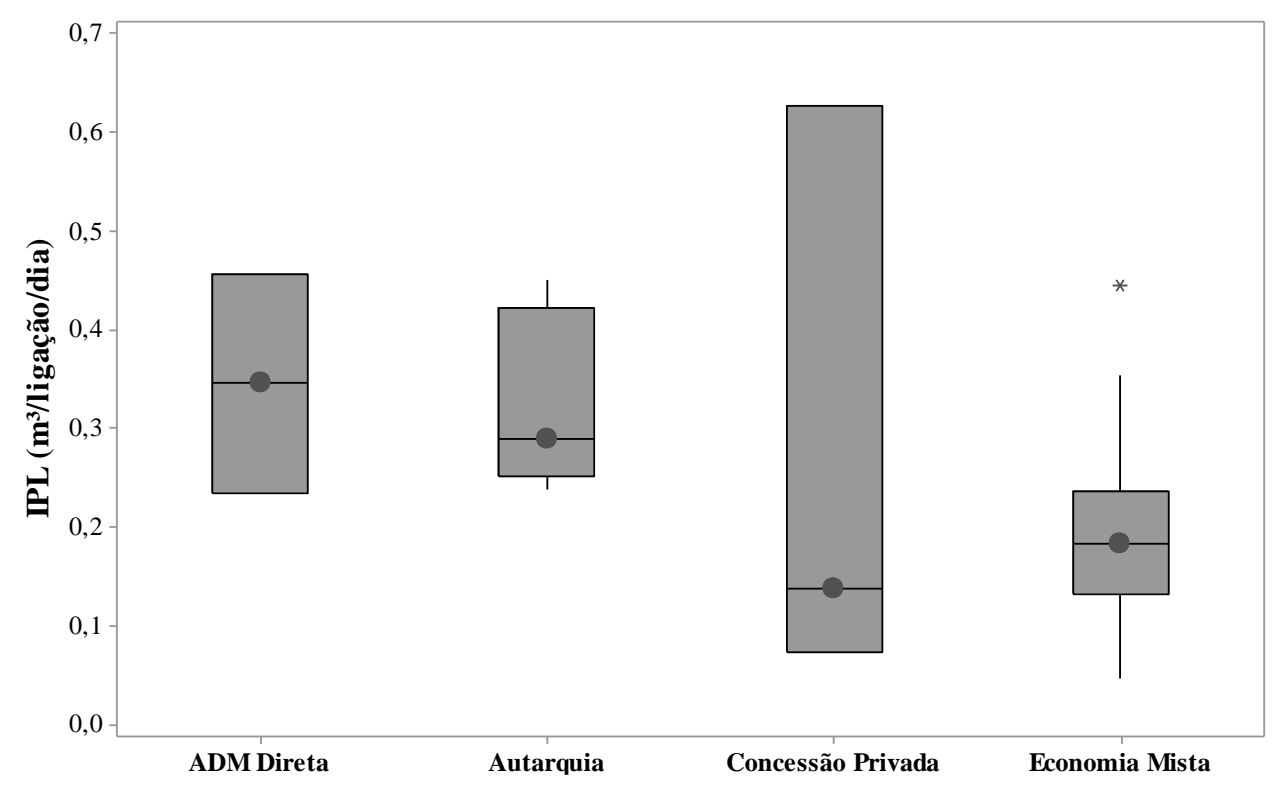

\subsection{Assentamentos precários}

Por fim, analisou-se também a influência da existência de favelas, assentamentos precários, aglomerados subnormais ou qualquer que seja a nomenclatura atribuída as populações marginalizadas, nos IPL municipais. Com valor-p significativo $(0,018)$ o teste estatístico indicou que há diferença do IPL entre o cluster de municípios com e sem favelas. A inferência do teste t é confirmada pelo boxplot da distribuição do IPL de municípios para os 
dois clusters (Figura 21), onde verifica-se que a mediana do IPL de município com favelas é superior à dos municípios sem favela, o que realça a discussão apresentada previamente de que a presença de aglomerados subnormais e assentamentos precários pode ser um dos fatores de influência dos elevados níveis de perdas em alguns municípios.

Figura 21 - IPL e existência de favelas.

IPL por existência/ausência de favelas

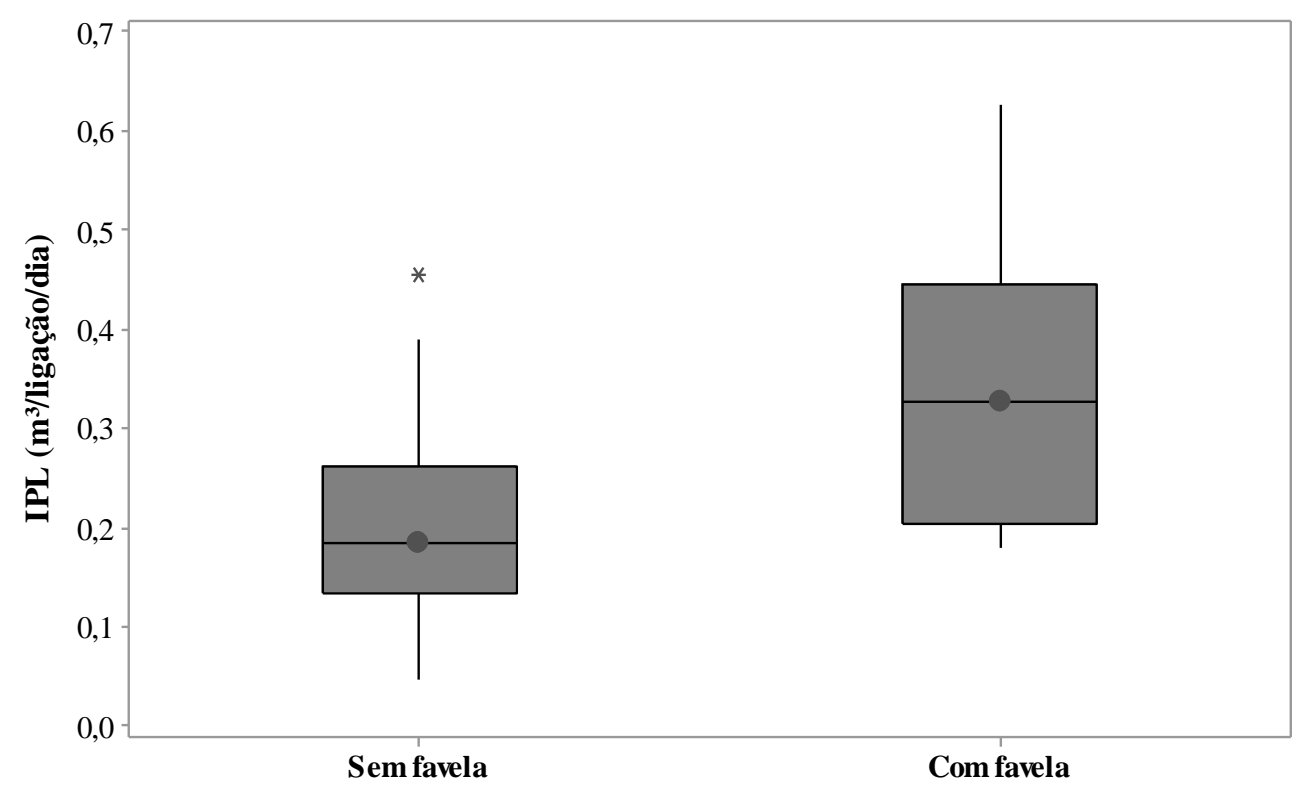

\subsubsection{Classificação dos níveis de perdas de água}

Para condução da estatística do estudo, os produtos do benchmarking (valores do IPL) foram organizados em classes de desempenho. Buscando na literatura valores de referência que se enquadrassem a realidade da operação dos sistemas brasileiros, bem como a unidade do indicador selecionado, utilizou-se como referência de desempenho os valores propostos por Gerhard Zimmer, que estabeleceu estes valores a partir da execução de programas de redução de perdas em sistemas com manutenção básica da Europa Oriental, Oriente Médio, Ásia e África (SHARMA, 2008).

Com adaptações da versão original proposta, esta classificação foi aplicada somente para o teste estatístico de associação que buscou identificar quais práticas de controle estão associadas aos desempenhos superiores no controle de perdas. Para tanto, baseado nas classes apresentadas no Quadro 13, assumiu-se para fins desta pesquisa que os desempenhos superiores, menor IPL, estão na faixa da Classe A, à medida que os níveis de perdas mais elevados, desempenho inferior, se encontram na Classe B. 
Quadro 13- Parâmetros de referência de desempenho no controle de perdas de água.

\begin{tabular}{|c|c|}
\hline Desempenho & Nível de perdas por ligação \\
\hline Classe A & $<0,250 \mathrm{~m}^{3} /$ ligação/dia \\
\hline Classe B & $>0,250 \mathrm{~m}^{3} /$ ligação/dia \\
\hline
\end{tabular}

Fonte: Adaptado de Sharma (2008).

Observa-se pelo mapa das Bacias PCJ (Figura 22), produzido a partir dos produtos do benchmarking, que a maior proporção dos municípios 68,2\% se enquadram na Classe A de perdas de água, assumida nesta pesquisa como categoria de desempenhos superiores das operadoras no controle de perdas de água. Assim, considerando os municípios enquadrados nesta classe (A), na etapa estatística analisou-se quais práticas de controle estão associadas a mesma.

Figura 22- Municípios analisados e classes de IPL.

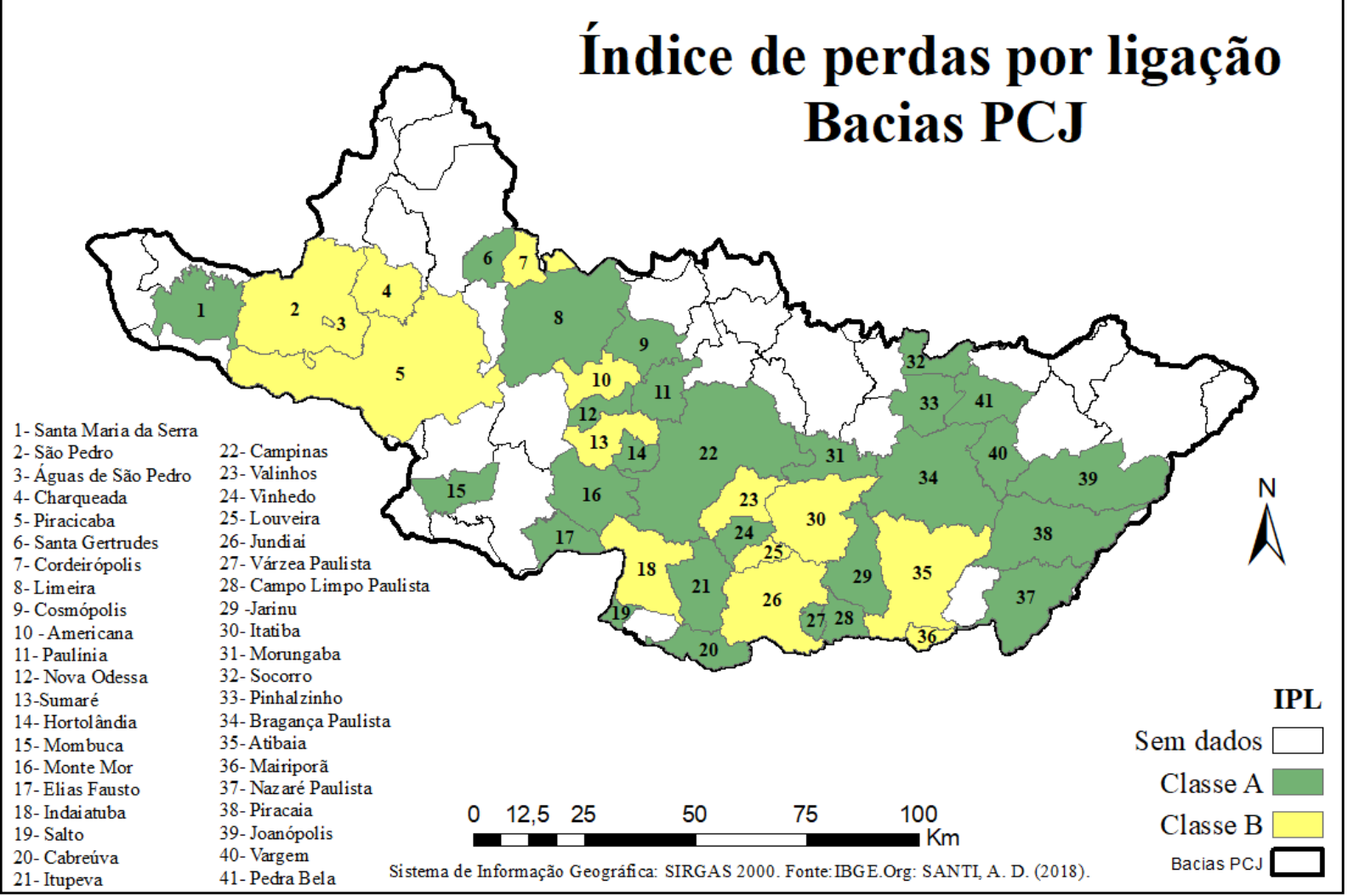

Fonte: Elaborado pela autora. 


\subsection{Práticas de controle de perdas de água aplicadas pelas operadoras das bacias PCJ}

Como apresentado nos procedimentos metodológicos da presente pesquisa, as práticas de controle de perdas de água identificadas na literatura (54 no total) foram organizadas em oito caixas de processos de controle. Sem esgotar o assunto, neste subcapítulo são apresentadas e discutidas as práticas de controle de perdas pelas empresas de saneamento que operam no contexto das bacias PCJ.

\subsubsection{Práticas de "Gerenciamento de Pressão"}

Para o Processo 1 - “Gerenciamento de Pressão" investigou-se o emprego das seis práticas apresentadas no Quadro 14.

Quadro 14- Práticas de Gerenciamento de Pressão.

\begin{tabular}{|c|c|}
\hline PROCESSO & PRÁTICAS \\
\hline \multirow{7}{*}{$\begin{array}{l}\text { Gerenciamento da } \\
\text { pressão de água na } \\
\text { rede }\end{array}$} & $\begin{array}{l}\text { P1. Utilização de medidores de pressão e acompanhamento das } \\
\text { pressões na rede. }\end{array}$ \\
\hline & P2. Centro de telecontrole para acompanhar as pressões na rede. \\
\hline & P3. Utilização de válvulas redutoras de pressão. \\
\hline & P4. Redução da pressão de água no período noturno. \\
\hline & P5. A pressão média da rede dentro do estabelecido pela NBR \\
\hline & 12218/1994 (100 KPa (10 mca) de pressão dinâmica e 500 KPa (50 \\
\hline & $\begin{array}{l}\text { mca) de pressao estatica). } \\
\text { P6. Reservatórios automatizados. }\end{array}$ \\
\hline
\end{tabular}

Vê-se pela Figura 23 que as práticas 3 e 5 são as mais empregadas pelas operadoras das bacias PCJ.

Figura 23- Distribuição das práticas de "Gerenciamento de Pressão" empregadas nas bacias PCJ.

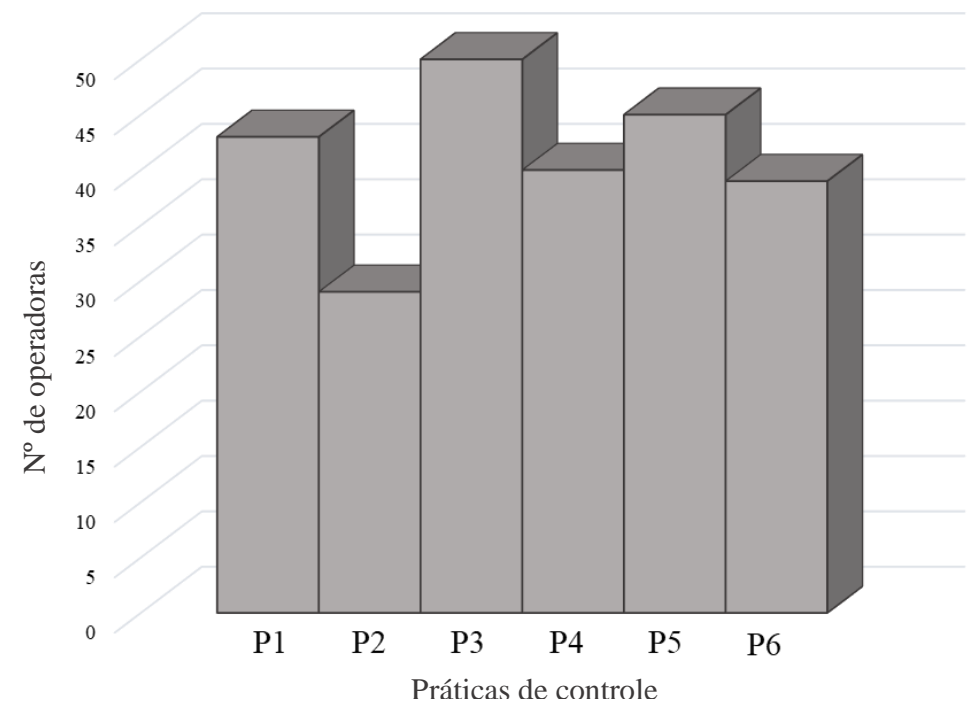

Fonte: Elaborado pela autora. 
A prática 3, adotada por 76,9\% dos municípios em estudo, diz respeito a utilização de válvulas redutoras de pressão (VRP). Para Thornton et al. (2008), o gerenciamento de pressão é o caminho mais eficaz e eficiente para reduzir a ocorrência de vazamentos responsáveis pelos elevados níveis de perdas físicas, sendo considerado a atividade de controle com menor custobenefício. Fanner (2007), identifica o gerenciamento de pressão como uma ferramenta de sucesso a curto, médio e longo prazo no controle de vazamentos, argumentando que existem inúmeras técnicas para o gerenciamento de pressão, sendo a redução de pressão, mediante a instalação de válvulas, a ferramenta mais utilizada. Esta técnica tem sido aplicada em inúmeros países ao redor do mundo, tendo em vista os benefícios aos sistemas de abastecimento, como destacam os autores Lambert et al. (2001), Fanner (2007) e Thornton et. al. (2008):

a) Ampliação da vida útil da infraestrutura de distribuição em função da redução da frequência de vazamentos;

b) Redução dos níveis de perdas de água;

c) Redução de extravasamento de reservatórios

d) Conservação da água;

e) Distribuiç̧ão eficiente;

f) Redução dos custos com energia;

g) Redução das reclamações de clientes;

As VRP's, sejam elas de mola, pistão, diafragma, mecânica ou eletrônicas, buscam limitar a pressão de água na rede sempre que esta exceder o valor padrão, prevenindo a ruptura de tubulações pelo excesso de pressão, sem prejudicar o abastecimento público (ARAUJO, 2005). García-Todolí, Iglesias-Rey \& Martínez-Solano (2017) defendem que as válvulas são essenciais para a correta operação do sistema e sem a instalação das mesmas os custos e investimentos para operação das redes se elevam. De acordo com McKenzie e Wegelin (2009), a utilização de VRP é comum em áreas onde a pressão de água aumenta durante a noite, pela diminuição do consumo, estando este aspecto vinculado a Prática 4 , que aborda a redução da pressão no período noturno, implementada por $65,1 \%$ das operadoras.

Salvo os visíveis benefícios do uso das VRP's, a determinação do local ideal para a instalação das válvulas é um dos principais desafios do gerenciamento de pressão (SALDARRIAGA; SALCEDO, 2015). Nesta perspectiva, diversos estudos (e.g. ARAUJO et al. (2006); NICOLINI; ZOVATTO (2009); DAI; LI (2014); SALDARRIAGA; SALCEDO (2015); GUPTA, et al. (2017); GARCÍA-TODOLÍ, et al. (2017)), têm desenvolvido modelos matemáticos para identificar os pontos mais adequados para a instalação das VRP's, bem como 
o número necessário, de forma a garantir a eficiência na operação. Araujo, Ramos e Coelho (2006) verificaram em seu estudo que a seleção do melhor local para a instalação das válvulas e o número adequado destes equipamentos variam em função da tipologia e das características de cada sistema, informações que podem ser obtidas e analisadas utilizando softwares computacionais. Para a tomada de decisão adequada do local de instalação das válvulas, Araujo et al. (2006) e Dai e Li (2014) reforçam a necessidade da construção de cenários com simulação de demandas múltiplas.

De acordo com Parra et al. (2017), para melhorar a gestão da pressão tecnologias avançadas, que controlam a pressão baseadas no tempo, no fluxo de água ou que possibilitam o controle remoto, estão sendo empregadas. Para os autores a decisão sobre qual método utilizar, seja ele VRP's convencionais ou dispositivos avançados, deve-se considerar a demanda de água, os volumes de perdas, os custos de investimentos, bem como equipe disponível para manejá-los (PARRA, et al., 2017)

Nesta perspectiva, é importante assinalar que, apesar da maior parte dos municípios em estudo utilizarem VRP's para gerenciar a pressão de água na rede, não é possível afirmar que estas válvulas foram instaladas baseadas em estudos e modelos minuciosos e completos que definem os pontos mais adequados e críticos para instalação.

A segunda prática mais frequente no contexto do Processo 1 (P5) está intimamente ligada a Prática 3, discutida acima, e versa sobre o atendimento legal do padrão de pressão de água na rede. A norma que estabelece o padrão adequado de pressão no Brasil é a NBR 12.218, de $1994^{26}$ que, "fixa as condições exigíveis na elaboração de projeto de rede de distribuição de água para abastecimento público" (ABNT, 1994). De acordo com esta norma, a pressão estática $^{27}$ máxima nas tubulações deve ser $500 \mathrm{KPa}$ enquanto a dinâmica ${ }^{28}$ mínima deve ser 100 $\mathrm{KPa}$. Entre todos os sistemas analisados, 69,2\% assumiram que a pressão de água na rede está dentro do previsto na norma na maior parte do tempo. Vale ressaltar que muitos operadores relataram o uso das VRP's para manter a pressão dentro do padrão vigente, em função das particularidades de alguns sistemas que elevam a pressão de água na rede.

$\mathrm{O}$ uso de medidores de pressão para acompanhamento das pressões ne rede (P1) é a terceira prática mais empregada pelas empresas de água das Bacias PCJ, 66,1\%. Esses medidores ou loggers podem ser automáticos ou manuais, sendo que o diferencial entre as duas tipologias está relacionado a forma que os dados de pressão serão coletados. Nos medidores

\footnotetext{
${ }^{26}$ Atualizada em maio de 2017. Alteração da pressão estática máxima para $400 \mathrm{KPa}$.

${ }^{27}$ Pressão em determinado ponto da rede, sob condição de consumo nulo (ABNT, 1994).

${ }^{28}$ Pressão em determinado ponto da rede, sob condição de não consumo nulo (ABNT, 1994).
} 
manuais os dados de pressão gravados devem ser baixados manualmente, demandando uma equipe disponível para visitas regulares ao local onde o medidor está instalado, elevando os custos com pessoal contínuo e transporte. Em contrapartida, os medidores automáticos transmitem os dados para um computador remoto em uma base diária, semanal ou mensal, de acordo com o programado pela empresa (STURM; THORNTON; KUNKEL, 2008).

O uso de medidores automáticos tem uma estreita relação com os centros de telecontrole (P2), presentes em 44,6\% dos sistemas analisados, por alimentá-los com dados atualizados constantemente. No contexto da medição de pressão, verificou-se em campo que alguns sistemas que não monitoram as pressões na rede têm essa ação realizada, periodicamente, pela Agência Reguladora para fins de fiscalização do cumprimento da norma.

\subsubsection{Práticas de "Gerenciamento de Infraestrutura"}

No tocante ao Processo 2, denominado "Gerenciamento de infraestrutura", foram analisadas oito práticas (Quadro 15) relacionadas a manutenção das tubulações e outros componentes das redes, incluindo a calibragem de equipamentos e o treinamento de pessoal para exercer adequadamente as ações.

Quadro 15- Práticas de Gerenciamento de Infraestrutura.

\begin{tabular}{|cl|}
\hline PROCESSO & \multicolumn{1}{c|}{ PRÁTICAS } \\
\hline & P7. Substituição de ramais prediais antigos. \\
& P8. Macromedição. \\
& P9. Cadastro georreferenciado das tubulações. \\
P10. Plano de manutenção anual da rede (Limpeza/Reabilitação). \\
Gerenciamento & P11. Controle de qualidade dos materiais e equipamentos utilizados na \\
Infraestrutura & manutenção da rede. \\
& P12. Estabelecimento de procedimentos operacionais padrões. \\
& P13. Calibragem periódica dos equipamentos da rede (medidores, \\
& válvulas). \\
& P14. Treinamento para a equipe de manutenção e operação (Certificação). \\
\hline
\end{tabular}

Aplicadas pela mesma proporção de municípios, observa-se pelos dados expressos na Figura 24 que as Práticas 7 e 11 são as mais empregadas pelas empresas de saneamento das Bacias PCJ. Associadas, 78,4\% das operadoras atestaram efetuar a substituição dos ramais prediais antigos (P7) para reduzir problemas relacionados a ocorrência de vazamentos. Para tanto o uso de materiais de qualidade é fundamental visando elevar a eficiência das redes e minimizar manobras de manutenção nas mesmas, o que nos remete a execução da Prática 11 a qual versa sobre o controle da qualidade dos materiais adquiridos para manutenção dos sistemas que, quando negligenciada geram problemas permanentes na operação dos sistemas (TSUTIYA, 2006). De acordo com Tsutiya (2006), a vida útil das partes constituintes de um 
sistema de distribuição variam, entre outros aspectos, em função da qualidade do material utilizado. Assim, Morais e Almeida (2006) associam a falha no controle da qualidade como uma das causas dos elevados níveis de perdas de água.

O grande entrave na aquisição de materiais qualificados está relacionado aos processos licitatórios de compra de materiais, obrigatórios às entidades controladas direta ou indiretamente pela União, Estados, Distrito Federal e Municípios, conforme a Lei no 8666/93, no qual é priorizado o menor preço (BRASIL 1993). Isto demonstra que a compra de materiais perpassa procedimentos técnicos, envolvendo também processos administrativos, como aponta Tsutiya (2006).

Vê-se que, apesar de $94 \%$ das operadoras (autarquias e administração pública direta) que operam no contexto das bacias PCJ terem o dever de seguir a referida lei, $78,4 \%$ das operadoras atestam realizar o controle da qualidade dos materiais adquiridos. Este controle pode ser conduzido a partir da inclusão de especificações e imposição de restrições no momento da licitação, tal como pelo estabelecimento de normas específicas que visam inspecionar se os lotes entregues atendem as especificidades do material solicitado (TSUTIYA, 2006). A durabilidade do material, o material da superfície interna e externa, peso e a facilidade de instalação e interligações são um dos critérios a serem considerados na seleção dos materiais para compra (TSUTIYA, 2006).

Esta prática está diretamente associada a Prática 12, empregada por 73,6\% das operadoras, que trata do estabelecimento de procedimentos operacionais padrões, ou seja, guias/manuais que orientem a equipe em como proceder em determinadas situações, como por exemplo, quais os caminhos para solicitar a compra de novos materiais para a manutenção da rede ou como proceder com a identificação de uma ligação fraudulenta. O estabelecimento destes procedimentos padrões contribui para a otimização do funcionamento dos sistemas, evitando que ações sejam postergadas até a definição do que se fazer para resolver determinadas questões. 
Figura 24- Aderência das práticas de "Gerenciamento de Infraestrutura" empregadas nas bacias PCJ.

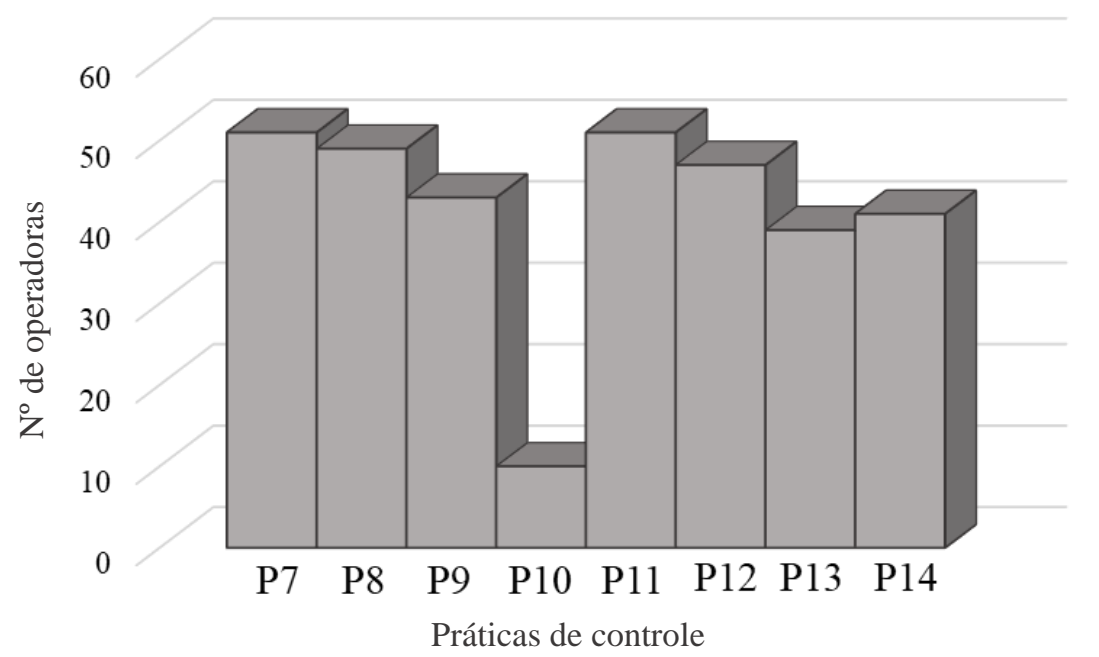

Fonte: Elaborado pela autora.

Em segunda instância encontra-se a Prática 8, com aderência em 75,3\% das operadoras, que versa sobre o uso de macromedidores para mapeamento das vazões de água na rede. De acordo com Andrews e Schneider (1983), a macromedição corresponde a todas as medições realizadas desde a captação de água até as extremidades da rede de distribuição. Para Tsutiya (2006), a macromedição ultrapassa o campo do controle de perdas dando suporte também a outras ações como o diagnóstico do sistema, a dosagem de produtos químicos e na aplicação de indicadores qualitativos e quantitativos da empresa. Kurokawa e Bornia (2002) reforçam que a macromedição (P8) permite a geração de dados do volume distribuído em um sistema, possibilitando a análise do perfil de consumo dos usuários. É imprescindível considerar neste contexto que nenhum equipamento destinado a mensurar a vazão, seja ele velocimétrico, deprimogêneos, eletrônicos, volumétricos ou de canal aberto, são capazes de determinar estes valores diretamente, sendo estes dados obtidos a partir das relações entre a velocidade do fluido e a área da seção transversal da tubulação, como exortam Frangipani e Gomes (2007).

A macromedição não pode ser vista como uma operação isolada (ALVES et al., 2003) e, se praticada de forma desarticulada com outras ações, não é eficaz no controle de perdas. Para que esta prática seja eficiente, Oliveira et al. (2009) defendem a importância da setorização da área (zonas de medição) que, no contexto das bacias PCJ está presente em 64,6\% dos municípios em estudo, como ilustrado na Figura 27 que será discutida adiante. Este dado indica que nem todos os municípios das bacias PCJ que macromedem o volume de água distribuído são organizados em setores de medição, o que dificulta o controle das perdas, uma vez que o estalebelicimento destes setores elevam a credibilidade da comparação do volume macromedido (que entra em determinado setor) e micromedido (OLIVEIRA, et al., 2009), 
resultando em um nível de perdas que retrate adequadamente o cenário de determinado município.

No que concerne às medições, sejam elas de vazão, pressão, velocidade, tempo ou consumo, deve-se dar especial atenção não só para a instalação adequada dos equipamentos medidores, mas também para calibração dos mesmos, fundamental para que as informações, utilizadas para fins de planejamento e tomada de decisão sejam de qualidade (SOARES, et al., 2011; ABES, 2013). Neste panorama, de acordo com as informações ilustradas na Figura 26, 60\% das operadoras realizam a calibração periódica dos equipamentos da rede (Prática 13).

No que diz respeito ao gerenciamento de infraestrutura o emprego de ferramentas tecnológicas, que auxiliem na melhoria da gestão dos sistemas, são cada dia mais frequentes. Entre elas o georreferenciamento das redes, empregado por 66,1\% das empresas em estudo, tem apoiado no planejamento da manutenção e operação dos sistemas (JUNQUEIRA; LAUTENSCHLAGER; PAREDES, 2009). Associado a Prática 54 presente no processo "Investimento e Inovação" que será debatido mais adiante, o uso dos Sistemas de Informação Geográfica (SIG) possibilitam a integração de dados do cadastro técnico (espacialização geográfica) com os dados do cadastro comercial gerando informações de situações atuais (diagnóstico) e também de cenários futuros em um único ambiente, subsidiando assim a tomada de decisão no controle de perdas (BARROS FILHO; SÁ; GOMES, 2004; TSUTIYA, 2006; SANTOS; PEREIRA, 2016).

Além de contribuir com a melhoria no controle dos processos e das rotinas de operação e manutenção dos sistemas de abastecimento de água, facilitando a identificação da localização específica de vazamentos ou as operações de abertura e fechamento de VRP's, o uso dos SIGs reduz gastos com manobras de recuperação e de compras de equipamentos (SANTOS; PEREIRA, 2015). Posto as vantagens da utilização de mecanismos tecnológicos como o SIG, Barros Filho et al. (2004) denotam a imprescindibilidade da atualização constante da base cartográfica, cerne destes sistemas, condicionando a este fator a segurança e confiabilidade dos dados e análises geradas (SANTOS; PEREIRA, 2015).

Indo ao centro da execução das práticas, observa-se que todas demandam uma equipe adequada para eficiente exequibilidade das ações. Nesta conjuntura que se enquadra a Prática 14, empregada por $63 \%$ das operadoras, que aborda o treinamento e capacitação de funcionários para manutenção e operação do sistema como um todo. Consoante ao exposto por Tsutiya (2006), os esforços e investimentos dispendidos para a elaboração de um bom projeto de rede com materiais e equipamento de boa qualidade serão em vão se a equipe que irá gerir o sistema 
e usufruir dos equipamentos não for qualificada e orientada sobre os procedimentos operacionais padrões. Thornton et al. (2008) exortam também que o sucesso das ações de controle depende muito das decisões tomadas pela equipe de operação e manutenção baseado nos ensinamentos recebidos.

Atualmente o treinamento (interno ou externo à empresa de saneamento), no qual a equipe é instruída para exercer atividades específicas seguindo os procedimentos préestabelecidos, é a ferramenta mais comum utilizada pelas operadoras de saneamento para capacitação da mão-de-obra (TSUTIYA, 2006). Porém, a crescente preocupação com o controle de perdas tem impulsionado as operadoras a investirem em cursos de capacitação oferecidos por entidades vinculadas a um sistema (nacional ou internacional) de certificação, intervenção associada a Prática 52 do Processo 8, empenhada por 60\% das operadoras do PCJ, que discute as práticas de investimento e inovação das empresas.

A certificação pressupõe que os funcionários tenham sido submetidos a aprovação de exames teóricos e práticos estando ao final habilitados para atuarem em um determinado processo ou serviço, sendo imprescindível a renovação periódica do certificado (TSUTIYA, 2006). É fundamental argumentar que a qualificação da mão de obra não deve ser designada apenas a equipe responsável pelo controle de perdas reais ou físicas, que demandam treinamento técnico para manejar os equipamentos de pesquisa de vazamento com eficiência, por exemplo, como apresentam Thornton et al. (2008), AWWA (2009) e Hamilton e McKenzie (2014). O treinamento voltado ao controle de perdas aparentes deve receber especial atenção, pois, com o advento das novas tecnologias de micromedidores é possível checar no ato da leitura elevadas variações no consumo que podem estar relacionadas às fraudes. Assim, o adequado treinamento dos leituristas, ação correlatada com a Prática 33 do Processo 5, desempenhado por $78,4 \%$ das operadoras, além de prevenir possíveis erros de medição por parte da equipe de leitura, antecipa a solução de problemas relacionados a fraudes, por exemplo (TSUTIYA, 2006; KUNKEL; THORNTON; STURM, 2008; AWWA, 2009; CARTEADO; VERMESCH, 2016).

Por fim, a prática menos implementada pelas operadoras de saneamento relacionadas ao gerenciamento de infraestrutura é a Prática 10, adotada por apenas 15,3\% das empresas. A baixa aderência desta prática, que prevê um plano de manutenção da rede, é um forte indicativo de que as operadoras em estudo não têm controle efetivo sobre a infraestrutura dos sistemas. Thornton et al. (2008) comentam que todos os componentes de um sistema de água alcançam sua vida útil, sendo indiscutível o estabelecimento de um plano que programe a manutenção ou substituição dos ativos para que possam continuar a prover serviços de qualidade. 
Para a melhor compreensão da importância de um Plano de manutenção do sistema é elementar clarificar a essência das terminologias manutenção, reparação e reabilitação. De acordo com o World Bank (2001), a manutenção da rede pode ser preventiva, onde estão incluídas as ações de limpeza de incrustações, pesquisa de vazamentos, ligações clandestinas e fiscalização de hidrômetros, ou corretivas/reativas, que ocorrem quando as manutenções preventivas são insuficientes degradando o sistema e demandado assim ações de reparação ou reabilitação. Neste contexto, Alegre et al. (2005) apontam as reparações como intervenções pontuais que buscam corrigir alguma avaria na rede, enquanto a reabilitação corresponde a qualquer intervenção física que prolongue a vida útil de um sistema ou melhore o seu desempenho hidráulico (GOMES; BEZERRA, 2007), estando incluída nesta categoria a substituição das redes. Frente a estes aspectos vê-se a importância do estabelecimento de um plano de manutenção, não só para prevenir a ocorrência de perdas físicas, mas também, na redução de custos elevados com ações de maior dimensão para corrigir os danos na rede. 


\subsubsection{Práticas de "Controle da corrosão nas tubulações"}

De acordo com Li et al. (2016), as tubulações de material metálico ainda existem em grande proporção nos sistemas de abastecimento de água ao redor do globo. Swietlik et al. (2012) reportam que na América 56,6\% das redes de abastecimento de água são de ferro. No Brasil, é fato que a maioria dos sistemas brasileiros, frequentemente operados pela administração pública direta, são compostos em boa parte por tubulações de material metálico, as quais apresentam inúmeras desvantagens tanto em termos técnicos e econômicos, relacionados a corrosão e incrustações que demandam elevado custo de manutenção e troca destas redes, como em termos de saúde pública onde a qualidade da água fornecida pode ser deteriorada pela dissolução de produtos resultantes da corrosão da tubulação (FREITAS; BRILHANTE; ALMEIDA, 2001; LI et al. 2016). Para prevenir as adversidades deste tipo de tubulação existem três práticas essenciais que devem ser empregadas (Quadro 16), as quais são analisadas e discutidas nesta seção.

Quadro 16 - Práticas para controlar a corrosão das tubulações.

\begin{tabular}{|ll|}
\hline \multicolumn{1}{|c|}{ PROCESSO } & \multicolumn{1}{c|}{ PRÁTICAS } \\
\hline & P15.Revestimento interno da tubulação. \\
Controle da corrosão em tubulações & P16. Revestimento externo da tubulação. \\
& P17. Priorização do uso de tubulação de material não \\
& metálico. \\
\hline
\end{tabular}

O primeiro passo para controlar a corrosão das redes de abastecimento é selecionar adequadamente o material da tubulação, evitando o uso de tubulações compostas por materiais metálicos (SINGH, 2014). Conforme expresso na Figura 25, 100\% das operadoras em análise declararam priorizar a compra de materiais não metálicos, como PVC e PEAD, para substituição das redes. Salvo este aspecto, muitos municípios alegaram a existência de alguns trechos com tubulações metálicas, normalmente localizadas nos centros municipais onde há uma urbanização consolidada, o que dificulta a troca das redes, pelos transtornos causados a população relacionados ao corte de abastecimento e obstrução de vias públicas quando o Método não Destrutivo (MND) é inviável (VENTURINI, 2002).

Buscando atuar neste cenário, a Fundação Agência das Bacias PCJ tem estabelecido contratos em parceria com a Caixa Econômica Federal e alguns municípios das bacias para financiar a troca das redes de água em pontos críticos dos municípios. Outro caminho que as operadoras têm buscado para financiar projetos deste gênero são os recursos financeiros disponibilizados pelo FEHIDRO. Para pleitear recursos deste fundo, os interessados devem submeter projetos que atestem a viabilidade técnica e econômica das ações sendo sujeitos a análise para aprovação ou não do apoio financeiro. 
Figura 25 - Práticas para controle da corrosão das tubulações.

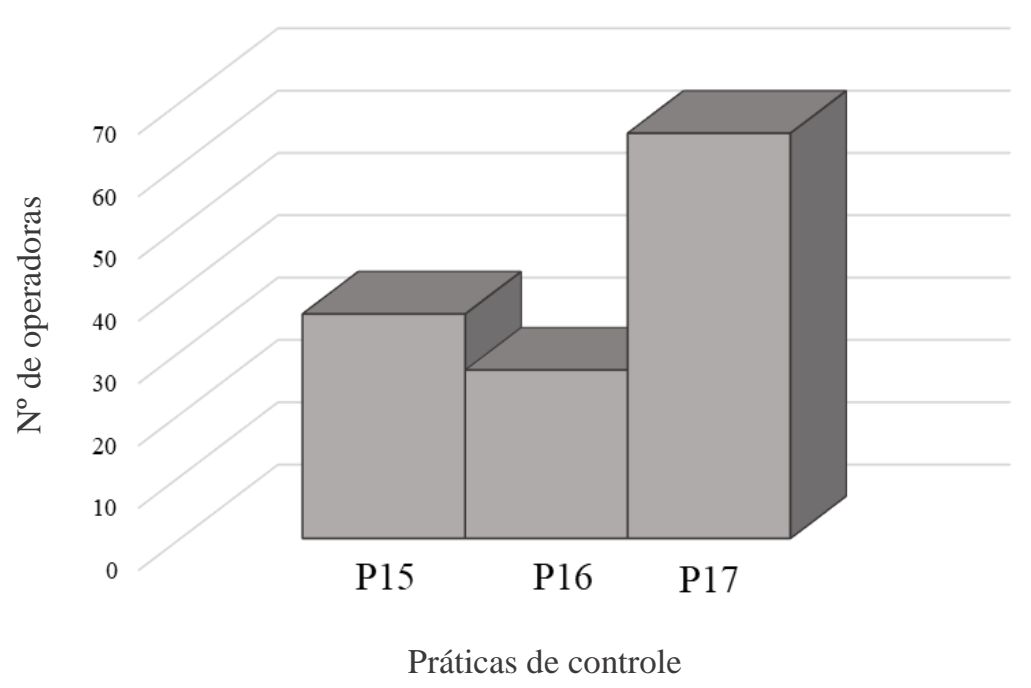

Fonte: Elaborado pela autora.

O grande desafio das operadoras de água, no que diz respeito às redes de distribuição, corresponde a manutenção das mesmas, principalmente das tubulações compostas por material metálico, que sofrem impactos de diferentes fatores que aceleram sua degradação e reduzem sua vida útil. De acordo com Cole e Marney (2012) e Rezaei, Ryan e Stoianov (2015), as características do solo (tais como salinidade, $\mathrm{pH}$, porosidade e capacidade de troca catiônica), em que uma tubulação é introduzida influem nas atividades eletroquímicas que ocorrem na superfície das tubulações, promovendo a corrosão das redes. Os autores discorrem ainda que os fatores ambientais como as chuvas, umidade e variações na temperatura também são fatores intervenientes da degradação das tubulações.

É neste sentido que se insere a Prática 16, aplicada por $41,5 \%$ das operadoras, que reporta sobre o uso de revestimentos externos nas tubulações protegendo-as dos fatores acima citados. Além da proteção por um revestimento externo (mantas betuminosas ou argamassa de cimento), que funcione como uma barreira prevenindo as reações eletroquímicas entre o material da tubulação e o meio, Singh (2014) apresenta uma técnica complexa que força a transformação do material da superfície da tubulação em um cátodo que não reaja com o meio. Tendo em vista que há uma baixa aderência da aplicação de proteções externas físicas das tubulações tão pouco se aplicará técnicas complexas de proteção. Assim, cabe apresenta ainda algumas propriedades que devem ser considerados para que o revestimento de proteção seja eficaz, conforme recomendado por Singh (2014):

$\checkmark$ Baixa permeabilidade;

$\checkmark$ Resistência a produtos abrasivos; 
$\checkmark$ Boa flexibilidade e alongamento;

$\checkmark$ Resistência ao impacto e temperatura;

$\checkmark$ Facilidade de aplicação e reparação se necessário.

No que se refere a instalação dos revestimentos externos, além das características acima citadas deve-se preparar adequadamente a superfície da tubulação retirando qualquer resíduo que prejudique a vida útil dos revestimentos (SINGH, 2014).

Apesar da corrosão ser um dos principais problemas a serem controlados, para evitar a ruptura das redes e consequentes vazamentos e elevação dos níveis de perdas físicas, as incrustações nestas tipologias de tubulação são frequentes e, além de afetar a estrutura do tubo em si, prejudicam o abastecimento pela diminuição do fluxo de água que passa na rede. Para prevenir a obstrução das redes ao longo do tempo (Figura 26), Venturi e Barbosa (2002) dissertam sobre as algumas técnicas que podem ser aplicadas.

Figura 26 - Incrustações em tubulação de ferro.

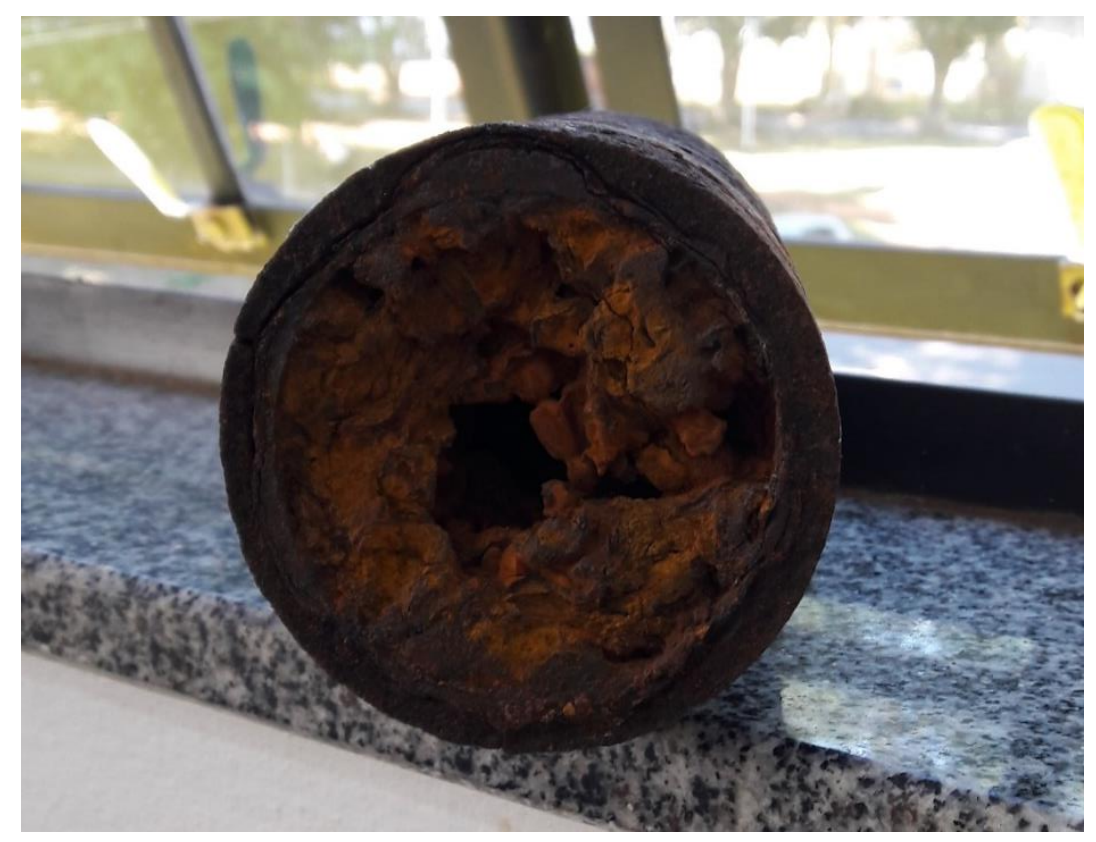

Fonte: Ilustração fornecida por uma das operadoras em estudo.

A primeira técnica apresentada consiste nas limpezas hidráulicas periódicas (com diferentes tipos de equipamentos que possibilitam corrigir todas as deformações na tubulação), sendo um método corretivo. Como ação preventiva da ocorrência de incrustações e também de corrosão, os autores apontam o uso de revestimento de argamassa de cimento e resina epóxi, que apesar de diminuírem o diâmetro da tubulação reduzem a ocorrência de rupturas (VENTURI; BARBOSA, 2002). De acordo com o exposto na Figura 26, apresentada acima, $55 \%$ das operadoras declararam que para aquelas tubulações em que se faz necessário o uso de medidas preventivas de corrosão e obstrução são utilizados revestimentos internos (Prática 15). 


\subsubsection{Práticas de "Controle e Detecção de vazamentos"}

É indiscutível que todas as práticas apresentadas anteriormente nos Processos 1,2 e 3 são ações que indiretamente contribuem para o controle e redução da ocorrência de vazamentos nas redes. Porém, existem ações específicas direcionadas ao controle de vazamentos (Quadro 17), as quais serão discutidas nesta seção.

Quadro 17 - Práticas de "Controle e detecção de vazamentos".

\begin{tabular}{|ll|}
\hline PROCESSO & \multicolumn{1}{c|}{ PRÁTICAS } \\
\hline & P18.Utilização de escutas de solo para detectar vazamentos não visíveis. \\
& P19.Definição da melhor frequência de pesquisa de vazamentos. \\
& P20. Equipe que atua em tempo integral no reparo dos vazamentos. \\
& P21.Utilização de modelos computacionais/matemáticos de simulação \\
& para detecção de fugas. \\
& P22.Utilização de método de consumo zero para detectar vazamentos \\
Controle e & não visíveis. \\
detecção de & P23.Utilização de método de consumo mínimo noturno para detectar \\
vazamentos & vazamentos não visíveis. \\
& P24. Organização do sistema em zonas de medição (setorização, DMC). \\
& P25. Equipe exclusiva para “caça vazamentos". \\
& P26. Teste de estanqueidade nos hidrômetros. \\
& P27.Canal de comunicação para que o usuário possa alertar sobre \\
& vazamentos nas ruas (visíveis). \\
\hline
\end{tabular}

Na literatura, o "Controle e detecção de vazamentos" se enquadra como uma das quatro ações fundamentais para a redução da ocorrência das perdas físicas/reais (THORNTON, et al. 2008). Todas as 10 práticas descritas no Quadro 17 devem ser executadas de forma articulada na busca de resultados mais eficazes, tendo em vista que estas ações são interligadas, muitas vezes dependentes umas das outras.

Tomemos como exemplo a Prática 27 que, como ilustrado na Figura 27 é a mais aplicada pelas operadoras das bacias PCJ (80\%), e versa sobre a existência de canais de comunicação (0800, SAC, Ouvidoria, Protocolos, etc) destinados aos usuários para que os mesmos relatem a ocorrência de vazamentos visíveis. Analisando as outras práticas descritas no Quadro 17, observa-se que esta ação está estreitamente associada a Prática 20 (exercida por 78,4\% das operadoras), que questiona sobre a presença de uma equipe disponível em tempo integral para o reparo dos vazamentos. Esta associação de práticas nos traz a reflexão de que uma ação não atinge o seu objetivo se não for articulada com outras. No exemplo citado, de nada resolve a existência de um canal de comunicação para alertas de vazamentos se não houver uma equipe que possa repará-los com agilidade e qualidade, sendo esta segunda prática outra ação 
fundamental do pilar de ações para o controle de perdas físicas, como defendido por Thronton et al. (2008).

Figura 27 - Aderência das práticas de controle de vazamentos.

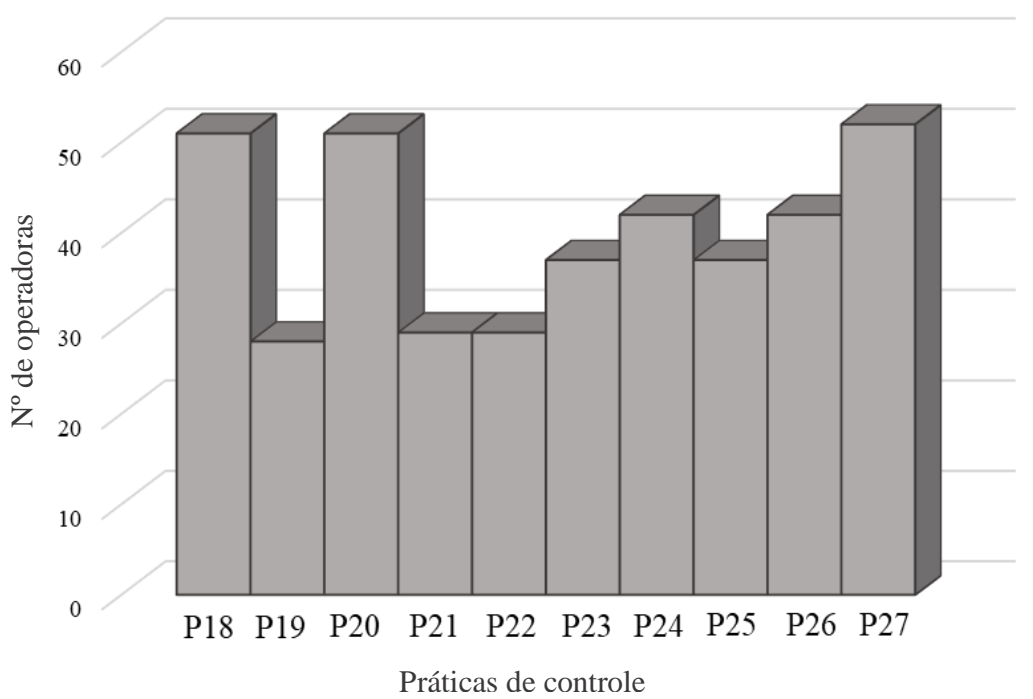

Fonte: Elaborado pela autora.

Tendo em vista que o tempo de execução entre a detecção, localização exata do vazamento e o reparo dos mesmos é reconhecido como o principal fator que contribui para o volume de perdas reais (THORNTON et al. 2008; AWWA, 2009), atuar pró-ativamente, buscando detectar vazamentos com antecedência para restaurá-los com agilidade evitando a perda de grandes volumes de água e a interrupção do abastecimento, é uma boa prática no controle de perdas (AWWA, 2009). É neste sentido que se enquadra a Prática 18, empregada por $78,4 \%$ das operadoras em estudo, que faz menção ao uso de equipamento tecnológicos que dão suporte a pesquisa de vazamentos não visíveis.

O desenvolvimento de dispositivos para a pesquisa de vazamentos tem se concentrado em tecnologias que se baseiam em princípios acústicos, como as escutas de solo, gravadores de ruídos e os correlacionadores de ruídos, em função do elevado custo e dificuldade de implementação dos sensores de fluxo inseridos nas tubulações, convencionalmente utilizados para a detecção de vazamentos (SEYOUM, et al. 2017). De acordo com Rogers (2014), para que os equipamentos sejam utilizados com sucesso e precisão é primordial que a equipe tenha conhecimento completo da rede, que o vazamento gere ruído suficiente e que as tubulações possuam boa qualidade de propagação de som.

$\mathrm{Na}$ perspectiva da pesquisa de vazamentos, para que estas sejam viáveis economicamente é de suma importância que as operadoras realizem estudos de custo-benefício para definir a melhor frequência da pesquisa (Prática 19, empregada por $43 \%$ das operadoras 
em estudo) e que tenham uma equipe exclusiva e capacitada para exercer a função de "caça vazamentos" (P25).

No que diz respeito a equipe de caça vazamentos, Henrie, Carpenter \& Nicholas (2016) exprimem que, além do treinamento da equipe que atua em campo com os equipamentos de detecção de vazamento, faz-se necessário a capacitação da equipe que atua nas salas de controle onde as informações provenientes dos correlacionadores de ruídos estáticos são atualizadas constantemente. A capacitação desta equipe é essencial para que os controladores saibam interpretar as informações sobre vazamentos apresentadas no display da sala de controle e balancear as informações sobre possíveis falso alarmes e, quando reais, como atuar utilizando os procedimentos padrões existentes. Os autores reforçam ainda que uma equipe altamente qualificada e treinada, periodicamente, é capaz de diagnosticar com rapidez e precisão a ocorrência de vazamentos adotando ações apropriadas para corrigir as adversidades no sistema e reduzir a ocorrência de perdas (HIRNER; CARPENTER; NICHOLAS, 2016).

Como já abordado anteriormente, a ocorrência de vazamentos nas tubulações está intimamente associada ao gerenciamento da pressão de água na rede e a manutenção das tubulações (TSUTIYA, 2006; FANNER, et al., 2007; THORNTON et al., 2008, GOMES; SOUZA; MARQUES, 2013; ROGERS, 2014; REZAEI; RYAN; STOIANOV, 2015). Buscando o intercâmbio de práticas que envidam esforços para reduzir as perdas de água na distribuição, autores como Alegre et al. (2005) e Wright et al. (2015) apresentam a setorização como uma técnica popular e cada vez mais aplicada pelas empresas de saneamento, onde distintas práticas são empregadas com maior eficiência.

A setorização, existente em 64,6\% das áreas em estudo (P24), corresponde a divisão dos municípios em zonas de gerenciamento, em inglês denominadas District Meteres Areas (DMA), onde a operação do sistema é facilmente controlada em tempo real (JITONG; JOTHITYANGKOON, 2017). Apesar da AWWA (2014) defender que um setor abrange normalmente entre 500 a 3000 ligações, Alegre et al. (2005) e Gomes et al. (2015), debatem que a dimensão de uma zona de medição varia em função de fatores como a topologia da rede, as condições locais e a densidade populacional. Morrison et al. (2007) exortam ainda que o tamanho do setor influencia na identificação de vazamentos, assumindo que quanto maior o setor mais difícil a definição da ocorrência de vazamentos. Entre os diversos benefícios da setorização, como a otimização do monitoramento das pressões de água e o acompanhamento dos volumes perdidos a partir da comparação entre o volume macromedido e o micromedido 
no setor, Rogers (2014) e Jitonge \& Jothityangkoon (2017) reforçam ainda que esta prática auxilia na rápida detecção e localização de vazamentos, reduzindo as perdas de água.

A setorização é base para tantas outras práticas de controle de vazamentos, como as práticas 22 e 23 apresentadas nesta subseção, que investigam a ocorrência de vazamentos não visíveis mediante o método de consumo zero e consumo mínimo noturno dos usuários, respectivamente. Entre uma das práticas menos empregadas em relação ao controle e detecção de vazamentos $(44,6 \%)$, o método de consumo zero (P22) pressupõe o isolamento/interrupção do abastecimento nos setores, partindo do princípio de que uma rede isolada apresenta vazão nula, sendo que a medição de qualquer vazão indica a ocorrência de vazamentos não visíveis (SILVA, et al. 2003). Em relação ao método de consumo mínimo noturno (utilizado por 56,9\% das operadoras em análise), a ocorrência de vazamentos não visíveis é identificada quando a vazão mínima noturna, que normalmente se mantem estável entre $3 \mathrm{~h}$ e $4 \mathrm{~h}$ da manhã, tem um aumento súbito (ALEGRE, et al., 2005; TSUTIYA, 2006; VERDE, et al., 2014). Tendo em vista que a aplicação deste método depende da interpretação humana dos dados de consumo, a partir da identificação de alteração no consumo noturno, deve-se utilizar outros equipamentos e métodos para investigar a localização do possível vazamento (FARAH; SHAHROUR, 2017).

Tendo em vista que a setorização altera a configuração das redes, como a realocação de válvulas e macromedidores, Alegre et al. (2005) alertam para a necessidade de um planejamento minucioso da operação do sistema, apresentando o uso de simulações hidráulicas como essenciais para apoiar a nova configuração hidráulica, prevendo possíveis impactos no sistema. De acordo com Rogers (2014), os modelos hidráulicos (Prática 21, menos empregada nos sistemas em estudo, 44,6\%) são uma ferramenta poderosa que reproduz com precisão o funcionamento das redes, prevendo possíveis adversidades, como a ocorrência de vazamentos, consoante ao exposto por Soldevila et al. (2016). O uso da modelagem é fundamental para o entendimento da relação entre pressão e vazamentos e possibilita, através da simulação, estimar o potencial de redução de perdas frente as diferentes estratégias de gerenciamento da pressão e o tempo médio de reparo (AWWA, 2014; PARRA; KRAUSE, 2017). Araujo, Ramos e Coelho (2006) exortam ainda que o uso de modelos matemáticos otimiza o processo de definição do número de equipamentos (VRP's e macromedidores, por exemplo) a serem instalados e o local mais adequado para a instalação dos mesmos.

Por fim, a última prática relacionada ao controle de vazamentos diz respeito aos testes de estanqueidade em hidrômetros (P26), realizado por 64,6\% das operadoras em estudo. Nas visitas in loco verificou-se que são utilizadas pelas operadoras das bacias PCJ distintas técnicas para realizar a aferição dos micromedidores. Boa parte das empresas não contam com 
laboratórios de teste de bancada, que possibilita a aferição dos hidrômetros dentro da própria organização, terceirizando o serviço para outras empresas que tenham capacidade de aferir sobre a qualidade do lote de micromedidores. Por outro lado, algumas operadoras têm investido em equipamentos de campo que, no momento da instalação dos micromedidores, verificam se os mesmos estão estanques e calibrados. Apesar das operadoras utilizarem diferentes caminhos para aferir os hidrômetros, todos os medidores devem atender as especificações das seguintes normativas brasileiras:

o NBR 14005:1997: Prescreve o método a ser empregado na verificação de medidores de vazão nominal entre $15 \mathrm{~m}^{3} / \mathrm{h}$ a $1500 \mathrm{~m} 3 / \mathrm{h}$ (ABNT, 1997).

○ NBR NM 212:1999: Estabelece as características técnicas, metrológicas e os métodos de ensaio dos medidores de água fria de vazão nominal até $15 \mathrm{~m}^{3} / \mathrm{h}$ (ABNT, 1999)

○ NBR 8194:2013: Padroniza o formato das medições, dimensões e conexões dos medidores de água potável destinados à instalação em unidades consumidoras (ABNT, 2013).

○ Portaria INMETRO n 246/00: Determina as condições que devem satisfazer os medidores de água com vazão nominal entre $0,6 \mathrm{~m}^{3} / \mathrm{h}$ e $15 \mathrm{~m}^{3} / \mathrm{h}$. (INMETRO, 2000).

○ Portaria INMETRO n ${ }^{\circ}$ 436/11: Estabelece que os laboratórios de aferição devem expressar a incerteza de medição dos ensaios de acordo com a versão mais recente do "Guia para a expressão da incerteza de medição". Determina que as bancadas de ensaio devem possui incerteza de medição com valor de até 1/3 do erro máximo admissível para as vazões de ensaio (INMETRO, 2011). 


\subsubsection{Práticas de "Controle de Erros de Medição"}

A medição adequada do volume de água consumido é uma aliada fundamental no controle de perdas de água, estando os erros de medição diretamente associados as perdas aparentes que conduzem as perdas no faturamento (PIECHNICK et al., 2011). Para conter esta problemática e prevenir a operação onerosa das empresas de saneamento algumas ações são essenciais, conforme expresso no Quadro 18, e são debatidas nesta subseção.

Quadro 18 - Práticas para o controle de erros de medição.

\begin{tabular}{|cl|}
\hline PROCESSO & \multicolumn{1}{c|}{ PRÁTICAS } \\
\hline & P28. Troca corretiva de hidrômetros. \\
& P29. Troca preventiva otimizada de hidrômetros. \\
& P30. Fiscalização de hidrômetros para verificar erros de medição. \\
Controle de erros & P31. Utilização de hidrômetros de maior precisão. \\
de medição & P32.Utilização de hidrômetros com telemetria através de rádio \\
& frequência. \\
& P33. Treinamento adequado da equipe de leitura dos hidrômetros \\
\hline
\end{tabular}

Os dados coletados em campo indicam que a prática mais usual entre as operadoras em estudo, relacionada ao controle de erros de medição, é a troca corretiva de hidrômetros (Prática 28) desempenhada por 93,8\% das empresas de saneamento (Figura 28). Segundo Tsutiya (2006), a troca dos hidrômetros corresponde a um dos itens indispensáveis em um programa de redução de perdas, posto que os hidrômetros apresentam vida útil que, quando atingida começam a gerar imprecisões gradativas de leitura, aumentando os níveis de perdas. O referido autor disserta ainda que a troca corretiva ocorre quando problemas estruturais comprometem o funcionamento adequado dos hidrômetros, sendo um método caro e pouco funcional, com aponta Bovo et al. (2008). Para prevenir essas adversidades, a Portaria 246 do Inmetro estabelece que devam ser realizadas verificações periódicas nos hidrômetros não superior a cinco anos (INMETRO, 2000), estando este aspecto relacionado a manutenção preventiva dos mesmos (P29). 
Figura 28 - Aderência das ações de controle de erros de medição.

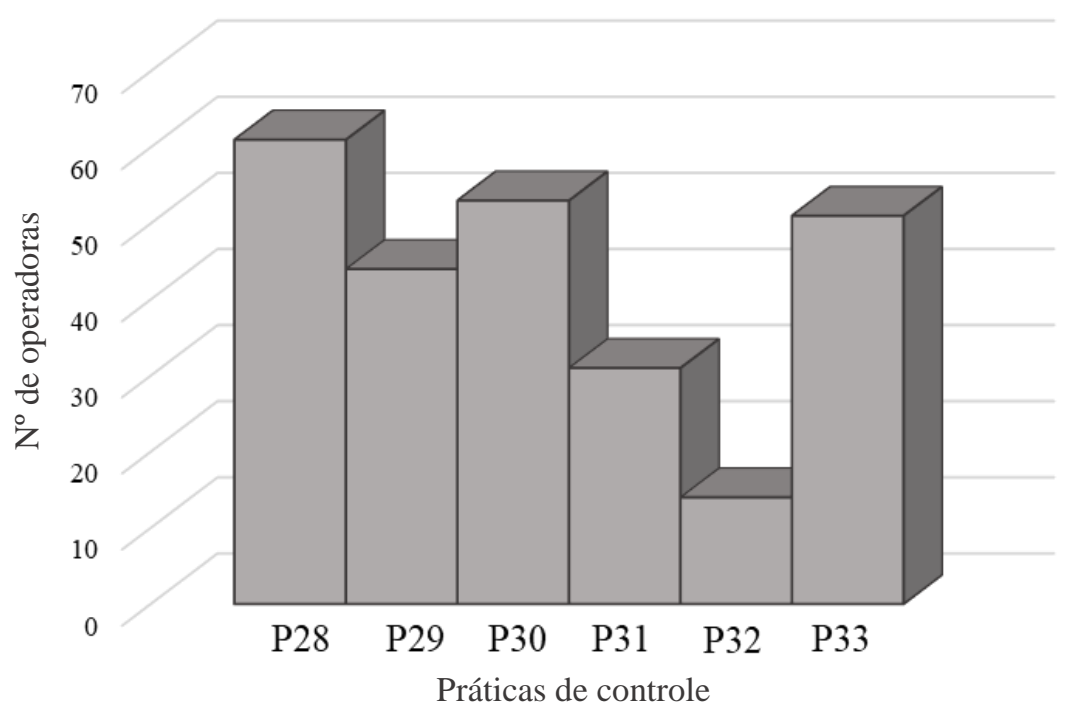

Fonte: Elaborado pela autora.

No que diz respeito a troca preventiva otimizada dos micromedidores, realizada por 67,7 $\%$ das operadoras do PCJ, Tsutiya (2006) enfatiza que as operadoras devem estabelecer um tempo para efetuar a troca do hidrômetro após a instalação, respeitando sempre as normativas vigentes de forma a prevenir o mau funcionamento dos equipamentos, ou quando um determinado volume de medição for atingido. Nesta perspectiva, é de suma importância que as empresas de saneamento instituam uma metodologia que investigue o desempenho metrológico dos medidores que, associada a fiscalização periódica dos mesmos (Prática 30, desenvolvida por $81,5 \%$ das empresas em estudo) diminuem o tempo de ocorrência dos erros, otimizando assim a troca preventiva de hidrômetros e contribuindo positivamente na redução dos níveis de perdas aparentes (SCALIZE et al., 2014).

$\mathrm{Na}$ perspectiva da troca de hidrômetros, o inciso $5^{\circ}$ da Resolução ARES-PCJ $\mathrm{n}^{\circ} 50$ de 2014 define que “a substituição do hidrômetro, decorrente do desgaste normal de seus mecanismos, será executada pelo prestador de serviços sempre que necessário sem ônus para o usuário", sendo cobrado dos usuários as substituições necessárias em função da violação dos medidores pelos usuários (ARES-PCJ, 2014).

Dentro os diversos fatores que provocam erros de medição nos hidrômetros, como as fraudes que serão discutidas no próximo subitem, destaca-se as características dos equipamentos utilizados. Os micromedidores são classificados de acordo com o seu princípio de funcionamento em duas categorias: taquimétricos ou velocimétricos e volumétricos (BOVO et al. 2008) e, de acordo com sua sensibilidade no registro de pequenas vazões em três classes: A, B e C. Apesar da maior precisão e sensibilidade dos hidrômetros volumétricos e classe C, 
no Brasil, os medidores velocimétricos e classe B são os mais atrativos no mercado pelo baixo custo e simplicidade de manutenção (PEREIRA; ILHA, 2008). Cenário semelhante foi verificado no contexto das bacias PCJ, tendo em vista que menos da metade das operadoras em estudo $(47,6 \%)$ utilizam micromedidores de maior precisão (P31).

Além das ações relacionadas a manutenção e qualidade dos equipamentos de medição, a equipe responsável pela apuração do consumo dos usuários (leituristas), tem um papel fundamental no controle dos erros de medição. Como já discutido no subitem 5.2.2 deste documento, o treinamento da equipe de leitura (Prática 33, empregada por 78,4\%) é essencial para que os mesmos executem suas funções com vigor e qualidade (TSUTIYA, 2006; KUNKEL; THORNTON; STURM, 2008; AWWA, 2009; CARTEADO; VERMESCH, 2016).

Por último, no tocante a apuração do volume de água consumido pelos usuários, a medição remota tem se destacado pela praticidade, agilidade na leitura, segurança e confiabilidade dos dados gerados, eliminando estimativas de consumo (LOUREIRO; ALVÁRES; COELHO, 2007; AWWA, 2009). Com um forte histórico no setor de gás e eletricidade esta tecnologia cresceu nos últimos anos no setor de água (AWWA, 2009). Entre as formas de medição remota a mais comum é por radiofrequência, utilizando veículos com receptores ou fixos em postes, que reúnem múltiplas leituras quase que simultaneamente, enviando os dados de consumo para uma central (AWWA, 2009; NEVES; NOGUEIRA, 2014). Além de otimizar a apuração do consumo dos usuários a medição remota identifica rapidamente vazamento nas tubulações alertando sobre oscilações bruscas no consumo dos usuários (AWWA, 2009). Associado a esta tecnologia está a Prática 32, menos empregada pelas empresas de saneamento em estudo, 21,5\%. 


\subsubsection{Práticas de "Controle de fraudes"}

As fraudes são uma das causas da ocorrência dos erros de medição nos hidrômetros, discutidos no subitem anterior, e as principais responsáveis pelos níveis de perdas de água aparentes. No Quadro 19 estão expressas algumas das práticas indicadas na literatura como apropriadas para controlar a ocorrência desses eventos, as quais serão discutidas na sequência.

Quadro 19 - Práticas para o controle de fraudes e ligações clandestinas.

\begin{tabular}{|ll|}
\hline \multicolumn{1}{|c|}{ PROCESSO } & \multicolumn{1}{c|}{ PRÁTICAS } \\
\hline & P34. Conscientização da população sobre o problema das fraudes e \\
& ligações clandestinas. \\
& P35. Inspeção regular de ligações suspeitas e inativas. \\
& P36. Reparo de hidrômetros inclinados. \\
Controle de fraudes & P37. Utilização de tecnologias para detectar ligações clandestinas. \\
& P38. Acompanhamento do consumo mensal dos usuários para detectar \\
& fraudes. \\
& P39. Atuação em áreas de pobreza para controlar as fraudes. \\
& P40. Denúncia de fraudes pela comunidade. \\
& P41. Atualização anual do cadastro dos usuários. \\
\hline
\end{tabular}

A prática mais frequente nas bacias PCJ, no contexto do controle de fraudes, não diz respeito a uma ação direta das operadoras dos serviços de saneamento e sim a uma prática da comunidade no combate a ocorrência destes eventos. Consoante aos dados expressos na Figura 29, $87,7 \%$ das prestadoras de serviços em estudo contam com o auxílio da comunidade na denúncia de ligações fraudulentas (Prática 40) que, como defende Tsutiya (2006), é um dos caminhos para a detecção desses episódios e, tem produzido bons resultados no controle de perdas de água aparente (CARTEADO; VERMERSCH, 2016). Conforme verificado nas coletas em campo, as fraudes são, na maioria das vezes, relatadas via Ouvidoria, SAC ou outros canais de comunicação disponibilizados pelas empresas de saneamento. 
Figura 29 - Aderência das práticas para o controle de fraudes.

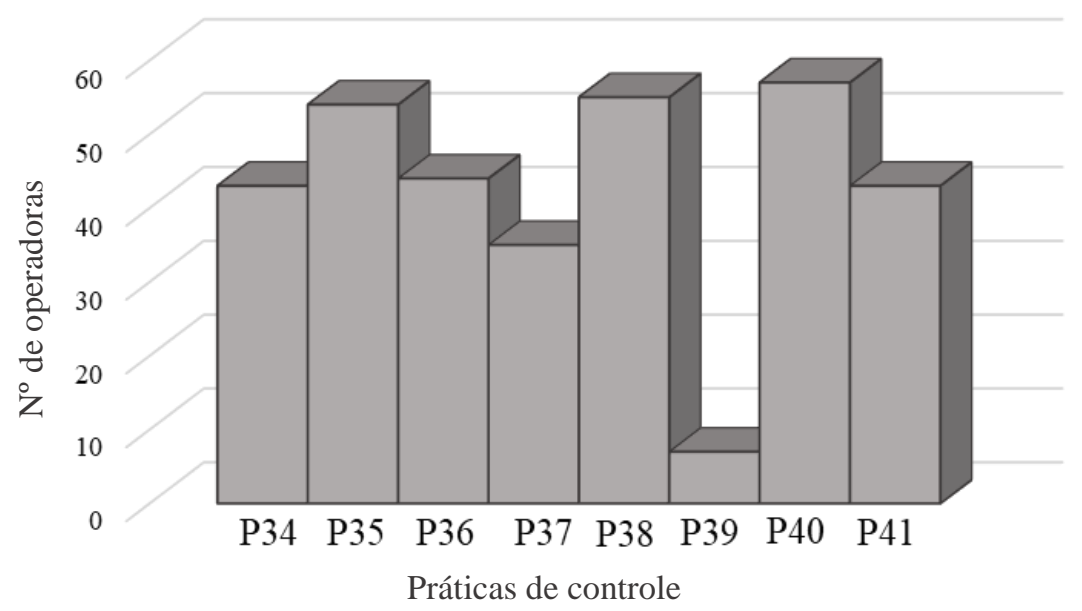

Fonte: Elaborado pela autora.

Entre outros caminhos pertinentes para a identificação de fraudes, destaca-se a análise do histórico de consumo dos usuários, relacionado a Prática 38, desempenhada por 84,5\% das prestadoras em análise. Esta prática, além de auxiliar na constatação de vazamentos, conforme discutido anteriormente alguns métodos no subitem 5.2.4, contribui também com a identificação de fraudes nas ligações. É imprescindível que quando detectada qualquer alteração no consumo uma equipe seja conduzida ao local para verificar a real ocorrência da irregularidade (TSUTIYA, 2006).

Associada ao acompanhamento do consumo dos usuários é fundamental que sejam planejadas inspeções regulares das ligações suspeitas e inativas, Prática 35 (realizada por 83\% das operadoras), que, muito além de averiguar a execução de irregularidades buscam demonstrar aos usuários a ativa atuação da operadora na fiscalização e coibição de fraudes de forma a desestimular que novos usuários adotem a postura de fraudadores (ALEGRE et al., 2005; ABES, 2015).

A fraude relacionada a inclinação de hidrômetros não está associada ao furto da água física em si, mas sim à manipulação dos componentes da rede que geram problemas em termos econômicos pela submedição dos medidores inclinados. A prática de corrigir hidrômetros que se encontram nesta situação (Prática 36) é aplicada por 67,6\% das prestadoras dos serviços de água do PCJ. De acordo com Tsutiya (2006) existem hidrômetros que podem ser desinclinados sem comprometer a leitura, sendo este um processo rápido e de baixo custo, e outros cuja desinclinação compromete a leitura adequada em função do abrigo estar fora dos padrões da operadora, sendo necessário nestes casos a instalação de novos medidores, o que eleva o custo da operação. 
Saindo do campo de ações reativas para o controle de fraudes, as campanhas de sensibilização dos usuários sobre os problemas relacionados as irregularidades na rede e as penalidades passíveis a estes eventos são apresentadas como práticas mínimas de prevenção (ALEGRE et al., 2005; TSUTIYA, 2006; ABES, 2015). De acordo com as informações coletadas em campo, 66,15\% das empresas de água já atuaram ou atuam periodicamente na realização de campanhas que divulgam aos usuários questões relacionadas as fraudes (P34), sensibilizando-os sobre os riscos de executar irregularidades no que diz respeito ao abastecimento de água.

No que tange as penalidades relacionadas as fraudes nas ligações de água, estas são tratadas como furto qualificado e, se confirmadas, se enquadram no Art. 155 do Código Penal, "Subtrair, para si ou para outrem, coisa alheia móvel”, que prevê, além de multa, reclusão de dois a oito anos para o fraudador. Além das penalidades impostas pelo referido artigo, o fraudador está sujeito as sanções do Art. 132 (três meses a um ano de detenção) por expor outros usuários a perigo direto ou iminente ao manipular a rede arriscando comprometer a qualidade da água fornecida (BRASIL, 1940). Os valores das multas a serem aplicadas são estabelecidos dentro do regulamento de serviços de cada operadora. No que diz respeito às normativas que atuam no território das bacias PCJ, no Art. 107 da Resolução n 50 da ARES-PCJ, no Art. 82 da Deliberação ARSESP n ${ }^{\circ} 106$ e no Art. 114 da Resolução no 003 da ARSAE, estabelecesse que o prestador de serviços poderá interromper o fornecimento de água em casos que forem comprovados ligações clandestinas e manipulação indevidas dos componentes da rede pública (ARSESP, 2009; ARSAE-MG, 2010; ARES-PCJ, 2014).

Em termos de prevenção, a atualização anual do cadastro dos usuários é fundamental para prevenir as perdas aparentes em função da desatualização cadastral. Esta ação (Prática 41), conduzida por $66,15 \%$ das operadoras, possibilita acompanhar as ações relacionadas ao cadastro de novas ligações e desativação de outras, auxiliando a identificar ligações não cadastradas, clandestinas ou que foram reativadas sem autorização da operadora (TSUTIYA, 2006; MUTIKANGA et al., 2011).

A suspeita de ligações clandestinas, popularmente conhecidas como "gato", ocorre usualmente em função da não procura do usuário para religação do ramal após o corte efetuado. Uma vez instaurada a suspeita de ligação irregular de água uma equipe de fiscalização é direcionada ao possível local fraudado para aplicar as medidas adequadas para conter este problema, estando os usuários sujeitos a todas as penalidades legais aplicáveis. Utilizando o mesmo princípio dos geofones, utilizados na pesquisa de vazamentos, novas tecnologias estão 
sendo aplicadas para otimizar a detecção de ligações clandestinas, como por exemplo o Sistema de Radar de Penetração no Solo (Ground Penetrating Radar System), que detecta ligações não autorizadas (CARTEADO; VERMERSCH, 2016) e o uso de câmeras de vídeo-inspeção que quando introduzidas na rede, manualmente, permitem não só detectar ligações clandestinas, mas também, obstruções e deformidades nas redes. De acordo com os dados coletados em campo, 53,8\% das operadoras em estudo atestaram utilizar tecnologias na detecção de ligações irregulares (P37).

No contexto de ligações clandestinas deve-se sempre discutir a existência de assentamento precários, denominados pelo IBGE como aglomerados subnormais, onde a população geralmente tem seu abastecimento através de ligações irregulares por questões fundiárias, que na maioria dos casos impedem o abastecimento legal por rede. De acordo com Oliveira et al. (2015), no Brasil as perdas aparentes nessas áreas oscilam entre $15 \%$ a $25 \%$ reforçando a necessidade da adoção de ações que reduzam estes níveis. Tomando como base o Censo de Aglomerados Subnormais de 2010, 11 municípios pertencentes as bacias PCJ apresentam aglomerados subnormais. Analisando a Figura 31, exposta acima, vê-se que a Prática 39, que aborda a questão do controle de fraudes em áreas de vulnerabilidade social, é a menos empregada entre todas as práticas. Esta divergência ocorre, pois, na elaboração do gráfico foi considerado a proporção da adoção das práticas em relação ao número total de municípios em análise. Assim, considerando para esta prática apenas os municípios que se enquadram nesta situação temos que sete, dos 11 municípios $(63,3 \%)$ atuam, em diferentes níveis, em áreas de pobreza para controlar as perdas de água.

Entre os níveis de atuação nas áreas de vulnerabilidade social há duas operadoras bem estruturadas, com setores específicos dentro da organização que lidam com as questões relacionadas ao saneamento nessas áreas, de forma a garantir o acesso dos usuários aos serviços sem tornar a operação dos sistemas onerosa. Em contrapartida as outras operadoras atuam de forma menos assídua, com ações pontuais que envolvem Programas e campanhas de sensibilização da população em relação aos riscos que as fraudes podem oferecer. 


\subsubsection{Práticas de "Planejamento Estratégico"}

As práticas que são discutidas nesta subseção (Quadro 20) englobam ações relacionadas ao setor administrativo e de planejamento das operadoras de água. Por se tratarem de ações participativas e contínuas das empresas, estas práticas foram categorizadas como práticas de "Planejamento Estratégico" tendo em vista a relação direta destas ações com o processo participativo, dinâmico e contínuo que, segundo Rezende (2008), definem o planejamento estratégico de uma organização.

\begin{tabular}{|ll|}
\hline \multicolumn{1}{l|}{} & \multicolumn{1}{c|}{ Quadro 20 - Práticas de Planejamento Estratégico. } \\
\hline PROCESSO & \multicolumn{1}{c|}{ PRÁTICAS } \\
\hline & P42. Estabelecimento de um Plano/Programa de combate as perdas de água. \\
& P43. Definição de uma meta de redução de perdas. \\
& P44. Departamento/Seção específica da organização voltado ao controle de \\
& perdas. \\
Planejamento & P45. Diagnóstico da situação das perdas no município. \\
Estratégico & P46. Uso de indicadores para avaliar o desempenho no controle de perdas. \\
& P47. Desenvolvimento de estudos de priorização de zonas mais críticas para \\
& o controle de perdas. \\
& P48. Análises de custo benefício para ações no controle de perdas. \\
& P49. Reunião periódicas para análise dos resultados das ações de controle e \\
& planejamento das consecutivas. \\
\hline
\end{tabular}

As informações consolidadas na Figura 30 refletem que o estabelecimento de um Plano ou Programa de Combate as perdas de água (P42) e a definição de uma meta de redução de perdas (P43) são as práticas com maior aderência pelas empresas de saneamento no que diz respeito ao planejamento estratégico, 90,7\% ambas as práticas. Estas práticas não devem ser discutidas isoladamente uma vez que, as metas de redução de perdas são estabelecidas dentro do contexto de um Plano ou Programa de controle. Vale lembrar que além das metas estabelecidas dentro de cada Plano de perdas, há a meta do Plano de Bacias que estabelece que todos os municípios devem atingir o nível de perdas de 25\% até 2020 (COBRAPE, 2010). 
Figura 30 - Aderência das práticas de "Planejamento Estratégico".

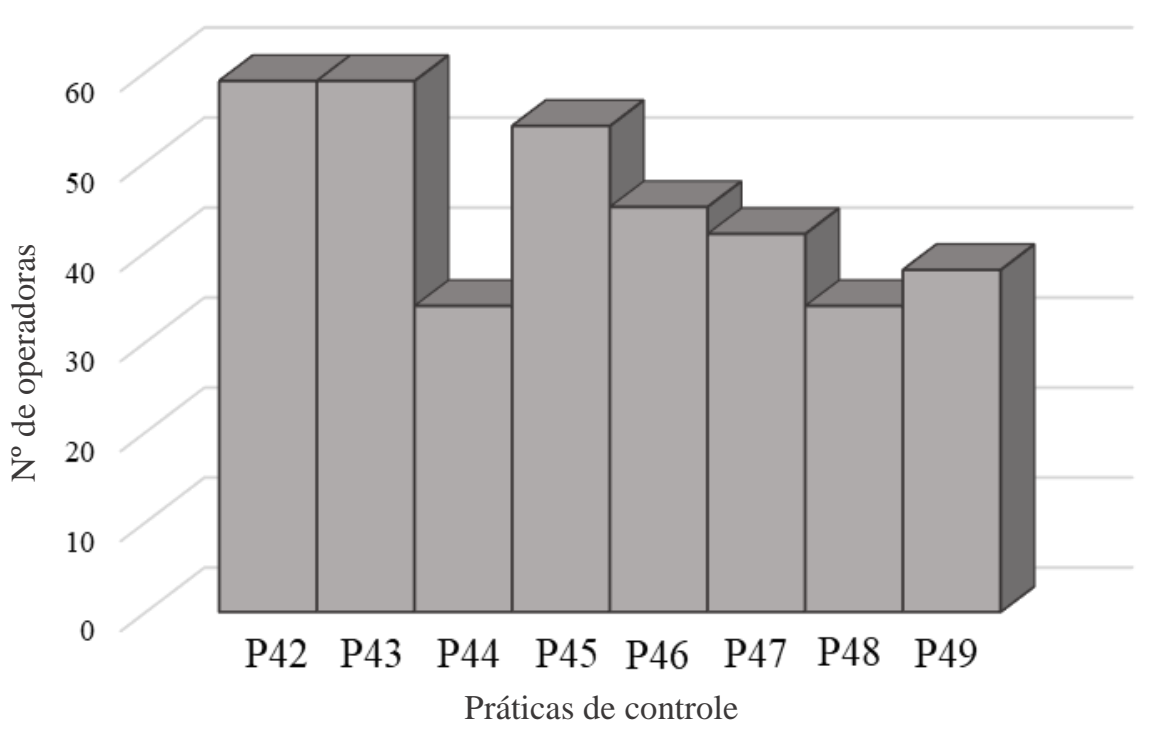

Fonte: Elaborado pela autora.

Thorton et al. (2008) defendem que os Planos e Programas de controle de perdas são excelentes ferramentas na gestão eficiente da água. Desde a criação dos Comitês PCJ tem-se investido em ações voltadas ao controle de perdas, a partir de recursos provenientes da cobrança pelo uso dos recursos hídricos. Seguindo os Planos de Aplicação Plurianual do PCJ e enquadrados dentro do Programa de Duração Continuada 5 do PCJ (PDC 5) - Promoção do Uso Racional de Recursos Hídricos, 36 Planos e Programas de combate a perdas foram elaborados ou revisados com recursos provenientes da Cobrança Federal, Cobrança Paulista e FEHIDRO, conforme ilustrado na Figura 31 (FUNDAÇÃO AGÊNCIA DAS BACIAS PCJ, 2017), utilizando $1,6 \%$ dos $\mathrm{R} \$ 205,5$ milhões direcionados ao controle de perdas de águas nas bacias.

Figura 31 - Fonte de recursos para elaboração ou revisão de Planos/Programas de combate as perdas de água em sistemas de abastecimento.

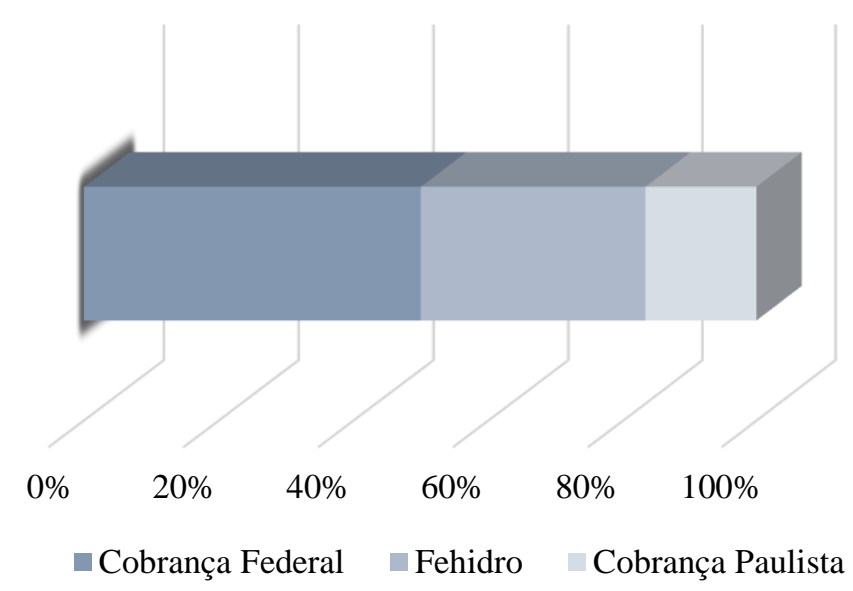

Fonte: Elaborado pela autora. 
Antes de se elaborar um Plano ou Programa de controle é essencial entender as causas das perdas, realizando um diagnóstico do sistema como um todo, definindo as possíveis causas que geram os volumes perdidos (THORNTON et al. 2008). No contexto das Bacias PCJ, 83,1\% das operadoras de água contam com um diagnóstico das perdas nos sistemas (P45), como ferramenta de suporte as ações de planejamento, o que justifica a indicação de complementação de alguns Planos pela Fundação Agência das Bacias PCJ (2013). Além da etapa de diagnóstico, a Abes (2013) apresenta que um Plano/Programa de perdas deve conter no mínimo: metas definidas, indicadores de controle, planos de ação, estruturação e priorização de ações e métodos para acompanhamento das ações e avaliação dos resultados. Vê-se nesta perspectiva que as práticas expostas no Quadro 20 são complementares, tendo maior eficiência quando articuladas umas com as outras.

No que diz respeito ao monitoramento das ações previstas nos Planos, o uso de indicadores de desempenho são uma boa ferramenta neste processo. Como já apresentado no subitem 4.1.1.1, os indicadores são fundamentais para avaliar a eficiência das ações e planejar as intervenções consecutivas (HAMILTON; MCKENZIE, 2014), porém, deve-se sempre investigar qual o indicador mais adequado em cada realidade, tomando como base as criticidades que envolvem o uso dos indicadores expressos em percentual. Estes indicadores dão suporte a análise dos resultados das ações de controle que, em um contexto de planejamento estratégico, devem ser discutidas periodicamente em reuniões que envolvam toda a equipe orientada ao controle de perdas (P49). Entre as operadoras em análise 69,2\% relataram o uso de indicadores de desempenho (P46) no processo de monitoramento e planejamento de novas ações e 58,5\% atestam realizar reuniões periódicas para discutir as ações empregadas e planejar as futuras (P49).

Para reduzir a elevação dos custos de operação dos sistemas em função das perdas de água, estudos de priorização de áreas mais críticas para o controle, que considerem critérios técnicos, sociais e relacionados a qualidade da água, devem ser conduzidos de forma a otimizar o uso dos recursos financeiros disponíveis (muitas vezes escassos) além de tempo e recurso humano para a execução das ações (MORAIS, et al. 2010). Associado aos estudos de priorização (P47) devem estar as análises de custo benefício (P48) das ações de controle, ou seja, ensaios que indiquem quais ações produzirão um melhor resultado em termos de volume recuperado em determinada área (AWWA, 2009). No âmbito das operadoras das bacias em estudo, 64,6\% atestam conduzir estudos de priorização de áreas críticas para o controle (P47) e $52,3 \%$ conduzem análises de custo-benefício das ações (P48). 
Por fim, para que as ações de controle discutidas nas subseções anteriores sejam mais eficientes e otimizadas, a consolidação de um departamento ou seção dentro da organização, com uma equipe especializada e contratada especificadamente para a gestão das perdas é de suma importância. Quando se tem um setor de perdas institucionalizado dentro da organização as práticas de controle são mais assíduas e frequentes. No contex to do planejamento estratégico, a Prática 44 que versa sobre a existência de um departamento/seção específica da organização voltado ao controle de perdas é a menos presente entre as operadoras em estudo, $52 \%$. 


\subsubsection{Práticas de "Investimento e Inovação"}

As práticas que compõem o processo de "Investimento e Inovação" são ações relacionadas ao uso dos recursos financeiros das organizações na aquisição de novos equipamentos, infraestruturas e tecnologias, além do investimento em softwares e metodologias de melhoria contínua que auxiliam no combate as perdas. No Quadro 21 estão expressas as práticas que são discutidas nesta subseção.

Quadro 21- Práticas de "Investimento e Inovação".

\begin{tabular}{|cl|}
\hline PROCESSO & \multicolumn{1}{c|}{ PRÁTICAS } \\
\hline & P50. Investimento em tecnologias voltadas ao controle de perdas. \\
& P51. Adoção de metodologias como MASPP e Six Sigma. \\
Investimento e & P52. Investimento em cursos de capacitação/treinamento dos funcionários \\
Inovação & voltados ao controle de perdas. \\
& P53. Uso de SIG no auxílio ao controle de perdas. \\
& P54. Investimento na elaboração de manuais de gerenciamento de perdas. \\
\hline
\end{tabular}

Entre todos os processos, as práticas de investimento e inovação são a menos empregadas pelas operadoras em estudos. Consoante ao exposto na Figura 32, o investimento em cursos de capacitação e treinamento da equipe (P52) é o mais praticado entre as organizações em análise, $60 \%$. Tendo em vista que 55\% dos sistemas em análise são operados em um modelo centralizado, pela administração pública direta, a baixa aderência das práticas que demandam investimentos das operadoras pode ser explicada pela carência de recursos financeiros para a melhoria do setor que, neste cenário ocorrem em baixa escala (LISBOA; HELLER; SILVEIRA, 2013).

Figura 32- Aderência das práticas de investimento e inovação.

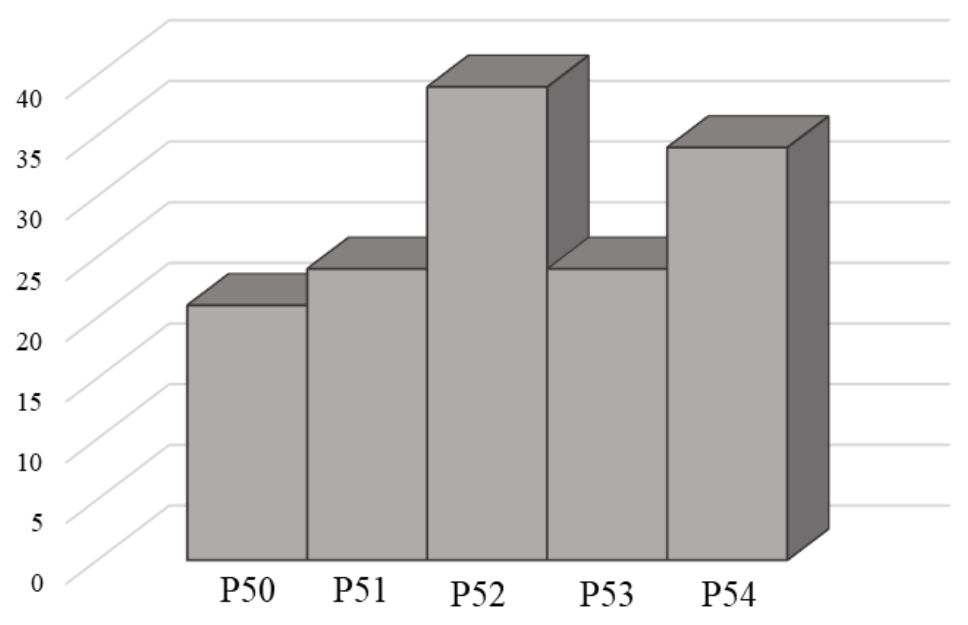

Fonte: Elaborado pela autora. 
Um dos caminhos que as operadoras podem seguir para elevar o investimento em ações de controle de perdas corresponde ao pleito de recursos financeiros junto a instituições que dão suporte econômico a estas organizações. No contexto das Bacias PCJ, as operadoras podem pleitear recursos do FEHIDRO e junto a Fundação Agência das Bacias PCJ que investe em ações a partir da captação de recursos da Cobrança Federal e Paulista. No que diz respeito a prática 52, mais empregada neste processo, $7 \%$ das organizações investiram na capacitação/treinamento das equipes a partir de recursos provenientes das instituições citadas (FUNDAÇÃO AGÊNCIA DAS BACIAS PCJ, 2017).

A segunda prática mais aplicada corresponde ao investimento em manuais/guias de gerenciamento de perdas (P54) que facilitem a rotina de todos os envolvidos nas ações de controle. Nos dados consolidados dos projetos financiados com recursos do FEHIDRO e da Agência das bacias PCJ não foi identificado nenhum que solicitasse recursos para elaboração de guias ou manuais. Assim, presume-se que as operadoras que atestaram investir neste tipo de ação, $52 \%$, utilizam recursos internos das organizações ou de outras fontes não analisadas.

No aspecto da inovação se enquadra a Prática 51 que aborda a adoção de metodologias de melhoria contínua no combate as perdas. Apesar da baixa representatividade de trabalhos científicos que denotem sobre a importância e os benefícios da aplicação destas metodologias no controle de perdas, há experiências de sucesso no Brasil, como a companhia Águas de Niterói, a Companhia de Saneamento do Paraná (Sanepar), Rio Branco e a mais assídua na aplicação das ferramentas, a Sabesp (ABES, 2013).

As ferramentas de melhoria contínua mais aplicadas no contexto nacional do saneamento são a Six Sigma e o Método de Análise e Solução de Problemas de Perdas D’água e de Faturamento - MASPP, desenvolvidos como uma adaptação do ciclo PDCA (Plan, Do, Check, Act) (ABES, 2015). O objetivo da aplicação destas metodologias é reduzir, mediante um processo de planejamento, monitoramento e ação, as não conformidades dos processos operacionais, elevando a qualidade dos serviços (POHLMANN, et al., 2015). Temos, como exemplo, a redução de 30\% do volume de água perdido por ligação na implementação da metodologia Six Sigma na Unidade de Gerenciamento Regional Santo Amaro da Sabesp (ABES, 2013). No âmbito das bacias PCJ o uso destas metodologias foi verificado apenas nos municípios operados pela companhia estadual, que corresponde a 36,9\% da amostra total.

No enredo da inovação se enquadra ainda o uso dos Sistemas de Informação Geográficas (SIG) no suporte ao controle de perdas (P53). Estes sistemas, ainda com pouca aderência entre as operadoras em análise, $36,9 \%$, têm um grande potencial de uso no combate as perdas. Como já discutido anteriormente, o potencial do SIG não está atrelado apenas ao georreferenciamento 
das redes, que apoia o planejamento da manutenção das mesmas (JUNQUEIRA; LAUTENSCHLAGER; PAREDES, 2009). Muito além disso, os SIGs integram dados de diversas fontes e formatos, gerando cenários que subsidiam a tomada de decisão no controle de perdas e, com uma base cartográfica constantemente atualizada, propiciam a localização de vazamentos e favorecem as manobras dos equipamentos da rede, reduzindo custos e otimizando o tempo de operação (BARROS FILHO; SÁ; GOMES, 2004; TSUTIYA, 2006; RAUEN et al., 2016; SANTOS; PEREIRA, 2016).

Enfim, a ação menos praticada pelas organizações em estudo, diz respeito ao investimento em tecnologias voltadas ao controle de perdas, 32,3, \% (P50). O investimento na aquisição de tecnologias se enquadra na mesma lógica apresentada previamente sobre o caminho para solicitar apoio financeiro de fontes externas. Dados do FEHIDRO e da Fundação Agência das Bacias PCJ indicam que apenas 9,2\% das organizações solicitaram recursos destas instituições, para projetos que envolvem tecnologias como equipamentos para pesquisa de vazamentos e softwares de georreferenciamento para suporte ao controle de perdas.

Para solicitar o aporte de recursos do FEHIDRO as organizações podem consultar o passo a passo das etapas e documentos necessários no "Manual de Procedimentos Operacionais para Investimento" - Anexo II da Deliberação Cofehidro n 158/2015 disponível na plataforma eletrônica da instituição (COFEHIDRO, 2015). No que diz respeito a solicitação de financiamentos com recursos das Cobranças PCJ, são lançadas anualmente Deliberações dos Comitês PCJ com o cronograma e os critérios necessários para pleitear os recursos. Na plataforma eletrônica da Fundação Agência das Bacias PCJ também são disponibilizados editais em vigência, como por exemplo editais do ICMBio, Caixa Econômica Federal e BNDES, que são outras possíveis fontes para captação de recursos. 


\subsubsection{Considerações sobre as práticas de controle de perdas adotadas nas Bacias PCJ}

Os pontos discutidos nas subseções anteriores demonstram o empenho das operadoras que atuam no âmbito das bacias PCJ para controlar as perdas de água na distribuição. Dados do uso de recursos da cobrança Federal, Paulista e do FEHIDRO registram o interesse das operadoras em pleitear financiamentos destas fontes na busca da melhoria dos sistemas, de forma a reduzir os atuais níveis de perdas de água. Vê-se pela compilação dos dados que a maior parte dos recursos voltados ao controle de perdas são direcionados à troca de redes, setorização e instalação de válvulas redutoras de pressão e macromedidores (FUNDAÇÃO AGÊNCIA DAS BACIAS PCJ, 2017). Salvo estes aspectos, os dados coletados em campo demonstram que, na média, o Processo 7 composto por práticas de "Planejamento Estratégico" é o que apresenta maior aderência de ações entre as organizações em estudos.

As discussões apresentadas acima foram baseadas na análise dos resultados para os 65 municípios que responderam ao Questionário B. Considerando os 41 municípios cuja credibilidade dos dados quantitativos foi satisfatória para fins de análise de desempenho, a Figura 33 traz um panorama da aderência das práticas dentro deste filtro. Vê-se que entre as 54 práticas analisadas, 49 são aplicadas por mais de 50\% dos municípios, enquanto cinco práticas (P32, P10, P50, P39 e P31) apresentam baixa aderência de aplicação.

Figura 33 - Proporção da adoção das práticas de controle na amostra de 41 municípios.

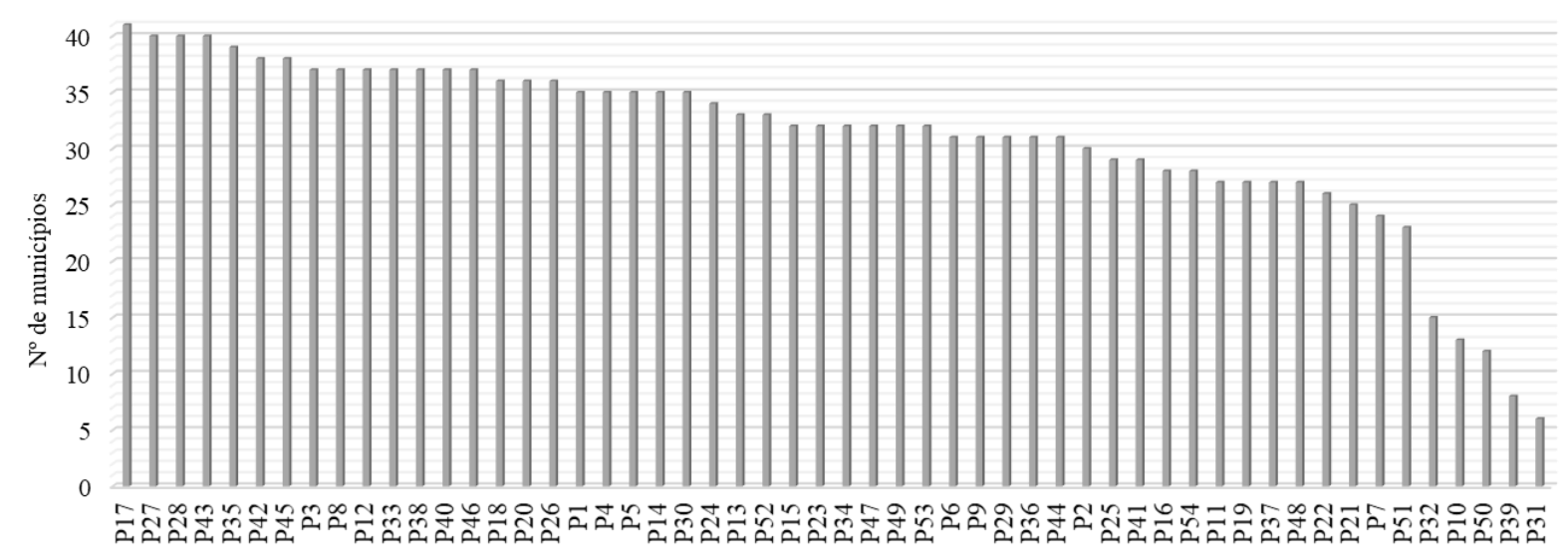

Fonte: Elaborado pela autora.

As práticas com baixa aplicação $(<40 \%)$, para esta amostra são semelhantes a amostra geral, em que foram analisados os 65 municípios, e equivalem às práticas que demandam investimentos da operadora (P31, P32 e P50), melhoria na estrutura organizacional no que diz respeito a manutenção de equipamentos (P10) e controle de fraudes (P39).

Analisando as práticas com maior aderência entre os municípios (90-100\%) (P17, P27 P28, P43, P35, P42, P45, P3, P8, P12, P33, P38, P40, P46) verifica-se que as mesmas estão distribuídas entre os diferentes processos de controle, o que demonstra que as operadoras atuam 
nas diversas dimensões relacionadas ao controle de perdas de água, e não apenas em um único conjunto de ações, o que é fundamental para que a redução dos níveis de perdas seja efetiva, uma vez que as mesmas ocorrem em diferentes partes de um sistema de distribuição.

Frente aos pontos abordados nesse subcapítulo é evidente a importância do mix de práticas de cada processo na obtenção de resultados mais eficientes e satisfatórios, como por exemplo a instituição de setores que, associados ao uso de SIG e modelos hidráulicos possibilitam análises avançadas da ocorrência e prevenção de vazamentos (AWWA, 2009). Nesta perspectiva, e como anunciado por Thornton et al. (2008), para garantir o equilíbrio econômico de sua operação, as empresas de água devem desenvolver estratégias que estabeleçam um balanço na execução de todas as práticas de controle de perdas, sendo imprescindível considerar a viabilidade econômica de cada prática frente aos custos relacionados ao volume perdido e ao que será produzido em maior escala para atender a demanda. 


\subsection{Análise estatística dos dados}

\subsubsection{Análise descritiva}

O conjunto de dados analisados estatisticamente nesta etapa corresponde às informações dos 41 municípios (apresentados previamente no Quadro 12 do subitem 5.1.2), entre os 65 analisados nas etapas antecedentes, cuja credibilidade dos dados de volume de água se enquadram na escala pré-estabelecida na metodologia. Na Tabela 4 as medidas descritivas da variável resposta (IPL) estão expostas. Observando-a afere-se que o nível médio de perdas (m³/ligação/dia) dos 41 municípios equivale a 0,237, como já demonstrado na Figura 18 do item 5.1.3.1 deste documento, enquanto a moda (valor mais frequente do IPL) corresponde à 0,290 m³/ligação/dia. Pelos valores de mínimo e máximo observa-se que o menor IPL identificado é $0,048 \mathrm{~m}^{3} /$ ligação/dia (Pedra Bela) e o maior 0,627 m³/ligação/dia (Sumaré). Em relação à medida de desvio padrão, esta evidencia que a distância padrão de cada IPL para o IPL médio é de $0,124 \mathrm{~m}^{3} /$ ligação/dia. Por fim, o coeficiente de variação de 52,3\% denota que os valores de IPL são bastante heterogêneos, com elevada variação em relação à média do conjunto de dados.

Tabela 4 - Medidas descritivas da variável IPL.

\begin{tabular}{|cc|}
\hline \multicolumn{1}{|c|}{ IPL } & \\
\hline Média & 0,237 \\
\hline Mediana & 0,203 \\
\hline Moda & 0,29 \\
\hline Mínimo & 0,048 \\
\hline Máximo & 0,627 \\
\hline Desvio padrão & 0,124 \\
\hline Coeficiente de variação (\%) & 52,3 \\
\hline
\end{tabular}

\subsubsection{Teste de diferença de média das práticas de controle de perdas de água}

Posto que o objetivo da análise estatística consiste em verificar quais práticas influenciam nos níveis de perdas de água, a comparação das médias do IPL para os grupos de municípios que adotam e não adotam cada uma das práticas (P1-P54) (grupos “sim” e "não"), partiu da hipótese nula (H0) de que a adoção ou não das práticas não impactam o IPL, ou seja, o IPL é significativamente próximo independentemente da adoção das práticas.

A aplicação dos testes de diferença de média demonstrou que, entre as 54 práticas em estudo, 33 produzem impactos significativos nos níveis de perdas, ou seja, com nível de significância de $5 \%$ (valor-p <0,05), os resultados indicam que há diferenças significativas no valor do IPL entre o grupo que adota uma prática (“Sim”) e o grupo que não emprega a mesma (Não). Nas Tabelas 5 e 6, as médias dos grupos para cada prática, bem como o valor-p da análise de impacto podem ser visualizados. 
Interpretando os dados expressos na Tabela 5 vê-se, por exemplo, que para a P1 a média do IPL para o grupo de municípios que emprega a mesma ("Sim”) é significativamente menor do que a do grupo que não emprega ("Não"), o que pode ser visualizado também pelo valor-p $>0,05$ que demonstra que há diferença significativa no IPL quando a prática é ou não adotada. A intepretação das outras práticas segue o mesmo padrão do exemplo citado.

Assim, analisando todos as práticas em estudo, observa-se que o Processo 1 (Gerenciamento de Pressão de água na rede), Processo 3 (Controle da Corrosão nas tubulações), Processo 4 (Controle de vazamentos) e Processo 8 (Investimento e Inovação) apresentam mais de 70\% das práticas significativas, ou seja, práticas cuja aplicação afetam os níveis de perdas de água seja positivamente (quando o IPL médio grupo "Sim" é menor do que o grupo "Não"), ou negativamente (quando o grupo "Sim" apresenta IPL médio maior do que o grupo "Não", ou seja, mesmo que a prática de controle seja empregada não há redução no IPL).

Salvo os processos com maior proporção de práticas significativas, as práticas de controle com diferença entre os grupos com maior significância (valor-p < 0,0001) são: P2, P7, P9, P19, P21, P22, P51 e P54. Analisando as médias do IPL para estas práticas observa-se que a média do IPL para os grupos de munícipios que não aplicam as práticas é quase o dobro do IPL médio dos municípios que adotam as ações de controle. Entre as práticas com maior significância a P7 é a única prática entre todas as analisadas onde os grupos de municípios foram organizados em "Sim" e "Parcialmente". Apesar da diferença na organização dos grupos de municípios para esta prática, os dados expressos na Tabela 5 indicam que o IPL médio segue a mesma tendência das demais práticas onde o nível médio de perdas de água dos municípios cuja troca dos ramais prediais antigos foi parcial equivale ao dobro IPL médio dos municípios onde a troca foi realizada por completo. 
Tabela 5 - Comparação de média do IPL com a aplicação/não aplicação das práticas de controle.

IPL

\begin{tabular}{|c|c|c|c|c|c|}
\hline & & & $\mathbf{N}$ & Média $\pm E P$ & Valor-p \\
\hline \multirow{12}{*}{ 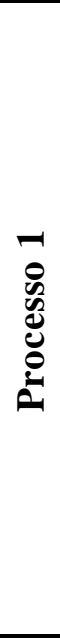 } & \multirow{2}{*}{$\mathrm{P} 1$} & Sim & 6 & $0,220 \pm 0,020$ & \multirow{2}{*}{0,0328} \\
\hline & & Não & 35 & $0,336 \pm 0,048$ & \\
\hline & \multirow{2}{*}{$\mathrm{P} 2$} & Sim & 30 & $0,192 \pm 0,018$ & \multirow{2}{*}{0,0001} \\
\hline & & Não & 11 & $0,360 \pm 0,030$ & \\
\hline & \multirow{2}{*}{ P3 } & Sim & 37 & $0,249 \pm 0,020$ & \multirow{2}{*}{0,0592} \\
\hline & & Não & 4 & $0,127 \pm 0,060$ & \\
\hline & \multirow{2}{*}{$\mathrm{P} 4$} & Sim & 35 & $0,210 \pm 0,018$ & \multirow{2}{*}{0,0004} \\
\hline & & Não & 6 & $0,394 \pm 0,044$ & \\
\hline & \multirow{2}{*}{ P5 } & Sim & 35 & $0,216 \pm 0,019$ & \multirow{2}{*}{0,0061} \\
\hline & & Não & 6 & $0,362 \pm 0,047$ & \\
\hline & \multirow{2}{*}{ P6 } & Sim & 31 & $0,200 \pm 0,019$ & \multirow{2}{*}{0,0003} \\
\hline & & Não & 10 & $0,352 \pm 0,034$ & \\
\hline \multirow{16}{*}{ 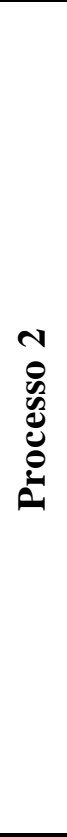 } & \multirow{2}{*}{ P7 } & Sim & 24 & $0,165 \pm 0,018$ & \multirow{2}{*}{0,0001} \\
\hline & & Parcial & 17 & $0.339 \pm 0.022$ & \\
\hline & \multirow{2}{*}{ P8 } & Sim & 37 & $0,230 \pm 0,020$ & \multirow{2}{*}{0,2813} \\
\hline & & Não & 4 & $0.302 \pm 0.062$ & \\
\hline & \multirow{2}{*}{ P9 } & Sim & 31 & $0,198 \pm 0,018$ & \multirow{2}{*}{0,0001} \\
\hline & & Não & 10 & $0,359 \pm 0,032$ & \\
\hline & \multirow{2}{*}{ P10 } & Sim & 13 & $0,179 \pm 0,033$ & \multirow{2}{*}{0,0388} \\
\hline & & Não & 28 & $0,264 \pm 0,022$ & \\
\hline & \multirow{2}{*}{$\mathrm{P} 11$} & Sim & 27 & $0,240 \pm 0,024$ & \multirow{2}{*}{0,8722} \\
\hline & & Não & 14 & $0,233 \pm 0,034$ & \\
\hline & \multirow{2}{*}{$\mathrm{P} 12$} & Sim & 37 & $0,227 \pm 0,020$ & \multirow{2}{*}{0,1078} \\
\hline & & Não & 4 & $0,332 \pm 0,061$ & \\
\hline & \multirow{2}{*}{$\mathrm{P} 13$} & Sim & 33 & $0,208 \pm 0,019$ & \multirow{2}{*}{0,0015} \\
\hline & & Não & 8 & $0,357 \pm 0,039$ & \\
\hline & \multirow{2}{*}{ P14 } & Sim & 35 & $0,219 \pm 0,020$ & \multirow{2}{*}{0,0219} \\
\hline & & Não & 6 & $0,343 \pm 0,048$ & \\
\hline
\end{tabular}

IPL

\begin{tabular}{|c|c|c|c|c|c|}
\hline & & & $\mathbf{N}$ & Média \pm EP & Valor-p \\
\hline \multirow{6}{*}{$\begin{array}{l}n \\
0 \\
0 \\
\delta \\
d \\
0 \\
0\end{array}$} & \multirow{2}{*}{ P15 } & Sim & 32 & $0,212 \pm 0,020$ & \multirow{2}{*}{0,0118} \\
\hline & & Não & 9 & $0,327 \pm 0,039$ & \\
\hline & \multirow{2}{*}{ P16 } & Sim & 28 & $0,193 \pm 0,020$ & \multirow{2}{*}{0,0004} \\
\hline & & Não & 13 & $0,332 \pm 0,030$ & \\
\hline & \multirow{2}{*}{ P17 } & Sim & 41 & $0,237 \pm 0,019$ & \\
\hline & & Não & 0 & 0 & \\
\hline \multirow{20}{*}{ 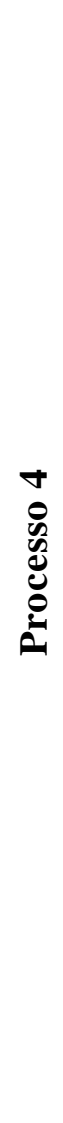 } & \multirow{2}{*}{ P18 } & Sim & 36 & $0,227 \pm 0,020$ & \multirow{2}{*}{0,1378} \\
\hline & & Não & 5 & $0,315 \pm 0,055$ & \\
\hline & \multirow{2}{*}{ P19 } & Sim & 27 & $0,182 \pm 0,019$ & \multirow{2}{*}{0,0001} \\
\hline & & Não & 14 & $0,344 \pm 0,026$ & \\
\hline & \multirow{2}{*}{$\mathrm{P} 20$} & Sim & 36 & $0,223 \pm 0,020$ & \multirow{2}{*}{0,0392} \\
\hline & & Não & 5 & $0,344 \pm 0,053$ & \\
\hline & \multirow{2}{*}{ P21 } & Sim & 25 & $0,176 \pm 0,020$ & \multirow{2}{*}{0,0001} \\
\hline & & Não & 16 & $0,332 \pm 0,025$ & \\
\hline & \multirow{2}{*}{ P22 } & Sim & 26 & $0,183 \pm 0,020$ & \multirow{2}{*}{0,0001} \\
\hline & & Não & 15 & $0,331 \pm 0,026$ & \\
\hline & \multirow{2}{*}{$\mathrm{P} 23$} & Sim & 32 & $0,208 \pm 0,020$ & \multirow{2}{*}{0,0026} \\
\hline & & Não & 9 & $0,343 \pm 0,037$ & \\
\hline & \multirow{2}{*}{ P24 } & $\operatorname{Sim}$ & 34 & $0,217 \pm 0,020$ & \multirow{2}{*}{0,0195} \\
\hline & & Não & 7 & $0,335 \pm 0,044$ & \\
\hline & \multirow{2}{*}{$\mathrm{P} 25$} & Sim & 29 & $0,213 \pm 0,022$ & \multirow{2}{*}{0,0472} \\
\hline & & Não & 12 & $0,297 \pm 0,034$ & \\
\hline & \multirow{2}{*}{ P26 } & Sim & 36 & $0,226 \pm 0,020$ & \multirow{2}{*}{0,1247} \\
\hline & & Não & 5 & $0,317 \pm 0,054$ & \\
\hline & \multirow{2}{*}{ P27 } & Sim & 40 & $0,290 \pm 0,125$ & \multirow{2}{*}{0,6726} \\
\hline & & Não & 1 & $0,236 \pm 0,020$ & \\
\hline
\end{tabular}

\begin{tabular}{|c|c|c|c|c|c|}
\hline \multirow{12}{*}{ 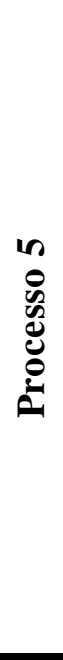 } & \multirow{2}{*}{ P28 } & Sim & 40 & $0,456 \pm 0,121$ & \multirow{2}{*}{0,0738} \\
\hline & & Não & 1 & $0,232 \pm 0,019$ & \\
\hline & \multirow{2}{*}{ P29 } & Sim & 31 & $0,208 \pm 0,020$ & \multirow{2}{*}{0,0058} \\
\hline & & Não & 10 & $0,329 \pm 0,036$ & \\
\hline & \multirow{2}{*}{ P30 } & Sim & 35 & $0,225 \pm 0,021$ & \multirow{2}{*}{0,144} \\
\hline & & Não & 6 & $0,306 \pm 0,050$ & \\
\hline & \multirow{2}{*}{ P31 } & Sim & 35 & $0,225 \pm 0,051$ & \multirow{2}{*}{0,8023} \\
\hline & & Não & 6 & $0,239 \pm 0,021$ & \\
\hline & \multirow{2}{*}{ P32 } & Sim & 15 & $0,177 \pm 0,030$ & \multirow{2}{*}{0,0164} \\
\hline & & Não & 26 & $0,272 \pm 0,023$ & \\
\hline & \multirow{2}{*}{ P33 } & Sim & 37 & $0,238 \pm 0,021$ & \multirow{2}{*}{0,9334} \\
\hline & & Não & 4 & $0,232 \pm 0,063$ & \\
\hline \multirow{16}{*}{$\begin{array}{l}0 \\
0 \\
0 \\
0 \\
0 \\
0 \\
0 \\
0\end{array}$} & \multirow{2}{*}{ P34 } & Sim & 32 & $0,204 \pm 0,019$ & \multirow{2}{*}{0,0005} \\
\hline & & Não & 9 & $0,357 \pm 0,036$ & \\
\hline & \multirow{2}{*}{ P35 } & Sim & 39 & $0,231 \pm 0,020$ & \multirow{2}{*}{0,1311} \\
\hline & & Não & 2 & $0,367 \pm 0,086$ & \\
\hline & \multirow{2}{*}{ P36 } & Sim & 31 & $0,216 \pm 0,021$ & \multirow{2}{*}{0,0484} \\
\hline & & Não & 10 & $0,304 \pm 0,038$ & \\
\hline & \multirow{2}{*}{ P37 } & Sim & 27 & $0,189 \pm 0,020$ & \multirow{2}{*}{0,0002} \\
\hline & & Não & 14 & $0,331 \pm 0,028$ & \\
\hline & \multirow{2}{*}{ P38 } & Sim & 37 & $0,231 \pm 0,020$ & \multirow{2}{*}{0,3067} \\
\hline & & Não & 4 & $0,298 \pm 0,062$ & \\
\hline & \multirow{2}{*}{ P39 } & Sim & 8 & $0,315 \pm 0,116$ & \multirow{2}{*}{0,6134} \\
\hline & & Não & 33 & $0,335 \pm 0,062$ & \\
\hline & \multirow{2}{*}{$\mathrm{P} 40$} & Sim & 37 & $0,234 \pm 0,021$ & \multirow{2}{*}{0,6083} \\
\hline & & Não & 4 & $0,268 \pm 0,063$ & \\
\hline & \multirow{2}{*}{ P41 } & Sim & 2 & $0,196 \pm 0,020$ & \multirow{2}{*}{0,8813} \\
\hline & & Não & 7 & $0,336 \pm 0,031$ & \\
\hline
\end{tabular}


Tabela 6 - Comparação de média do IPL com a aplicação/não aplicação das práticas de controle.

IPL

\begin{tabular}{|c|c|c|c|c|c|}
\hline & & & $\mathbf{N}$ & Média $\pm E P$ & Valor-p \\
\hline \multirow{16}{*}{ 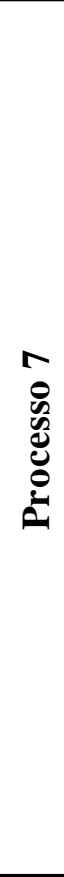 } & \multirow{2}{*}{ P42 } & Sim & 38 & $0,235 \pm 0,020$ & \multirow{2}{*}{0,6173} \\
\hline & & Não & 3 & $0,272 \pm 0,072$ & \\
\hline & \multirow{2}{*}{$\mathrm{P} 43$} & Sim & 40 & $0,237 \pm 0,020$ & \multirow{2}{*}{0,9855} \\
\hline & & Não & 1 & $0,235 \pm 0,126$ & \\
\hline & \multirow{2}{*}{ P44 } & Sim & 31 & $0,212 \pm 0,021$ & \multirow{2}{*}{0,0192} \\
\hline & & Não & 10 & $0,316 \pm 0,037$ & \\
\hline & \multirow{2}{*}{$\mathrm{P} 45$} & Sim & 38 & $0,220 \pm 0,018$ & \multirow{2}{*}{0,0008} \\
\hline & & Não & 3 & $0,458 \pm 0,063$ & \\
\hline & \multirow{2}{*}{ P46 } & Sim & 37 & $0,234 \pm 0,021$ & \multirow{2}{*}{0,6142} \\
\hline & & Não & 4 & $0,268 \pm 0,063$ & \\
\hline & \multirow{2}{*}{ P47 } & Sim & 32 & $0,218 \pm 0,021$ & \multirow{2}{*}{0,0638} \\
\hline & & Não & 9 & $0,305 \pm 0,040$ & \\
\hline & \multirow{2}{*}{ P48 } & Sim & 27 & $0,203 \pm 0,022$ & \multirow{2}{*}{0,0113} \\
\hline & & Não & 14 & $0,304 \pm 0,031$ & \\
\hline & \multirow{2}{*}{ P49 } & Sim & 32 & $0,219 \pm 0,021$ & \multirow{2}{*}{0,0815} \\
\hline & & Não & 9 & $0,301 \pm 0,040$ & \\
\hline \multirow{10}{*}{ 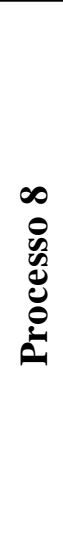 } & \multirow{2}{*}{ P50 } & Sim & 12 & $0,307 \pm 0,034$ & \multirow{2}{*}{0,0184} \\
\hline & & Não & 29 & $0,208 \pm 0,022$ & \\
\hline & \multirow{2}{*}{ P51 } & Sim & 23 & $0,167 \pm 0,020$ & \multirow{2}{*}{0,0001} \\
\hline & & Não & 18 & $0,327 \pm 0,023$ & \\
\hline & \multirow{2}{*}{ P52 } & Sim & 33 & $0,219 \pm 0,021$ & \multirow{2}{*}{0,0483} \\
\hline & & Não & 8 & $0,315 \pm 0,042$ & \\
\hline & \multirow{2}{*}{ P53 } & Sim & 32 & $0,203 \pm 0,019$ & \multirow{2}{*}{0,0005} \\
\hline & & Não & 9 & $0,358 \pm 0,036$ & \\
\hline & \multirow{2}{*}{ P54 } & Sim & 28 & $0,190 \pm 0,020$ & \multirow{2}{*}{0,0001} \\
\hline & & Não & 13 & $0,340 \pm 0,029$ & \\
\hline
\end{tabular}

Fonte: Elaborado pela autora.

Somado a análise das diferenças dos IPL entre os grupos "Sim" e "Não", analisando a Figura 34 verifica-se que entre as 33 práticas que impactam significativamente o IPL, as práticas P7, P51, P21, P32, P10, P19, P22, P37, P54, P2 quando aplicadas (grupo de municípios “sim") apresentam os 10 menores IPL médio, respectivamente, estando todos abaixo do limite de perdas de água atribuído para serem classificados como desempenhos superiores, Classe A (>0,250 m³/ligação/dia). 


\section{Figura 34 - Práticas cuja aplicação geram os menores IPL médio.}

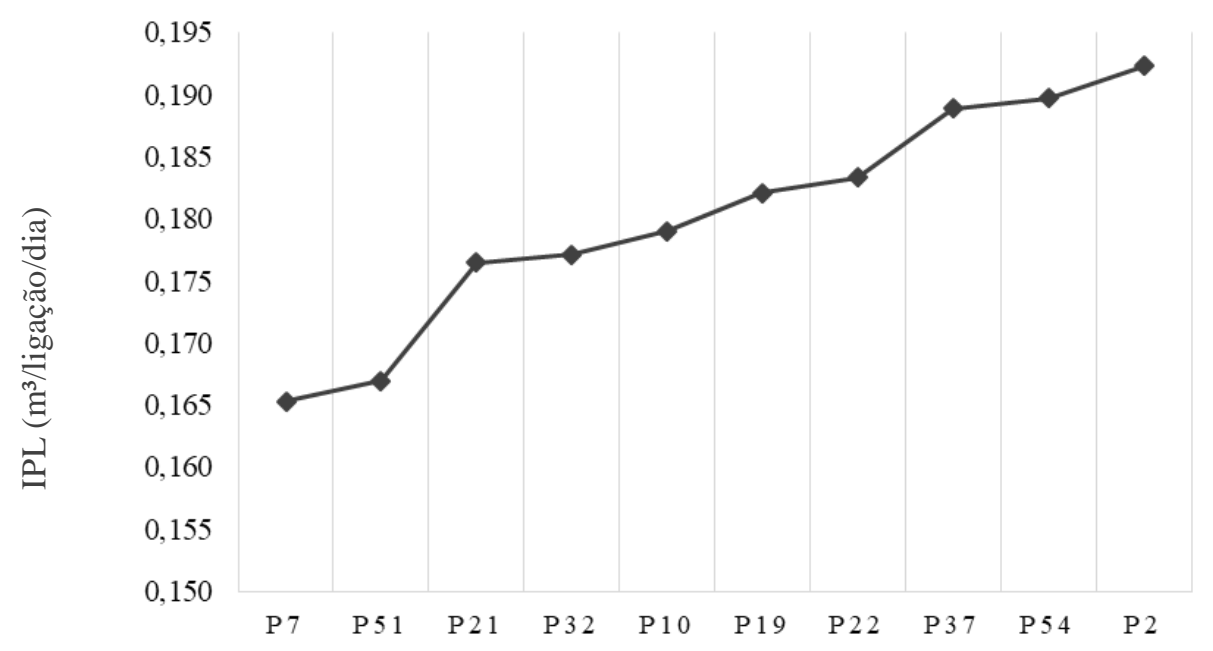

Os dados gerados possibilitam analisar ainda a relação do IPL médio dos municípios quando da aplicação da prática e não aplicação da mesma (Figura 35). Constata-se que para quase a totalidade das práticas a aplicação impacta positivamente o nível de perdas, enquanto a não aplicação impacta negativamente, produzindo níveis acima do valor assumido como desempenho superior $\left(<0,250 \mathrm{~m}^{3} /\right.$ ligação/dia). Destaca-se ainda que entre todas as práticas em análise a P50 produz efeito contrário as demais, onde o IPL médio dos municípios que aplicam a prática é superior $\left(0,307 \mathrm{~m}^{3} /\right.$ ligação/dia) ao do grupo que não emprega a mesma $(0,208$ $\mathrm{m}^{3} /$ ligação/dia).

Abordando a existência de investimento em tecnologias voltadas ao controle de perdas de água, o resultado encontrado para a P50 pode indicar o uso ineficiente dos recursos financeiros investidos em perdas. Este cenário pode estar associado a alguns relatos identificados in loco onde equipamentos destinados ao controle de perdas, tais como macromedidores, micromedidores e escutas de solo, embora tenham sido adquiridos não foram de fato instalados e utilizados pela equipe das operadoras. 
Figura 35 - Gráfico de radar demonstrando a variação do IPL de acordo com aplicação/não aplicação das práticas de controle.

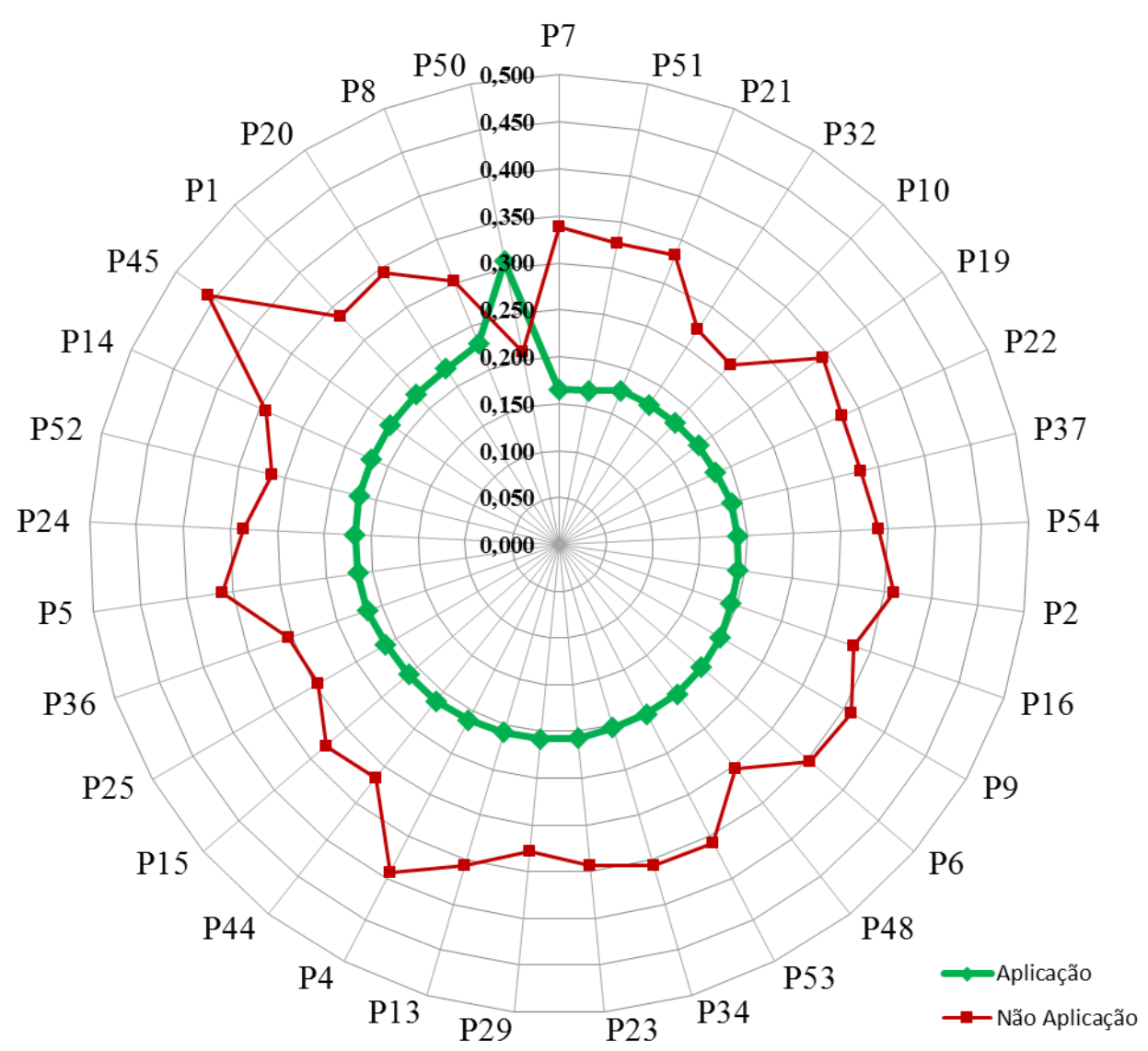

Fonte: Elaborado pela autora

\subsubsection{Análise da relação das práticas de controle com o desempenho}

O cruzamento das práticas de controle de perdas de água com as categorias de desempenho “Superior”/“Inferior” possibilitou identificar quais práticas tem uma relação de dependência com o IPL, ou seja, quais estão associadas aos níveis de perdas de água. O valor-p do teste exato de Fisher indicou que entre 54 práticas de controle de perdas 24 estão associadas com o IPL, onde ter um desempenho "Superior" no controle de perdas, ou seja, menores níveis dependem da adoção da prática e ter um desempenho "Inferior" está associado a não adotar a prática.

Observando os dados expressos nas Tabelas 7, 8, 9 e 10 é possível identificar que há um padrão nos dados quando a associação é significativa (P-Fisher <0,05). Analisando o cruzamento da P2 com o IPL, por exemplo, visualiza-se que o grupo de municípios "Sim" apresentam maior distribuição (80\%) dentro da categoria de IPL "Superior", ao passo que o grupo "Não" apresenta maior proporção na categoria "Inferior". O mesmo padrão de distribuição dos municípios entre os grupos pode ser observado para as outras 23 práticas, excetuando-se a P50 que será discutida a parte mais adiante. 
Por outro lado, para as práticas onde o teste não acusou associação, a diferença da proporção de municípios entre os grupos é pouco significativa. Na P1, por exemplo, a mesma proporção de municípios (50\%) que não adotam a prática estão alocadas no grupo com desempenho "Superior" e "Inferior", indicando assim que o nível de perdas de água ser menor ou maior independe da adoção ou não da prática, ou seja, não há relação de dependência entre as variáveis.

Tabela 7 - Teste exato de Fisher IPL x P1 a P14.

Tabela 8 - Teste exato de Fisher IPL x P15 a P27.

\begin{tabular}{|c|c|c|c|c|c|}
\hline & \multicolumn{2}{|c|}{ Desempenho } & \multirow{2}{*}{$\begin{array}{l}\text { Fisher } \\
\text { valor-p }\end{array}$} \\
\hline & & & Superior & Inferior & \\
\hline \multirow{12}{*}{ 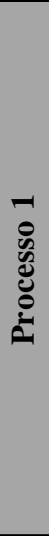 } & \multirow{2}{*}{$\mathrm{P} 1$} & Sim & $69 \%$ & $31 \%$ & \multirow{2}{*}{0,2368} \\
\hline & & Não & $50 \%$ & $50 \%$ & \\
\hline & \multirow{2}{*}{$\mathrm{P} 2$} & Sim & $80 \%$ & $20 \%$ & \multirow{2}{*}{0,0028} \\
\hline & & Não & $27 \%$ & $73 \%$ & \\
\hline & \multirow{2}{*}{ P3 } & Sim & $62 \%$ & $38 \%$ & \multirow{2}{*}{0,1733} \\
\hline & & Não & $100 \%$ & $0 \%$ & \\
\hline & \multirow{2}{*}{$\mathrm{P} 4$} & Sim & $74 \%$ & $26 \%$ & \multirow{2}{*}{0,012} \\
\hline & & Não & $17 \%$ & $83 \%$ & \\
\hline & \multirow{2}{*}{ P5 } & Sim & $71 \%$ & $29 \%$ & \multirow{2}{*}{0,0781} \\
\hline & & Não & $33 \%$ & $67 \%$ & \\
\hline & \multirow{2}{*}{ P6 } & Sim & $77 \%$ & $23 \%$ & \multirow{2}{*}{0,009} \\
\hline & & Não & $30 \%$ & $70 \%$ & \\
\hline \multirow{16}{*}{ 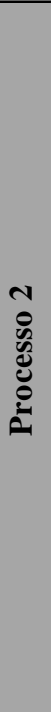 } & \multirow{2}{*}{ P7 } & Sim & $92 \%$ & $8 \%$ & \multirow{2}{*}{0,0001} \\
\hline & & Parcial & $29 \%$ & $71 \%$ & \\
\hline & \multirow{2}{*}{ P8 } & Sim & $70 \%$ & $30 \%$ & \multirow{2}{*}{0,097} \\
\hline & & Não & $25 \%$ & $75 \%$ & \\
\hline & \multirow{2}{*}{ P9 } & Sim & $81 \%$ & $19 \%$ & \multirow{2}{*}{0,0009} \\
\hline & & Não & $20 \%$ & $80 \%$ & \\
\hline & \multirow{2}{*}{ P10 } & Sim & $85 \%$ & $15 \%$ & \multirow{2}{*}{0,0673} \\
\hline & & Não & $57 \%$ & $43 \%$ & \\
\hline & \multirow{2}{*}{ P11 } & Sim & $67 \%$ & $33 \%$ & \multirow{2}{*}{0,2663} \\
\hline & & Não & $64 \%$ & $36 \%$ & \\
\hline & \multirow{2}{*}{$\mathrm{P} 12$} & Sim & $68 \%$ & $32 \%$ & \multirow{2}{*}{0,3154} \\
\hline & & Não & $50 \%$ & $50 \%$ & \\
\hline & \multirow{2}{*}{$\mathrm{P} 13$} & Sim & $73 \%$ & $27 \%$ & \multirow{2}{*}{0,0613} \\
\hline & & Não & $38 \%$ & $63 \%$ & \\
\hline & \multirow{2}{*}{ P14 } & Sim & $71 \%$ & $29 \%$ & 00781 \\
\hline & & Não & $33 \%$ & $67 \%$ & $0,0 / 81$ \\
\hline
\end{tabular}

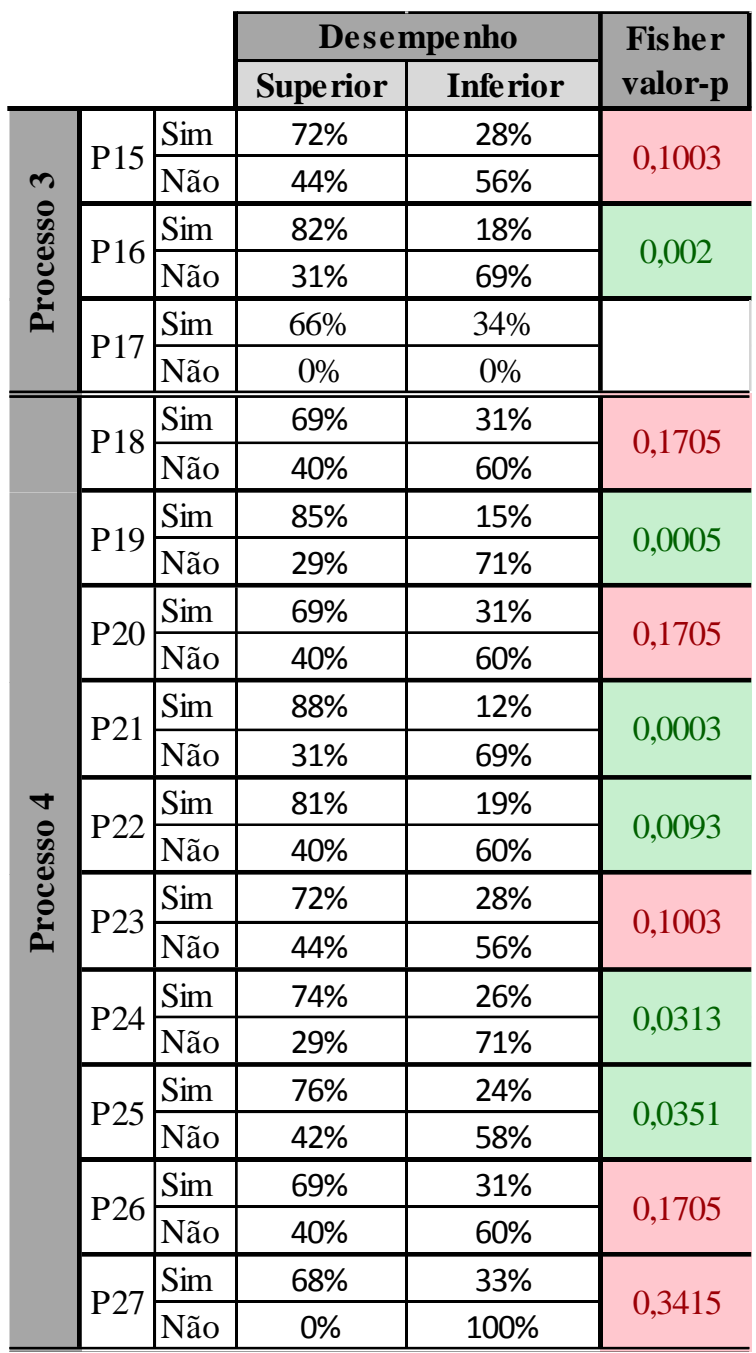


Tabela 9 - Teste exato de Fisher IPL x P28 a P41.

\begin{tabular}{|c|c|c|c|c|c|}
\hline & \multicolumn{2}{|c|}{ Desempenho } & \multirow{2}{*}{$\begin{array}{l}\text { Fisher } \\
\text { valor-p }\end{array}$} \\
\hline & & & Superior & Inferior & \\
\hline \multirow{12}{*}{ 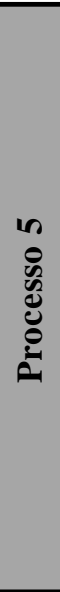 } & \multirow{2}{*}{ P28 } & Sim & $68 \%$ & $33 \%$ & \multirow{2}{*}{0,3415} \\
\hline & & Não & $0 \%$ & $100 \%$ & \\
\hline & \multirow{2}{*}{ P29 } & Sim & $77 \%$ & $23 \%$ & \multirow{2}{*}{0,009} \\
\hline & & Não & $30 \%$ & $70 \%$ & \\
\hline & \multirow{2}{*}{ P30 } & Sim & $69 \%$ & $31 \%$ & \multirow{2}{*}{0,2368} \\
\hline & & Não & $50 \%$ & $50 \%$ & \\
\hline & \multirow{2}{*}{ P31 } & Sim & $67 \%$ & $33 \%$ & \multirow{2}{*}{0,3552} \\
\hline & & Não & $66 \%$ & $34 \%$ & \\
\hline & \multirow{2}{*}{ P32 } & Sim & $80 \%$ & $20 \%$ & \multirow{2}{*}{0,0998} \\
\hline & & Não & $58 \%$ & $42 \%$ & \\
\hline & \multirow{2}{*}{ P33 } & Sim & $65 \%$ & $35 \%$ & \multirow{2}{*}{0,6847} \\
\hline & & Não & $75 \%$ & $25 \%$ & \\
\hline \multirow{16}{*}{ 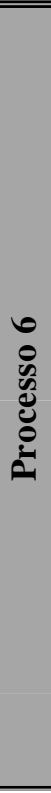 } & \multirow{2}{*}{ P34 } & Sim & $78 \%$ & $22 \%$ & \multirow{2}{*}{0,0034} \\
\hline & & Não & $22 \%$ & $78 \%$ & \\
\hline & \multirow{2}{*}{ P35 } & Sim & $69 \%$ & $31 \%$ & \multirow{2}{*}{0,111} \\
\hline & & Não & $0 \%$ & $100 \%$ & \\
\hline & \multirow{2}{*}{ P36 } & Sim & $77 \%$ & $23 \%$ & \multirow{2}{*}{0,009} \\
\hline & & Não & $30 \%$ & $70 \%$ & \\
\hline & \multirow{2}{*}{ P37 } & Sim & $81 \%$ & $19 \%$ & \multirow{2}{*}{0,0046} \\
\hline & & Não & $36 \%$ & $64 \%$ & \\
\hline & \multirow{2}{*}{ P38 } & Sim & $68 \%$ & $32 \%$ & \multirow{2}{*}{0,3154} \\
\hline & & Não & $50 \%$ & $50 \%$ & \\
\hline & \multirow{2}{*}{ P39 } & Sim & $50 \%$ & $50 \%$ & \multirow{2}{*}{0,555} \\
\hline & & Não & $57 \%$ & $43 \%$ & \\
\hline & \multirow{2}{*}{ P40 } & Sim & $68 \%$ & $32 \%$ & \multirow{2}{*}{0,3154} \\
\hline & & Não & $50 \%$ & $50 \%$ & \\
\hline & \multirow{2}{*}{ P41 } & Sim & $83 \%$ & $17 \%$ & \\
\hline & & Não & $25 \%$ & $75 \%$ & 0,0007 \\
\hline
\end{tabular}

Tabela 10- Teste exato de Fisher IPL x P42 a P54

\begin{tabular}{|c|c|c|c|c|c|}
\hline & \multicolumn{2}{|c|}{ Desempenho } & \multirow{2}{*}{$\begin{array}{l}\text { Fisher } \\
\text { valor-p }\end{array}$} \\
\hline & & & Superior & Infe rior & \\
\hline \multirow{16}{*}{ 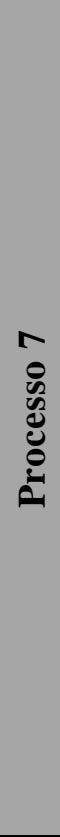 } & \multirow{2}{*}{ P42 } & Sim & $68 \%$ & $32 \%$ & \multirow{2}{*}{0,2305} \\
\hline & & Não & $33 \%$ & $67 \%$ & \\
\hline & \multirow{2}{*}{ P43 } & Sim & $65 \%$ & $35 \%$ & \multirow{2}{*}{0,6585} \\
\hline & & Não & $100 \%$ & $0 \%$ & \\
\hline & \multirow{2}{*}{ P44 } & Sim & $74 \%$ & $26 \%$ & \multirow{2}{*}{0,047} \\
\hline & & Não & $40 \%$ & $60 \%$ & \\
\hline & \multirow{2}{*}{ P45 } & Sim & $71 \%$ & $29 \%$ & \multirow{2}{*}{0,0341} \\
\hline & & Não & $0 \%$ & $100 \%$ & \\
\hline & \multirow{2}{*}{ P46 } & Sim & $68 \%$ & $32 \%$ & \multirow{2}{*}{0,3154} \\
\hline & & Não & $50 \%$ & $50 \%$ & \\
\hline & \multirow{2}{*}{ P47 } & Sim & $75 \%$ & $25 \%$ & \multirow{2}{*}{0,0251} \\
\hline & & Não & $33 \%$ & $67 \%$ & \\
\hline & \multirow{2}{*}{ P48 } & Sim & $81 \%$ & $19 \%$ & \multirow{2}{*}{0,0046} \\
\hline & & Não & $36 \%$ & $64 \%$ & \\
\hline & \multirow{2}{*}{ P49 } & Sim & $72 \%$ & $28 \%$ & \multirow{2}{*}{0,1003} \\
\hline & & Não & $44 \%$ & $56 \%$ & \\
\hline \multirow{10}{*}{ 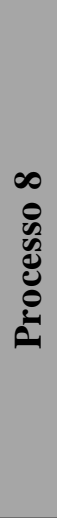 } & \multirow{2}{*}{ P50 } & Sim & $42 \%$ & $58 \%$ & \multirow{2}{*}{0,0351} \\
\hline & & Não & $76 \%$ & $24 \%$ & \\
\hline & \multirow{2}{*}{ P51 } & Sim & $91 \%$ & $9 \%$ & \multirow{2}{*}{0,0001} \\
\hline & & Não & $33 \%$ & $67 \%$ & \\
\hline & \multirow{2}{*}{ P52 } & Sim & $73 \%$ & $27 \%$ & \multirow{2}{*}{0,0613} \\
\hline & & Não & $38 \%$ & $63 \%$ & \\
\hline & \multirow{2}{*}{ P53 } & Sim & $78 \%$ & $22 \%$ & \multirow{2}{*}{0,0034} \\
\hline & & Não & $22 \%$ & $78 \%$ & \\
\hline & \multirow{2}{*}{ P54 } & Sim & $82 \%$ & $18 \%$ & \multirow{2}{*}{0,002} \\
\hline & & Não & $31 \%$ & $69 \%$ & \\
\hline
\end{tabular}

Visualizando as associações existentes, os mapas perceptuais construídos pela análise de correspondência múltipla (ACM) ilustram claramente quais grupos de municípios "Sim" / "Não" estão relacionados as categorias de desempenho "Superior" / "Inferior". Analisando as Figuras 36 e 37, onde os mapas estão organizados, examina-se que todas as práticas alocadas na região esquerda do Eixo 1 estão associadas ao desempenho "Superior" e as representadas na região direita do referido eixo estão relacionadas ao desempenho "Inferior" no controle de perdas de água. Em referência ao Processo 1- “Gerenciamento de pressão", entre as 24 práticas de controle que apresentaram associação pelo teste exato de Fisher, três estão localizadas dentro deste processo (P2, P4 e P6). 
Figura 36 - Mapa perceptual das classes de desempenho com as categorias das práticas dos Processos 1-4.
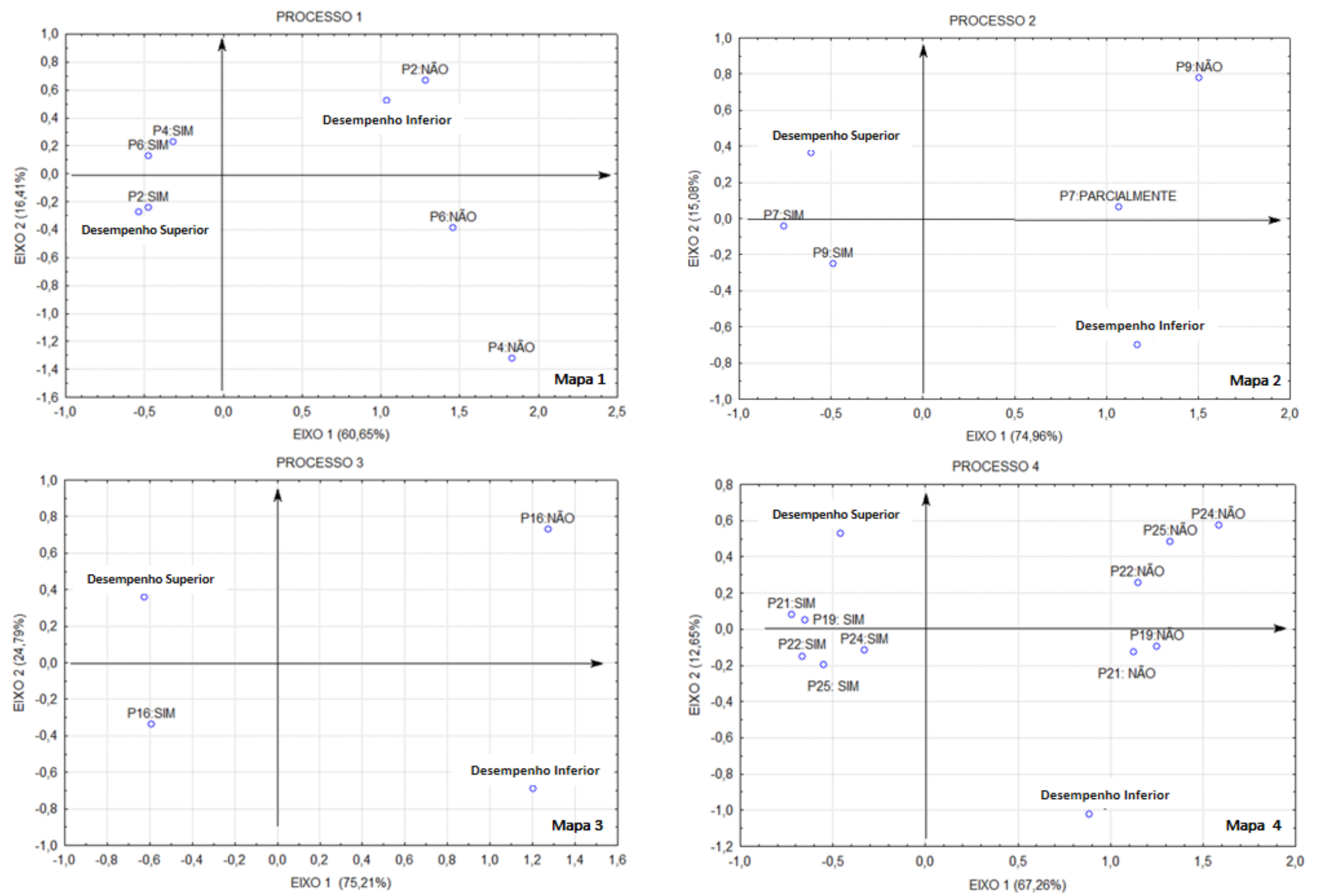
O Mapa perceptual 1 da ACM apresentado na Figura 36 demonstra que, dentro do Processo 1, ter um centro de telecontrole para acompanhar as pressões de água na rede (P2), reduzir a pressão de água no período noturno (P4) e contar com a automatização dos reservatórios (P6) são práticas relacionadas a ter um desempenho no controle de perdas “Superior” (IPL < 0,250 m³/ligação/dia), enquanto não as empregar está associado a ocorrência de níveis de perdas de água elevados. É possível analisar ainda, pela interpretação do Mapa 1, que a $\mathrm{P} 2$, considerada uma prática tecnológica ostensiva para o controle de perdas reais (BRASIL, 2014b) está mais próximo do ponto do "Desempenho Superior", o que sugere maior associação entre estas variáveis, em relação as outras duas práticas.

A respeito do Processo 2 - "Gerenciamento de Infraestrutura", a Tabela 7 e o Mapa perceptual 2 da Figura 36 demonstram que apenas duas práticas deste processo estão associadas ao IPL (P7 e P9). Salvo a associação de ambas as práticas, onde a aplicação da prática está relacionada a ocorrência de bons desempenhos e a não aplicação/aplicação parcial está associada ao desempenho inferior no controle de perdas de água, o teste de Fisher e a proximidade dos pontos da representação perceptual (Mapa 2), demonstram maior grau de associação da troca total dos ramais prediais antigo (P7) em relação ao cadastro georreferenciado das tubulações (P9), com os níveis de perdas.

No tocante ao Processo 3- "Controle da corrosão nas tubulações", a P17 que se refere a priorização do uso de materiais não metálico na troca das redes não foi considerada no teste exato de Fisher pois, tem aderência em 100\% das operadoras analisadas. Neste sentido, apenas a P15 e P16 foram analisadas nos testes, estando apenas a existência de revestimento externo da rede (P16) associada a ocorrência de desempenho superior no controle de perdas de água. Em relação ao Processo 4, onde foram investigadas a associação de práticas para o controle de vazamentos, a aplicação de 50\% das práticas (P19, P21, P22, P24 e P25) (Mapa 4 da Figura 36) tendem a produzir níveis baixos de perdas, ao passo que a não aplicação das mesmas refletem em níveis elevados.

Entre os oito processos de controle de perdas analisados, o Processo 5 apresenta a menor quantidade de práticas associadas, estando apenas a troca preventiva de hidrômetros (P29) relacionada ao "Desempenho Superior" quando empregada, à medida que a não adoção desta prática reflete em níveis de perdas de água mais elevados (Mapa 5 da Figura 37). A baixa associação das práticas deste processo pode ser justificada pela representatividade discrepante de municípios nos grupos "Sim" e "Não" das práticas 28, 30, 31 e 33. 
Figura 37 - Mapa perceptual das classes de desempenho com as categorias das práticas dos Processos 5-8.
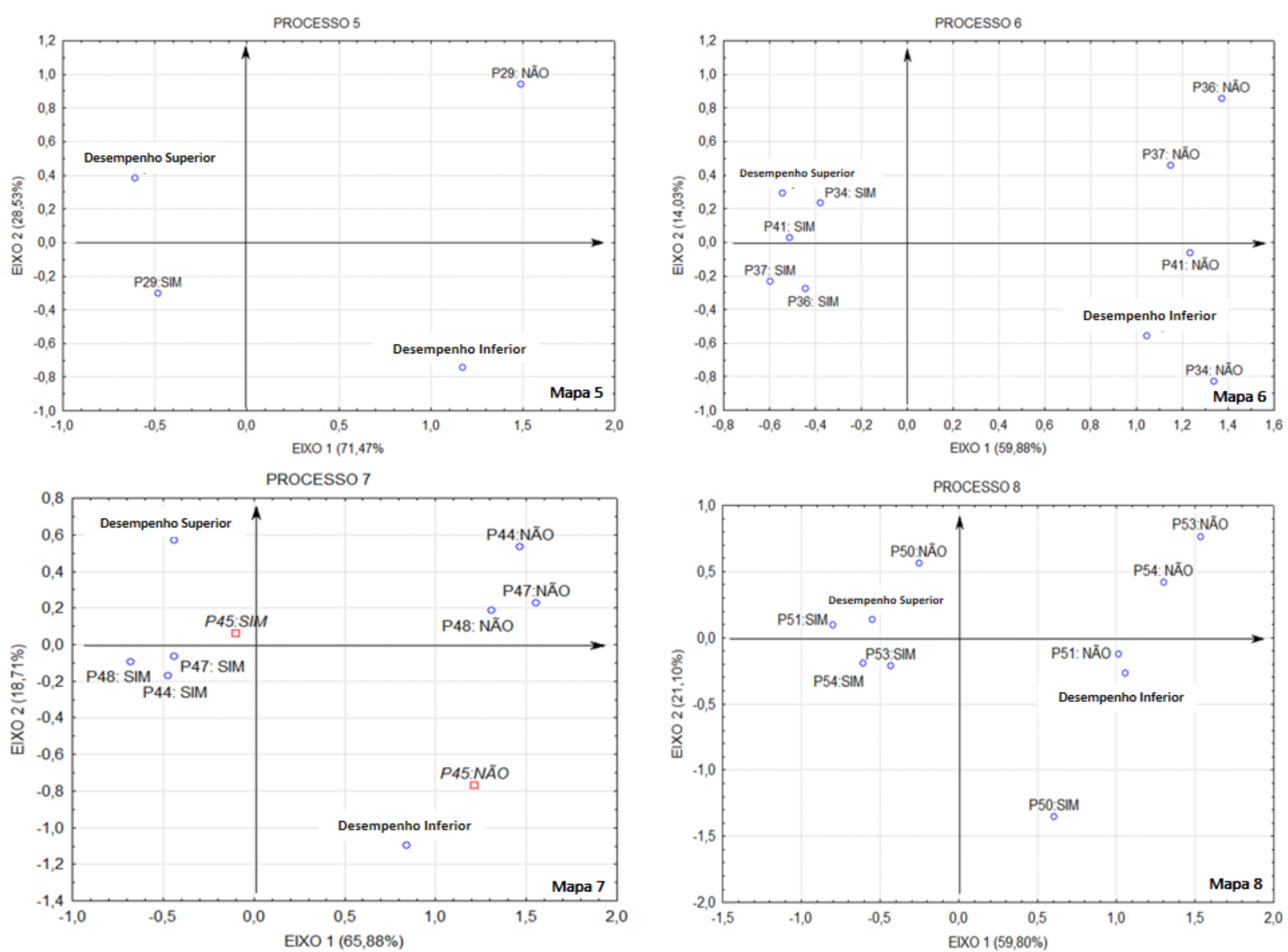
Examinando os valores-p do teste de Fisher, apresentadas previamente na Tabela 7, e o mapa perceptual do Processo 6 (Mapa 6 da Figura 37), vê-se que entre as quatro práticas que estão associadas ao IPL (P34, P36, P37 e P41), a proximidade dos pontos do Mapa 6 sugere que a realização de ações de conscientização populacional sobre fraudes e ligações clandestinas (P34), bem como a atualização anual do cadastro dos usuários, apresentam maior associação com as categorias de IPL ("Desempenho Superior" quando presentes e "Desempenho Inferior" quando ausentes).

Dados do Processo 7 indicam que quatro das oito práticas que o compõem estão associadas as categorias de IPL em estudo (P44, P45, P47, P48). Interpretando o Mapa perceptual 7, verifica-se que a P45, que prevê a existência de um diagnóstico, está representada em um formato distinto das demais visualizadas anteriormente. Este formato de representação demonstra que esta prática corresponde a uma variável suplementar que, apesar da baixa representatividade de dados para um dos grupos em análise, os testes de associação acusaram a existência de dependência entre a mesma e as categorias de IPL. Este aspecto verificado no mapa reforça o apresentado por Thornton et al. (2008) sobre a importância do entendimento das causas das perdas de água através de um diagnóstico do sistema que subsidie o planejamento de ações que conduzam a bons desempenhos no controle das perdas.

Por fim, ao passo que o Processo 5 é o que apresenta menor número de práticas associadas ao IPL, o Processo 8 se enquadra como o que apresenta o maior número de práticas de controle associadas, considerando o total que o compõem (4 em 5). Analisando o Mapa 8 (Figura 37) nota-se que todas as práticas seguem a mesma lógica identificada nos outros processos, onde a adoção da prática relaciona-se à categoria de "Desempenho Superior" enquanto a não aplicação associa-se a ocorrência do "Desempenho Inferior”, excetuando a P50. Como verificado na análise de comparação de médias, entre as 24 práticas cujo valor-p acusou a dependência das variáveis, a P50 apresenta uma associação negativa entre as variáveis (Tabela 10), uma vez que a maior proporção de municípios do grupo "Sim" está dentro da classe de “Desempenho Inferior" (58\%), enquanto a maior parcela de municípios que não empregam a prática se enquadram como com melhores desempenhos (76\%). Este aspecto reforça que pode haver um desperdício de recursos financeiros investidos em tecnologias de controle de perdas de água, que não produziram resultados efetivos na redução dos níveis de perdas seja pela instalação e uso inadequado de equipamentos ou até mesmo a não utilização do que foi adquirido com o investimento. 


\section{CONCLUSÕES}

O desenvolvimento desta pesquisa produziu contribuições em diferentes aspectos. Em primeira instância, buscando aplicar a técnica de benchmarking para avaliar o desempenho das operadoras no controle de perdas de água, a partir de um indicador específico, o trabalho vislumbrou selecionar um indicador para uso neste processo que fosse adequado à realidade dos sistemas de saneamento brasileiro, ou seja, um indicador que retratasse o cenário das perdas de água, utilizando dados básicos que possam ser gerados por qualquer sistema, por mais simples que seja sua operação.

A consulta aos especialistas do setor de saneamento demonstrou que os indicadores que se propõe a avaliar as perdas de água reais e aparentes de forma desagregada (um indicador específico para cada tipo de perda) são inexequíveis no contexto nacional geral pela indisponibilidade de dados para cálculo destes indicadores, uma vez que há eminente dificuldade das operadoras em controlar as perdas físicas, sendo irreal controlar as perdas aparentes que envolvem questões mais complexas. Nesta perspectiva, respaldado por pesquisas científicas que atestam sua eficiência na mensuração das perdas de água, o IPL foi o indicador selecionado para avaliar o desempenho das operadoras de saneamento que atuam nas Bacias PCJ. Apesar da seleção deste indicador para aplicação no contexto da área de estudo, o mesmo poderia ser empregado para analisar qualquer sistema de saneamento. Assim, os resultados produzidos nesta etapa da pesquisa fornecem um norte e um embasamento de como mensurar as perdas de água, considerando municípios que apresentam dificuldades no planejamento e monitoramento do setor.

A aplicação da metodologia de análise da credibilidade dos dados de volume de água proposta pelo PNCDA foi fundamental não só para eleger dados seguros, que quando aplicados ao IPL retratassem adequadamente o nível de perda de água dos municípios das bacias, mas também possibilitou explorar os diferentes níveis de credibilidade dos dados quando considerado a natureza jurídica da operadora de água municipal. Os produtos desta análise trazem um alerta aos Comitês de Bacias, Agências Reguladoras e outras entidades de interesse, sobre a necessidade de assistência aos municípios operados pela administração pública direta que, em alguns casos, a credibilidade dos dados adquirida foi classificada como "informação inutilizável", o que sugere que se há dificuldade na produção de dados operacionais básicos do sistema, o controle de perdas é inexistente pois, sem mensurar adequadamente o volume que entra em um sistema de distribuição (macromedição) é incoerente aferir quanto se perde. Esta metodologia se mostrou eficiente e aplicável, podendo ser replicada em outros estudos que visem analisar a genuidade dos dados básicos de operadoras de água. 
O cálculo do IPL dos municípios, considerando as categorias estabelecidas para fins da análise estatística aplicada (Desempenho Superior/Inferior) revelou que a maior proporção das operadoras dos municípios se enquadram como "Desempenho Superior" no controle das perdas de água na distribuição (68,3\%). Este aspecto se associa aos resultados da análise das práticas de controle de perdas de água empregadas pelas operadoras que denotam que os recursos investidos pelos Comitês PCJ no controle de perdas tem incentivado as operadoras de saneamento a adotarem práticas de controle, concentradas principalmente na troca de redes, estabelecimento de setores e instalação de válvulas redutoras de pressão e macromedidores, com o intuito de reduzir os níveis de perdas de água nas bacias. As respostas atribuídas ao Questionário B evidenciaram ainda que as práticas de "Planejamento Estratégico" são, na média, as mais empregadas pelas operadoras, à medida que as ações relacionadas à “Investimento e Inovação" tem menor aplicação.

A análise do IPL dos municípios por clusters, apontou que, considerando o porte dos municípios, natureza jurídica da operadora e existência/ausência de favelas, há diferenças significativas entre o IPL dos de pequeno porte (IPL menor) e grande porte (IPL maior), entre o IPL dos municípios autarquiados (IPL maior) e aqueles geridos por uma organização de economia mista (IPL menor) e por fim, verificou-se que IPL médio dos municípios que apresentam favelas é significativamente superior ao IPL dos que não apresentam, o que pode estar associado as fraudes e ligações clandestinas presentes nestas áreas.

$\mathrm{Na}$ mesma perspectiva de comparação de grupos, considerando a aplicação/não aplicação das práticas de controle, o teste de comparação de média aplicado na etapa de análise estatística demonstrou que entre todas as práticas $61,1 \%$ produzem impactos significativos nos níveis de perdas, onde há diferenças significativas no valor do IPL entre o grupo que adota uma prática ("Sim") e o grupo que não emprega a mesma ("Não").

Atendendo ao objetivo geral da pesquisa, os desempenhos das operadoras calculados pela técnica de benchmarking foram organizados em duas classes Classe A (Desempenho Superior) e Classe B (Desempenho Inferior) e cruzados com os grupos de municípios que aplicam/não aplicam as práticas. O cruzamento pelo teste exato de Fisher e análise de correspondência múltipla indicaram que 24 práticas de controle, localizadas na maior parte dentro do processo "Investimento e Inovação" estão associadas ao IPL, onde os mapas perceptuais ilustram que ter um "Desempenho Superior" depende da adoção da prática enquanto o "Desempenho Inferior" está associado a não a adotar. É importante assinalar nesta perspectiva que a associação das práticas com os desempenhos é fruto dos valores assumidos 
como "Superior" e "Inferior" nesta pesquisa. Possivelmente se a escala do valor do IPL fosse mais ou menos restritiva para a classificação dos desempenhos os resultados estatísticos da associação de práticas de controle poderiam ser diferentes dos encontrados neste trabalho.

As proximidades dos pontos do mapa perceptual sugerem que, dentro de cada processo, algumas práticas apresentam maior associação do que outras, sendo elas: Redução da pressão de água no período noturno (P2 - Processo 1); Troca dos ramais prediais antigos (P7 - Processo 2); Revestimento externo nas redes (P16 - Processo 3); Utilização de modelos computacionais/matemáticos de simulação para detecção de fugas (P21 - Processo 4); Troca preventiva de hidrômetros (P29 - Processo 5); Ações de conscientização populacional sobre fraudes e ligações clandestinas (P34 - Processo 6); Diagnóstico da situação das perdas (P45 Processo 7) e Adoção de metodologias como MASPP e Six Sigma (P51- Processo 8).

A identificação das práticas que estão associadas aos desempenhos superiores no controle de perdas de água pode orientar outras operadoras, não só nas Bacias PCJ, mas também em outras localidades, que buscam iniciar suas ações no controle de perdas de água. Porém a definição de quais práticas de controle de perdas de água aplicar não devem ater-se exclusivamente às assertivas deste estudo, haja visto o caráter exploratório do mesmo, sendo indispensáveis a realização de análises de custo benefício de quais práticas de controle produzirão melhores resultados à curto prazo e longo prazo para cada caso.

Por fim, independentemente da identificação de práticas de controle que estão associadas aos níveis de perdas, é imprescindível declarar a importância do mix entre as práticas de cada processo na obtenção de resultados mais eficientes e satisfatórios, considerando sempre as condições ambientais e econômicas de cada região na seleção das práticas. A gestão e controle das perdas são a chave para a melhoria das redes de abastecimento, onde a garantia do equilíbrio econômico de sua operação sujeita-se ao desenvolvimento de estratégias que estabeleçam um balanço na execução de todas as práticas de controle de perdas, sendo imprescindível considerar a viabilidade econômica de cada uma frente aos custos relacionados ao volume perdido e ao que será produzido em maior escala para atender a demanda assegurando a sustentabilidade econômica, social e ambiental dos serviços. 


\section{REFERÊNCIAS 29}

ABBOTT, M.; COHEN, B. Productivity and efficiency in the water industry. Utilities Policy, v. 17, n. 1, p. 233-244, 2009.

ABCON - Associação Brasileira das Concessionárias Privadas de Serviços Públicos de Água e Esgoto. Modelos de gestão em saneamento Concessões e Parcerias Público-Privada características e desafios. XII Simpósio Ítalo-Brasileiro de Engenharia Sanitária e Ambiental. Natal- RN. 27 p. 2014.

ABCON- Associação Brasileira das Concessionárias Privadas de Serviços Públicos de Água e Esgoto. Panorama da participação privada no saneamento - Brasil 2017. Edição Especial - Gestores Municipais. 100 p. 2017.

ABES - Associação Brasileira de Engenharia Sanitária e Ambiental. Perdas em sistemas de abastecimento de água: diagnóstico, potencial de ganhos com sua redução e propostas de medidas para o efetivo combate. 45p. 2013.

ABES. Associação Brasileira de Engenharia Sanitária e Ambiental. Controle e redução de perdas nos sistemas públicos de abastecimentos de água Posicionamentos e Contribuições Técnicas da Abes. 99 p. 2015.

ABNT. ASSOCIAÇÃO BRASILEIRA DE NORMAS TÉCNICAS. NBR 12218 - Projeto de rede de distribuição de água para abastecimento público. 4 p. 1994.

ABNT. ASSOCIAÇÃO BRASILEIRA DE NORMAS TÉCNICAS. NBR 14005 - Medidor velocimétrico para água fria, de $15 \mathrm{~m}^{\mathbf{3}} / \mathbf{h}$ até $1500 \mathbf{~ m}^{\mathbf{3}} / \mathbf{h}$ de vazão nominal. 13 p. 1997.

ABNT. ASSOCIAÇÃO BRASILEIRA DE NORMAS TÉCNICAS. NBR NM 212 -

Medidores velocimétricos de água potável fria até 15m³/h. 19 p. 1999.

ABNT. ASSOCIAÇÃO BRASILEIRA DE NORMAS TÉCNICAS. NBR 8194 - Medidores de água potável- Padronização. 11 p. 2013.

AÇÃO ECO CUENCAS. Mudança climática e crise hídrica os desafios da governança das águas nas bacias PCJ. 70 p. 2016.

ADASA - Agência Reguladora de Águas, Energia e Saneamento Básico do Distrito Federal. Abastecimento de Água - Conceito. [2015?] Disponível em:

http://www.adasa.df.gov.br/index.php?option=com_content\&view=article \&id=838\%3Aabast ecimento-de-agua\&catid=74\&Itemid=316 Acesso em: 02 jun. 2016

29 De acordo com a Associação Brasileira de Normas Técnicas (ABNT NBR 6023). 
ADERASA. Benchmarking en América Latina. Taller de Trabajo de Benchmarking de Empresas Públicas de Agua y Saneamiento en Centro América. Costa Rica: University of Florida, InterAmerican Development Bank. 41 p. 2007.

AESABESP - Associação dos Engenheiros da Sabesp. A necessidade de se reduzir as perdas. Revista Saneas. Ano XIII, Edição 55. 52 p. 2015.

AESBE/ASSEMAE - Associação das Empresas de Saneamento Básico Estaduais e Associação Nacional dos Serviços Municipais de Saneamento. Indicadores de Perdas nas Entidades Prestadores de Serviços Públicos de Saneamento, Documento Preliminar - $1^{\text {a }}$ Revisão. Brasília, DF,17p, 1998.

AGHTM. Rendement des Réseaux d'eau Potable. Définition des Termes Utilisés. Association Générale dos Hygiénistes et Techniciens Municipaux - AGHTM, Techniques Sciences Méthodes, 4 Bis, 22p. 1990.

ALEGRE, H.; COELHO, S.T. Infrastructure Asset Management of Urban Water Systems. In: “Water Supply System Analysis - Selected Topics". OSTFELD, A. (Ed.), InTech, p. 49-73, 2012.

ALEGRE, H.; COELHO, S.T.; ALMEIDA, M.; VIEIRA, P. Controlo de perdas de água em sistemas públicos de adução e distribuição. LNEC, IRAR e INAG. 328 p. 2005.

ALEGRE, H.; COVAS, D. Gestão patrimonial de infra-estruturas de abastecimento de água - Uma abordagem centrada na reabilitação. Série Guias Técnicos (16). ERSAE, LNEC, IST. 510 p. 2010.

ALEGRE, H.; HIRNER, W.; BAPTISTA, J.M.; PARENA, R. Performance indicators for water supply services. Internacional Water Association. London. 276 p. 2000.

ALVES, W. C.A.; COSTA, A.J.M.P.; SANCHEZ, J.G.; NIIDA, O.I. DTA D2 Macromedição. Programa Nacional de Combate ao Desperdício de água (SNSA). 82 p. 2003.

ANDREWS, G. R.; SCHNEIDER, F. B. Concepts and Notations for Concurrent Programming. Computing Surveys. V.15, n. 2, p. 3-43, 1983.

ANEEL. Agência Nacional de Energia Elétrica. Manual de gestão de processos Organizacionais da ANEEL. 69 p. 2012. Disponível em: < http://www2.aneel.gov.br/arquivos/PDF/manual_de_gestao_de_processos_rm_capa_2013_03 _15.pdf > Acesso em: 17 out. 2016.

ARAUJO, L. S. Controlo de Perdas na Gestão Sustentável dos Sistemas de Abastecimento de Água. Tese (Doutorado) - Universidade Técnica de Lisboa, Lisboa, 2005. 
ARAUJO, L.S.; RAMOS, H.; COELHO, S.T. Pressure Control for Leakage Minimisation in Water Distribution Systems Management. Water Resources Management. n.20, p. 133-149, 2006.

ARES-PCJ - Agência Reguladora dos Serviços de Saneamento das Bacias dos Rios Piracicaba, Capivari e Jundiaí. Resolução Ares-PCJ no 50 - Estabelece as Condições Gerais de Prestação dos Serviços Públicos de Abastecimento de Água Tratada e de Esgotamento Sanitário, no âmbito dos municípios associados à Agência Reguladora PCJ. 35 p. 2014.

ARREGUI, F.J.; MARTINEZ, B.; SORIANO, J.; PARRA, J.C. Tools for improving decision making in water meter Management. IWA Water Loss. Cidade do Cabo. 8 p. 2009.

ARSAE-MG - Agência Reguladora de Serviços de Abastecimento de água e de esgotamento sanitário do Estado de Minas Gerais. Resolução normativa no 003, de 07 de outubro de 2010. 43 p. 2010.

ARSESP - Agência Reguladora de saneamento e energia do estado de São Paulo. Deliberação Arsesp no 106, de 13 de novembro de 2009- Estabelece as condições gerais para a prestação e utilização dos serviços públicos de abastecimento de água e de esgotamento sanitário. 64 p. 2009.

\section{ASIAN PRODUCTIVITY IMPROVEMENT. Benchmarking- A Quality and Productivity}

Improvement Tool. Tokyo, Japan. 2001.

ATT (Association of Drinking Water from Reservoirs); BDEW (German Association of Energy and Water Industries); DBVW (German Alliance of Water Management Associations); DVGW (German Technical and Scientific Association for Gas and Water); DWA (German Association for Water, Wastewater and Waste); VKU (Association of Local Utilities). Profile of the German water industry (2005). 75 p. 2005.

ATT (Association of Drinking Water from Reservoirs); BDEW (German Association of Energy and Water Industries); DBVW (German Alliance of Water Management Associations); DVGW (German Technical and Scientific Association for Gas and Water); DWA (German Association for Water, Wastewater and Waste); VKU (Association of Local Utilities). Profile of the German water industry (2008). 107 p. 2008.

ATT (Association of Drinking Water from Reservoirs); BDEW (German Association of Energy and Water Industries); DBVW (German Alliance of Water Management Associations); DVGW (German Technical and Scientific Association for Gas and Water); DWA (German Association for Water, Wastewater and Waste); VKU (Association of Local Utilities). Profile of the German water industry (2011). 104 p. 2011. 
ATT (Association of Drinking Water from Reservoirs); BDEW (German Association of Energy and Water Industries); DBVW (German Alliance of Water Management Associations); DVGW (German Technical and Scientific Association for Gas and Water); DWA (German Association for Water, Wastewater and Waste); VKU (Association of Local Utilities). Profile of the German water industry (2015). 84 p. 2015.

AWWA - American Water Works Association. Committee Report: Water Accountability. AWWA Leak Detection and Water Accountability Committee. Journal AWWA, p.108-111, 1996.

AWWA - American Water Works Association. Water audits and loss control programs (Manual of water supply practices; M 36). 3rd ed. Denver, CO, 285 p. 2009.

AWWA - American Water Works Association. Water Loss Control - Apparent and Real Losses. 2 p. 2012. Disponível em:

<http://www.awwa.org/portals/0/files/resources/water\%20knowledge/water\%20loss\%20contr ol/apparent-real-losses-awwa-updated.pdf > Acesso em: 23. Jun. 2016.

AWWA - American Water Works Association. Benchmarking Performance Indicators for Water and Wastewater: 2013 Survey Data and Analyses Report. American Water Works Association. Denver. 2014.

BAGGIO, M. Como Formular e Executar Estratégia de Combate às Perdas, com Foco em Resultados? $1^{\circ}$ Seminário Nacional de Gestão e Controle de Perdas de Água - ABES, Porto Alegre. 2015.

BARROS FILHO, M.B.B.; SÁ, L.A.C.M.; GOMES, H.P. Utilização de SIG no monitoramento de avarias em redes de abastecimento de água. IV SEREA - Seminário Hispano-Brasileiro sobre Sistemas de Abastecimento Urbano de água. João Pessoa. 12 p. 2004.

BASTOS, C. C. O.; GOMES, H. P.; SILVA, J. S. O. P. "Reabilitação do sistema de abastecimento de água da cidade de Fundão - Brasil”, In: RAMOS, H. M., COVAS, D. I. C., GONÇALVES, F. V., SOARES, A. K. (eds). Alterações Climáticas e Gestão da Água e Energia em Sistemas de Abastecimento e Drenagem. $1^{a}$ ed., Lisboa, Portugal. p. 174-186. 2008 .

BDEW - German Association of Energy and Water Industries. Benchmarking: "Learning from the best" Comparison of performance indicators in the German water sector. 16 p. 2012. 
BERARDI, L.; LIU, S.; LAUCELLI, D.; XU, S.; XU, P.; ZENG, W.; GIUSTOLISI, O. Energy saving and leakage control in Water Distribution Networks: a joint research project between Italy and China. Procedia Engineering. v. 70, p. 152-161, 2014.

BERG, S. V. The art and science of Benchmarking: what will we take home. Conference on Global Developments in Water Industry Performance Benchmarking. Perth, Australia: Public Utilities Research Center. 2003.

BERG, S. Conflict Resolution: Benchmarking Water Utility Performance. Public Admin. Dev. n 27, p. 1-11. 2007

BERG, S. Water Utility Benchmarking: measurements, methodologies and performance incentives. IWA Publishing, London. 172 p. 2010.

BERG, S.; PADOWSKI, J.C. Overview of Water Utility Benchmarking Methodologies: From Indicators to Incentives. Public Utility Research Center, University of Florida. 8 p. 2007. Disponível em:

http://warrington.ufl.edu/centers/purc/purcdocs/papers/0712_Berg_Overview_of_Water.pdf.

Acesso em: 05 jul. 2016

BEZERRA, S.T.M.; CHEUNG, P.B. Perdas de água: tecnologias de controle. João Pessoa: Editora da UFPB, 220 p. 2013.

BHAGWAN, J. Benchmarking in the South African water services sector - a need for improving efficiencies and services delivery. Biennial Conference of the Water Institute of Southern Africa (WISA). 11 p. 2002.

BLOKLAND, M. "Benchmarking for Improved Water Utility Performance - course". Benchmarking water organizations. São Carlos: EESC/USP, 2013.

BONI, V.; QUARESMA, S.J. Aprendendo a entrevistar: Como fazer entrevistas em Ciências Sociais. Revista Eletrônica dos Pós-Graduandos em Sociologia Política da UFSC, v.2, nº 1, p.68-80, 2005.

BORDUQUE, M. Água subterrânea na terceirização de serviços de saneamento. X Encontro Nacional de Perfuradores de Poços. 21-31. 1997.

BOVO, A.; TOMISAWA, A.K.; FERREIRA, A.C.S; PEREIRA, L.G.; PAULO, P.F. Guia Prático - Técnicas para Controle e Redução de Perdas Aparentes - Processo Comercial. São Paulo, 139 p. 2008.

BRADEN, J.B.; MANKIN, P.C. Economic and Financial Management of Small Water Systems: Issue Introduction. Journal of Contemporary Water Research and Education, 128, p. 1-5, 2004. 
BRASIL. Lei No 2.848, de 7 de dezembro e 1940. Código Penal. Diário Oficial da União. 31.12.1940.

BRASIL. Constituição da República Federativa do Brasil. Brasília, DF: Senado Federal: Centro Gráfico, 292 p. 1988.

BRASIL. Lei No 8.666, de 21 de Junho de 1993. Regulamenta o art. 37, inciso XXI, da Constituição Federal, institui normas para licitações e contratos da Administração Pública e dá outras providências. Diário Oficial da União. 22.06.1993.

BRASIL. Resolução do Conselho Curador do FGTS nº 476 de 31 de maio 2005. Aprova o Programa Saneamento para Todos. Diário Oficial da União. 03.06.2005.

BRASIL. Lei $\mathrm{n}^{\circ} 11.445$, de 5 de janeiro de 2007. Estabelece diretrizes nacionais para o saneamento básico e dá outras providências. Brasília: Diário Oficial da União 08 jan. 2007. 2007.

BRASIL. Sistema Nacional de Informações sobre Saneamento. Glossário de Indicadores Água e Esgotos: Indicadores econômicos financeiros e administrativos. Brasília: SNSA/MCIDADES, 25 p. 2014.

BRASIL. Ministério da Saúde. Fundação Nacional de Saúde. Redução de perdas em sistemas de abastecimento de água. 2 ed. - Brasília: Funasa, 172 p. 2014 b.

BRASIL. Sistema Nacional de Informações sobre Saneamento. Diagnóstico dos Serviços de Água e Esgotos - 2016. Brasília: SNSA/MCIDADES, 220 p. 2018.

BRITOON, T.C.; STEWART, R.A.; O'HALLORAN, K.R. Smart metering: enabler for rapid and effective post meter leakage identification and water loss management. Journal of Cleaner Production. v.54, p. 166-176, 2013.

CABRERA JR, E.; DANE, P.; HASKINS, S.; THEURETZBACHER-FRITZ. Benchmarking Water Services: Guiding water utilities to excellence. IWA Publishing, London. 188 p. 2011.

CABRERA JR., E.; ARREGUI, R.; COBACHO, R.; TRULL, O. Practical Application of Metric Benchmarking in Water Supply Systems. Water Supply, v.2, n.4, p. 173-180. 2002.

CAMP, R. C. Benchmarking: identificando, analisando e adaptando as melhores práticas que levam à maximização da performance empresarial: o caminho da qualidade total. 3 . ed. São Paulo: Pioneira, 107 p. 1998.

CAMP, R.C. Best Practice Benchmarking: the Path to Excellence. GBN Review 2003/04. 6 p. 2003. 
CARPINETTI, L. C. R.; MELO, A. M. D. What to benchmark? A systematic approach and cases. Esmerald. Benchmarking: An international Journal, v. 9, n. 3, p. 244-255, 2002.

CARTEADO, F.; VERMERSCH, M. Apparent Water Losses generated by Unauthorised Consumption: Assessment and Corrective Actions. Water Loss Specialist Group of the International Water Association. 18 p. 2016.

CHAPMAN, S.K; LELES, A.L. Movimento pela Redução das Perdas de Água na Distribuição. Novos modelos de parceria em água e saneamento. Collaboration Lab Brasil. Campinas. 2015.

CHARALAMBOUS, B.; FOUFEAS, D. PETROULIAS, N. Leak detection and water loss management. Water Utility Journal, n. 8, p. 25-30, 2014.

CHAU-HUYEN, T.N.; NITIVATTANANON, V. Application of process benchmarking for urban water supply system: case of hue city, Vietnam. Proceedings: International

Conference on Sustainable Urban Environmental Practices. p. 3-18. 2008.

CHOI, Y.J.; AHN, J.C.; IM, H.T.; KOO, A. Best Management Practices for Water Loss Control in Seoul. Procedia Engineering, n. 89, p. 1585-1593, 2014.

COBRAPE. Planos das Bacias Hidrográficas dos Rios Piracicaba, Capivari e Jundiaí 2010 - 2020: Relatório Final. Piracicaba, 815 p. 2010 Disponível em: <http://www.comitepcj.sp.gov.br/download/PB/PCJ_PB-2010-2020_RelatorioFinal.pdf〉

COFEHIDRO - Conselho de Orientação do Fundo Estadual de Recursos Hídricos. Deliberação $\mathrm{n}^{\circ} 158$ de 23 de julho de 2015. Aprova novo Manual de Procedimentos Operacionais de Investimento. Diário Oficial do Estado. 30.07.2015.

COLE, I.S.; MARNEY, D. The science of pipe corrosion: A review of the literature on the corrosion of ferrous metals in soils. Corrosion Science. n. 56, p. 5-16, 2012.

CORTON, M.L. Benchmarking in the Latin American water sector: the case of Peru. Utilities Policy, v.11, p.133-142, 2003.

CORTON, M.L.; BERG, S.V. Benchmarking Central American water utilities. Utilities Policy, v. 17, p. 267-275, 2009.

CRIMINISI, A.; FONTANAZZA, C. M.; FRENI, G.; LA LOGGIA, G. Evaluation of the apparent losses caused by water meter under- registration in intermittent water supply. Water Science and Technology. v. 60, n. 9, p. 2373-2382, 2009. 
DANILENKO, A.; VAN DEN BERG, C.; MACHEVEM, B.; MOFFIT, L.J. The IBNET Water Supply and Sanitation Blue Book 2014. World Bank Group. 169 p. 2014.

DANCEY, C.; REIDY, J. Estatística Sem Matemática para Psicologia: Usando SPSS para Windows. Porto Alegre, Artmed. 608 p. 2006.

DAI, P.D.; LI, P. Optimal Localization of Pressure Reducing Valves in Water Distribution Systems by a Reformulation Approach. Water Resources Management. V. 28, p. 3057-3074. 2014.

DE ALBUQUERQUE, C. On the right track: good practices in realising the rights to water and sanitation. Lisboa, Portugal: ARSAR, 2012.

DELGADO-GALVÁN, X.; PÉREZ-GARCÍA, R.; IZQUIERDO, J.; MORA-RODRÍGUEZ, J. An analytic hierarchy process for assessing externalities in water leakage management. Mathematical and Computer Modelling. v. 52 (7-8), p. 1194-1202. 2010. DEMAJOROVIC, J.; CARUSO, C.; JACOBI, P.R. Cobrança do uso da água e comportamento dos usuários industriais na bacia hidrográfica do Piracicaba, Capivari e Jundiaí. Rev. Adm. Pública, v. 49, n. 5, p. 1193-1214, 2015.

D'ERCOLE, M.; RIGHETTI, M.; UGARELLI, R.M.; BERARDI, L.; BERTOLA, P. An integrated modeling approach to optimize the management of a water distribution system: improving the sustainability while dealing with water loss, energy consumption and environmental impacts. Procedia Engineering. v.162, p. 433-440, 2016.

DIGHADE, R.R.; KADU, M.S.; PANDE, A.M. Challenges in Water Loss Management of Water Distribution Systems in Developing Countries. International Journal of Innovative Research in Science, Engineering and Technology. v.3, n.6, p. 13838-13846. 2014.

DZIEDZIC, R.M.; KARNEY, B.W. Integrating data for water demand management. Procedia Engineering. v.70, p.583-591, 2014.

ELMUTI, D.; KATHAWALA, Y. An overview of benchmarking process: a tool for continuous improvement and competitive advantage. Benchmarking for Quality Management \& Technology. v.4, n.4, p. 229-243. 1997.

ENVIRONMENT CANADA. 2011 Municipal Water Use Report. 24 p. 2011.

EUROPEAN COMMISSION. EU Reference Document Good Practices on Leakage Management WFD CIS WG PoM. 117 p. 2015.

FANNER, P. V.; STURM, R.; THORNTON, J.; LIEMBERGER, R.; DAVIS, S. E.; HOOGERWERF, T. Leakage Management Technologies. AwwaRF. 380 p. 2007. 
FARAH, E.; SHAHROUR, I. Leakage Detection Using Smart Water System: Combination of Water Balance and Automated Minimum Night Flow. Water Resource Management. 13 p. 2017

FERREIRA, L. Do acesso à água e do seu reconhecimento como direito humano. Revista de Direito Público. Londrina, v.6, n.1, p.55-69, 2011.

FIGUEIRA, J.; ROY, B. Determining the weights of criteria in the ELECTRE type methods with a revised Simos' procedure. European Journal of Operational Research. n.139. p. 317-326. 2002.

FIGUEIREDO FILHO, D.B; SILVA JÚNIOR, J.A. Desvendando os Mistérios do Coeficiente de Correlação de Pearson. Revista Política Hoje. v.18, n,1, p.115- 146, 2009.

FRANGIPANI, M.; GOMES, A.S. Macromedição - Técnicas de operação em sistemas de abastecimento de água. Brasíli: SNSA, 81 p. 2007.

FRAUENDORFER, R.; LIEMBERGER, R. The issues and challenges of reducing nonrevenue water. Mandaluyong City, Philippines: Asian Development Bank, 51 p. 2010.

FREITAS, M.B.; BRILHANTE, O.M.; ALMEIDA, L.M. Importância da análise de água para a saúde pública em duas regiões do Estado do Rio de Janeiro: enfoque para coliformes fecais, nitrato e alumínio. Caderno Saúde Pública. v. 17, n. 3. p. 651-660. 2001.

FUNDAÇÃO AGÊNCIA DAS BACIAS PCJ. Atualização dos valores dos preços unitários básicos das cobranças PCJ - Relatório de Fundamentação. 199 p. 2013 a.

FUNDAÇÃO AGÊNCIA DAS BACIAS PCJ. Relatório de Gestão das Bacias PCJ -2013. Piracicaba: Gráfica Tempo/Agência PCJ. 100 p. 2013 b.

FUNDAÇÃO AGÊNCIA DAS BACIAS PCJ. Mapa dos projetos. 2017 [?]. Disponível em: $<$ http://www.agenciapcj.org.br/novo/projetos/mecanismo-de-abatimento/58-projetos/mapados-projetos > Acesso em: 19. Set. 2017.

FURUSAWA, R.T. Contribuição ao dimensionamento da rede de distribuição de água por critério de custo global. Dissertação. Escola Politécnica da Universidade de São Paulo. Departamento de Engenharia Hidráulica e Sanitária. 225 p. 2011.

GARCÍA-TODOLÍ, S.; IGLESIAS-REY, P.L.; MARTÍNEZ-SOLANO, F.J. Experimental Analysis of Proportional Pressure Reducing Valves for Water Distribution Systems. World Environmental and Water Resources Congress 2017. Asce. p. 635-647. 2017. 
GO ASSOCIADOS. Manual sobre Contratos de Performance e Eficiência para

Empresas de Saneamento do Brasil. Preparado para a International Finance Corporation IFC. 68 p. 2013.

GOMES, H. P.; BEZERRA, S. T. M. "Reabilitação de sistemas de distribuição de água”. In: GOMES H., GARCIA R., REY (eds). Abastecimento de Água - O Estado da Arte e

Técnicas Avançadas. 1a ed., João Pessoa, Brasil, Editora Universitária da UFPB. 2007.

GOMES, A. Montagem de Programas de Desenvolvimento Operacional. Seminário de Gestão Organizacional e Instrumentos de Planejamento. Controle e Avaliação. AESBE, 2012.

GOMES, H.P. Sistemas de Abastecimento de Água: Dimensionamento Econômico e Operação de Redes e Elevatórias. UFPB, $3^{\text {a }}$ ed., 277 p. 2009.

GOMES, R.; SOUSA, J.; MARQUES, A.S. The influence of pressure/leakage relationships from existing leaks in the benefits yielded by pressure management. Water Utility Journal. v.5, p. 25-32, 2013.

GONZÁLES-GÓMEZ, F.; MARTÍNEZ-ESPIÑEIRA, R.; GARCÍA-VALIÑAS, M.A.; GARCÍA-RUBIO, M.A. Explanatory factors of urban water leakage rates in Southern Spain. Utilities Policy. n.22, p.22-30, 2012.

GOMES, R.; SOUSA, J.; MURANHO, J.; SÁ MARQUES, A. Different design criteria for di strict metered areas in water distribution networks. Procedia Engineering. v.119, p. 12211230, 2015.

GUÉRIN-SCHNEIDER, L.; NAKHLA, M. Emergence of an innovative regulation mode in water utilities in France: between commission regulation and franchise bidding. European Journal of Law and Economics, 33(1), 23-45. 2012.

GUPTA, A.; BOKDE, N.; MARATHE, D.; KULAT, K. Leakage Reduction in Water Distribution Systems with Efficient Placement and Control of Pressure Reducing Valves Using Soft Computing Techniques. Engineering, Technology \& Applied Science Research. v.7, n. 2, p. 1528-1534, 2017.

HAIR JR. J.F.; BLACK, W.C.; BABIN, B.J.; ANDERSON, R.E.; TATHAM, R.L. Análise multivariada de dados. 6 ed. Porto Alegre: Bookman, 2009.

HAMILTON, S.; MCKENZIE, R.; SEAGO, C. A Review of Performance Indicators for Real Losses from Water Supply Systems. UK house of commons report. 9p. 2006.

HAMILTON, S.; MCKENZIE, R. Water Management and Water Loss. IWA Publishing. 204 p. 2014. 
HÄRDLE, W.; SIMAR, L. Applied multivariate statistical analysis. 2. ed. Berlin: Springer, 2007.

HENRIE, M.; CARPENTER, O.; NICHOLAS, E. Pipeline Leak Detection Handbook. Elsevier. 324 p. 2016.

HERNÁNDEZ-SANCHO, F.; MOLINOS-SENANTE, M.; SALA-GARRIDO, R.; DEL SAZ-SALAZAR, S. Tariffs and efficient performance by water suppliers: an empirical approach. Water Policy, v.14, n. 5, p. 854-864. 2012.

IBGE - Instituto Brasileiro de Geografia e Estatística. Censo 2010: Aglomerados Subnormais - Primeiros Resultados. Rio de Janeiro: 2011.

IBGE - Instituto Brasileiro de Geografia e Estatística. Censo Demográfico 2010. Rio de Janeiro, 2010.

IBNET - The International Benchmarking Network for Water and Sanitation Utilities.

IBNET Indicators. 2016. Disponível em: <https://www.ib-

net.org/en/texts.php?folder_id=100\&L=1\&S=2> Acesso em: 05 jul. 2016.

INMETRO - Instituto Nacional de Metrologia, Qualidade e Tecnologia. Portaria n 246 de 17 de outubro de 2000. Aprova o Regulamento Técnico Metrológico, que estabelece as condições a que devem satisfazer os hidrômetros para água fria, de vazão nominal até quinze metros cúbicos por hora. Diário Oficial da União. 17.10.2000.

INMETRO - Instituto Nacional de Metrologia, Qualidade e Tecnologia. Portaria n. ${ }^{\circ}$ 436, de 16 de novembro de 2011. Alterar o artigo $2^{\circ}$ da Portaria Inmetro $n^{\circ} 246 / 2000$. Diário Oficial da União. 16.11.2011.

JITONG, T.; JOTHITYANGKOON, C. Reducing water loss in a water supply system using a district metering area (DMA): A case study of the Provincial Waterworks Authority (PWA), Lop Buri Branch. Engineering and Applied Science Research. v.44, n. 3, p. 154-160, 2017.

JUNQUEIRA, R. F.; LAUTENSCHLAGER, S. R.; PAREDES, E. A. Aplicação de SIG na gestão da manutenção de redes de Distribuição de água. Congresso Brasileiro de Engenharia Sanitária e Ambiental, 25 p. 2009.

KALINKOV, P.; VLADOV, G.; RADOVANOV, V. Studies and procedures of water loss reduction in the water supply system of the town of Vidin. Water Utility Journal, n.1, p. 11$17,2011$. 
KANAKOUDIS, V.; GONELAS, K. Applying Pressure Management to Reduce Water Losses in Two Greek cities' WDSs: Expectations, Problems, Results and Revisions. Procedia Engineering. n.89, p.318-325, 2014.

KANAKOUDIS, V.; TSITSIFLI, S. Results of an urban water distribution network performance evaluation attempt in Greece. Urban Water Journal, v. 7, p. 267-285, 2010.

KANAKOUDIS, V.; TSITSIFLI, S.; SAMARAS, P. ZOUBOULIS, A.; BANOVEC, P. A new set of water losses-related performance indicators focused on areas facing water scarcity conditions. Desalination and Water Treatment. v. 51, p. 2994-3010, 2012.

KANG, D. Real-time optimal control of water distribution systems. Procedia Engineering. n.70, p. 917-923, 2014.

KARADÍREK, I.E. Urban water losses management in turkey: the legislation and challenges. Anadolu University Journal of Science and Technology A- Applied Sciences and Engineering. v.17, n.3, p. 572-584, 2016.

KINGDOM, B.; KNAPP, J.; LACHANCE, P.; OLSTEIN, M. Performance Benchmarking for Water Utilities. Denver: AWWA, 226 p. 1996.

KINGDOM, B.; LIEMBERGER, R. MARIN, P. The Challenge of Reducing Non-Revenue Water (NRW) in Developing Countries How the Private Sector Can Help: A Look at Performance-Based Service Contracting. The World Bank, Washington, DC. 52 p. 2006.

KLATT, K.U.; MARQUARDTB, W. Perspectives for process systems engineering - personal views from academia and industry. Computers and Chemical Engineering, n. 33, 536-550, 2009.

KÖELBL, J. Process benchmarking in water supply industry: The process of water loss management (WLM). PhD Thesis. Graz University of Technology, Austria. 203 p. 2009.

KÖELBL, J.; MAYR, H.; THEURETZBACHER-FRITZ, H.; NEUNTEUFEL, R.; PERFLER, R.; GANGL, G.; KAINZ, H.; HABERL, R. Experiences with Water Loss PIs in the Austrian Benchmarking Project. IWA Water Loss. Romania. 10 p. 2007.

KÖELBL, J.; MAYR, H.; THEURETZBACHER-FRITZ, H.; NEUNTEUFEL, R.; PERFLER, R. Austrian Case Study on Process Benchmarking of Water Loss Management. Second International Conference on Water Loss Management, Telemetry and SCADA in Water Distribution Systems. Ohrid, Macedonia. 10 p. 2008. 
KOO, D.; PIRATLA, K.; MATTHEWS, J.C. Towards Sustainable Water Supply: Schematic Development of Big Data Collection Using Internet of Things (IoT). Procedia Engineering, v.118, p. 489-497, 2015.

KUNKEL, G.P.E.; THORNTON, J.; STURM, R. Controlling Apparent Losses - Capturing Missing Revenue and Improving Consumption Data Integrity. In: Water Loss Control $2^{\circ} \mathrm{Ed}$. p. $155-170.2008$.

KURIAN, M.; MCCARNEY, P. Peri-urban Water and Sanitation Services: Policy, Planning and Method. Springer Science and Business Media, Springer Netherlands. 300 p. 2010.

KUROKAWA, E.; BORNIA, A.C. Utilizando a carta "X" para avaliação de dados diários da macromedição de um sistema de distribuição de água tratada. XXVIII Congresso

Interamericano de Ingeniería Sanitaria y Ambiental. 8 p. 2002.

LAMBERT, A. Losses from Water Supply Systems: Standard Terminology and Recommended Performance Measures. The blue pages. IWA. 13 p. 2000.

LANNIER, A.; PORCHER, S. Efficiency in the public and private French water utilities: prospects for benchmarking. Applied Economics. v.46, n. 5, p. 556-572, 2014.

LEÃO. N.F. PAIVA. E.B., RIBEIRO. A. J. Z e MATOS. L. C. A Importância da Implantação de Um Projeto de Micromedição Para o Desenvolvimento de Uma Política de Gestão, Controle e Redução de Perdas. Anais do $24^{\circ}$ Congresso da Associação Brasileira de Engenharia Sanitária, Belo Horizonte, Minas Gerais, Brasil, 2007.

LI, M.; LIU, Z.; CHEN, Y.; HAI, Y. Characteristics of iron corrosion scales and water quality variations in drinking water distribution systems of different pipe materials. Water Research. v. 106, n. 1, p. 593-603. 2016.

LIN, H.Y.; LIN, B.W.; LI, P.H.; KAO, J.J. The application of the cluster identification method for the detection of leakages in water distribution networks. Int. J. Environ. Sci. Technol. v. 12, n. 8, p. 2687-2696. 2015.

LISBOA, S.S.; HELLER, L.; SILVEIRA, R.B. Desafios do planejamento municipal de saneamento básico em municípios de pequeno porte: a percepção dos gestores. Eng. Sanit Ambient. 18 (4), 341-348. 2013.

LOUREIRO, J.M.S. Benchmarking entre os tribunais da relação portugueses - Custos correntes e desempenho funcional. Tribunal da Relação do Porto. 46 p. 2013. 
LOUREIRO, D.; ÁLVARES, A.; COELHO, S.T. Aplicação de sistemas de telemetria domiciliária em sistemas de distribuição de água. I Conferência INSSAA - Modelação de Sistemas de Abastecimento de água. 10 p. 2007.

MAIN, D.; NG, L.; NORTH, A. The Canadian national water and wastewater benchmarking initiative: Using process to drive improvement. IWA Publishing. Water Science \& Technology: Water Supply. v.6, n. 5, p. 111-121, 2006.

MAIRE, J.L.; BRONET, V.; PILLET, M. A typology of "best practices" for a benchmarking process. Benchmarking: An International Journal, v. 12, n. 1, p. 45-60, 2005.

MANN, S. R.; ABBAS, A.; KOHL, H.; ORTH, R.; GÖRMER, M. Global Survey on Business Improvement and Benchmarking. Germany: Global Benchmarking Network. 2010.

MARQUES, M.C.S.; HADDAD, J.; GUARDIA, E.C. Eficiência energética: teoria \& prática. Itajubá: Fupai. 244p. 2007.

MARQUES. R.C.; MONTEIRO, A.J. Application of performance indicators to control losses - results from the Portuguese water sector. Water Science and Technology: Water Supply. v. 3, n. 1-2, p. 127-133, 2003.

MBUVI, D.; WITTE, K.; PERELMAN, S. Urban water sector performance in Africa: a stepwise bias-corrected efficiency and effectiveness analysis. Utilities Policy, v. 22, 31-40. 2012.

MCCORMACK, C. H. Canadian Utilities Learn to Fly through Benchmarking of Water Loss Management. IWA Leakage, Conference Proceedings, Halifax, Canada. 6 p. 2005.

MCKENZIE, R. S.; WEGELIN, W. Implementation of Pressure Management in Municipal Water Supply Systems. IWA Presentation paper_0309. Pretoria, South Africa, IWA Publishing. 18 p. 2009.

MEADOWS, D. Indicators and information systems for sustainable development. The Sustainability Institute. 95 p. 1998. Disponível em: 〈http://www.iisd.org/pdf/s_ind_2.pdf> Acesso em: 25 jul. 2016.

MERKS, C.; TROW, S.; LAMBERT, A. Boas práticas na gestão de perdas de água. Jornal Água\&Ambiente. p. 26-27. 2016.

MILNES, D. Metric and Process Benchmarking for Utility Optimisation. Water Research Centre. 2006. Disponível em: <http://www.ewaonline.eu/tl_files/_media/content/documents_pdf/Publications/EWAter/documents/32_Pres_7_Milnes.pdf > Acesso em: 02 Set. 2016. 
MINISTÉRIO DA SAÚDE. Redução de Perdas em Sistemas de Abastecimento de Água. $2^{\circ}$ Edição. Brasília. 176 p. 2014.

MOLINARI, A. Panorama mundial. In: GALVÃO JUNIOR, A. C.; SILVA, A. C.

Regulação: indicadores para prestação de serviços de água e esgoto. Fortaleza: Expressão Gráfica Ltda.ARCE. p. 54-74. 2006.

MOLINOS-SENANTE, M.; MOCHOLÍ-ARCE, M.; SALA-GARRIDO, R. Estimating the environmentaland resource costs of leakage in water distribution systems: A shadow price approach. Science of the Environment, n.568, p.180-188, 2016.

MORAIS, D.C.; CAVALCANTE C.A.V.; ALMEIDA, A.T. Priorização de áreas de controle de perdas em redes de distribuição de água. Pesquisa Operacional, v.30, n.1, p.15-32, 2010.

MORAIS, D.C.; ALMEIDA, A.T. Modelo de Decisão em Grupo para Gerenciar Perdas de Água. Pesquisa Operacional. v. 26, p. 567-584, 2006.

MORRISON, J.; TOOMS, S.; ROGERS, D. District Metered Areas Management to Monitor and Reduce Leakage. DMA Management Guindance Notes. IWA, 100 p., 2007.

MOURA, E. M.; DIAS, I. C. S.; SILVA, J. S.; SILVA, F. C. Abordagem sobre perdas de água em sistemas de abastecimento: breve explanação sobre os tipos e principais causas. In:

IV SEREA - Seminário Hispano-Brasileiro sobre Sistemas de Abastecimento Urbano de Água. João Pessoa, 2004.

MURANHO, J.; FERREIRA, A.; SOUSA, J.; GOMES, A.; SÁ MARQUES, A. Technical performance evaluation of water distribution networks based on EPANET. Procedia Engineering, v. 70, p. 1201-1210, 2014.

MURUNGI, C.; BLOKLAND, M.W. Benchmarking for the provision of water supply and sanitation services to the urban poor: an assessment framework. International. Journal of Water. v.10, p.155-174, 2016.

MUTIKANGA, H. E.; SHARMA, S. K.; VAIRAVAMOORTHY, K.; CABRERA JR., E. Using performance indicators as a water loss management tool in developing countries. Journal of Water Supply, Research and Technology -AQUA. P. 471-481, 2010.

MUTIKANGA, H. E.; SHARMA, S. K.; VAIRAVAMOORTHY, K. Assessment of apparent losses in urban water systems. Water and Environment Journal. v. 25, p. 327-335, 2011. Methods and tools for managing losses in water distribution systems. Journal of Water Resources Planning and Management. v.139, p. 166-174, 2013. 
MUTIKANGA, H. Water Loss Management: Tools and Methods for Developing Countries. UNESCO-IHE, the Netherlands. 276 p. 2012.

NEVES, M.G.F.; NOGUEIRA, P.L. Estudo de caso de economia de água em um edifício residencial no bairro de Campo Limpo. III Simpósio Internacional de Gestão de Projetos. 10 P. 2014.

NICOLINI, M.; ZOVATTO, L. Optimal Location and Control of Pressure Reducing Valves in Water Networks. Journal of Water Resources Planning and Management. v.135, n. 3, p. 178-187. 2009.

NWWBI - National water e wastewater benchmarking initiative. Public Report 2013. Aecom. 87 p. 2013.

OLIVEIRA, F.G.R.; REIS, F.A.G.V.; GIORDANO, L.C.; MEDEIROS, G.A. Controle de perdas em sistema de abastecimento de água: O Caso do município de Poços de Caldas (MG). Engenharia Ambiental - Espírito Santo do Pinhal. v.6, n. 1, p. 309-320, 2009.

OLIVEIRA, E. Saneamento em áreas irregulares: qual o caminho? Assemae. 2016. Disponível em: 〈http://www.assemae.org.br/artigos/item/1515-saneamento-em-areasirregulares-qual-o-caminho> Acesso em: 09 ago. 2016.

OLIVEIRA, G.; SCAZUFCA, P.; MARCATO, F.S.; ORJUELA, G.; AROUCA, L.F.A.; AGUIAR, S.S. Perdas de Água: Desafios ao Avanço do Saneamento Básico e à Escassez Hídrica. GO Associados. 113 p. 2015. Disponível em:

〈http://www.tratabrasil.org.br/datafiles/estudos/perdas-de-agua/Relatorio-Perdas-2013.pdf > Acesso em: 26 mai. 2016.

ONU- Organização das Nações Unidas. Objetivos de Desenvolvimento Sustentável. 49 p. 2015. Disponível em: < https://nacoesunidas.org/wp-content/uploads/2015/10/agenda2030-ptbr.pdf> Acesso em: 04 Ago. 2016.

PARRA, S.; KRAUSE, S.; KRONLEIN, F.; GUNTHERT, F.W.; KLUNKE, T. Intelligent pressure management by pumps as turbines in water distribution systems: results of experimentation. Water Science \& Technology: Water Supply. IWA Publishing. 12 p. 2017.

PARENA, R.; SMEETS, E. Benchmarking Initatives in the Water Industry. Water Science and Technology 44(2-3), p. 103-110, 2001.

PARENA, R.; SMEETS, E.; TROQUET, I. Process Benchmarking in the Water Industry. International Water Association. 62 p. 2002. 
PARRA, S.; KRAUSE, S. Pressure management by combining pressure reducing valves and pumps as turbines for water loss reduction na energy recovery. Int. Sus. Dev. Plann. v.12, n.01, p. 89-97, 2017.

PEREIRA, L.G.; ILHA, M.S.O. Avaliação da submedição de água em edificações residenciais unifamiliares: o caso das unidades de interesse social localizadas em Campinas, no estado de São Paulo. Ambiente Construído. v.8, n.2, p. 7-21. 2008.

PIECHNICKI, A.S.; KOVALESKI, J.L.; SOUZA, M.V.; PIECHNICKI, F.; BARAN, L.R. Utilização da metodologia de análise e solução de problemas na redução das perdas de água: Um estudo de caso na SANEPAR. Revista de Engenharia e Tecnologia, v. 3, n. 2, p. 90-99. 2011.

PINTO, V.C. A Privatização do Saneamento Básico. Consultoria Legislativa. 12 p. 2003.

PMSS - Programa de Modernização do Setor de Saneamento. Programa Nacional Combate ao Desperdício Água - PNCDA. 2015a. Disponível em: < http://www.pmss.gov.br/index.php/biblioteca-virtual/programa-nacional-combate-aodesperdicio-agua-pncda> Acesso em: 15 Ago. 2016.

PMSS - Programa de Modernização do Setor de Saneamento. Projeto COM+ÁGUA Apresentação. 2015b. Disponível em: <http://www.pmss.gov.br/index.php/projeto-comagua/apresentacao> Acesso em: 15 Ago. 2016.

PNCDA - Programa Nacional de Combate ao desperdício de água. Documento Técnico de Apoio $n^{0}$ A2 - Indicadores de perdas nos sistemas de abastecimento de água. Ministério das Cidades, Secretaria Nacional de Saneamento Ambiental. Brasília, DF. 80 p. 2003.

PNQS - Prêmio Nacional de Qualidade no Saneamento. O Prêmio. 2017[?]. Disponível em: < http://abes-dn.org.br/pnqsnew/institucional/> Acesso em: 28/06/2017.

PNUD - Programas das Nações Unidas para o Desenvolvimento. Movimento pela redução da perda de água é lançado em Brasília. 2015. Disponível em: < http://www.pnud.org.br/Noticia.aspx?id=4215> Acesso em: 04 Ago. 2016.

POHLMANN, P.H.M.; FRANCISCO, A.A.; FERREIRA, M.A.; JABBOUR, C.J.C. Tratamento de água para abastecimento humano: contribuições da metodologia Seis Sigma. Eng. Sanit. Ambient. v.20, n.3, p. 485-492. 2015.

RAUEN, V.A.B.; GROHMANN, C.H.; GOVEIA, S.S.; MIOTO, C.L.; MARINI, L.B.; PARANHOS FILHO, A.C.; ALMEIDA, M.H.T. Geotecnologias na determinação da vulnerabilidade à ocorrência de vazamentos em redes de abastecimento de água. Geociências. v.35,n.3, p. 414-425, 2016. 
ReCESA - Rede Nacional de Capacitação e Extensão Tecnológica em Saneamento Ambiental. Abastecimento de água: gerenciamento de perdas de água e energia elétrica em sistemas de abastecimento: guia do profissional em treinamento: nível 2. Secretaria Nacional de Saneamento Ambiental (org). Salvador: ReCESA, 139p. 2008.

RENZETTI, S.; DUPONT, D. Buried Treasure: The Economic of Leak Detection and Water Loss Prevention in Ontario. Environmental Sustainability Research Centre - ESRC, Brock University. Working Paper Series, 14 p. 2013.

REZAEI, H.; RYAN, B.; STOIANOV, I. Pipe failure analys is and impact of dynamic hydraulic conditions in water supply networks. Procedia Engineering. n.119, p. 253-262. 2015.

REZENDE, D.A. Planejamento Estratégico para organizações privadas e públicas: guia prático para elaboração do projeto de plano de negócios. Rio de Janeiro:Brasport. 160 p. 2008.

RIOS, J.C.; SANTOS-TELLEZ, R.U.; RODRIGUEZ, P.H.; LEYVA, E.A.; MARTÍNEZ, V.N. Methodology for the identification of apparent losses in water distribution networks. Procedia Engineering. v.70, p. 238-247, 2014.

ROGERS, D. Leaking water networks: an economic and environmental disaster. Procedia Engineering. n. 70, p. 1421-1429, 2014.

ROSSIGNEUX, N. V. Q.; FERNANDES, C. V. S. Estabelecendo a importância relativa do controle de perdas em redes de distribuição de água - o exemplo de uma rede hipotética. In:

IV SEREA - Seminário Hispano-Brasileiro sobre Sistemas de Abastecimento Urbano de Água. João Pessoa, 2004.

SABESP. Situação dos Mananciais. 2016. Disponível em: < http://www2.sabesp.com.br/mananciais/DivulgacaoSiteSabesp.aspx > Acesso em: 04 Ago. 2016.

SALAMONI, S.S.; DELLA, J.P.; BACK, A.J. Avaliação das perdas na distribuição de água: estudo de caso em São Bento Baixo, Nova Veneza -SC. Revista Tecnologia e Ambiente, v.20, p. 93-106, 2014.

SALDARRIAGA, J.; SALCEDO, C.A. Determination of optimal location and settings of Pressure Reducing Valves in Water Distribution Networks for minimizing water losses. Procedia Engineering. n.119, p. 973-983. 2015.

SANTOS, D.D.; MONTENEGRO, S.M.G.L. Avaliação da metodologia para controle de perdas de água em rede de distribuição no Recife-PE. Revista DAE. nº 197, 56-70 p. 2014. 
SANTOS, A.C.P.A.; PEREIRA, J.A.R. Controle e espacialização dos pontos de vazamentos em redes de distribuição de água de áreas urbanas: caso do $3^{\circ}$ setor de distribuição de água da Região Metropolitana de Belém. Revista Eletrônica em Gestão, Educação e Tecnologia Ambiental. v.19, n.2. p. 1439-1451. 2015.

SANTOS, A.C.P.A.; PEREIRA, J.A.R. SIG no gerenciamento de SAAS. Revista DAE. $\mathrm{n}^{\circ}$ 202, p. 76- 86 p. 2016.

SÃO PAULO. Decreto $n^{\circ} 61.430$ de 17 de agosto de 2015. Aprova e fixa os valores a serem cobrados pela utilização dos recursos hídricos de domínio do Estado de São Paulo na Unidade de gerenciamento de recursos hídricos Piracicaba Capivari e Jundiaí. 2015. DOE 18/08/2015. Disponível em: 〈http://www.agenciapcj.org.br/docs/cobranca/DecretoSP 61430-2015.pdf> Acesso em: 18 ago. 2016.

SCALIZE, P.S.; LEITE, W.C.A.; CAMPOS, M.A.S. Substituição Racional de Hidrômetros em sistemas de abastecimento de água. Revista Eletrônica de Engenharia Civil. v.9, n.3, p. 1-9. 2014.

SCHNEIDER, D.D.; SANTOS, R.; MARTINEZ, R.C.; COUTINHO, S.M.V.; MALHEIROS, T.F.; TEMÓTEO, T.G. Indicadores para serviços de abastecimento de água e esgotamento sanitário voltados às populações vulneráveis. Revista Brasileira de Ciências Ambientais. n.17, p.65-76, 2010.

SCHOUTEN, M.; HALIN, R.D. Resolving strategy paradoxes of water loss reduction: A synthesis in Jakarta. Resources, Conservation and Recycling. n.54, p. 1322-1330. 2010.

SEPPÄLÄ, O.T. Performance benchmarking in Nordic water utilities. Procedia Economic and Finance, n.21, p. 399-406, 2015.

SEYOUM, S.; ALFONSO, L.; ANDEL, S.J.; KOOLE, W.; GROENEWEGEN, A.; GIESEN, N. Shazam-like household water leakage detection method. Procedia Engineering. n. 186, p. 452-459. 2017.

SHARMA, S. Performance Indicator of Water Losses in Distribution System. UNESCOIHE. Delft, The Netherlands. 19 p. 2008.

SICHE, R.; AGOSTINHO, F.; ORTEGA, E.; ROMEIRO, A. Índices versus indicadores: precisões conceituais na discussão da sustentabilidade de países. Revista Ambiente \& Sociedade. v.10, n.2, p. 137-148, 2007.

SILVA, B.O.C.; MONTEIRO, C.O.; TORRES, C.G.V.; SHINZATO, E.; MOKARZEL, F.C.; GUIBOSHI, M.; PELLEGRINI, T.C. Controle de perdas de água em sistemas de distribuição. 
PHD 2537 - Água em ambientes urbanos. Escola Politécnica da Universidade de São Paulo. 14 p. 2003.

SIMOS, J .L'evaluation environnementale: Un processus cognitif négocié. Thèse de doctorat, DGF-EPFL, Lausanne. 1990a.

SIMOS, J. Evaluer l'impact sur l'environnement: Une approche originale par l'analyse multicritère et la négociation. Presses Polytechniques et Universitaires Romandes,Lausanne. 1990b.

SINGH, R. Pipeline Integrity Handbook - Risk Management and Evaluation. Elsevier. 303 p. 2014.

SNIS - Sistema Nacional de Informação sobre Saneamento. SNIS Série História. 2016. Disponível em: 〈http://app.cidades.gov.br/serieHistorica> Acesso em: 09 Set. 2016.

SNSA - Secretaria Nacional de Saneamento Ambiental. Plano Nacional de Saneamento Básico - Mais saúde com qualidade de vida e cidadania. Brasília. 220 p. 2014.

SOARES, C.H.G.; BATISTA, T.C.; FREIRE, R.C.S.; LUCIANO, B.A.; ARAUJO, M.P. Utilização de macromedidores eletromagnéticos em sistemas de abastecimento de água. IX Semetro. 5 p. 2011.

SOBRINHO, R.A.; BORJA, P.C. Gestão das perdas de água e energia em sistema de abastecimento de água da Embasa: um estudo dos fatores intervenientes na RMS.

Engenharia Sanitária e Ambiental. v.21, n. 4, p. 783- 795, 2016.

SOLDEVILA, A.; BLESA, J.; TORNIL-SIN, S.; DUVIELLA, E.; FERNADEZ-CANTI, R.; PUIG, V. Leak localization in water distribution networks using a mixed model-based/datadriven approach. Control Engineering Practice. n.55, p. 162-173, 2016.

SOUZA, E.V.; SILVA, M.A.C. Management system for improving the efficiency of use water systems water supply. Procedia Engineering. v.70, p.458-466, 2014.

STAHRE, P.; ADAMSSON, J. Performance benchmarking. A powerful management tool for water and wastewater utilities. WATERMARQUE. 3.5. 2004.

STAPENHURST, T. The benchmarking book: A how-to-guide to best practice for managers and practitioners. Oxford: Elsevier, 496 p. 2009.

STORTO, C. L. Benchmarking operational efficiency in the integrated water service provision: Does contract type matter? Benchmarking: An International Journal, v. 21, n. 6, p. 917-943, 2014. 
STURM, R.; THORNTON, J.; KUNKEL, G.P.E. Controlling Real Losses in the FieldProactive Leak Detection. In: Water loss control manual. $2^{\text {nd }}$ ed. New York: Mc Graw-Hill. p. 259-294. 2008.

STURM, R.; GASNER, K.; WILSON, T.; PRESTON, S. Real Loss Component Analysis: A Tool for Economic Water Loss Control. Water Research Foundation - WRF. 173 p. 2014.

TARDELLI FILHO, J. Aspectos relevantes do controle de perdas em sistemas públicos de abastecimento de água. Revista DAE. v.64, nº 201, 6-20. 2016.

SWIETLIK, J.; RACZYK-STANISLAWIAK, U.; PISZORA, P.; NAWROCKI, J. Corrosion in drinking water pipes: the importance of green rusts. Water Research. v. 46, 1-10. 2012

TEUTEBERG, F.; KLUTH, M.; AHLEMAN, F.; SMOLNIK, S. Semantic process benchmarking to improve process performance. Benchmarking: An International Journal. v. 20, n. 4, p. 484-511, 2013.

THE WORLD BANK. Reducing Water Loss in Developing Countries Using performance-Based Service Contracting. Water Sector Board Practitioner Notes (P- notes), v. 4, p. 1-4, 2008.

THORNTON, J.; STHURM, R.; KUNKEL, G. Water loss control manual. $2^{\text {nd }}$ ed. New York: Mc Graw-Hill, 632p. 2008.

TONETO JÚNIOR, SAIANI, C.C.S.; RODRIGUES, R.L. Perdas de água: entraves ao avanço do saneamento básico e riscos de agravamento à escassez hídrica no Brasil. Fundace. 52 p. 2013. Disponível em: <

http://prattein.com.br/home/images/stories/230813/Desenvolvimento_Sustentavel/estudo_per das gua.pdf> Acesso em: 04 Ago. 2016.

TSUTIYA, M. T. Abastecimento de água. $3^{\text {a }}$ edição. São Paulo - Departamento de Engenharia Hidráulica e Sanitária da Escola Politécnica da Universidade de São Paulo. 659 p. 2006.

UNITED NATIONS DEVELOPMENT PROGRAMME. Beyond scarcity: Power, poverty and the global water crisis [Human Development Report 2006]. United Nations. New York, USA, p. 440. 2006.

VAN DEN BERG, C. Drivers of non-revenue water: A cross-national analysis. Utilities Policy, v. 36, p. 71-78, 2015. 
VAN DEN BERG, C.; DANILENKO, A. The IBNET Water Supply and Sanitation Performance Blue Book: The International Benchmarking Network for Water and Sanitation Utilities Databook. The World Bank. Washington, D. C., p. 176. 2011.

VAN DIJK, M.P.; BLOKLAND, M.W. Introduction and reflection on benchmarking for the delivery of water and sanitation services to the urban poor. International Journal of Water. v.10, p. 109- 121, 2016. Disponível em: http://ocw.unescoihe.org/pluginfile.php/3954/mod_resource/content/1/IJW10020301\%20Van\%20Dijk\%20\%20Blokland.pdf Acesso em: 06 jul. 2016.

VENTURI, M.A.A.G.; BARBOSA, P.S.F. Subsídios à escolha de técnicas de reabilitação de redes de distribuição de água. Seminário- Planejamento, Projeto e Operação de Redes de Abastecimento de Água: O Estado da Arte e Questões. 14 p. 2002.

VERDE, D.; CIMA, E.; FERRANTE, M.; BRUNONE, B.; MENICONI, S. The Dependence of District Minimum Night Flow on Pressure Head: The case study of Lenola. Procedia Engineering. v.89, p. 1224-1230, 2014.

VILANOVA, M. R. N.; MAGALHÃES FILHO, P.; BALESTIERI, J. A. P. Performance measurement and indicators for water supply management: Review and international cases. Renewable and Sustainable Energy Reviews, n. 43, p. 1-12, 2015.

WATER AND SANITATION PROGRAM. A review in Bangladesh, India, and Pakistan: Bencharking for performance improvement in urban utilities. The World Bank. Dhaka, Bangladesh, p. 52. 2010.

WATSON, G.H. How process benchmarking supports corporate strategy. Planning Review. v.21, n.1, p.12-15, 1997.

WIRNARNI, W. Infrastructure Leakage Index (ILI) as Water Losses Indicator. Civil Engineering Dimension. v.11, n.2, p. 126-134, 2009.

WORLD BANK, Managing Urban Water Supply and Sanitation: Operation and Maintenance. Department of Operations Evaluation, 2001.

WORLD HEALTH ORGANIZATION; UNITED NATIONS INTERNATIONAL CHILDREN'S EMERGENCY FUND. Drinking Water Equity, Safety and Sustainability: Thematic Report on Drinking [Joint Monitoring Programme for Water Suply and Sanitation]. WHO/UNICEF/UN. Geneva, Switzerland, p. 24. 2011.

WRIGHT, R.; ABRAHAM, E.; PARPAS, P.; STOIANOV, I. Optimized control of pressure reducing valves in water distribution networks with dynamic topology. Procedia Engineering. v. 119, p. 1003-1011, 2015. 
XU, Q.; LIU, R.; CHEN, Q.; LI, R. Review on water leakage control in distribution networks and the associated environmental benefits. Journal of Environmental Sciences. v.26, p. 955961, 2014.

YOSHII, M.P.C. Práticas que promovem o acesso aos serviços de abastecimento de água e esgotamento sanitário em aglomerados subnormais no município de Piracicaba -SP. Dissertação. Escola de Engenharia de São Carlos: EESC/USP. 120 p. 2017.

ZYOUD, S.H.; KAUFMANN, L.G.; SHAHEEN, H.; SAMHAN, S.; FUCHS-HANUSCH, D. A framework for water loss management in developing countries under fuzzy environment: Integration of Fuzzy AHP with Fuzzy TOPSIS. Expert Systems with Applications. n.6, p. 86-105, 2016. 


\section{APÊNDICE I}

\section{QUESTIONÁRIO A - DADOS OPERACIONAIS}

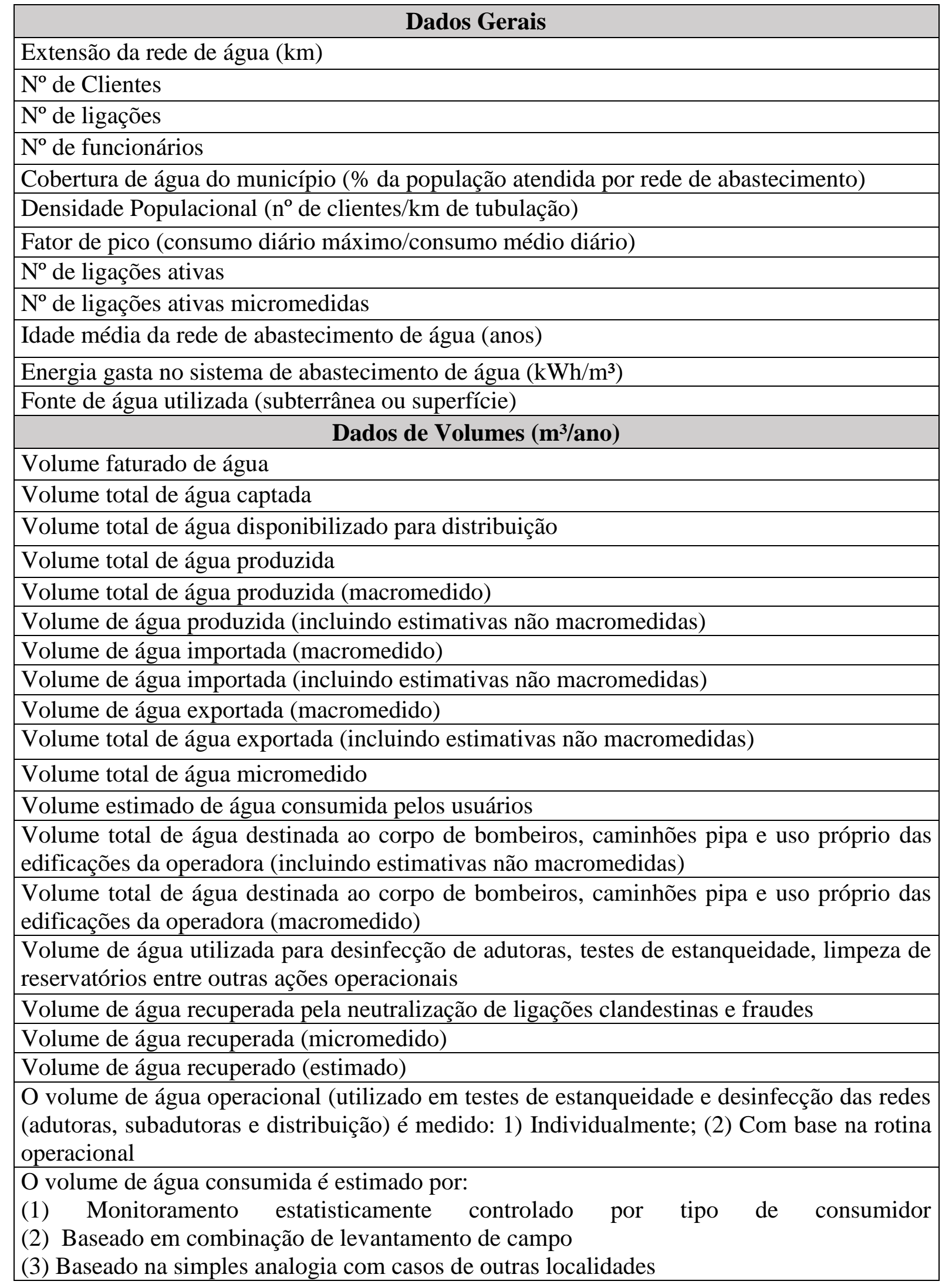




\section{APÊNDICE II \\ QUESTIONÁRIO B - PRÁTICAS DE CONTROLE DE PERDAS DE ÁGUA NA DISTRIBUIÇÃO}

\begin{tabular}{|c|l|}
\hline \multirow{4}{*}{\begin{tabular}{c} 
Gerenciamento $\begin{array}{c}\text { Ae Pressão } \\
\text { de }\end{array}$ \\
\cline { 2 - 2 }
\end{tabular}} & $\begin{array}{l}\text { A operadora utiliza medidores de pressão e acompanha as pressões na rede? } \\
\text { na rede? }\end{array}$ \\
\cline { 2 - 2 } & A operadora utiliza válvulas redutoras de pressão? \\
\cline { 2 - 2 } & No período noturno a pressão de água é reduzida? \\
\cline { 2 - 2 } & $\begin{array}{l}\text { A pressão média da rede está dentro do estabelecido pela NBR 12218/1994? (100 } \\
\text { KPa (10 mca) de pressão dinâmica e 500 KPa (50 mca) de pressão estática). }\end{array}$ \\
\cline { 2 - 2 } & Os reservatórios são 100\% automatizados? \\
\hline
\end{tabular}

\begin{tabular}{|c|c|}
\hline \multirow{8}{*}{$\begin{array}{c}\text { Gerenciamento } \\
\text { de } \\
\text { Infraestrutura }\end{array}$} & Os ramais prediais antigos são substituídos? \\
\hline & A operadora utiliza macromedidores para mapear as vazões de água na rede? \\
\hline & $\begin{array}{l}\text { A operadora tem um cadastro com informações das tubulações para acompanhar } \\
\text { quando é necessário a substituição? }\end{array}$ \\
\hline & A operadora conta com um plano de manutenção anual? (Limpeza/Reabilitação) \\
\hline & $\begin{array}{l}\text { A operadora tem um controle de qualidade dos materiais e equipamentos } \\
\text { utilizados na manutenção da rede? }\end{array}$ \\
\hline & A operadora tem estabelecido procedimentos operacionais padrões? \\
\hline & Os equipamentos da rede (medidores, válvulas) são periodicamente calibrados? \\
\hline & $\begin{array}{l}\text { A operadora fornece treinamento para a equipe de manutenção e operação? } \\
\text { (Certificação) }\end{array}$ \\
\hline
\end{tabular}

Controle da Corrosão em Tubulações
A tubulação é revestida internamente? (argamassa de cimento, epóxi)

A tubulação é revestida externamente com mantas betuminosas, argamassa de cimento, para proteção?

É priorizado o uso de tubulações de material não-metálico?

\begin{tabular}{|c|c|}
\hline \multirow{10}{*}{$\begin{array}{l}\text { Controle de } \\
\text { Vazamentos }\end{array}$} & $\begin{array}{l}\text { A operadora utiliza escutas de solo (geofones mecânicos ou eletrônicos) para } \\
\text { detectar vazamentos não visíveis? }\end{array}$ \\
\hline & $\begin{array}{l}\text { A operadora realiza análises de custo-benefício para definir a melhor frequência } \\
\text { de pesquisa de vazamentos? }\end{array}$ \\
\hline & $\begin{array}{l}\text { A operadora conta com uma equipe que atua em tempo integral para reparar os } \\
\text { vazamentos? }\end{array}$ \\
\hline & $\begin{array}{l}\text { A operadora utiliza modelos computacionais/matemáticos de simulação para } \\
\text { detecção de fugas? }\end{array}$ \\
\hline & $\begin{array}{l}\text { A operadora utiliza método de consumo zero para detectar vazamentos não } \\
\text { visíveis? }\end{array}$ \\
\hline & $\begin{array}{l}\text { A operadora utiliza método de consumo mínimo noturno para detectar } \\
\text { vazamentos não visíveis? }\end{array}$ \\
\hline & $\begin{array}{l}\text { A operadora estabelece zonas de medição para facilitar o controle de } \\
\text { vazamentos? (setorização, DMC) }\end{array}$ \\
\hline & A operadora conta com uma equipe de "caça vazamentos"? \\
\hline & A operadora realiza teste de estanqueidade nos hidrômetros? \\
\hline & $\begin{array}{l}\text { Há um canal de comunicação para que o usuário possa alertar sobre vazamentos } \\
\text { nas ruas (visíveis)? }\end{array}$ \\
\hline
\end{tabular}




\begin{tabular}{|l|l|}
\hline \multirow{4}{*}{$\begin{array}{c}\text { Controle de } \\
\text { Erros de }\end{array}$} & A operadora efetua a troca corretiva de hidrômetros? \\
\cline { 2 - 2 } Medição & A operadora efetua a troca preventiva otimizada de hidrômetros? \\
\cline { 2 - 2 } & A operadora fiscaliza os hidrômetros para verificar erros de medição? \\
\cline { 2 - 2 } & A operadora utiliza hidrômetros de maior precisão? \\
\cline { 2 - 2 } & A operadora utiliza hidrômetros com telemetria através de radio frequência? \\
\cline { 2 - 2 } & A operadora fornece treinamento para a leitura adequada dos hidrômetros? \\
\hline
\end{tabular}

\begin{tabular}{|c|c|}
\hline \multirow{8}{*}{$\begin{array}{l}\text { Controle de } \\
\text { Fraudes e } \\
\text { Ligações } \\
\text { Clandestinas }\end{array}$} & $\begin{array}{l}\text { A operadora atua para conscientizar a população sobre o problema das fraudes e } \\
\text { ligaçoes clandestinas? }\end{array}$ \\
\hline & A operadora inspeciona regularmente ligações suspeitas e inativas? \\
\hline & A operadora repara hidrômetros inclinados? \\
\hline & A operadora utilizada tecnologias para detectar ligações clandestinas? \\
\hline & A operadora acompanha o consumo mensal dos usuários para detectar fraudes? \\
\hline & A operadora atua em áreas de pobreza para controlar as fraudes? \\
\hline & $\begin{array}{l}\text { A operadora conta com o auxílio da comunidade na denúncia de ligações } \\
\text { clandestinas ou fraudes? }\end{array}$ \\
\hline & eradora atualiza anu \\
\hline
\end{tabular}

\begin{tabular}{|c|l|}
\hline \multirow{5}{*}{$\begin{array}{c}\text { Planejamento } \\
\text { Estratégico }\end{array}$} & A operadora apresenta uma Plano/Programa de redução de perdas de água? \\
\cline { 2 - 3 } & A operadora tem uma meta de redução de perdas estabelecida? \\
\cline { 2 - 3 } & $\begin{array}{l}\text { A operadora tem um departamento/seção específica para o controle de perdas? } \\
\text { A operadora tem um diagnóstico da situação das perdas no município? (causa, } \\
\text { volumes perdidos) }\end{array}$ \\
\cline { 2 - 2 } & $\begin{array}{l}\text { A operadora utiliza indicadores para avaliar o seu desempenho no controle de } \\
\text { perdas? }\end{array}$ \\
\cline { 2 - 2 } & $\begin{array}{l}\text { A operadora desenvolve estudo de priorização de zonas mais críticas para o } \\
\text { controle de perdas? }\end{array}$ \\
\cline { 2 - 3 } & A operadora conduz análises de custo-benefício para o controle de perdas? \\
\cline { 2 - 3 } & $\begin{array}{l}\text { A operadora realiza reuniões periódicas para analisar os resultados das ações de } \\
\text { controle e planejar as ações consecutivas? }\end{array}$ \\
\hline
\end{tabular}

\begin{tabular}{|l|l|}
\hline \multirow{4}{*}{$\begin{array}{c}\text { Investimento e } \\
\text { Inovação }\end{array}$} & $\begin{array}{l}\text { A operadora investe em novas tecnologias voltadas ao controle de perdas? } \\
\text { (Dispositivos de controle de fluxo, sistemas de deteção de ligações clandestinas) }\end{array}$ \\
\cline { 2 - 2 } & $\begin{array}{l}\text { A operadora adota metodologias como o MASPP, Six Sigma ou Ciclo Deming } \\
\text { no controle de perdas? }\end{array}$ \\
\cline { 2 - 2 } & $\begin{array}{l}\text { A operadora investe em cursos de capacitação/treinamento dos funcionários } \\
\text { voltado ao controle de perdas? }\end{array}$ \\
\cline { 2 - 2 } & A operadora utiliza SIGs para auxiliar no controle de perdas? \\
\cline { 2 - 3 } & A operadora investe na elaboração de manuais de gerenciamento de perdas? \\
\hline
\end{tabular}

